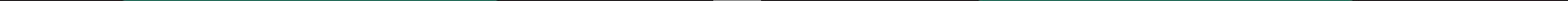




\section{Propositions}

1. Genome diversity should be used more often to identify key factors in both nematode virulence and host susceptibility.

(this thesis)

2. The effector MiMSP32 contributes to nematode virulence by suppressing the host target 12-oxophytodienoate reductase 2 .

(this thesis)

3. Careful consideration of the visualization of the predicted data before it is gathered improves the design process of an experiment.

4. Molecular plant genetics would evolve faster if an economically relevant crop is chosen as model plant.

5. The 'race to a COVID-19 vaccine' is an excellent illustration of how scientists focus too much on competition.

6. Climate change makes it impossible to preserve the Dutch biodiversity.

7. Exactly following the protocol guarantees successful cake baking, but it hinders new insights.

Propositions belonging to the thesis, entitled

Using genome diversity to decipher nematode virulence and host susceptibility

Ava Verhoeven

Wageningen, 18 January 2021 


\section{Using genome diversity to decipher nematode virulence and host susceptibility}

Ava Verhoeven 


\section{Thesis committee}

\section{Promotor}

Prof. dr G. Smant

Professor/head of the department, Laboratory of Nematology

Wageningen University \& Research

\section{Co-promotors}

Dr A. Goverse

Associate professor, Laboratory of Nematology

Wageningen University \& Research

Dr M.G. Sterken

Assistant professor, Laboratory of Nematology

Wageningen University \& Research

\section{Other members}

Prof. dr R.A.A. van der Vlugt, Wageningen University \& Research

Prof. dr Y. Bai, Wageningen University \& Research

Prof. dr T. Kyndt, Ghent University, Belgium

Dr A. Verhage, Rijk Zwaan Breeding B.V., De Lier

This research was conducted under the auspices of the Graduate School of Experimental Plant Sciences. 


\title{
Using genome diversity to decipher nematode virulence and host susceptibility
}

\author{
Ava Verhoeven
}

Thesis

submitted in fulfilment of the requirements for the degree of doctor

at Wageningen University

by the authority of the Rector Magnificus,

Prof. dr A.P.J. Mol,

in the presence of the

Thesis Committee appointed by the Academic Board

to be defended in public

on Monday 18 January 2021

at 4:00 p.m. in the Aula. 
Ava Verhoeven

Using genome diversity to decipher nematode virulence and host susceptibility 184 pages.

PhD thesis, Wageningen University, Wageningen, The Netherlands (2021) With references, with summaries in English and Dutch

ISBN: 978-94-6395-563-8

DOI https://doi.org/10.18174/532058 
To Yvar

+ 78-07-2010 



\section{Table of Contents}

\section{Chapter 1}

General introduction

\section{Chapter 2}

A cluster of MiMSP32-like secretory proteins in root-knot nematodes is under strong positive selection

\section{Chapter 3}

The promiscuous effector MiMSP32 of Meloidogyne incognita contributes to nematode virulence in tomato

\section{Chapter 4}

The effector target AtOPR2 regulates susceptibility of Arabidopsis thaliana to Meloidogyne incognita

\section{Chapter 5}

$R$-gene independent variation in susceptibility of Solanum lycopersicum

to Meloidogyne incognita

\section{Chapter 6}

General discussion

\section{Addendum}

Summary

Samenvatting

Acknowledgements

About the author 


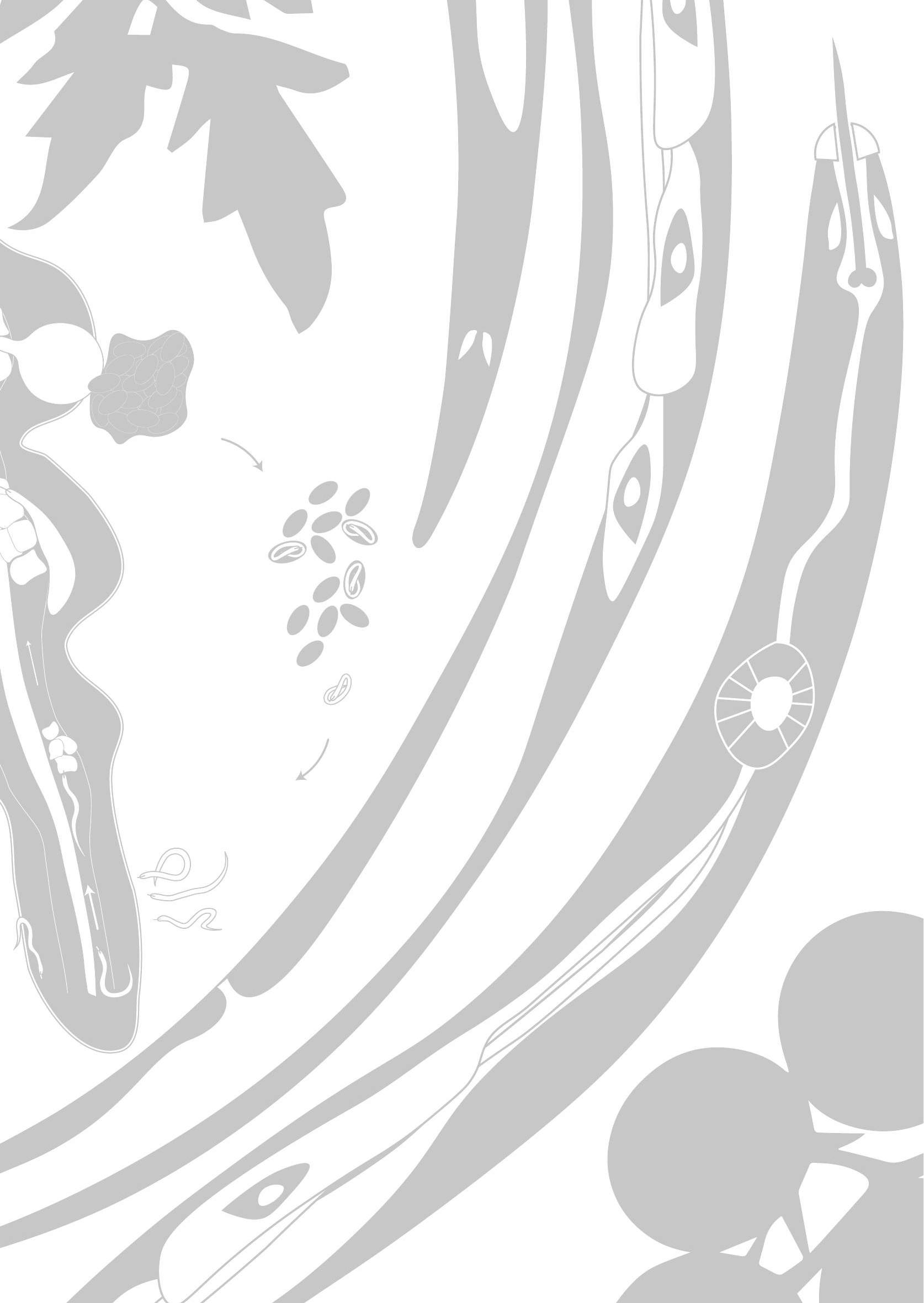




\section{Chapter 1}

General introduction

Ava Verhoeven

Laboratory of Nematology, Department of Plant Sciences, Wageningen University \& Research, Wageningen, The Netherlands 
$\therefore$ they are a Species of aquatic Animals, and may be denominated Worms, Eels, or Serpents, which they much resemble.'

John Turberville Needham, 1743

\section{Plant-parasitic nematodes}

Of all multicellular eukaryotic organisms on Earth, nematodes are the most numerous (Decraemer \& Hunt, 2013), with thousands of nematodes per $100 \mathrm{~g}$ dry soil (Van Den Hoogen et al..2019). These typically tiny unsegmented roundworms can be divided in groups of various feeding types, such as bacterivores, fungivores, and plant feeders. Phylogenetically speaking, nematodes can be classified in twelve distinct clades. Within this classification system, plant parasitism has evolved independently multiple times in at least four different clades (van Megen et al., 2009). While some plant-parasitic nematodes are found in clade 1, 2 or 10, most are grouped in clade 12. The first discovery of a plant-parasitic nematode species (i.e. Anguina tritici from clade 12) was described by Needham in 1743 (Needham, 1743). In contrast to these seed gall nematodes, most of the 4100 currently described plant-parasitic nematodes species feed belowground on plant roots (Decraemer \& Hunt. 2013). Although root-parasitic nematodes display a variety of lifestyles, similar morphological characteristics have developed in different clades by convergent evolution. For example, all root-parasitic nematode species have large salivary glands and a needle-like stylet to penetrate the sturdy plant cell walls in order to feed on the cell content (Hussey, 1989).

Among root-parasitic nematodes, four main lifestyles can be distinguished, i.e. the migratory ectoparasitic, the migratory endoparasitic, the sedentary ectoparasitic, and the sedentary endoparasitic lifestyle. Throughout their entire life, migratory ectoparasitic nematodes migrate in the soil while intermittently feeding on plant root cells from outside the plant. Migratory endoparasites invade roots of a host plant and subsequently feed on multiple plant cells while migrating though the plant root system. Migration of these endoparasites through plant roots typically causes severe damage. Sedentary ectoparasites can (partially) penetrate plant roots and create a permanent feeding site at specific stages in their life cycle. Sedentary endoparasitic nematodes are completely embedded within the plant and remain attached to their permanent feeding site during nearly all stages of development (Lambert \& Bekal, 2002). Typical representatives of sedentary nematodes (belonging to clade 12) are the cyst nematodes and root-knot nematodes. As root-knot nematodes (Meloidogyne spp.) cause most of all agronomic damage, they are among the best-studied plant-parasitic nematodes (Jones et al., 2013).

\section{Global agronomical problems with M. incognita}

The genus of root-knot nematodes includes more than 90 widely distributed and highly polyphagous species (Moens et al.. 2009). The extremely wide host range, including both 
monocotyledons and dicotyledons, makes M. incognita one of the most important and invasive of all plant pathogens (Trudgill \& Blok, 2001; Jones et al., 2013; Bebber et al.. 2014). Nearly every higher plant species is a host for at least one species of root-knot nematodes (Mitchum et al. 2013). M. incognita is part of the tropical root-knot nematodes, which is a very successful group of closely related root-knot nematodes. As the common name implies, it is endemic to tropical and subtropical regions (Coyne et al., 2018). Although M. incognita reproduces clonally without sex, it is highly adaptive to environmental variation (Blanc-Mathieu et al., 2017).

M. incognita control can be based on three different strategies, i.e. chemical control, biological control, and the use of nematode resistance genes in crops. The previously widely applied and effective chemical control by nematicides is increasingly banned due to environmental and health concerns. Biological control using antagonists such as nematopathogenic bacteria and fungi as a replacement for chemical control is not yet sufficiently effective to be applied on a large scale (Collange et al., 2011). Even though the potential activity of several of these antagonists is promising in the greenhouse, variable and inconsistent results are achieved in field trials (Bardin \& Pugliese, 2020). In the 1940s, the resistance (R) gene Mi-7.2 against multiple species of tropical root-knot nematodes was identified in Solanum peruvianum and introgressed into cultivated tomato S. Iycopersicum (Smith, 1944). To date, the Mi-1.2 gene remains the most widely used R-gene against tropical root-knot nematodes in tomato (Barbary et al., 2015). However, the breakdown of Mi-7.2 resistance at high soil temperatures (Ammati et al., 1986) is becoming a problem, especially since global temperatures are increasing due to climate change (Reddy, 2015). Additionally, damage caused by a growing number of resistance-breaking, virulent $M$. incognita populations is a major problem worldwide (Kaloshian et al., 1996; Iberkleid et al., 2014: Guan et al., 2017). Therefore, there is a clear demand for new forms of nematode resistance in crops, including novel non R-gene based resistances such as the so-called susceptibility (S) genes. The $S$-gene concept is based on natural variation in plant genes responsible for a compatible interaction between host and parasite (van Schie \& Takken, 2014).

\section{Lifecycle of M. incognita}

Depending on environmental conditions and plant susceptibility, the lifecycle of $M$. incognita takes around six weeks to complete (Bartlem et al., 2013). Therefore, multiple generations of M. incognita can occur within one growing season. The infection cycle of $M$. incognita starts when juveniles (J2) hatch from eggs in the soil and subsequently invade the root of a host plant at the elongation zone (Figure 1). Thereafter, the juveniles stealthily migrate between cortical cells in the direction of the root tip. For this intercellular migration, M. incognita uses both mechanical force and plant cell wall degrading enzymes present in their stylet secretions to separate cortical tissue cells at the middle lamella (Williamson \& Hussey, 1996). After making a $U$-turn around the endodermis inside the root tip, the nematodes move into the differentiating vascular tissue (Wyss \& Grundler, 1992). 
Inside the vascular cylinder of the plant, the juveniles of $M$. incognita develop a permanent feeding site harboring four to ten so-called multiple giant cells (Blok et al., 2008). These giant cells arise from undifferentiated vascular plant cells by repeated mitosis without intermittent cytokinesis, and several rounds of endoreduplication (Gheysen \& Mitchum, 2011). Resulting hypertrophied cells contain multiple endopolyploid nuclei and an extraordinary high density of subcellular organelles (Abad \& Williamson, 2010). While feeding, nematodes profit from the extremely active metabolism and efficient delivery of assimilates from the plant vasculature into the giant cells (Bartlem et al., 2013). Cells surrounding the giant cells are also hypertrophic and hyperplastic, forming a large protective gall. Juvenile nematodes feed on the cytoplasm of giant cells for several weeks, and in this period they develop into two more additional juvenile stages (J3 and, J4) and the final adult stage. Although juveniles of M. incognita can develop into males occasionally, males are believed to play no role in reproduction (Abad et al., 2008). Adult females therefore reproduce clonally by mitotic parthenogenesis and secrete 200-400 eggs per adult female, all of which are deposited in a gelatinous matrix outside of the root.

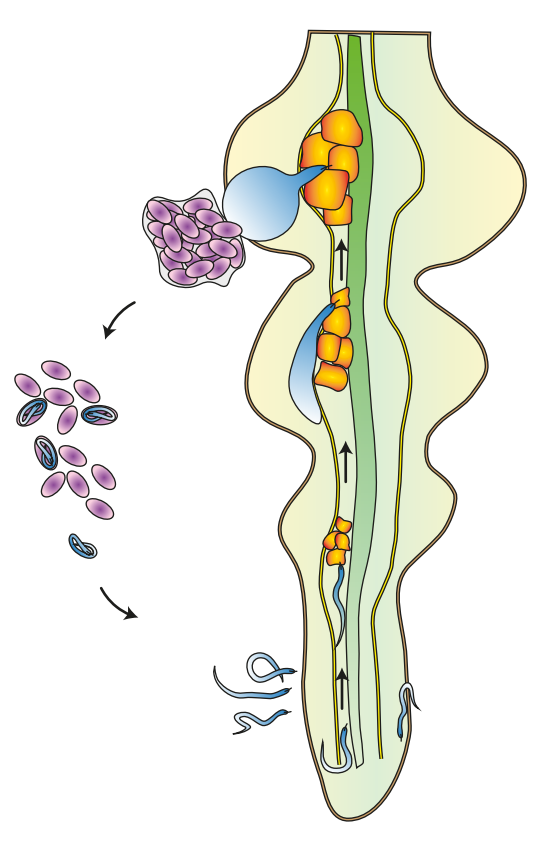

Figure 1. Schematic representation of the $M$. incognita life cycle.

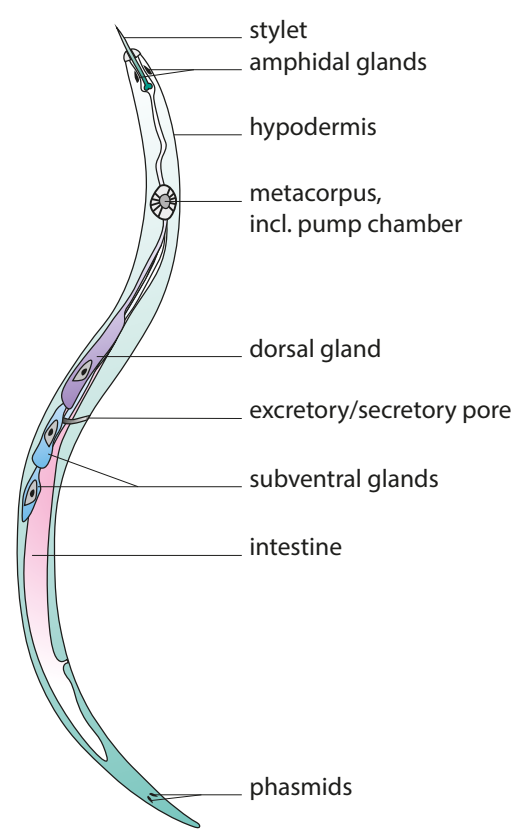

Figure 2. Schematic representation of a M. incognita juvenile with secretory organs. 


\section{Effectors of M. incognita}

The elaborate changes in plant roots leading to the formation of giant cells and root galls are most likely orchestrated by effectors in secretions of M. incognita (Favery et al., 2016) (Table 1). Effector containing secretions of $M$. incognita are produced by specialized esophageal gland cells, i.e. one dorsal gland cell and two subventral gland cells (Figure 2). While compounds from the two subventral gland cells are associated with both the pre-parasitic and parasitic phases, secretions from the dorsal gland cells dominate in later parasitic stages (Hussey \& Mims, 1990; Nguyen et al., 2018). Effector delivery from the nematode gland cells into the plant apoplast or cytoplasm takes place via a protractible stylet (Hussey, 1989; Mejias et al., 2019). Alternatively, effectors can be secreted by amphidal glands, the hypodermis along the nematode body or via phasmids or the excretory/secretory pore (Haegeman et al., 2012; Mitchum et al., 2013).

In general, nematode effectors are thought to enable host invasion, to suppress and avoid host defense responses, and to reprogram root cells into giant cells (Mejias et al., 2019). So far, several $M$. incognita effectors have been found to enable host invasion by the degradation of plant cell walls (Haegeman et al., 2012). The suppression of plant defenses is done for example by interfering with various plant metabolic or signaling pathways (Shi et al., 2018b). Likewise, effectors can protect the nematode from harmful plant substances, e.g. by detoxifying reactive oxygen species (Dubreuil et al., 2007; Molinari \& Rosso, 2014). Plant defenses can also be altered by effectors targeting several plant phytohormones (Gheysen \& Mitchum, 2019). In similar fashion, M. incognita also likely directly secretes plant hormone mimics of cytokinins and auxins to manipulate plant processes (De Meutter et al., 2003; De Meutter et al.. 2005). Less studied functions of effectors include feeding site initiation, expansion and maintenance, and the degradation of plant proteins by the ubiquitination-protease pathway (Mitchum et al., 2013).

> Table 1. List of the (putative) M. incognita effectors so far identified in earlier studies. Nematode localization abbreviations: $\mathrm{DG}=$ dorsal glands, SVG = subventral glands, $\mathrm{AG}=$ amphidal glands, RG = rectal glands. Expression abbreviations: TE = transient expression, IL = immunolocalization. Selection was based on the total score $\geq-5$ (in which an unknown protein description $=-3$, an unknown (predicted) effector function $=-1$, nematode localization not in either SVG or DG $=-1$, unknown in planta silencing effects $=-1$, unknown in planta overexpression effects = -7). 


\begin{tabular}{|c|c|c|c|c|c|c|c|c|c|c|c|c|c|c|}
\hline Gene ID & $\begin{array}{l}\text { Common } \\
\text { name }\end{array}$ & $\begin{array}{l}\text { Alterna- } \\
\text { tive } \\
\text { name }\end{array}$ & $\begin{array}{l}\text { (Predicted) } \\
\text { function }\end{array}$ & $\begin{array}{l}\text { Protein } \\
\text { description }\end{array}$ & $\begin{array}{l}\text { Nematode } \\
\text { organs }\end{array}$ & Methods & Secretion & $\begin{array}{l}\text { Develop- } \\
\text { mental } \\
\text { stage } \\
\end{array}$ & $\begin{array}{l}\text { in planta } \\
\text { RNAi effects }\end{array}$ & $\begin{array}{l}\text { in planta } \\
\text { overexpression } \\
\text { effects }\end{array}$ & Host target & $\begin{array}{l}\text { Host } \\
\text { localization }\end{array}$ & References & $\begin{array}{l}\text { Total } \\
\text { score }\end{array}$ \\
\hline Minc10536 & MicM3 & & $\begin{array}{l}\text { Plant defense } \\
\text { suppression }\end{array}$ & $\begin{array}{l}\text { Chorismate } \\
\text { mutase }\end{array}$ & Sve & ISH & Signal peptide & $\begin{array}{l}\text { Pre-parasitic } \\
\text { Early parasitic }\end{array}$ & $\begin{array}{l}\text { VICS reduced } \\
\text { virulence }\end{array}$ & $\begin{array}{l}\text { Increased } \\
\text { susceptibility }\end{array}$ & & $\begin{array}{l}\text { Cytoplasm \& } \\
\text { nucleus (TE) }\end{array}$ & (Wang et al. 2018) & 0 \\
\hline AF402771 & MiCRT & & $\begin{array}{l}\text { Plant defense } \\
\text { suppression by } \\
\text { calcium signaling }\end{array}$ & Calreticulin & $\begin{array}{l}\text { SvG and } \\
\text { DC }\end{array}$ & IL & Secreted & $\begin{array}{l}\text { Migration } \\
\text { Pre-parasitic } \\
\text { Early parasitic } \\
\text { Late parasitic }\end{array}$ & $\begin{array}{l}\text { Soaking dsRNA, } \\
\text { siRNA and HICS } \\
\text { reduced virulence }\end{array}$ & $\begin{array}{l}\text { Increased } \\
\text { susceptibility } \\
\text { Suppression of PTI } \\
\text { defenses } \\
\end{array}$ & & $\begin{array}{l}\text { Cytoplasm \& } \\
\text { nucleus (TE) } \\
\text { apoplast (IL) }\end{array}$ & $\begin{array}{l}\text { Jaubert et al. 2002b; } \\
\text { Jaubert et al.2005; } \\
\text { Arguel et al. 2012; } \\
\text { Jaouannet et al.2013) }\end{array}$ & 0 \\
\hline Minc03597 & MilsE5 & & $\begin{array}{l}\text { Plant defense } \\
\text { suppression }\end{array}$ & $\begin{array}{l}\text { Zinc-finger } \\
\text { protein }\end{array}$ & Svo & ISH & Signal peptide & $\begin{array}{l}\text { Pre-parasitic } \\
\text { Early parasitic }\end{array}$ & $\begin{array}{l}\text { VICS reduced } \\
\text { virulence }\end{array}$ & $\begin{array}{l}\text { Induced } \\
\text { susceptibility } \\
\text { Suppression of JA, } \\
\text { SA, ABA }\end{array}$ & & Nucleus (TE) & (Shiet al. 2018b) & 0 \\
\hline AY134435 & MiMSPI6 & $16 D 10$ & $\begin{array}{l}\text { Transcriptional } \\
\text { regulation to } \\
\text { promote giant cell } \\
\text { induction }\end{array}$ & $\begin{array}{l}\text { CLE-like } \\
\text { peptide }\end{array}$ & Sve & $\mathrm{ISH}, \mathrm{IL}$ & Signal peptide & $\begin{array}{l}\text { Early parasitic } \\
\text { Late parasitic }\end{array}$ & $\begin{array}{l}\text { Soaking dsRNA } \\
\text { reduced virulence }\end{array}$ & $\begin{array}{l}\text { Induction of root } \\
\text { growth }\end{array}$ & $\begin{array}{l}\text { Arabidopsis } \\
\text { scarecrow-like } \\
\text { transcription } \\
\text { factors AtSCL6\&17 }\end{array}$ & & 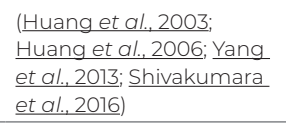 & 0 \\
\hline $\begin{array}{l}\text { Minc18876/ } \\
\text { KX907771/ } \\
\text { Minc10604// } \\
\text { Minc10606/ } \\
\text { Minc04822 }\end{array}$ & MiSGCRl & & $\begin{array}{l}\text { Plant defense } \\
\text { suppression }\end{array}$ & $\begin{array}{l}\text { Small } \\
\text { glycine- and } \\
\text { cysteine-rich }\end{array}$ & DC & ISH & Signal peptide & $\begin{array}{l}\text { Early parasitic } \\
\text { Late parasitic }\end{array}$ & $\begin{array}{l}\text { Soaking siRNA } \\
\text { reduced virulence }\end{array}$ & $\begin{array}{l}\text { Suppression of } \\
\text { necrosis }\end{array}$ & & $\begin{array}{l}\text { Cytoplasm \& } \\
\text { nucleus (TE) }\end{array}$ & (Nguyen et al. 2018) & 0 \\
\hline $\begin{array}{l}\text { EF370395/ } \\
\text { EF370396 }\end{array}$ & MiVAP2 & & $\begin{array}{l}\text { Recognition } \\
\text { between plant and } \\
\text { nematode }\end{array}$ & $\begin{array}{l}\text { Venom } \\
\text { allergen-like } \\
\text { protein }\end{array}$ & Sve & $\mathrm{ISH}$ & Signal peptide & $\begin{array}{l}\text { Pre-parasitic } \\
\text { Early parasitic }\end{array}$ & $\begin{array}{l}\text { VICS induced } \\
\text { transcripts }\end{array}$ & $\begin{array}{l}\text { Progeny of } \\
\text { VIGS induced } \\
\text { susceptibility }\end{array}$ & & & $\begin{array}{l}(\text { Wang et al. 2007; Chiet } \\
\text { (1.,2016) }\end{array}$ & 0 \\
\hline $\begin{array}{l}\text { AF100549/ } \\
\text { AF323087 }\end{array}$ & MiENGI & O1C11B & $\begin{array}{l}\text { Plant cell wall } \\
\text { degradation }\end{array}$ & $\begin{array}{l}\text { Beta-1,4-endo- } \\
\text { glucanase }\end{array}$ & SvG & ISH & Signal peptide & $\begin{array}{l}\text { Pre-parasitic } \\
\text { Early parasitic }\end{array}$ & $\begin{array}{l}\text { Soaking dsRNA } \\
\text { reduced virulence }\end{array}$ & & & & 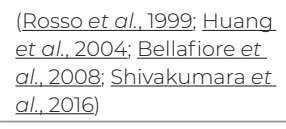 & -7 \\
\hline ABN64198 & MiCSTT & & $\begin{array}{l}\text { Detoxification of } \\
\text { ROS }\end{array}$ & $\begin{array}{l}\text { Clutathi- } \\
\text { one-s-trans- } \\
\text { ferase }\end{array}$ & Sve & ISH, IL & $\begin{array}{l}\text { No canonical } \\
\text { signal peptide; } \\
\text { Secreted }\end{array}$ & Early parasitic & $\begin{array}{l}\text { Soaking dsRNA } \\
\text { reduced virulence }\end{array}$ & & & & $\begin{array}{l}\text { (Dubreuil et al. 2007: } \\
\text { Wang et al. 2012) }\end{array}$ & -1 \\
\hline MC585322 & MiMIF-2 & & $\begin{array}{l}\text { Interfering } \\
\text { with the } \\
\text { annexin-mediated } \\
\text { plant immune } \\
\text { responses }\end{array}$ & $\begin{array}{l}\text { Macrophage } \\
\text { migration } \\
\text { inhibitory } \\
\text { factor }\end{array}$ & $\begin{array}{l}\text { hypoder- } \\
\text { mis }\end{array}$ & IL & $\begin{array}{l}\text { Non-classical } \\
\text { secretion }\end{array}$ & $\begin{array}{l}\text { Early-parasitic } \\
\text { Late parasitic }\end{array}$ & $\begin{array}{l}\text { HICS reduced } \\
\text { virulence }\end{array}$ & $\begin{array}{l}\text { Induced } \\
\text { susceptibility }\end{array}$ & $\begin{array}{l}\text { Arabidopsis } \\
\text { annexins AnnAtt } \\
\text { and AnnAt4 }\end{array}$ & $\begin{array}{l}\text { Cytoplasm } \\
\text { (IL) }\end{array}$ & (Zhao et al. 2019) & -1 \\
\hline AF013289 & $\begin{array}{l}\text { MiMSPI/ } \\
\text { MivAPI }\end{array}$ & & $\begin{array}{l}\text { recognition } \\
\text { between plant and } \\
\text { nematode }\end{array}$ & $\begin{array}{l}\text { Venom } \\
\text { allergen-like } \\
\text { protein }\end{array}$ & Sve & ISH & Signal peptide & $\begin{array}{l}\text { Pre-parasitic } \\
\text { Early parasitic }\end{array}$ & $\begin{array}{l}\text { Soaking dsRNA } \\
\text { reduced virulence }\end{array}$ & & & & $\begin{array}{l}\text { (Ding et al. 2000; } \\
\text { Chaudhary et al. 2019) }\end{array}$ & -1 \\
\hline $\begin{array}{l}\text { AF527788/ } \\
\text { AAQ09004 }\end{array}$ & MiPELI & $34 \mathrm{CO} 4$ & $\begin{array}{l}\text { Plant cell wall } \\
\text { degradation }\end{array}$ & Pectate lyase & Sve & ISH & Signal peptide & $\begin{array}{l}\text { Pre-parasitic } \\
\text { Early parasitic }\end{array}$ & $\begin{array}{l}\text { Soaking dsRNA } \\
\text { reduced virulence }\end{array}$ & & & & $\begin{array}{l}\text { (Huang et al.2003; } \\
\text { Huang et al. 2005a; } \\
\text { Shivakumara et al. 2016) }\end{array}$ & -1 \\
\hline Minc11290 & MiPFN3 & & $\begin{array}{l}\text { Disrupts the actin } \\
\text { cytoskeleton }\end{array}$ & Profilin 3 & Svo & ISH & $\begin{array}{l}\text { No canonical } \\
\text { signal peptide }\end{array}$ & $\begin{array}{l}\text { Pre-parasitic } \\
\text { Early parasitic }\end{array}$ & & $\begin{array}{l}\text { Induced } \\
\text { susceptibility } \\
\text { Dwarf phenotype }\end{array}$ & $\begin{array}{l}\text { Arabidopsis actin } \\
\text { monomers }\end{array}$ & $\begin{array}{l}\text { Actin } \\
\text { filaments } \\
\text { (TE) }\end{array}$ & $\begin{array}{l}\text { (Leelarasamee et al.. } \\
\underline{2018)}\end{array}$ & -1 \\
\hline AY098646 & MiPGl & & $\begin{array}{l}\text { Plant cell wall } \\
\text { degradation }\end{array}$ & $\begin{array}{l}\text { Polygalacturo- } \\
\text { nase }\end{array}$ & Svo & $\mathrm{ISH}$ & Signal peptide & Pre-parasitic & $\begin{array}{l}\text { Soaking dsRNA } \\
\text { reduced virulence }\end{array}$ & & & & $\begin{array}{l}\text { (Jaubert et al., 2002a; } \\
\text { Shivakumara et al. 2016) }\end{array}$ & -1 \\
\hline AAF37276 & MiXYLI & & $\begin{array}{l}\text { Plant cell wall } \\
\text { degradation }\end{array}$ & $\begin{array}{l}\text { Beta-1,4-en- } \\
\text { doxylanase }\end{array}$ & Sve & ISH & Signal peptide & & $\begin{array}{l}\text { Soaking dsRNA } \\
\text { reduced virulence }\end{array}$ & & & & $\begin{array}{l}\text { (Mitreva-Dautova et al.. } \\
\frac{2006 ; \text { Shivakumara et }}{\alpha 1.2016)}\end{array}$ & -1 \\
\hline AAR85527 & Mil4-3-3-b & & $\begin{array}{l}\text { Plant defense and } \\
\text { interaction with } \\
\text { pathogen }\end{array}$ & $14-3-3$ & SVG \& DC & $\mathrm{ISH}, \mathrm{IL}$ & $\begin{array}{l}\text { No canonical } \\
\text { signal peptide; } \\
\text { Secreted }\end{array}$ & All stages & & & & $\begin{array}{l}\text { Cytoplasm \& } \\
\text { nucleus (TE) }\end{array}$ & $\begin{array}{l}\text { Jaubert et al.2004; } \\
\text { Bellafiore et al.,2008; } \\
\text { Vieira et at.1.2012; Wang } \\
\text { et al. 2012) }\end{array}$ & -2 \\
\hline FN179274 & MiASP2 & & $\begin{array}{l}\text { Plant protein } \\
\text { degradation }\end{array}$ & $\begin{array}{l}\text { Aspartyl } \\
\text { protease-like }\end{array}$ & Sve & IL & Secreted & $\begin{array}{l}\text { Migration } \\
\text { Early parasitic }\end{array}$ & & & & Apoplast (IL) & $\begin{array}{l}\frac{(\text { Neveu et al. 2003b; }}{\text { Vieira et al.,2011) }} \\
\text { lat. }\end{array}$ & -2 \\
\hline AF049139 & MiCBPT & $42 \mathrm{CO6}$ & $\begin{array}{l}\text { Plant cell wall } \\
\text { degradation }\end{array}$ & $\begin{array}{l}\text { Cellulose-bind- } \\
\text { ing protein }\end{array}$ & Sve & ISH & Signal peptide & Pre-parasitic & & & & & $\begin{array}{l}\text { (Ding et al., 1998; Huang } \\
\text { et al. 2003) }\end{array}$ & -2 \\
\hline
\end{tabular}




\begin{tabular}{|c|c|c|c|c|c|c|c|c|c|c|c|c|c|c|}
\hline Gene ID & $\begin{array}{l}\text { Common } \\
\text { name }\end{array}$ & $\begin{array}{l}\text { Alterna- } \\
\text { tive } \\
\text { name } \\
\end{array}$ & $\begin{array}{l}\text { (Predicted) } \\
\text { function }\end{array}$ & $\begin{array}{l}\text { Protein } \\
\text { description }\end{array}$ & $\begin{array}{l}\text { Nematode } \\
\text { organs }\end{array}$ & Methods & Secretion & $\begin{array}{l}\text { Develop- } \\
\text { mental } \\
\text { stage } \\
\end{array}$ & $\begin{array}{l}\text { in planta } \\
\text { RNAi effects }\end{array}$ & $\begin{array}{l}\text { in planta } \\
\text { overexpression } \\
\text { effects }\end{array}$ & Host target & $\begin{array}{l}\text { Host } \\
\text { localization }\end{array}$ & References & $\begin{array}{l}\text { Total } \\
\text { score }\end{array}$ \\
\hline $\begin{array}{l}\text { AY509032/ } \\
\text { AY422834 }\end{array}$ & MiCMT & $02 \mathrm{CO6B}$ & $\begin{array}{l}\text { Plant defense } \\
\text { suppression }\end{array}$ & $\begin{array}{l}\text { Chorismate } \\
\text { mutase }\end{array}$ & SvG & $\mathrm{ISH}$ & Signal peptide & Early parasitic & & & & & $\begin{array}{l}\text { (Huang et al. 2004; } \\
\text { Huang et al. 2005b) }\end{array}$ & -2 \\
\hline $\begin{array}{l}\text { AY509033/ } \\
\text { AY422835 }\end{array}$ & MiCM2 & O6D09B & $\begin{array}{l}\text { Plant defense } \\
\text { suppression }\end{array}$ & $\begin{array}{l}\text { Chorismate } \\
\text { mutase }\end{array}$ & Sve & $\mathrm{ISH}$ & Signal peptide & $\begin{array}{l}\text { Pre-parasitic } \\
\text { Early parasitic }\end{array}$ & & & & & $\begin{array}{l}\text { (Huang et al. 2004; } \\
\text { Huang et al. 2005b) }\end{array}$ & -2 \\
\hline AJ557572 & MiCPLT & & $\begin{array}{l}\text { Plant protein } \\
\text { degradation }\end{array}$ & $\begin{array}{l}\text { Cathepsin } \\
\text { Lcystein } \\
\text { protease }\end{array}$ & Intestine & $\mathrm{ISH}$ & $\begin{array}{l}\text { Putative signal } \\
\text { peptide }\end{array}$ & $\begin{array}{l}\text { Early parasitic } \\
\text { Late parasitic }\end{array}$ & $\begin{array}{l}\text { HICS reduced } \\
\text { virulence }\end{array}$ & & & & $\begin{array}{l}\text { (Neveu et al. 2003a; } \\
\text { Antonino De Souza Jret } \\
\text { al. 2013) }\end{array}$ & -2 \\
\hline AF323086 & MiENG2 & & $\begin{array}{l}\text { Plant cell wall } \\
\text { degradation }\end{array}$ & $\begin{array}{l}\text { Beta-1,4-endo- } \\
\text { glucanase }\end{array}$ & Sve & $\mathrm{ISH}$ & Signal peptide & $\begin{array}{l}\text { Pre-parasitic } \\
\text { Late parasitic }\end{array}$ & & & & & (Ledger et al, 2006) & -2 \\
\hline AY422836 & MiENG3 & 05A12B & $\begin{array}{l}\text { Plant cell wall } \\
\text { degradation }\end{array}$ & $\begin{array}{l}\text { Beta-1,4-endo- } \\
\text { glucanase }\end{array}$ & Sve & $\mathrm{ISH}$ & Signal peptide & All stages & & & & & (Huang et al., 2004) & -2 \\
\hline AY422837 & MiENG4 & O8Е08B & $\begin{array}{l}\text { Plant cell wall } \\
\text { degradation }\end{array}$ & Cellulase & SvG & $\mathrm{ISH}$ & Signal peptide & $\begin{array}{l}\text { Pre-parasitic } \\
\text { Early parasitic }\end{array}$ & & & & & (Huang et al., 2004) & -2 \\
\hline KC237722.1 & MilDLT & & $\begin{array}{l}\text { Ciant cell } \\
\text { formation }\end{array}$ & $\begin{array}{l}\text { Inflorescence } \\
\text { deficient in } \\
\text { abscission-like } \\
\text { peptide }\end{array}$ & & & Signal peptide & & $\begin{array}{l}\text { HICS reduced } \\
\text { virulence }\end{array}$ & & $\begin{array}{l}\text { Presumably binds } \\
\text { to Arabidopsis } \\
\text { receptor-like } \\
\text { kinases such as } \\
\text { HAE and HSL2 }\end{array}$ & & $\begin{array}{l}(\text { Tucker \& Yang, 2013; Kim } \\
\text { et al. 2018) }\end{array}$ & -2 \\
\hline $\begin{array}{l}\text { AJ278663/ } \\
\text { Minc00158/ } \\
\text { Minco0344// } \\
\text { Minc00365// } \\
\text { Minc0 } 4584 / \\
\text { Minc10365/ } \\
\text { Minc10366 }\end{array}$ & MiMAPT & & $\begin{array}{l}\text { Recognition } \\
\text { between plant } \\
\text { and nematode, } \\
\text { induction of giant } \\
\text { cells }\end{array}$ & $\begin{array}{l}\text { MAP-1 gene } \\
\text { family }\end{array}$ & $A C \& S V C$ & $\mathrm{ISH}, \mathrm{IL}$ & Secreted & $\begin{array}{l}\text { Pre-parasitic } \\
\text { Early parasitic } \\
\text { Late parasitic }\end{array}$ & & & & $\begin{array}{l}\text { Cytoplasm } \\
\text { (TE) } \\
\text { Apoplast (IL) }\end{array}$ & $\begin{array}{l}\text { (Semblat et al., 2001; } \\
\text { Castagnone-Sereno et } \\
\text { al., 2009; Vieira et al.,2011; } \\
\text { Tomalova et a al. 2012; } \\
\text { Vieira et al., 2012; Rutter } \\
\text { et al., 2014) }\end{array}$ & -2 \\
\hline AM749994 & MiMnSOD & & $\begin{array}{l}\text { Break Mi--medi- } \\
\text { ated resistance by } \\
\text { handling oxidative } \\
\text { stress }\end{array}$ & $\begin{array}{l}\text { Anti-oxidant } \\
\text { enzyme } \\
\text { manganese } \\
\text { superoxide } \\
\text { dismutase }\end{array}$ & Intestine & $\mathrm{ISH}$ & $\begin{array}{l}\text { Mitochondrial } \\
\text { transit peptide }\end{array}$ & Pre-parasitic & & $\begin{array}{l}\text { Active response to } \\
\text { oxidative stress }\end{array}$ & & & $\begin{array}{l}(\text { Rosso, 2009; Molinari \& } \\
\text { Rosso, 2014) }\end{array}$ & -2 \\
\hline $\begin{array}{l}\text { AY327873/ } \\
\text { Minc11772 }\end{array}$ & MiPEL2 & $02 \mathrm{~B} 02 \mathrm{~B}$ & $\begin{array}{l}\text { Plant cell wall } \\
\text { degradation }\end{array}$ & Pectate lyase & Sve & $\mathrm{ISH}$ & Signal peptide & $\begin{array}{l}\text { Pre-parasitic } \\
\text { Early parasitic }\end{array}$ & & & & & $\begin{array}{l}\text { (Huang et al. 2004; } \\
\text { Huang et al. 2005a) } \\
\end{array}$ & -2 \\
\hline $\begin{array}{l}\text { AY861685/ } \\
\text { Minc17928 }\end{array}$ & MiPEL3 & & $\begin{array}{l}\text { Plant cell wall } \\
\text { degradation }\end{array}$ & Pectate lyase & Sve & IL & Secreted & $\begin{array}{l}\text { Migration } \\
\text { Pre-parasitic } \\
\text { Early parasitic }\end{array}$ & & & & Apoplast (IL) & $\begin{array}{l}\text { (Vieira et al., 20117 Vieira } \\
\text { et al. 2012) }\end{array}$ & -2 \\
\hline AY714229 & MiSERT & & $\begin{array}{l}\text { Plant protein } \\
\text { degradation }\end{array}$ & $\begin{array}{l}\text { Chymotryp- } \\
\text { sin-like serine } \\
\text { protease }\end{array}$ & & & Signal peptide & Late parasitic & $\begin{array}{l}\text { HIOS reduced } \\
\text { virulence }\end{array}$ & & & & $\begin{array}{l}\frac{(d a \text { Rocha Fragoso et al. }}{\text { 2005: Antonino De Souza }} \\
\text { Jreet al. 2013) }\end{array}$ & -2 \\
\hline AJ286352 & MiSXP1 & & Unknown & $\begin{array}{l}\text { SXP/RAL-2 } \\
\text { protein }\end{array}$ & Sve & $\mathrm{ISH}$ & Signal peptide & Early parasitic & & & & & (Tytgat et al., 2005) & -2 \\
\hline EU475876 & MiXYL3 & & $\begin{array}{l}\text { Plant cell wall } \\
\text { degradation }\end{array}$ & $\begin{array}{l}\text { Beta-1,4-en- } \\
\text { doxylanase }\end{array}$ & & & Signal peptide & & $\begin{array}{l}\text { Soaking dsRNA } \\
\text { reduced virulence }\end{array}$ & & & & $\begin{array}{l}\text { (Haegeman et al. 2009; } \\
\text { Shivakumara et al. 2016) }\end{array}$ & -2 \\
\hline Minc03866 & & & & C-type lectin & Sve & $\mathrm{ISH}$ & & & $\begin{array}{l}\text { Soaking siRNA } \\
\text { reduced virulence }\end{array}$ & & & & (Danchin et al., 2013) & -2 \\
\hline CL2552Contigl_1 & & & $\begin{array}{l}\text { Plant cell growth } \\
\text { regulation }\end{array}$ & $\begin{array}{l}\text { Transthyre- } \\
\text { tin-like protein }\end{array}$ & Sve & $\mathrm{ISH}$ & Secreted & & & & & & (Bellafiore et al., 2008) & -2 \\
\hline CL321Contigl_1 & & & $\begin{array}{l}\text { Plant cell } \\
\text { proliferation }\end{array}$ & $\begin{array}{l}\text { Translationally } \\
\text { controlled } \\
\text { tumor protein }\end{array}$ & Sve & ISH & Secreted & & & & & & (Bellafiore et al., 2008) & -2 \\
\hline CL480Contig2_l & & & $\begin{array}{l}\text { Plant-nematode } \\
\text { interactions or } \\
\text { metabolism }\end{array}$ & $\begin{array}{l}\text { Triose- } \\
\text { phosphate } \\
\text { isomerase }\end{array}$ & sve & $\mathrm{ISH}$ & Secreted & & & & & & (Bellafiore et al. 2008) & -2 \\
\hline AY135365 & Auxins & & $\begin{array}{l}\text { Ciant cell } \\
\text { formation }\end{array}$ & $\begin{array}{l}\text { Conjugated } \\
\text { forms of auxin }\end{array}$ & & & Secreted & & & & & & (De Meutter et al. 2005) & -3 \\
\hline
\end{tabular}




\begin{tabular}{|c|c|c|c|c|c|c|c|c|c|c|c|c|c|c|}
\hline Gene ID & $\begin{array}{l}\text { Common } \\
\text { name }\end{array}$ & $\begin{array}{l}\text { Alterna- } \\
\text { tive } \\
\text { name }\end{array}$ & $\begin{array}{l}\text { (Predicted) } \\
\text { function }\end{array}$ & $\begin{array}{l}\text { Protein } \\
\text { description }\end{array}$ & $\begin{array}{l}\text { Nematode } \\
\text { organs }\end{array}$ & Methods & Secretion & $\begin{array}{l}\text { Develop- } \\
\text { mental } \\
\text { stage } \\
\end{array}$ & $\begin{array}{l}\text { in planta } \\
\text { RNAi effects }\end{array}$ & $\begin{array}{l}\text { in planta } \\
\text { overexpression } \\
\text { effects }\end{array}$ & Host target & $\begin{array}{l}\text { Host } \\
\text { localization }\end{array}$ & References & $\begin{array}{l}\text { Total } \\
\text { score }\end{array}$ \\
\hline AY142117 & Cytokinins & & $\begin{array}{l}\text { Ciant cell } \\
\text { formation }\end{array}$ & $\begin{array}{l}\text { iPm, } Z \text {, } \\
\text { BA-types of } \\
\text { cytokinins }\end{array}$ & & & Secreted & & & & & & (De Meutter et al., 2003) & -3 \\
\hline AY422833 & MiASPI & & $\begin{array}{l}\text { Plant protein } \\
\text { degradation }\end{array}$ & $\begin{array}{l}\text { Cathepsin } \\
\text { D-like aspartic } \\
\text { protease }\end{array}$ & & & $\begin{array}{l}\text { Putative signal } \\
\text { peptide }\end{array}$ & $\begin{array}{l}\text { Early parasitic } \\
\text { Late parasitic }\end{array}$ & & & & & $\begin{array}{l}\text { (da Rocha Fragoso et al. } \\
\text { 2009; Vieira et al. 2011); } \\
\text { Antonino De Souza Jret } \\
\text { al. 2013) }\end{array}$ & -3 \\
\hline AF531169 & MilsE6 & & $\begin{array}{l}\text { Plant defense } \\
\text { suppression }\end{array}$ & & Sve & $\mathrm{ISH}$ & Signal peptide & Early parasitic & $\begin{array}{l}\text { HICS reduced } \\
\text { virulence }\end{array}$ & $\begin{array}{l}\text { Induced } \\
\text { susceptibility } \\
\text { Suppression of JA }\end{array}$ & & Nucleus (TE) & (Shiet al. 2018a) & -3 \\
\hline Minc19205 & MiMSPI2 & 17AOT & $\begin{array}{l}\text { Plant defense } \\
\text { suppression }\end{array}$ & & DC & $\mathrm{ISH}$ & Signal peptide & $\begin{array}{l}\text { Early parasitic } \\
\text { Late parasitic }\end{array}$ & $\begin{array}{l}\text { VICS reduced } \\
\text { virulence } \\
\text { Induction of JA } \\
\text { and SA related } \\
\text { genes }\end{array}$ & $\begin{array}{l}\text { Suppression of } \\
\text { SA and JA related } \\
\text { genes }\end{array}$ & & $\begin{array}{l}\text { Cytoplasm } \\
\text { (TE) }\end{array}$ & $\begin{array}{l}\text { (Huang et al.,2003; Xie et } \\
\underline{a l ., 2016)}\end{array}$ & -3 \\
\hline CL5Contig2_1 & MiMSP21 & $30 \mathrm{C} 11$ & & $\begin{array}{l}\text { Acid } \\
\text { phosphatase }\end{array}$ & Sve & $\mathrm{ISH}$ & Signal peptide & $\begin{array}{l}\text { Pre-parasitic } \\
\text { Early parasitic }\end{array}$ & & & & $\begin{array}{l}\text { Cytoplasm } \\
\text { (TE) }\end{array}$ & $\begin{array}{l}\text { (Huang et al. 2003; } \\
\text { Zhang et al.. 2015) }\end{array}$ & -3 \\
\hline CLl191Contig1_1 & MiMSP26 & 05005 & & $\begin{array}{l}\text { Zinc metallo- } \\
\text { peptidase }\end{array}$ & Sve & $\mathrm{ISH}$ & Signal peptide & Early parasitic & & & & & (Huang et al. 2003) & -3 \\
\hline $\begin{array}{l}\text { Minc00108/ } \\
\text { Minc00107/ } \\
\text { Minc00121/ } \\
\text { Minc00122/ } \\
\text { Minc1149 }\end{array}$ & MiMSP29 & $10 \mathrm{co2}$ & & Thioredoxin & DC & $\mathrm{ISH}$ & Signal peptide & $\begin{array}{l}\text { Early parasitic } \\
\text { Late parasitic }\end{array}$ & & & & & (Huang et al., 2003) & -3 \\
\hline Minc01696 & MiMSP34 & $\begin{array}{l}\text { 10A07/ } \\
\text { 10A08 }\end{array}$ & & $\begin{array}{l}\text { Sodium/ } \\
\text { calcium/ } \\
\text { potassium } \\
\text { exchanger }\end{array}$ & Sve & $\mathrm{ISH}$ & Signal peptide & $\begin{array}{l}\text { Pre-parasitic } \\
\text { Early parasitic } \\
\text { Late parasitic }\end{array}$ & & & & & (Huang et al. 2003) & -3 \\
\hline Minc00801 & MiMSP40 & O8E1OB & $\begin{array}{l}\text { Suppressing PTI } \\
\text { and/or ETI signals }\end{array}$ & & Sve & $\mathrm{ISH}$ & Signal peptide & $\begin{array}{l}\text { Pre-parasitic } \\
\text { Early parasitic } \\
\text { Late parasitic }\end{array}$ & $\begin{array}{l}\text { Soaking dsRNA } \\
\text { reduced virulence }\end{array}$ & $\begin{array}{l}\text { Induced } \\
\text { susceptibility } \\
\text { Suppression of cell } \\
\text { death and callose } \\
\text { deposition } \\
\text { Induction of root } \\
\text { length }\end{array}$ & & $\begin{array}{l}\text { Cytoplasm \& } \\
\text { nucleus (TE) }\end{array}$ & $\begin{array}{l}\text { (Huang et al.,2004; Niu } \\
\text { et al..2016; Shivakumara } \\
\text { et al.,2016)}\end{array}$ & -3 \\
\hline AF531161 & MiMSP9 & $08 D 05$ & Transport & & SvG & ISH, IL & Signal peptide & $\begin{array}{l}\text { Pre-parasitic } \\
\text { Early parasitic } \\
\text { Late parasitic }\end{array}$ & $\begin{array}{l}\text { HICS reduced } \\
\text { virulence }\end{array}$ & $\begin{array}{l}\text { Induced } \\
\text { susceptibility } \\
\text { Accelerated shoot } \\
\text { growth }\end{array}$ & $\begin{array}{l}\text { Tomato } \\
\text { aquaporin } \\
\text { tonoplast intrinsic } \\
\text { protein } 2 \text { (TIP2) }\end{array}$ & & $\begin{array}{l}\text { (Huang et al.2003; Xue } \\
\text { et al.2013) }\end{array}$ & -3 \\
\hline \multirow[t]{2}{*}{ AF531166 } & MiPM & & $\begin{array}{l}\text { Plant cell } \\
\text { penetration }\end{array}$ & $\begin{array}{l}\text { Passe-muraille } \\
\text { protein }\end{array}$ & & & Signal peptide & Early-parasitic & & & $\begin{array}{l}\text { Soybean subunit } \\
\text { of the COP9 } \\
\text { signalosome } \\
\text { (CmCSNS) }\end{array}$ & Nucleus (TE) & (Bournaud et al., 2018) & -3 \\
\hline & & & & Sec- 2 protein & Sve & $\mathrm{ISH}$ & Secreted & & & & & & (Bellafiore et al., 2008) & -3 \\
\hline Minc17998 & & & Plant cell cycle & CDC48-like & Phasmids & $\mathrm{ISH}$ & Secreted & & & & & & (Bellafiore et al., 2008) & -3 \\
\hline AY134437 & & & & $\begin{array}{l}\text { Metallopepti- } \\
\text { dase }\end{array}$ & DC & $\mathrm{ISH}$ & Signal peptide & Early parasitic & & & & & (Jaouannet et al., 2012) & -3 \\
\hline AY134439 & & & & $\begin{array}{l}\text { Monopolar } \\
\text { spindle protein } \\
\text { kinase }\end{array}$ & Sve & $\mathrm{ISH}$ & Signal peptide & Early parasitic & & & & $\begin{array}{l}\text { Cytoplasm } \\
\text { (TE) }\end{array}$ & (Rutter et al. 2014) & -3 \\
\hline AY134443 & & & & Unknown & $\begin{array}{l}\mathrm{RC} / \\
\text { intestine }\end{array}$ & $\mathrm{ISH}$ & Signal peptide & Late parasitic & $\begin{array}{l}\text { Soaking siRNA } \\
\text { reduced virulence }\end{array}$ & & & & $\begin{array}{l}\text { (Danchin et al. 2013; } \\
\text { Rutter et al. 2014) }\end{array}$ & -3 \\
\hline AY142120 & MiMSP2 & 02002 & $\begin{array}{l}\text { Evade the plant } \\
\text { response }\end{array}$ & & Sve & $\mathrm{ISH}$ & Signal peptide & Early parasitic & $\begin{array}{l}\text { HICS reduced } \\
\text { virulence }\end{array}$ & & & $\begin{array}{l}\text { Cytoplasm } \\
\text { (TE) }\end{array}$ & $\begin{array}{l}\text { (Huang et al., 2003; } \\
\text { Zhang et al., 2015; Joshi } \\
\text { et al.1.2019) }\end{array}$ & -4 \\
\hline
\end{tabular}




\begin{tabular}{|c|c|c|c|c|c|c|c|c|c|c|c|c|c|c|}
\hline Gene ID & $\begin{array}{l}\text { Common } \\
\text { name }\end{array}$ & $\begin{array}{l}\text { Alterna- } \\
\text { tive } \\
\text { name }\end{array}$ & $\begin{array}{l}\text { (Predicted) } \\
\text { function }\end{array}$ & $\begin{array}{l}\text { Protein } \\
\text { description }\end{array}$ & $\begin{array}{l}\text { Nematode } \\
\text { organs }\end{array}$ & Methods & Secretion & $\begin{array}{l}\text { Develop- } \\
\text { mental } \\
\text { stage } \\
\end{array}$ & $\begin{array}{l}\text { in planta } \\
\text { RNAi effects }\end{array}$ & $\begin{array}{l}\text { in planta } \\
\text { overexpression } \\
\text { effects } \\
\end{array}$ & Host target & $\begin{array}{l}\text { Host } \\
\text { localization }\end{array}$ & References & $\begin{array}{l}\text { Total } \\
\text { score }\end{array}$ \\
\hline AY142121 & MiMSP7 & 07E12 & Gall formation & & DC & ISH & Signal peptide & $\begin{array}{l}\text { Early parasitic } \\
\text { Late parasitic }\end{array}$ & & $\begin{array}{l}\text { Faster and altered } \\
\text { gall formation and } \\
\text { egg enclosion }\end{array}$ & & $\begin{array}{l}\text { Cytoplasm } \\
\text { (TE) }\end{array}$ & $\begin{array}{l}\text { (Huang et al. 2003; dos } \\
\text { Santos de lima e Suuza } \\
\text { et al., 2011; Zhang et al.. } \\
\text { 2015) }\end{array}$ & -4 \\
\hline AY142119 & Mi6D4 & & $\begin{array}{l}\text { Ciant cell } \\
\text { formation and } \\
\text { maintenance }\end{array}$ & & SVG \& DC & IL & Secreted & $\begin{array}{l}\text { Early parasitic } \\
\text { Late parasitic }\end{array}$ & & & & Apoplast (IL) & $\begin{array}{l}\text { (Davis et al., 1992; Vieira } \\
\text { et al.,2011; Vieira et al. } \\
\text { 2012) }\end{array}$ & -5 \\
\hline AY422829 & MiEFFT & & $\begin{array}{l}\text { Manipulate } \\
\text { nuclear functions } \\
\text { of the host cell }\end{array}$ & & DC & ISH, IL & Secreted & Early parasitic & & & & $\begin{array}{l}\text { Nucleus (TE) } \\
\text { giant cell } \\
\text { nuclei (IL) }\end{array}$ & (Jaouannet et al. 2012) & -5 \\
\hline AY422830 & MiMSP18 & 17HO2 & & & DC & ISH & Signal peptide & $\begin{array}{l}\text { Early parasitic } \\
\text { Late parasitic }\end{array}$ & $\begin{array}{l}\text { Soaking dsRNA } \\
\text { reduced virulence }\end{array}$ & & & $\begin{array}{l}\text { Cytoplasm } \\
\text { (TE) }\end{array}$ & $\begin{array}{l}\text { Huang et al. 2003; } \\
\text { Zhanget al. 2015; } \\
\text { Shivakumara et al. 2016; } \\
\text { Shivakumara et al.1.2017) } \\
\text { Grossi-de-Sa et al. 2019) }\end{array}$ & -5 \\
\hline AY422831 & MiMSP2O & 30H07 & & & Svo & $\mathrm{ISH}$ & Signal peptide & $\begin{array}{l}\text { Pre-parasitic } \\
\text { Early parasitic }\end{array}$ & $\begin{array}{l}\text { Soaking dsRNA } \\
\text { reduced virulence }\end{array}$ & & & & $\begin{array}{l}\text { (Huang et al.,2003; } \\
\text { Shivakumara et al. 2016; } \\
\text { Shivakumara et al. 2017) }\end{array}$ & -5 \\
\hline AY422832 & MiMSP24 & $34 \mathrm{F06}$ & & & DC & $\mathrm{ISH}$ & Signal peptide & $\begin{array}{l}\text { Early parasitic } \\
\text { Late parasitic }\end{array}$ & $\begin{array}{l}\text { Soaking dsRNA } \\
\text { reduced virulence }\end{array}$ & & & & $\begin{array}{l}\text { (Huang et al.2003; } \\
\text { Shivakumara et al.,2016) }\end{array}$ & -5 \\
\hline AF531163 & MiMSP33 & $25 \mathrm{~B} 10$ & & & DC & $\mathrm{ISH}$ & Signal peptide & Early parasitic & $\begin{array}{l}\text { Soaking dsRNA } \\
\text { reduced virulence }\end{array}$ & & & & $\begin{array}{l}\text { (Huang et al.,2003; } \\
\text { Shivakumara et al..2016) }\end{array}$ & -5 \\
\hline AF531164 & MiMSP8 & 07H08 & $\begin{array}{l}\text { Transcriptional } \\
\text { activation activity }\end{array}$ & & DC & ISH & Signal peptide & $\begin{array}{l}\text { Early parasitic } \\
\text { Late parasitic }\end{array}$ & & & & Nucleus (TE) & $\begin{array}{l}\text { (Huang et al. 2003: } \\
\text { Zhang et al. 2015) }\end{array}$ & -5 \\
\hline
\end{tabular}

\section{Recent advances in M. incognita effector identification}

The identification of $M$. incognita effectors has undergone drastic changes, accelerated with the recent developments in high-throughput whole-genome sequencing. These developments have led to the availability of the M. incognita genome (Abad et al., 2008) with an increasing quality of sequencing, assembly and gene annotation (Blanc-Mathieu et al.. 2017). However, revealing the effector repertoire within the genome remains a challenge. The identification of effectors using the available genomics data is usually based on typical in silico selection criteria (Sonah et al., 2016) and further in vivo and in vitro experiments.

For effector identification in silico, it is possible to identify and prioritize orthologs of known effector genes conserved in plant-damaging nematode families (Danchin et al., 2013). However, most effector genes are pioneers without any homology or structural similarities to known genes. To search for these pioneer genes, gene expression can be compared between nematode life stages (Nguyen et al., 2018; Shukla et al., 2018). Likewise, potential effector genes can be identified by isolating gland-cell specific mRNA for transcriptomics (Rutter et al., 2014) or by a proteomic analysis of nematode secretions (Bellafiore et al., 2008; Wang et al.. 2012). Gene expansion and variation can indicate potential effector genes under high selection pressure. Therefore, gene copy number variations of putative effectors can be used as signatures of adaptive evolution. In the M. incognita genome, selection pressure forces certain gene regions to undergo more gene multiplications (Castagnone-Sereno et al., 2019). This evidence of positive, diversifying selection points at the involvement of loci in a molecular arms race with other organisms (Baskaran et al., 2017). Likewise, bioinformatic tools can be used to predict protein secretion by the detection of short patterns, such as signal peptides, non-classical secretion patterns and the absence of a transmembrane domain (Gahoi \& Gautam, 2017).

Additional in vivo and in vitro experimental evidence is required to validate potential effectors. For example, effector proteins within secretory organs can be detected by in situ hybridization or immunolocalization techniques followed by immunolabelling and mass spectrometry (Huang et al., 2003; Jaouannet et al., 2012). Likewise, immunolocalization with antibodies can be used to detect secreted effectors in plant cytoplasm or apoplast (Vieira et al., 2012). Although gene knock-outs remain impossible in plant-parasitic nematodes due to the smal size of the nematodes, their obligatory parasitic lifestyle and their incompatibility with microinjection (Dutta et al.. 2015), several gene silencing methods are available. To transiently silence a putative effector gene, preparasitic nematodes are traditionally soaked in double-stranded RNA (Rosso et al. 2005). More recently, soaking was performed with synthetic small interfering RNAs to increase target specificity and minimize off-target effects (Dalzell et al., 2010; Lilley et al., 2012). Additionally, gene silencing during feeding can be achieved by host-induced gene silencing (HICS), where the nematode ingests the double-stranded RNA generated by the plant (Xue et al., 2013). A recently used development is effector silencing mediated by indirect viral-induced gene silencing (VICS) in plants (Xie et al., 2016: Shi et al..2018b). To study effector working mechanisms, possible phenotypic effects can be identified by ectopic overexpression of the effector, such as an altered plant susceptibility or physiology (hao et al.. 2019). 


\section{Host targets and susceptibility genes}

The identification of host targets is another necessary requisite to unravel the working mechanisms of the many identified pioneer effectors (Abad \& Williamson, 2010; Vieira \& Cleason, 2019). To identify potential effector host targets, a broad non-target screening can be done with a yeast-two hybrid analysis using a cDNA library of nematode-infected plant tissue or an in planta immunoprecipitation assay followed by mass spectrometry (Varden et al., 2017). Potential interactors must be validated by additional interaction assays, such as co-expression in plant cells followed by co-immunoprecipitation assays, or fluorescence lifetime or complementation assays (Varden et al., 2017; Bournaud et al., 2018; Zhao et al., 2019). Additional studies with host-target knockouts in the host plant or in Arabidopsis as a model system (Sijmons et al., 1991) can reveal the effector working mechanism.

Host target genes hijacked by effectors are considered susceptibility (S)-genes, i.e. plant genes that can be used by the phytopathogen to facilitate the infection process or support compatibility (van Schie \& Takken, 2014). Presumably, S-genes are responsible for quantitative variation in plant susceptibility to phytopathogens. One effective method to locate quantitative variation of susceptibility in a natural population is by genome-wide association (CWA). CWA focuses on statistically significant associations between gene variants (usually SNPS) of different individuals and the associated trait of interest (Bush \& Moore, 2012). Recently, GWA was used to identify genes associated with root-knot nematode susceptibility in Arabidopsis and rice (Dimkpa et al.., 2015; Warmerdam et al., 2018; Warmerdam et al., 2019). Warmerdam et al. (2018) showed in their study that significant natural quantitative variation exists for the susceptibility to M. incognita in Arabidopsis that is not related to major R-genes. Therefore, it is likely that variation in host targets can result in a quantitative variation in plant susceptibility.

\section{Thesis outline}

The objective of this thesis was to identify novel effectors of $M$. incognita based on genetic variation in the genome of the nematode and to test the hypothesis that quantitative variation in susceptibility in tomato to M. incognita can be partially attributed to genetic variation in host targets of these novel effectors.

In Chapter 2, we address the potential of M. incognita gene diversification or positive selection in the search for effectors. We identified M. incognita major secretory protein 32 (MiMSP32) as a candidate effector gene in the M. incognita genome using positive selection as a criterion. As a pioneer protein with a signal peptide from the dorsal glands of M. incognita, MiMSP32 is a promising putative effector. Further sequence analyses indicate that the thirty identified MiMSP32-like potential genes derived from whole genome sequencing datasets can be classified into six clades within the Meloidogyne genus.

In Chapter 3, we use the positively selected, putative effector MiMSP32 to study effector promis- 
cuity and functionality. Here, we show that MiMSP32 is indeed an important virulence factor by silencing MiMSP32 in the nematode and overexpression in tomato plants. An untargeted yeast two-hybrid screen was used to identify host targets of the effector, which were confirmed by additional protein-protein interaction assays.

Chapter 4 questions how one of the MiMSP32 host targets, 12-oxo-phytodienoate reductase AtOPR2, regulates host susceptibility. Here, we show that AtOPR2 contributes to M. incognita susceptibility in Arabidopsis. The function of AtOPR2 was assessed by whole transcriptome analysis, and we performed additional assays to even further investigate its role. The results lead us to hypothesize a specific role of the OPR-proteins in root attraction, plant invasion or feeding site development of root-knot nematodes.

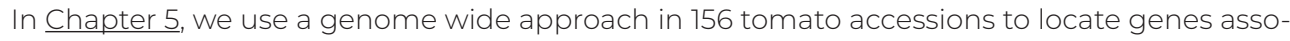
ciated with $R$-gene independent variation in susceptibility of tomato to $M$. incognita. By using additional RNA-Seq of isolated nematode-induced galls on a representative subset of ten tomato accessions, we identified 37 differentially regulated genes within the gene candidates from the GWA.

In Chapter 6, all main findings of this thesis are summized and discussed. Here, the hypothesis is suggested that host targets of positively selected nematode effectors are likely to generate a detectable genetic signal in genome-wide association studies of host susceptibility. Therefore, the overlap is studied between the host targets of MiMSP32 and the identified genes associated with R-gene independent variation in susceptibility to M. incognita.

\section{References}

Abad P, Gouzy J, Aury J-M, Castagnone-Sereno P, Danchin EGJ, Deleury E, Perfus-Barbeoch L, Anthouard V, Artiguenave F, Blok VC, et al. 2008. Genome sequence of the metazoan plant-parasitic nematode Meloidogyne incognita. Nature biotechnology 26(8): 909-915.

Abad P, Williamson VM. 2010. Plant nematode interaction: a sophisticated dialogue. Advances in Botanical Research 53 147-192.

Ammati M, Thomason I, McKinney H. 1986. Retention of resistance to Meloidogyne incognita in Lycopersicon genotypes at high soil temperature. Journal of nematology 18(4): 491.

Antonino De Souza Jr JD, Ramos Coelho R, Tristan Lourenço I, Da Rocha Fragoso R, Barbosa Viana AA, Pepino De Macedo LL, Mattar Da Silva MC, Gomes Carneiro RM, Engler G, De Almeida-Engler J, et al. 2013. Knocking-down Meloidogyne incognita proteases by plant-delivered dsRNA has negative pleiotropic effect on nematode vigor. PLOS ONE 8(12).

Arguel MJ, Jaouannet M, Magliano M, Abad P, Rosso MN. 2012. siRNAs trigger efficient silencing of a parasitism gene in plant parasitic root-knot nematodes. Genes 3(3): 391-408.

Barbary A, Djian-Caporalino C, Palloix A, Castagnone-Sereno P. 2015. Host genetic resistance to root-knot nematodes, Meloidogyne spp., in Solanaceae: from genes to the field. Pest Management Science 71(12): 1591-1598.

Bardin M, Pugliese M. 2020. Biocontrol Agents Against Diseases. In: Gullino ML, Albajes R, Nicot PC eds. Integrated Pest and Disease Management in Greenhouse Crops. Cham: Springer International Publishing, 385-407.

Bartlem DG, Jones MG, Hammes UZ. 2013. Vascularization and nutrient delivery at root-knot nematode feeding sites in host roots. Journal of experimental botany: ert415.

Baskaran P, Jaleta TC, Streit A, Rödelsperger C. 2017. Duplications and positive selection drive the evolution of parasitism-associated gene families in the nematode Strongyloides papillosus. Genome Biology and Evolution 9(3): 790-801.

Bebber DP, Holmes T, Gurr SJ. 2014. The global spread of crop pests and pathogens. Clobal Ecology and Biogeography 23(12): 
1398-1407

Bellafiore S, Shen Z, Rosso M-N, Abad P, Shih P, Briggs SP. 2008. Direct identification of the Meloidogyne incognita secretome reveals proteins with host cell reprogramming potential. PLoS Pathogens 4(10): e1000192.

Blanc-Mathieu R, Perfus-Barbeoch L, Aury J-M, Da Rocha M, Gouzy J, Sallet E, Martin-Jimenez C, Bailly-Bechet M, Castagnone-Sereno P, Flot J-F, et al. 2017. Hybridization and polyploidy enable genomic plasticity without sex in the most devastating plant-parasitic nematodes. PLoS Genetics 13(6): e1006777.

Blok VC, Jones JT, Phillips MS, Trudgill DL. 2008. Parasitism genes and host range disparities in biotrophic nematodes: the conundrum of polyphagy versus specialisation. BioEssays 30(3): 249-259.

Bournaud C, Gillet F-X, Murad AM, Bresso E, Albuquerque EVS, Grossi-de-Sá MF. 2018. Meloidogyne incognita PASSE-MURAILLE (MiPM) gene encodes a cell-penetrating protein that interacts with the CSN5 subunit of the COP9 signalosome. Frontiers in plant science $\mathbf{9}(904)$.

Bush WS, Moore JH. 2012. Chapter 11: Genome-Wide Association Studies. PLOS Computational Biology: Public Library of Science. el002822.

Castagnone-Sereno P, Mulet K, Danchin EGJ, Koutsovoulos GD, Karaulic M, Da Rocha M, Bailly-Bechet M, Pratx L, Perfus-Barbeoch L, Abad P. 2019. Gene copy number variations as signatures of adaptive evolution in the parthenogenetic, plant-parasitic nematode Meloidogyne incognita. Molecular Ecology 28(10): 2559-2572.

Castagnone-Sereno P, Semblat J-P, Castagnone C. 2009. Modular architecture and evolution of the map-1 gene family in the root-knot nematode Meloidogyne incognita. Molecular Cenetics and Genomics 282(5): 547

Chaudhary S, Dutta TK, Shivakumara TN, Rao U. 2019. RNAi of esophageal gland-specific gene Mi-msp-1 alters early stage infection behaviour of root-knot nematode, Meloidogyne incognita. Journal of General Plant Pathology 85(3): 232-242.

Chi Y, Wang X, Le X, Ju Y, Guan T, Li H. 2016. Exposure to double-stranded RNA mediated by tobacco rattle virus leads to transcription up-regulation of effector gene Mi-vap-from Meloidogyne incognita and promotion of pathogenicity in progeny. International journal for parasitology 46(2): 105-113.

Collange B, Navarrete M, Peyre G, Mateille T, Tchamitchian M. 2011. Root-knot nematode (Meloidogyne) management in vegetable crop production: The challenge of an agronomic system analysis. Crop protection 30(10): 1251-1262.

Coyne DL, Cortada L, Dalzell JJ, Claudius-Cole AO, Haukeland S, Luambano N, Talwana H. 2018. Plant-parasitic nematodes and food security in Sub-Saharan Africa. Annual review of phytopathology 56(1): 381-403.

da Rocha Fragoso R, Batista JAN, Neto OBO, Grossi de Sá MF. 2005. Isolation and characterization of a cDNA encoding a serine proteinase from the root-knot nematode Meloidogyne incognita. Experimental Parasitology 110(2): 123-133.

da Rocha Fragoso R, Lourenço IT, Batista JAN, Oliveira-Neto OB, Silva MCM, Rocha TL, Coutinho MV, Grossi-de-Sa MF. 2009. Meloidogyne incognita: Molecular cloning and characterization of a cDNA encoding a cathepsin D-like aspartic proteinase. Experimental Parasitology 121(2): 115-123.

Dalzell JJ, McMaster S, Fleming CC, Maule AG. 2010. Short interfering RNA-mediated gene silencing in Globodera pallida and Meloidogyne incognita infective stage juveniles. International journal for parasitology 40(1): 91-100.

Danchin EG, Arguel M-J, Campan-Fournier A, Perfus-Barbeoch L, Magliano M, Rosso M-N, Da Rocha M, Da Silva C, Nottet N, Labadie K. 2013. Identification of novel target genes for safer and more specific control of root-knot nematodes from a pan-genome mining. PLoS Pathogens.

Davis E, Aron L, Pratt L, Hussey R. 1992. Novel immunization procedures used to develop monoclonal antibodies that bind to specific structures in Meloidogyne spp. Phytopathology 82(10): 1244-1250.

De Meutter J, Tytgat T, Prinsen E, Gheysen G, Van Onckelen H, Gheysen G. 2005. Production of auxin and related compounds by the plant parasitic nematodes Heterodera schachtii and Meloidogyne incognita. Communications in agricultural and applied biological sciences 70(1): 51-60

De Meutter J, Tytgat T, Witters E, Gheysen G, Van Onckelen H, Gheysen G. 2003. Identification of cytokinins produced by the plant parasitic nematodes Heterodera schachtii and Meloidogyne incognita. Molecular Plant Pathology 4(4): 271-277.

Decraemer W, Hunt DJ. 2013. Structure and classification. Plant nematology, 3-39.

Dimkpa SON, Lahari Z, Shrestha R, Douglas A, Gheysen G, Price AH. 2015. A genome-wide association study of a global rice panel reveals resistance in Oryza sativa to root-knot nematodes. Journal of experimental botany 67(4): 1191-1200.

Ding X, Shields J, Allen R, Hussey R. 1998. A secretory cellulose-binding protein cDNA cloned from the root-knot nematode (Meloidogyne incognita). Molecular Plant-Microbe Interactions 11(10): 952-959.

Ding X, Shields J, Allen R, Hussey RS. 2000. Molecular cloning and characterisation of a venom allergen AG5-like cDNA from Meloidogyne incognita. International journal for parasitology 30(1): 77-81.

dos Santos de Lima e Souza D, de Souza Junior JDA, Grossi-de-Sá M, Rocha TL, Fragoso RdR, de Deus Barbosa AEA, de Oliveira GR, Nakasu EYT, de Sousa BA, Pires NF, et al. 2011. Ectopic expression of a Meloidogyne incognita dorsal gland protein in tobacco accelerates the formation of the nematode feeding site. Plant Science 180(2): 276-282.

Dubreuil G, Magliano M, Deleury E, Abad P, Rosso M. 2007. Transcriptome analysis of root-knot nematode functions induced 
in the early stages of parasitism. New Phytologist 176(2): 426-436.

Dutta TK, Banakar P, Rao U. 2015. The status of RNAi-based transgenic research in plant nematology. Frontiers in Microbiology 5(DEC).

Favery B, Quentin M, Jaubert-Possamai S, Abad P. 2016. Gall-forming root-knot nematodes hijack key plant cellular functions to induce multinucleate and hypertrophied feeding cells. Journal of Insect Physiology 84: 60-69.

Gahoi S, Gautam B. 2017. Genome-wide analysis of excretory/secretory proteins in root-knot nematode, Meloidogyne incognita provides potential targets for parasite control. Computational Biology and Chemistry 67: 225-233.

Gheysen G, Mitchum MG. 2011. How nematodes manipulate plant development pathways for infection. Current opinion in plant biology 14(4): 415-421.

Gheysen G, Mitchum MG. 2019. Phytoparasitic nematode control of plant hormone pathways. Plant Physiology. pp.01067.02018. Grossi-de-Sa M, Petitot A-S, Xavier DA, Sá MEL, Mezzalira I, Beneventi MA, Martins NF, Baimey HK, Albuquerque EVS, Grossi-de-Sa MF, et al. 2019. Rice susceptibility to root-knot nematodes is enhanced by the Meloidogyne incognita MSP18 effector gene. Planta 250(4): 1215-1227.

Guan T, Shen J, Fa Y, Su Y, Wang X, Li H. 2017. Resistance-breaking population of Meloidogyne incognita utilizes plant peroxidase to scavenge reactive oxygen species, thereby promoting parasitism on tomato carrying Mi-7 gene. Biochemical and Biophysical Research Communications 482(1): 1-7.

Haegeman A, Mantelin S, Jones JT, Gheysen G. 2012. Functional roles of effectors of plant-parasitic nematodes. Gene 492(1): 19-31.

Haegeman A, Vanholme B, Gheysen G. 2009. Characterization of a putative endoxylanase in the migratory plant-parasitic nematode Radopholus similis. Molecular Plant Pathology 10(3): 389-401.

Huang G, Dong R, Allen R, Davis EL, Baum TJ, Hussey RS. 2005a. Developmental expression and molecular analysis of two Meloidogyne incognita pectate lyase genes. International journal for parasitology 35(6): 685-692.

Huang G, Dong R, Allen R, Davis EL, Baum TJ, Hussey RS. 2005b. Two chorismate mutase genes from the root-knot nematode Meloidogyne incognita. Molecular Plant Pathology 6(7): 23-30.

Huang G, Dong R, Allen R, Davis EL, Baum TJ, Hussey RS. 2006. A root-knot nematode secretory peptide functions as a ligand for a plant transcription factor. Molecular Plant-Microbe Interactions 19(5): 463-470.

Huang G, Dong R, Maier T, Allen R, Davis EL, Baum TJ, Hussey RS. 2004. Use of solid-phase subtractive hybridization for the identification of parasitism gene candidates from the root-knot nematode Meloidogyne incognita. Molecular Plant Pathology 5(3): 217-222.

Huang G, Gao B, Maier T, Allen R, Davis EL, Baum TJ, Hussey RS. 2003. A profile of putative parasitism genes expressed in the esophageal gland cells of the root-knot nematode Meloidogyne incognita. Molecular Plant-Microbe Interactions 16(5): 376-381.

Hussey RS. 1989. Disease-inducing secretions of plant-parasitic nematodes. Annual review of phytopathology 27(1): 123-141.

Hussey RS, Mims CW. 1990. Ultrastructure of esophageal glands and their secretory granules in the root-knot nematode Meloidogyne incognita. Protoplasma 156(1-2): 9-18.

Iberkleid I, Ozalvo R, Feldman L, Elbaz M, Patricia B, Horowitz SB. 2014. Responses of tomato genotypes to avirulent and Mi-virulent Meloidogyne javanica isolates occurring in Israel. Phytopathology 104(5): 484-496.

Jaouannet M, Magliano M, Arguel MJ, Gourgues M, Evangelisti E, Abad P, Rosso M-N. 2013. The root-knot nematode calreticulin Mi-CRT is a key effector in plant defense suppression. Molecular Plant-Microbe Interactions 26(1): 97-105.

Jaouannet M, Perfus-Barbeoch L, Deleury E, Magliano M, Engler G, Vieira P, Danchin EG, Rocha MD, Coquillard P, Abad P. 2012. A root-knot nematode-secreted protein is injected into giant cells and targeted to the nuclei. New Phytologist 194(4): 924-931.

Jaubert S, Laffaire J-B, Abad P, Rosso M-N. 2002a. A polygalacturonase of animal origin isolated from the root-knot nematode Meloidogyne incognita. FEBS Letters 522(1-3): 109-112.

Jaubert S, Laffaire JB, Ledger TN, Escoubas P, Amri EZ, Abad P, Rosso MN. 2004. Comparative analysis of two 14-3-3 homologues and their expression pattern in the root-knot nematode Meloidogyne incognita. International journal for parasitology 34(7): 873-880.

Jaubert S, Laffaire JB, Piotte C, Abad P, Rosso M-N, Ledger TN. 2002b. Direct identification of stylet secreted proteins from root-knot nematodes by a proteomic approach. Molecular and Biochemical Parasitology 121(2): 205-211.

Jaubert S, Milac AL, Petrescu AJ, de Almeida-Engler J, Abad P, Rosso M-N. 2005. In planta secretion of a calreticulin by migratory and sedentary stages of root-knot nematode. Molecular Plant-Microbe Interactions 18(12): 1277-1284.

Jones JT, Haegeman A, Danchin EG, Gaur HS, Helder J, Jones MG, Kikuchi T, Manzanilla-López R, Palomares-Rius JE, Wesemael WM. 2013. Top 10 plant-parasitic nematodes in molecular plant pathology. Molecular Plant Pathology 14(9): 946-967.

Joshi I, Kumar A, Singh AK, Kohli D, Raman KV, Sirohi A, Chaudhury A, Jain PK. 2019. Development of nematode resistance 
in Arabidopsis by HD-RNAi-mediated silencing of the effector gene Mi-msp2. Scientific Reports 9(1): 17404.

Kaloshian I, Williamson VM, Miyao G, Lawn DA, WesterdahI BB. 1996. "Resistance-breaking" nematodes identified in California tomatoes. California Agriculture 50(6): 18-19.

Kim J, Yang R, Chang C, Park Y, Tucker ML. 2018. The root-knot nematode Meloidogyne incognita produces a functional mimic of the Arabidopsis INFLORESCENCE DEFICIENT IN ABSCISSION signaling peptide. Journal of experimental botany 69(12): 3009-3021.

Lambert K, Bekal S. 2002. Introduction to plant-parasitic nematodes. The plant Health instructor 10: 1094-1218.

Ledger TN, Jaubert S, Bosselut N, Abad P, Rosso M-N. 2006. Characterization of a new $\beta$-1,4-endoglucanase gene from the root-knot nematode Meloidogyne incognita and evolutionary scheme for phytonematode family 5 glycosyl hydrolases. Gene 382: 121-128.

Leelarasamee N, Zhang L, Gleason C. 2018. The root-knot nematode effector MiPFN3 disrupts plant actin filaments and promotes parasitism. PLOS Pathogens 14(3): el006947.

Lilley CJ, Davies LJ, Urwin PE. 2012. RNA interference in plant parasitic nematodes: a summary of the current status. Parasitology 139(5): 630-640.

Mejias J, Truong NM, Abad P, Favery B, Quentin M. 2019. Plant proteins and processes targeted by parasitic nematode effectors. Frontiers in plant science 10: 970-970.

Mitchum MG, Hussey RS, Baum TJ, Wang X, Elling AA, Wubben M, Davis EL. 2013. Nematode effector proteins: an emerging paradigm of parasitism. New Phytologist 199(4): 879-894

Mitreva-Dautova M, Roze E, Overmars H, de Graaff L, Schots A, Helder J, Goverse A, Bakker J, Smant G. 2006. A symbiont-independent endo-7, 4- $\beta$-xylanase from the plant-parasitic nematode Meloidogyne incognita. Molecular Plant-Microbe Interactions 19(5): 521-529.

Moens M, Perry RN, Starr JL. 2009. Meloidogyne species-a diverse group of novel and important plant parasites. Root-knot nematodes, 1-17.

Molinari S, Rosso L. 2014. Manganese superoxide dismutase in Meloidogyne incognita isolates selected for virulence on Mi-7-carrying tomato: gene expression and enzyme activity. Nematology 16(3): 249.

Needham JT. 1743. XVI. A letter from Mr. Turbevil Needham, to the President; concerning certain chalky tubulous concretions, called malm; with some microscopical observations on the farina of the red lily, and of worms discovered in smutty corn. Philosophical Transactions of the Royal Society of London 42(471): 634-641.

Neveu C, Abad P, Castagnone-Sereno P. 2003a. Molecular cloning and characterization of an intestinal cathepsin $L$ protease from the plant-parasitic nematode Meloidogyne incognita. Physiological and Molecular Plant Pathology 63(3): 159-165.

Neveu C, Jaubert S, Abad P, Castagnone-Sereno P. 2003b. A set of genes differentially expressed between avirulent and virulent Meloidogyne incognita near-isogenic lines encode secreted proteins. Molecular Plant-Microbe Interactions 16(12): $1077-1084$

Nguyen CN, Perfus-Barbeoch L, Quentin M, Zhao J, Magliano M, Marteu N, Da Rocha M, Nottet N, Abad P, Favery B. 2018. A root-knot nematode small glycine and cysteine-rich secreted effector, MiSGCRT, is involved in plant parasitism. New Phytologist 217(2): 687-699.

Niu J, Liu P, Liu Q, Chen C, Guo Q, Yin J, Yang G, Jian H. 2016. Msp40 effector of root-knot nematode manipulates plant immunity to facilitate parasitism. Scientific Reports 6: 19443

Reddy PP. 2015. Impacts on Nematode Pests. In: Reddy PP ed. Climate Resilient Agriculture for Ensuring Food Security. New Delhi: Springer India, 179-191.

Rosso LC. 2009. Cloning, sequence, and expression analysis of a new MnSOD-encoding gene from the root-knot nematode Meloidogyne incognita. Journal of nematology 41(1): 52-59.

Rosso M-N, Dubrana MP, Cimbolini N, Jaubert S, Abad P. 2005. Application of RNA interference to root-knot nematode genes encoding esophageal gland proteins. Molecular Plant-Microbe Interactions 18(7): 615-620.

Rosso M-N, Favery B, Piotte C, Arthaud L, De Boer JM, Hussey RS, Bakker J, Baum TJ, Abad P. 1999. Isolation of a CDNA encoding a $\beta-7$, 4-endoglucanase in the root-knot nematode Meloidogyne incognita and expression analysis during plant parasitism. Molecular Plant-Microbe Interactions 12(7): 585-591.

Rutter WB, Hewezi T, Abubucker S, Maier TR, Huang G, Mitreva M, Hussey RS, Baum TJ. 2014. Mining novel effector proteins from the esophageal gland cells of meloidogyne incognita. Molecular Plant-Microbe Interactions 27(9): 965-974.

Semblat J-P, Rosso M-N, Hussey RS, Abad P, Castagnone-Sereno P. 2001. Molecular cloning of a cDNA encoding an amphid-secreted putative avirulence protein from the root-knot nematode Meloidogyne incognita. Molecular Plant-Microbe Interactions 14(1): 72-79.

Shi Q, Mao Z, Zhang X, Ling J, Lin R, Zhang X, Liu R, Wang Y, Yang Y, Cheng X, et al. 2018a. The novel secreted Meloidogyne incognita effector MilSE6 targets the host nucleus and facilitates parasitism in Arabidopsis. Frontiers in plant science 9(252).

Shi Q, Mao Z, Zhang X, Zhang X, Wang Y, Ling J, Lin R, Li D, Kang X, Sun W. 2018b. A Meloidogyne incognita effector MilSE5 
suppresses programmed cell death to promote parasitism in host plant. Scientific Reports 8(1): 7256.

Shivakumara TN, Chaudhary S, Kamaraju D, Dutta TK, Papolu PK, Banakar P, Sreevathsa R, Singh B, Manjaiah KM, Rao U. 2017. Host-induced silencing of two pharyngeal gland genes conferred transcriptional alteration of cell wall-modifying enzymes of meloidogyne incognita vis-á-vis perturbed nematode infectivity in eggplant. Frontiers in plant science 8.

Shivakumara TN, Papolu PK, Dutta TK, Kamaraju D, Chaudhary S, Rao U. 2016. RNAi-induced silencing of an effector confers transcriptional oscillation in another group of effectors in the root-knot nematode, Meloidogyne incognita. Nematology 18(7): 857-870.

Shukla N, Yadav R, Kaur P, Rasmussen S, Goel S, Agarwal M, Jagannath A, Gupta R, Kumar A. 2018. Transcriptome analysis of root-knot nematode (Meloidogyne incognita)-infected tomato (Solanum lycopersicum) roots reveals complex gene expression profiles and metabolic networks of both host and nematode during susceptible and resistance responses. Molecular Plant Pathology 19(3): 615-633.

Sijmons PC, Grundler FMW, von Mende N, Burrows PR, Wyss U. 1991. Arabidopsis thaliana as a new model host for plant-parasitic nematodes. The Plant Journal 1(2): 245-254.

Smith PG. 1944. Embryo culture of a tomato species hybrid. Proceedings of the American Society for Horticultural Science 44: 473-416.

Sonah H, Deshmukh RK, Bélanger RR. 2016. Computational prediction of effector proteins in fungi: opportunities and challenges. Frontiers in plant science 7: 126.

Tomalova I, lachia C, Mulet K, Castagnone-Sereno P. 2012. The map-1 gene family in root-knot nematodes, Meloidogyne spp: A set of taxonomically restricted genes specific to clonal species. PLOS ONE 7(6): e38656.

Trudgill DL, Blok VC. 2001. Apomictic, polyphagous root-knot nematodes: exceptionally successful and damaging biotrophic root pathogens. Annual review of phytopathology 39(1): 53-77.

Tucker ML, Yang R. 2013. A gene encoding a peptide with similarity to the plant IDA signaling peptide (AtIDA) is expressed most abundantly in the root-knot nematode (Meloidogyne incognita) soon after root infection. Experimental Parasitology 134(2): 165-170.

Tytgat T, Vercauteren I, Vanholme B, De Meutter J, Vanhoutte I, Gheysen G, Borgonie G, Coomans A, Gheysen G. 2005. An SXP/RAL-2 protein produced by the subventral pharyngeal glands in the plant parasitic root-knot nematode Meloidogyne incognita. Parasitology Research 95(1): 50-54.

Van Den Hoogen J, Geisen S, Routh D, Ferris H, Traunspurger W, Wardle DA, De Goede RG, Adams BJ, Ahmad W, Andriuzzi WS. 2019. Soil nematode abundance and functional group composition at a global scale. nature 572(7768): 194-198.

van Megen H, van den Elsen S, Holterman M, Karssen G, Mooyman P, Bongers T, Holovachov O, Bakker J, Helder J. 2009. A phylogenetic tree of nematodes based on about 1200 full-length small subunit ribosomal DNA sequences. Nematology 11(6): 927-950.

van Schie CCN, Takken FLW. 2014. Susceptibility genes 101: How to be a good host. Annual review of phytopathology 52(1): 551-581.

Varden FA, De la Concepcion JC, Maidment JHR, Banfield MJ. 2017. Taking the stage: effectors in the spotlight. Current opinion in plant biology 38: 25-33.

Vieira P, Banora MY, Castagnone-Sereno P, Rosso M-N, Engler G, de Almeida Engler J. 2012. An immunocytochemical procedure for protein localization in various nematode life stages combined with plant tissues using methylacrylate-embedded specimens. Phytopathology 102(10): 990-996.

Vieira P, Danchin EGJ, Neveu C, Crozat C, Jaubert S, Hussey RS, Engler G, Abad P, de Almeida-Engler J, Castagnone-Sereno $\mathrm{P}$, et al. 2011. The plant apoplasm is an important recipient compartment for nematode secreted proteins. Journal of experimental botany 62(3): 1241-1253.

Vieira P, Gleason C. 2019. Plant-parasitic nematode effectors - insights into their diversity and new tools for their identification. Current opinion in plant biology 50: 37-43.

Wang X-R, Moreno YA, Wu H-R, Ma C, Li Y-f, Zhang J-a, Yang C, Sun S, Ma W-j, Geary TG. 2012. Proteomic profiles of soluble proteins from the esophageal gland in female Meloidogyne incognita. International journal for parasitology 42(13-14): 11771183.

Wang X, Li H, Hu Y, Fu P, Xu J. 2007. Molecular cloning and analysis of a new venom allergen-like protein gene from the root-knot nematode Meloidogyne incognita. Experimental Parasitology 117(2): 133-140.

Wang X, Xue B, Dai J, Qin X, Liu L, Chi Y, Jones J, Li H. 2018. A novel Meloidogyne incognita chorismate mutase effector suppresses plant immunity by manipulating the salicylic acid pathway and functions mainly during the early stages of nematode parasitism. Plant Pathology.

Warmerdam S, Sterken MG, van Schaik C, Oortwijn ME, Sukarta OC, Lozano-Torres JL, Dicke M, Helder J, Kammenga JE, Goverse A. 2018. Genome-wide association mapping of the architecture of susceptibility to the root-knot nematode Meloidogyne incognita in Arabidopsis thaliana. New Phytologist 218(2): 724-737. 


\section{Chapter 1}

Warmerdam S, Sterken MG, Van Schaik C, Oortwijn MEP, Lozano-Torres JL, Bakker J, Goverse A, Smant G. 2019. Mediator of tolerance to abiotic stress ERF6 regulates susceptibility of Arabidopsis to Meloidogyne incognita. Molecular Plant Pathology 20(1): 137-152.

Williamson VM, Hussey RS. 1996. Nematode pathogenesis and resistance in plants. The Plant Cel/ 8(10): 1735.

Wyss U, Grundler F. 1992. Feeding behavior of sedentary plant parasitic nematodes. Netherlands Journal of Plant Pathology 98(2): 165-173.

Xie J, Li S, Mo C, Wang G, Xiao X, Xiao Y. 2016. A novel Meloidogyne incognita effector mispl2 suppresses plant defense response at latter stages of nematode parasitism. Frontiers in plant science 7(JUNE2016).

Xue B, Hamamouch N, Li C, Huang G, Hussey RS, Baum TJ, Davis EL. 2013. The 8D05 parasitism gene of Meloidogyne incognita is required for successful infection of host roots. Phytopathology 103(2): 175-181.

Yang Y, Jittayasothorn Y, Chronis D, Wang X, Cousins P, Zhong GY. 2013. Molecular characteristics and efficacy of 16D10 siRNAs in inhibiting root-knot nematode infection in transgenic grape hairy roots. PLOS ONE 8(7).

Zhang L, Davies LJ, Elling AA. 2015. A Meloidogyne incognita effector is imported into the nucleus and exhibits transcriptional activation activity in planta. Molecular Plant Pathology 16(1): 48-60.

Zhao J, Li L, Liu Q, Liu P, Li S, Yang D, Chen Y, Pagnotta S, Favery B, Abad P, et al. 2019. A MIF-like effector suppresses plant immunity and facilitates nematode parasitism by interacting with plant annexins. Journal of experimental botany $70(20)$ : 5943-5958. 



\title{
Chapter 2
}

\section{A cluster of MiMSP32-like secretory proteins in root-knot nematodes is under strong positive selection}

\author{
Ava Verhoeven ${ }^{1}$ \\ Eliza C Martin² \\ Laura Manoliu ${ }^{2}$ \\ Joris JM van Steenbrugge ${ }^{1}$ \\ Anna Finkers-Tomczak ${ }^{1}$ \\ Pjotr Prins ${ }^{1}$ \\ Andrei J Petrescu ${ }^{2}$ \\ Aska Goverse $^{1}$ \\ Geert Smant ${ }^{1}$ \\ Mark G Sterken ${ }^{1}$
}

1: Laboratory of Nematology, Department of Plant Sciences, Wageningen University \& Research, Wageningen, The Netherlands

2: Department of Bioinformatics and Structural Biochemistry, Institute of Biochemistry of the Romanian Academy, Bucharest, Romania 


\begin{abstract}
Recent developments in high-throughput whole-genome sequencing have caused a major acceleration in the discovery of putative Meloidogyne incognita effectors, many of which have no homology with functionally annotated genes in other organisms. In this study, we used evidence of gene diversification and subsequent positive selection as a criterion to prioritize specific putative effector genes for further functional characterization. First, we revisited the catalogue of known esophageal gland specific genes in $M$. incognita, which are referred to as major secretory proteins (MiMSPs) (Huang et al., 2003; Abad et al., 2008). We found a remarkably high level of positive selection for MiMSP32-like predicted transcripts and splice variants. In addition, further sequence analyses indicate that the thirty identified MiMSP32-like potential genes derived from whole genome sequencing datasets can be classified into six clades within the Meloidogyne genus. Based on the positive selection and gene expansion, we hypothesize that MiMSP32 has undergone functional diversification. Since positive selection is a hallmark of important pathogen effectors in plants, our analyses warrant further functional characterization of MiMSP32 in planta to elucidate its possible role in host infection by Meloidogyne species.
\end{abstract}




\section{Introduction}

Plant-parasitic nematodes annually cause for billions of dollars of losses in global food production (Abad et al., 2008; Nicol et al., 2011). Worldwide crop yield losses due to plant-parasitic nematodes are estimated to vary between 8.8 and $14.6 \%$, depending on the region and the climate (Nicol et al., 2011). Among the most destructive plant parasitic nematodes are the root-knot nematodes (Meloidogyne spp.), which are globally distributed and able to infect the vast majority of vascular plants (Jones et al.. 2013; Mitchum et al.. 2013). The highly polyphagous Meloidogyne incognita is arguably the most invasive biological threat to agricultural productivity (Trudgill \& Blok, 2001; Jones et al., 2013; Bebber et al., 2014). This is the reason why M. incognita is one of the best studied species among plant parasitic nematodes (Abad \& Williamson, 2010). Although it reproduces asexually, it shows a high and unexpected capacity to adapt to environmental constraints by genomic regions with varying gene copy numbers in response to selection pressure (Castagnone-Sereno et al., 2019).

When M. incognita juveniles invade a host plant, they secrete a plethora of so-called effectors (Mitchum et al., 2013). Effectors are defined as secreted molecules aiding the infection process by targeting important host molecular pathways (Vieira \& Gleason, 2019). For example, the well-known M. incognita effector 16D10 affects root growth by a specific interaction with two putative plant SCARECROW-like transcription factors (Huang et al., 2006b). Second stage juveniles (J2s) of M. incognita secrete effectors with their protrusible stylet into the apoplast or cytoplasm of host cells (Hussey, 1989; Mejias et al., 2019). Most effectors are produced in the nematode esophageal glands, which are named after their position in the body of the nematode either subventral or dorsal esophageal gland cells. The subventral glands are most active in the initial stages of infection, such as root penetration and migration. The dorsal gland on the other hand increases both in size and in activity during later stages, when the nematode initiates and maintains several giant cells (Xue et al., 2013).

One large and particularly interesting set of putative secretory proteins was obtained from a gland cell-specific cDNA library derived by micro-aspiration from the esophageal gland cell cytoplasm of different parasitic stages of M. incognita (Huang et al., 2003). These M. incognita major secretory proteins (MiMSPs) included many 'pioneer genes' of unknown function that were found only within species of the Meloidogyne genus. Next generation sequencing revealed additional copies of these pioneer MiMSP genes within the M. incognita genome (Abad et al., 2008). Since their initial discovery, several of the pioneer genes have been studied to identify their impact on nematode virulence. However, for most of them, their specific molecular working mechanisms remain unknown. For example, gene silencing approaches have been used for some of the MiMSP genes to show their importance in the M. incognita infection process (Shivakumara et al., 2016). Moreover, some of the MiMSP genes have been found to function as effectors associated with the suppression of plant defense-related genes in host plants (Xie et al., 2016; Shi et al., 2018). Further support for a role of several of the MiMSP genes in parasitism was found by Shukla et al. (2018), as they showed a stage-specific expression profile during parasitic phases of $\mathrm{M}$. incognita infection in susceptible tomato plants. 
Evidence of positive, diversifying selection in nematode genomes points at the involvement of genes in a molecular arms race between other organisms (Baskaran et al., 2017). For example, positive selection operates on genomic regions involved in the immunity of the nematode Caenorhabditis elegans against the bacterial pathogen Bacillus thuringiensis (Papkou et al. 2019). For the interaction between nematode and plant host, evidence of positive selection has also been found in several nematode effectors (Xu et al., 2001; Blanc-Mathieu et al., 2017). To detect footprints of positive selection, the direction and magnitude of amino acid changes within a group of similar genes can be compared. These comparisons are made to estimate the ratio $\omega$ between nonsynonymous $\left(d_{N}\right)$ and synonymous $\left(d_{S}\right)$ mutations to find signs of divergent evolution (Stukenbrock, 2013; Booker et al., 2017). The ratio $\omega$ can then be used as a sign for an important role in plant-pathogen interactions for pioneering genes.

Recently, the developments in high-throughput whole-genome sequencing have caused a major shift in the identification of Meloidogyne incognita effectors (See Chapter 1 for an overview). In this chapter, we tested if gene diversification and positive selection can be used as a valid criterion to prioritize genes encoding putative secretory proteins for further functional characterization as effectors in plants. Thereby, we expanded the knowledge on 27 pioneer MiMSP genes identified in the genome sequence of M. incognita (Abad et al., 2008). We found evidence of positive selection for three MiMSPs, including MiMSP32, a putative secreted protein from the dorsal gland of M. incognita (Huang et al., 2003). We identified thirty MiMSP32-like potential genes using a comparative sequence analysis of whole-genome sequencing datasets of several other Meloidogyne species. Further cluster analysis showed a clear separation of MiMSP32-like potential genes over six clades within the genus Meloidogyne. Members of these six clades show no sequence similarity to any other functionally characterized genes or proteins in protein and nucleotide sequence databases. However, we noticed a remote homology with several proteins adopting a so-called Rossmann fold (a three-layer beta-alpha-beta ( $\beta a \beta)$-sandwich architecture). This structural homology suggests that MiMSP32-like genes folds in a similar fashion. Together, the remarkable characteristics of MiMSP32 point at a specific role in root knot nematode virulence on plants and warrant further functional characterization in planta.

\section{Results}

\section{Presence of pioneer $M$. incognita genes among root-knot nematode species}

Twelve years after the publication of the first M. incognita genome, the status of 27 previously identified pioneer genes (Abad et al., 2008) was revisited based on improved and novel -omics data available to date. First, we searched for significant mRNA sequence hits in a BLASTN at the Wormbase Parasite cDNA database of all published nematode genomes containing predicted transcripts and splice variants. Our search within all published nematode genomes placed all MiMSP-hits specifically within the genus Meloidogyne. We identified the majority of the 27 genes in the cDNA sequences of the most recent versions of the $M$. incognita genomes (Table 1). Within the 27 genes, we found four groups of identical hits, which we grouped together 
as close homologs. Additionally, we identified similarities for the pioneer genes only among CDNA sequences of other root-knot nematodes closely related to $M$. incognita (Figure 1). For MiMSP16, we did not find any similar cDNA sequences, although the MiMSP16 gene encodes the well-studied M. incognita effector 16D10 (Huang et al., 2006b; Yang et al., 2013; Shivakumara et al., 2016). To our surprise, the highest numbers of MiMSP-hits could be identified in CDNA sequences of $M$. arenaria and $M$. javanica and some were not at all represented in CDNA sequences of either of the two recent versions of the M. incognita genome.

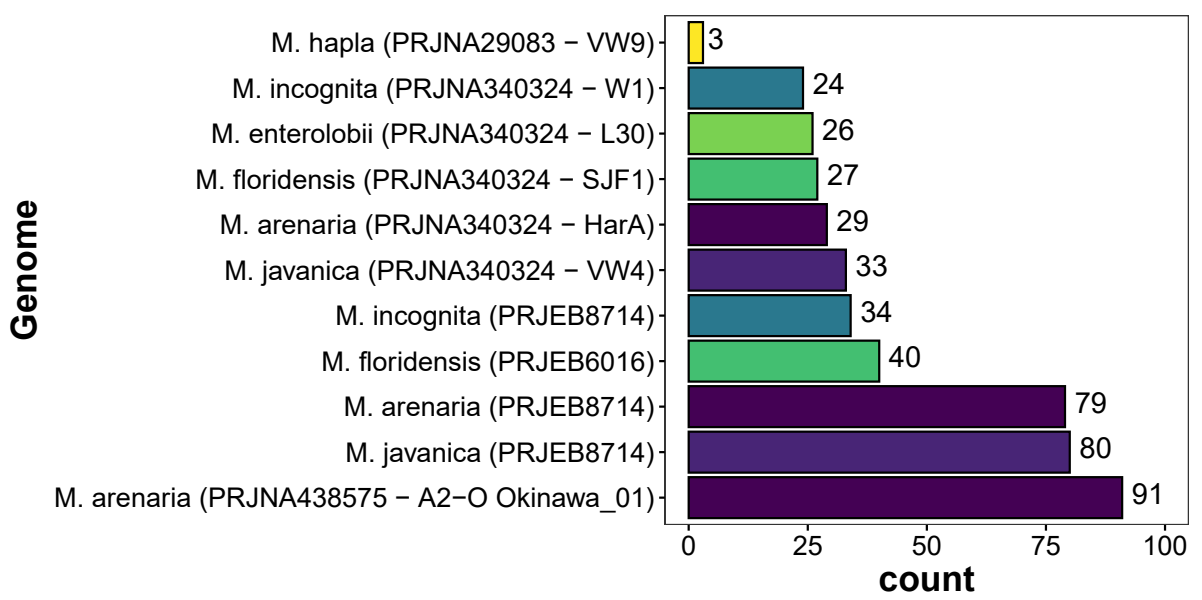

Figure 1. The 27 previously identified M. incognita MiMSP genes and their total unique BLASTN cDNA hits. The BLASTN search was performed within all published nematode genomes containing predicted transcripts and splice variants. All MiMSP gene hits belong to the root-knot nematode genus (Meloidogyne spp.). Colors indicate species.

\footnotetext{
> Table 1. Details of the 27 previously identified M. incognita MiMSP genes. Their alternative names, close homologs (identical groups are represented by the same shade of blue), expression data availability, and known effector characteristics are listed. Additionally, we highlighted (dark grey) the root-knot nematode species where we identified significantly similar genes by a BLASTN cDNA search within all published nematode genomes containing predicted transcripts and splice variants. Likewise, BLASTN CDNA hits within M. incognita are colored yellow. The MiMSP genes are sorted by their occurrence in nematode genomes.
} 


\begin{tabular}{|c|c|c|c|c|c|c|c|c|}
\hline Gene ID & $\begin{array}{c}\text { Common } \\
\text { name }\end{array}$ & Close homologs & $\begin{array}{l}\text { Alternative } \\
\text { (clone) name }\end{array}$ & 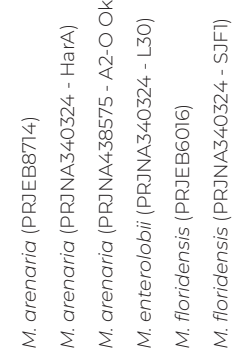 & 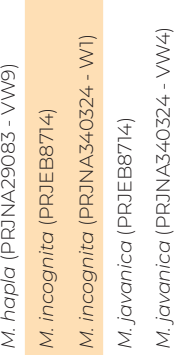 & $\begin{array}{l}\text { Expression during } \\
\text { parasticictages } \\
\text { confired }\end{array}$ & Effector characteristics & References \\
\hline$\overline{A F 53161}$ & MiMSP2 & MiMSP2 & 02002 & ++++++ & ++++ & & HICS reduced virulence & 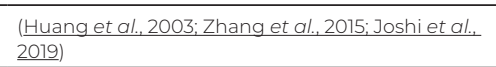 \\
\hline AY134436 & MiMSP17 & MiMSP17 & 16605 & ++++++ & 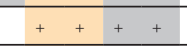 & & NA & (Huang et al. 2003) \\
\hline AVI344433 & MinSP24 & MimSP24 & $34+066$ & $+\ldots++++$ & ++++ & & Soaking dsRNA reduced virulence & (Huang et al, 2003; Shivakumara et al. 2016) \\
\hline AY135363 & MinSP27 & MiMSP27 & 02610 & ++++++ & $++\quad++$ & & NA & (Huang et $a l .2003)$ \\
\hline An'422121 & MinSP31 & MiMSP31, MiMSP32 & 35604 & ++++++ & $+\ldots++$ & & $\mathrm{NA}$ & (Huang et al. 2003) \\
\hline AV142116 & MinSP32 & MiMSP31, MiMSP32 & 19507 & ++++++ & ++++ & Yes; (Shukla et al.2018) & NA & (Huang et of .2003) \\
\hline AY142118 & MiMSP33 & MiMSP33 & 25810 & ++++++ & ++++ & & Soaking dsRNA reduced virulence & (Huang et al. 2003; Shivakumara et al. 2016) \\
\hline AF531169 & Minsp9 & Minspg & 08D05 & ++++++ & ++++ & Yes; (Xue et al. 2013) & 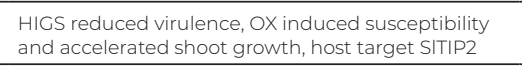 & (Huang et al.2003; Xue et al.2013) \\
\hline AF531160 & MimSPI & MiMSPI, MiMSPI2, MiMSP14 & $02 E 07$ & ++++ & ++++ & Ves: (Shukla et al. 2018) & $\mathrm{NA}$ & (Huang et $\alpha$ l. 2003; Z Zhang et $\alpha$ l. 2015) \\
\hline AVI34431 & MinSPP12 & MiMSPI, MiMSPI2, MiMSP14 & IIAOI & ++ & ++++ & Yes; (Xie et al, 2016) & $\begin{array}{l}\text { VICS reduced virulence and induced JA and } S A \\
\text { related genes, OX suppressed } S A \text { and } J \mathrm{~A} \text { related } \\
\text { genes }\end{array}$ & (Huang et al, 2003; Xie et al. 2016) \\
\hline Al134433 & MinSP14 & MiMSP1, MiMSP12, MiMSP14 & 13A12 & +++++ & $+2+++$ & & $\mathrm{NA}$ & (Huang et $\alpha .2003)$ \\
\hline An134439 & MiMSP2O & MiMSP20 & Зоно7 & +++++ & ++++ & & Soaking dsRNA reduced virulence & $\begin{array}{l}\text { (Huang et al, 2003; Shivakumara et al, 2016; } \\
\text { Shivivakumara et } 1 \text {.2017) }\end{array}$ \\
\hline Al134444 & MiMSP25 & MiMSP25 & $35 \mathrm{ASO2}$ & & ++++ & Yes; (shukla et al.2018) & NA & (Huang et $\alpha .2003)$ \\
\hline An 134432 & MinsPli3 & & 12но3 & $+1++++$ & 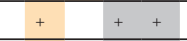 & & NA & (Huang et $a 1.2003)$ \\
\hline Al134442 & MinSP23 & & 34D01 & +++++ & $++\quad++$ & & $\mathrm{NA}$ & (Huang et $\alpha$ l. 2003) \\
\hline AF531164 & MinSPS & MinSP5 & 06007 & $++++1++$ & +++ & & NA & (Huang et $\alpha$ l. 2003; Z Zhang et al.2015) \\
\hline AF531165 & MinsP 6 & & $07 A 01$ & $+\quad++++$ & $\begin{array}{l}++++ \\
\end{array}$ & & NA & (Huang et al, 2003; Z Zhang et al, 2015) \\
\hline AF531167 & Minspil1 & MiMSPII & оэніо & +++ & +++ & & NA & (Huang et $\alpha$ l. 2003) \\
\hline AY134434 & Mimsp15 & & 14506 & ++ & ++ & & NA & (Huang et al. 2003) \\
\hline AY134438 & Minspi9 & MiMSP7, MiMSP15, MiMSP19, MiMSP35 & 21102 & ++ & ++ & & NA & (Huang et al. 2003) \\
\hline AY142119 & MinSP35 & MiMSP7, MiMSP15, MiMSP19, MiMSP35 & 28804 & $+++\quad+$ & ++ & & NA & (Huang et al. 2003) \\
\hline AF531166 & MiMSP7 & MiMSP7, MiMSP15, MiMSP19, MiMSP35 & O7EE12 & 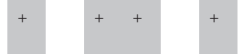 & ++ & & $\begin{array}{l}\text { Xxinduced fast and altered gall formation and egg } \\
\text { enclosion }\end{array}$ & 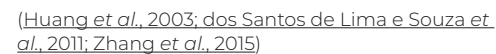 \\
\hline AY134437 & Minspl8 & Minspl8 & $17 \mathrm{HO2}$ & & & & Soaking dsRNA reduced virulence & 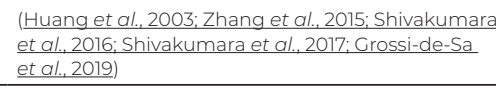 \\
\hline AF531168 & MinSPB & MiMSPB & 07H08 & ++ & + & & NA & (Huang et al, 2003: Zhang et al, 2015) \\
\hline AV134441 & MiMSP22 & MiMSP22 & $31 \mathrm{HO6}$ & + & + & & NA & 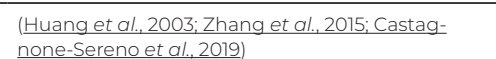 \\
\hline AY142120 & MinSP330 & Minsp30 & 35503 & + & 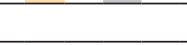 & Yes; (Shukla et al, 2018) & $\mathrm{NA}$ & (Huang et ofl.2003) \\
\hline AY134435 & MiMSP16 & MiMSP16 & 16010 & & & & 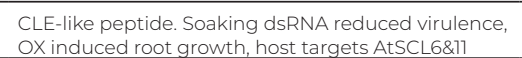 & 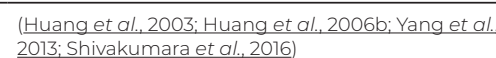 \\
\hline
\end{tabular}




\section{MiMSP17, MiMSP31, and MiMSP32 are under positive selection}

Gene copy number as well as the degree of positive selection on a gene can reveal signatures of adaptive evolution and thus be used to identify effectors (Baskaran et al., 2017). To identify positive selection in the 27 previously identified MiMSP genes, we compared models of codon substitution with a likelihood ratio test. The gene copy number was also included, as the minimum requirement for this analysis is to include a group of at least three genes. Therefore, we selected the six MiMSP genes that met this criterium with hits among the cDNA sequences of the M. incognita PRJEB8714 genome (Blanc-Mathieu et al., 2017) (Figure 2A). We aligned the MiMSP gene groups and used these alignments in the CODEML algorithm of PAML (phylogenetic analysis by maximum likelihood) (Yang, 1997; Yang \& Bielawski, 2000; Yang, 2007) within the EasyCodeML program (Gao et al., 2019). The log-likelihood ratio tests for MiMSP17, MiMSP31, and MiMSP32 significantly ( $a=0.0001$ ) favor model M8 versus M7, suggesting positive selection (Table 2; Supplemental Table S1). As the estimated $\omega$ ratio under model M8 for positive selection for MiMSP31 and MiMSP32 proved to be much larger than 1 (Figure 2B), we selected these two genes for further analyses.

\section{MiMSP31 and MiMSP32 show high sequence similarity}

MiMSP31 and MiMSP32 are both putative esophageal gland cell secretory proteins from the dorsal gland of M. incognita (Huang et al., 2003) that have been grouped together as one pioneer gene (Abad et al., 2008) and show the exact same cDNA hits (Table 1). To identify related proteins and nucleotide sequences in other organisms than nematodes, we used the longer MiMSP32 protein sequence (AAN52090.1) and nucleotide sequence (AY142116.1) in a BLASTP and BLASTN against the entire NCBI-database using standard settings with a standard selection for significance. For the protein sequence, significant hits included MiMSP31 and two unknown released proteins in M. javanica (Table 3). In addition, a hypothetical protein from Tetrapisispora blattae was identified, although sequence identity was very low. We did not identify any known conserved domains or other regions of interest within the MiMSP32 sequences. Likewise, we identified MiMSP33 as an additional shorter sequence expressed in the dorsal gland of M. incognita with a close homology to a part of the MiMSP32 nucleotide sequence (Table 4). Remarkably, MiMSP33 only has similarity to the nucleotide sequence and not to the protein sequence, likely because a frameshift in the translation has occurred relative to MiMSP32. We therefore concluded that MiMSP32 is a putative pioneer effector of tropical Meloidogyne species in an effector family together with MiMSP31 and possibly MiMSP33 as potentially smaller derivative proteins. 
A
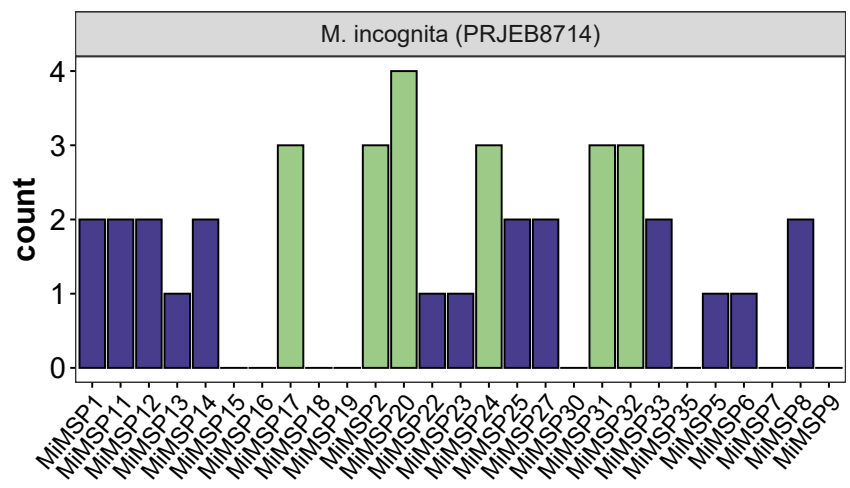

B

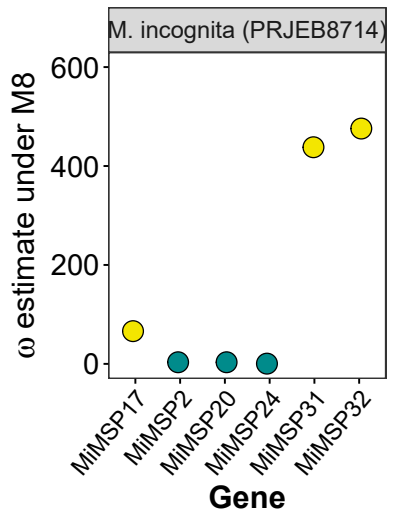

Figure 2. MiMSP17, MiMSP31, and MiMSP32 are under significant positive selection. (A) The 27 previously identified M. incognita MiMSP genes and their total unique BLASTN cDNA hits within the predicted transcripts and splice variants of the M. incognita PRJEB8714 genome. In green, the six MiMSP genes containing sufficient gene copies for use in CodeML $(n \geq 3)$. (B) The $\omega$-ratio estimate under the M8 model for positive selection in M. incognita. In yellow, the groups with a log-likelihood ratio test significantly favoring the M8 model for positive selection ( $\mathrm{P}<0.0001)$

Table 2. Estimates of parameters for the different models of evolution for MiMSP17, MiMSP31 and MiMSP32. In addition, log-likelihood ratio test values for model comparisons are given.

\begin{tabular}{|c|c|c|c|c|c|c|c|c|c|c|}
\hline \multirow{3}{*}{$\begin{array}{l}\text { Pioneer gene } \\
\text { MiMSP17 }\end{array}$} & \multicolumn{2}{|c|}{ Model } & \multicolumn{6}{|c|}{ Estimates of parameters } & \multirow{4}{*}{$\begin{array}{l}\text { Comparison } \\
\text { M7 vs.M8 }\end{array}$} & \multirow{2}{*}{$\frac{\text { LRT P-value }}{0.000}$} \\
\hline & \multirow[t]{2}{*}{ M8 } & \multirow{2}{*}{$\begin{array}{l}\text { Positive selection } \\
\beta+\omega S>1\end{array}$} & po: & 0.976 & $\mathrm{p}:$ & 0.704 & q: & 1.041 & & \\
\hline & & & pl: & 0.024 & $\omega:$ & 66.155 & & & & \\
\hline & M7 & null model; $\beta$ & $\mathrm{p:}$ & 0.008 & $\mathrm{q}:$ & 0.022 & & & & \\
\hline \multirow[t]{3}{*}{ MiMSP31 } & \multirow[t]{2}{*}{ M8 } & \multirow{2}{*}{$\begin{array}{l}\text { Positive selection } \\
\beta+\omega S>1\end{array}$} & po: & 0.981 & p: & 0.026 & q: & 0.025 & \multirow[t]{3}{*}{ M7 vs.M8 } & \multirow[t]{3}{*}{0.000} \\
\hline & & & pl: & 0.019 & $\omega:$ & 437.944 & & & & \\
\hline & M7 & null model; $\beta$ & $\mathrm{p}:$ & 0.079 & q: & 0.080 & & & & \\
\hline \multirow[t]{3}{*}{ MiMSP32 } & \multirow[t]{2}{*}{ M8 } & \multirow{2}{*}{$\begin{array}{l}\text { Positive selection } \\
\beta+\omega S>1\end{array}$} & po: & 0.981 & $\mathrm{p}:$ & 0.054 & $\mathrm{q}:$ & 0.051 & \multirow[t]{3}{*}{ M7 vs.M8 } & \multirow[t]{3}{*}{0.000} \\
\hline & & & pl: & 0.019 & $\omega:$ & 475.738 & & & & \\
\hline & M7 & null model; $\beta$ & $\mathrm{p}:$ & 0.078 & q: & 0.079 & & & & \\
\hline
\end{tabular}

Table 3. MiMSP32 BLASTP hits matching the MiMSP32 protein sequence (AAN52090.1).

\begin{tabular}{|c|c|c|c|c|c|c|c|c|c|}
\hline Description & Accession & $\begin{array}{l}\text { Identity } \\
\text { percent }\end{array}$ & $\begin{array}{l}\text { Sequence } \\
\text { length }\end{array}$ & $\begin{array}{l}\text { Total } \\
\text { identity }\end{array}$ & $\begin{array}{l}\text { Range } \\
\text { length }\end{array}$ & $\begin{array}{l}\text { Range } \\
\text { start }\end{array}$ & $\begin{array}{l}\text { Range } \\
\text { end }\end{array}$ & E-value & Score \\
\hline $\begin{array}{l}\text { putative esophageal gland } \\
\text { cell secretory protein } 31 \\
\text { [Meloidogyne incognita] }\end{array}$ & AAN52095.1 & 100 & 147 & 146 & 146 & 1 & 146 & 0 & 294 \\
\hline $\begin{array}{l}\text { unknown released protein } 1 \\
\text { [Meloidogyne javanica] }\end{array}$ & AAT28126.1 & 62.105 & 121 & 95 & 95 & 1 & 94 & 0 & 106 \\
\hline $\begin{array}{l}\text { unknown released protein } 2 \\
\text { [Meloidogyne javanica] }\end{array}$ & AAT28127.1 & 64.865 & 83 & 74 & 74 & 1 & 74 & 0 & 87.8 \\
\hline $\begin{array}{l}\text { hypothetical protein } \\
\text { TBLA_OCO1580 [Tetrapisis- } \\
\text { pora blattae CBS } 6284 \text { ] }\end{array}$ & XP_004179491.1 & 28.333 & 1408 & 120 & 153 & 794 & 912 & 1.4 & 42 \\
\hline
\end{tabular}




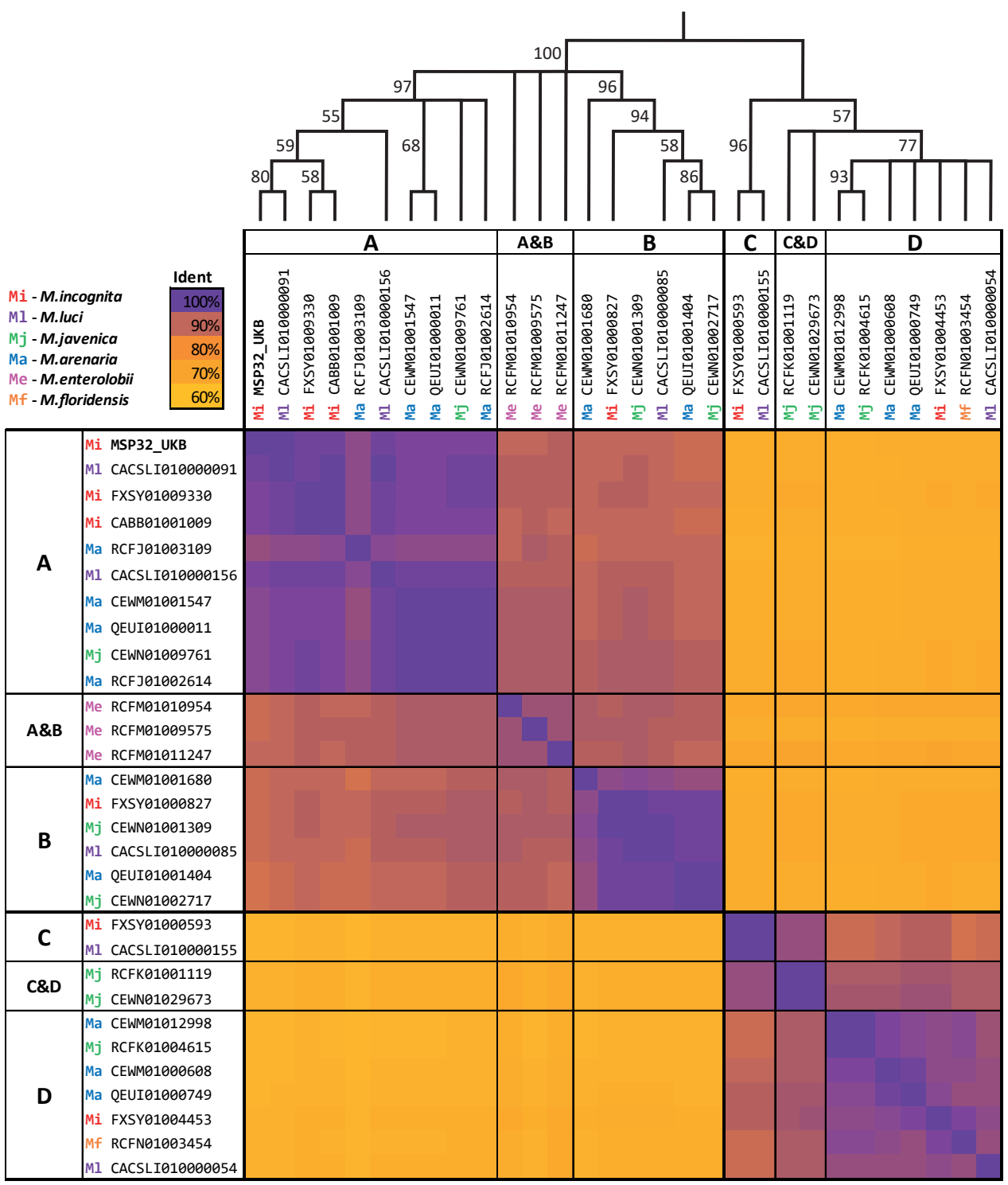

Figure 3. Clustering divided the identified MiMSP32-like translated sequences into two main groups. Included are only predicted protein translations with a full coverage of the MiMSP32 protein sequence with a start codon and no pre-mature stop-codon in the expected coding regions. Identity percentages are represented with a scale from 60\% (yellow) to 100\% (purple) and were calculated at protein sequence level on the core region (MiMSP32; aa 1:215), excluding the highly variable C-terminal end elongations, using the multiple sequence alignment shown in Figure 4. The tree was computed using the Maximum Likelihood method (PhyML implementation) and a substitution model selection based on Bayesian Information Criterion. Branches with a bootstrap support below 50 indicating a poor separation were collapsed. 
Table 4. MiMSP32 BLASTN hits matching the MiMSP32 mRNA sequence (AY142116.1).

\begin{tabular}{|c|c|c|c|c|c|c|c|c|c|}
\hline Description & Accession & $\begin{array}{l}\text { Identity } \\
\text { percent }\end{array}$ & $\begin{array}{l}\text { Sequence } \\
\text { length }\end{array}$ & $\begin{array}{l}\text { Total } \\
\text { identity }\end{array}$ & $\begin{array}{l}\text { Range } \\
\text { length }\end{array}$ & $\begin{array}{l}\text { Range } \\
\text { start }\end{array}$ & $\begin{array}{l}\text { Range } \\
\text { end }\end{array}$ & E-value & Score \\
\hline $\begin{array}{l}\text { Meloidogyne incognita } \\
\text { putative esophageal gland } \\
\text { cell secretory protein } 31 \\
\text { (msp31) mRNA, complete } \\
\text { cds }\end{array}$ & AY142121.1 & 99.799 & 497 & 496 & 522 & 1 & 496 & 0 & 911 \\
\hline $\begin{array}{l}\text { Meloidogyne incognita } \\
\text { putative esophageal gland } \\
\text { cell secretory protein } 31 \\
\text { (msp31) mRNA, complete } \\
\text { cds }\end{array}$ & AY142121.1 & 98.921 & 278 & 275 & 797 & 560 & 836 & 0 & 496 \\
\hline $\begin{array}{l}\text { Meloidogyne incognita } \\
\text { putative esophageal gland } \\
\text { cell secretory protein } 33 \\
\text { (msp33) mRNA, partial cds }\end{array}$ & AY142118.1 & 100 & 50 & 50 & 50 & 1 & 50 & 0 & 93.5 \\
\hline
\end{tabular}

\section{MiMSP32-like potential genes cluster into six branches within the Meloidogyne genus}

To identify additional genes potentially encoding a MiMSP32 homolog, we collected and organized all MiMSP32-like hits from whole genome sequencing projects within the Tylenchoidae superfamily. In addition to the earlier search among predicted transcripts and splice variants, we identified MiMSP32-like hits using TBLASTN in a whole genome sequencing database, using an E-value threshold of $10^{-5}$. Interestingly, all available genome sequences within the Meloidogynidae family contain multiple MiMSP32-like hits, while no significant similarities were identified in either Heteroderidae, Hoplolaimidae, or Pratylenchidae (Supplemental Figure S2). However, other Meloidogynidae families possibly still harbor MiMSP32-like sequences, as currently only four of the ten known Tylenchoidae families contain at least one sequenced nematode species.

Within the Meloidogyne genus, several of the matching potential genes showed a full coverage of the MiMSP32 protein sequence with a start codon and without a pre-mature stop codon in the expected coding region. These MiMSP32-like potential genes were identified in M. incognita, M. javanica, M. arenaria, M. Iuci, M. enterolobii and M. floridensis. Potential genes covering the complete MiMSP32 protein sequence were further retained for analysis and predicted protein translations were used to compute a phylogenetic tree using the Maximum Likelihood method (PhyML implementation) and a substitution model selection based on the Bayesian Information Criterion (Figure 3). The resulting tree consists of two main branches segregated at 65-70\% identity at protein level. The first branch further splits into three subgroups; A, B, and A\&B comprising of three $M$. enterolobii genes sharing 88-92\% identity with both group $A$ and B. The second main branch subdivides into two subgroups $C$ and $D$, while two genes from $M$. javanica share elevated identity (88-93\%) with both groups and were therefore labelled C\&D. Less conserved potential genes matching the MiMSP32 sequence were found in M. hapla and M. graminicola. Altogether, these results suggest a subdivision of MiMSP32-like proteins in six separate clades. 
The two main clusters of MiMSP32-like potential genes contain highly variable regions per subgroup

MiMSP32 belongs to the first subgroup A, sharing $>90 \%$ identity with the other Meloidogyne species homologs from the same subgroup A, but with only 60-70\% identity with the second group (C, D, C\&D clades - Figure 3). This second group partially maps with an UniprotKB entry (M. javanica Q5QH01), although the MjQ5QHO1 protein isoform lacks the region corresponding to the second half of the MiMSP32 protein. The multiple sequence alignment was further profiled to analyze various sequence properties (Figure 4). In this way, a highly acidic stretch was identified within the amino acid region 78-95 which is absent from the MjQ5QHOT-like group. In the first MiMSP32-like group, the amino acid region 78-95 comprises 8 negative charges from a total of around 17 amino acids. In all sequences of the second group, this region is slightly basic (charge +7 to +3 ). In addition, they contain a group specific alternate charged pattern "GKDKE" at the end of this region.

\section{MiMSP32 secondary structure suggests Rossmann $\beta a \beta$-sandwich architecture}

Next, we analyzed the amino acid sequence of MiMSP32 for predicted secondary structures and folding, to infer on possible biochemical activities. As a putative secretory protein, MiMSP32 contains an $\mathrm{N}$-terminal signal peptide. In addition, the secondary structure prediction profile is consistent with the Rossmann fold (CATH 3.40.50) comprising an al pha-beta core composed of five beta sheet segments and five alternatively distributed helical regions (Figure 5A). Consensus predictions of various post-translational modification such as $\mathrm{N}-, \mathrm{O}-$, C- glycosylation and S-, T-, Y- phosphorylation did not retrieve significant sites (with probability values over 50\%). However, the overall sequence homology of MiMSP32 with the available experimentally determined structures currently available in protein structure databases is very low. Very remote homology of MiMSP32 is shown by several protein fragments that all display the Rossmann three-layer beta-alpha-beta ( $\beta a \beta)$-sandwich architecture. For instance, the closest MiMSP32 homologue is human Ras-related binding protein C (PDB 3LLU). This matches to a small 64 amino acids region of MiMSP32 with an identity of around 28\% (Figure 5B).

Large structural differences exist within the Rossmann architecture proteins showing partial homology to MiMSP32. The 3D structure of the most homologous protein 3LLU does not at all resemble the 3D structure of the second most homologous protein, Bacillus cereus Imine Reductase BcSIRED 4 (PDB 4D3D) in terms of both orientation of the helical segments with respect to the overall sandwich, but most importantly in the beta sheet topology (Figure 5C). Altogether, the lack of a consistent template hampers the reliability of a 3D-model for homology modelling of MiMSP32, which led us to abandon this approach. Judging by the Rossmann fold architecture, regardless of how each loop is orientated versus the $\beta a \beta$-sandwich, we expect beta sheet segments to be solvent inaccessible as they should be located in the middle of the protein sandwich, leaving all other regions of the sequence to be close to the protein surface (therefore partially or fully solvent exposed). Moreover, the highly acidic region which is fundamentally different in the second group (the MjQ5QHOT-like group) is most likely solvent exposed. Together, 
we hypothesize that MiMSP32 probably folds in a similar fashion as a Rossmann architecture protein, and possibly carries the typical Rossmann-fold associated properties, such as binding with the ADP portion of dinucleotides such as FAD, NAD, and NADP (Hanukoglu, 2015).
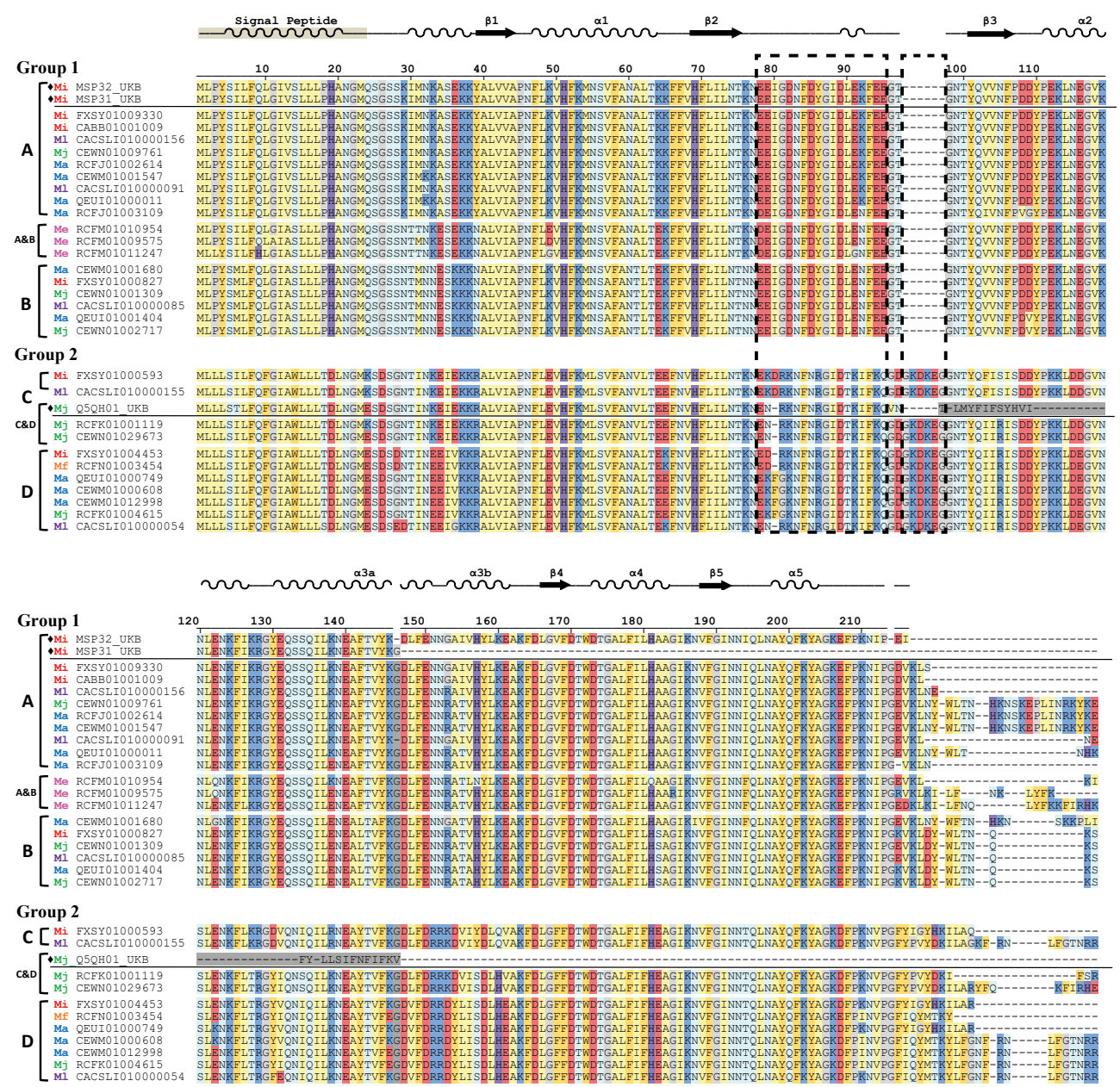

\begin{tabular}{|c|c|}
\hline \\
\hline Mi - M.incognita & Amino acid property color code: \\
\hline Ml - M.luci & Hydrophobic aliphatic (AVLIM) \\
\hline Mj - M.javenica & $\begin{array}{l}\text { Hydrophobic aromatic (FWY) } \\
\text { Neutral Polar (NQST) }\end{array}$ \\
\hline Ma - M.arenaria & Charged $+(\mathrm{KR})$ His, Cys \\
\hline Me - M.enterolobii & Charged - (DE) \\
\hline
\end{tabular}

Figure 4. Alignment of the identified MiMSP32-like translated sequences shows highly variable regions per group. Included are only predicted protein translations with a full coverage of the MiMSP32 protein sequence with a start codon and no pre-mature stop-codon in the expected coding regions. A highly acidic region around amino acids 78-95 is fundamentally different in group 2, and contains a small charged "GKDKE" pattern insertion (dashed boxes). 
A

MiMSP32

sspred

SS_pred

RSA_pred

RaptorX_SS3 RaptorX SS SSPRO SS3 SSPRO - SS8 Psipred SS3 Jnet_ss $\overline{3}$

PsiPred Con Jnet_coñf

RaptorX RSA SSPRO_RSA Jnet_RSA

SSPRO Diso RaptorX Di DisoPred

\section{MiMSP32}

sspred

SS_pred

RSA_pred

RaptorX SS3 RaptorX_SS8 SSPRO_SS3

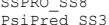
Jnet Ss 3

Psipred Conf Jnet_Conf

RaptorX_RSA SSPRO RSA

SSPRO Diso

Raptorx Di

DisoPred

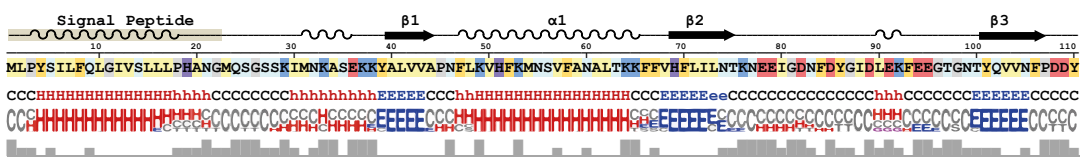

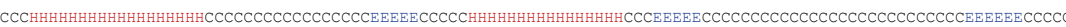
CCCHHHHHHHHHHHHHHHHHHCCCCCCCCCCCCCCCCEEEEEECCCSHHHHHHHHHHHHHHHHTSSEEEEECCCCCCCCCTTCCTTCCGGGCCCCCSCEEEEEECCTTC CCHHHHHHHHHHHECCCCCCCCCCCCCHHCHHHHHCEEE EECHHHHHHHHHHHHHHHHHHHHHCEEEEEECCCCHHHHCCCCCCCHHHCEECCCCEEEEE ECCCCC CCHHHHHHHHHHHHCT T T TTCCTTCCHHHHHHHHHHEEEE ECHHHHHHHHHHHHHHHHHHHHHEEEEEEEECCCHHHHHHHTTCCHHHHEEECSCEEEEEECCTTC CCCHHHHHHHHHHHHHHHHHCCCCCCCCCCCHHHHHCEE EE ECCCHHHHHHHHHHHHHHHHHCEEEEEEEEECCCCCCCCCCCCCCCHHHCCCCCCCCEEEE ECCCCC CCHHHHHHHHHHHHHHHCCCCCCCCCCHHHHHHCCCCCCEEEEECCHHHHHHHHHHHHHHHHHCCCCEEEEEEEECCCCCCCCCCCCCCCCCCCCCCCEEEEEECCCCC

9838899998899985063136776885214426662448998273477867788999999722305899997279851000264132266412545980787308974 97589999999888763177877777601332001135336763672899999999999988752771788531110766777377654512677777448888606874

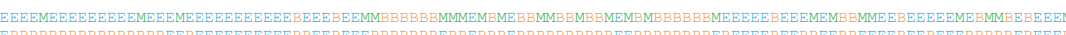

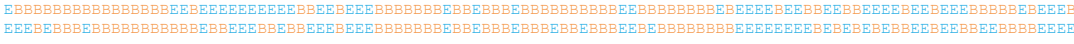

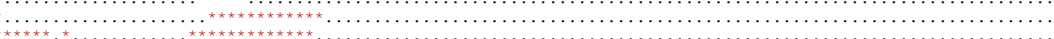

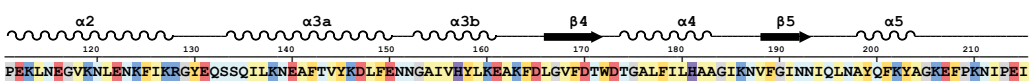
PEKLNEGVKNLENKFIKRGYEQSSQILKNEAFTVYKDLFENNGAIVHYLKEAKFDLGVFDTWDTGALFILHAAGIKNVFGINNIQLNAYQFKYAGKEFPKNIPEI
HHHHHHHHHHHHHHHHHCChhhhHHHHHHHHHHHHHHHHHCHHHHHHHCCCCeeecCHHHHHHHHhCCCCEEEECCCCCHHHHHHHCCCCCCCCCCC

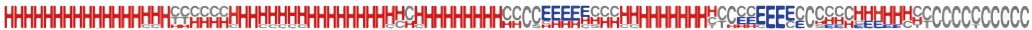
H

HHHHHHHHHHHHHHHHHCCHHHHHHHHHHHHHHHHHHHHHCHHHHHHHHHCCCCEEEECCCHHHHHHHHHHCCCCCEEEEECCCCCHHHHHHHCCCCCCCCCCC

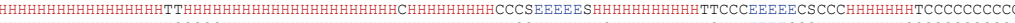

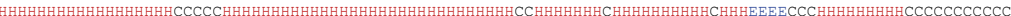
HHHHНHH

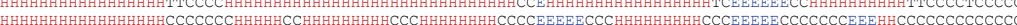
HHHHHHHHHHHHHCCHCHHHHHHHHCCCHHHHHHHHHHCCCHHHHHHHHHCCCCCEEEECCCCCHHHHHHHHCCCCCEECCCCEECCEEEECCCCCCCCCCCCC

488979989888872652552433586741057899998658507998998389856784574457879788166137640784014133020996587669999 1899999994211010011222311002220430445534861378868751456132311372316899931112664020251000011611565556788899

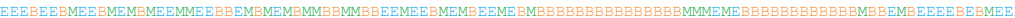
BEEBEEBBEEBEEEBBEEEBEEEEEBBEEEBBBBBEEBEEEEEBBEBBEEBEBBBBBBBBBBBBBBBBBBBBEBEBBBBBBBBEBBBBBBEBBEEEBEEEBEEE

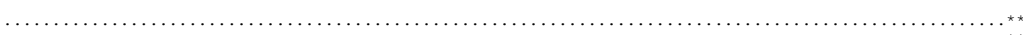

B

$3 L L U$

3LLU_SS

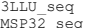

MSP32_ssp

\section{B1}

B2

B3

B4

\begin{tabular}{|c|c|}
\hline 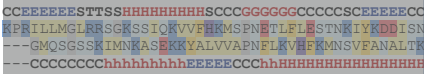 & 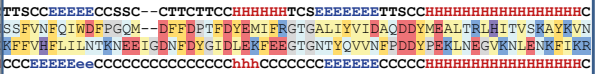 \\
\hline
\end{tabular}

B3

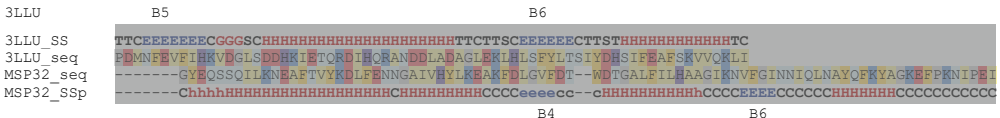

B4

C

3LLU - Human Ras-related GTP-binding protein C

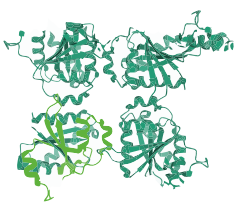

4D3D - Bacillus cereu Imine Reductase BcSIRED

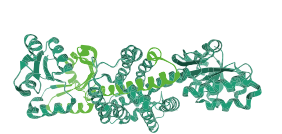

Amino acid property color code: Hydrophobic aliphatic (AVLIM) Hydrophobic aromatic (FWY) neutral Polar (NQST)

- Charged + (KR) = His, Cys - Charged-(DE) Pro, Gly

Figure 5. MiMSP32 protein structure resembles a beta-alpha-beta $(\beta a \beta)$-sandwich architecture. (A) Profile of MiMSP32 protein with the predicted secondary structure, intrinsically disordered regions and relative solvent accessibility, as predicted by several secondary structure recognition tools. The expected secondary structure is noted as either helix $(H, G, I)$, extended $(E)$, strand $(B)$, turn (T), bend (S), or coil (C). (B) Alignment of a fragment of the MiMSP32 sequence and predicted secondary structure to the most homologous 3D-structure available; Ras-related binding protein C (PDB 3LLU). (C) Examples of two protein structures containing a Rossmann fold with similarity to MiMSP32; Ras-related binding protein $C$ (PDB 3LLU) and imine reductase BCSIRED (PBD 4D3D). In light green, the region with homology to MiMSP32 is shown. 


\section{Discussion}

In this chapter, our main goal was to use evidence of gene diversification and positive selection as a selection criterion to identify genes in the genome of M. incognita important for nematode virulence on host plants. Using this approach, we found a remarkably high level of positive selection within M. incognita for MiMSP32, a previously identified gene encoding a putative secreted protein from the dorsal esophageal gland (Huang et al., 2003). With further sequence analyses we identified additional MiMSP32-like potential gene clusters in whole genome sequence datasets of several nematode species within the Tylenchoidae. We further discovered that MiMSP32 is specific for root knot nematodes and that MiMSP32-like potential genes segregate into six subgroups based on the presence of different variable regions.

\section{Several MiMSPs remain undiscovered within revised genome sequences}

All 27 MiMSPs that were originally identified based on mRNA isolated from esophageal gland cells of the root-knot nematode M. incognita (Huang et al., 2003) were called as pioneer genes in the first published M. incognita genome sequence (Abad et al., 2008). However, several of these pioneer genes could not be traced back within the latest version of the $M$. incognita genome. The absence of a particular predicted gene transcript within an updated genome sequence does not necessarily mean that the gene is not transcribed. Instead, cDNA prediction models for the annotation of genome sequences have significant error rates (Patthy, 2016). Alternatively, there might be other technical issues associated with the assembly of highly variable gene variants, short repetitive sequences, or long-read assemblies that lead to erroneous predictions (Watson \& Warr. 2019; Scalzitti et al., 2020). To reduce the effect of gene prediction models, they are often supported by vast amounts of transcriptomics data derived from different life stages of the organism. For example, the M. incognita PRJEB8714 genome by Blanc-Mathieu et al. (2017) includes seven Illumina-based transcriptomes (Danchin et al.., 2013), and a dataset of nine newly generated assemblies from RNA-Seq data. The number of MiMSPs lacking in the current annotated version of the M. incognita genome sequence suggests that the quality of available root-knot nematode genomes can be further improved by including transcriptome data of more life stages.

A notable absentee in the genomes was the putatively secreted M. incognita effector MiMSP16 (also known as 16D10). This protein is secreted from the subventral esophageal gland cells of parasitic second-stage juveniles (J2) affects root growth through its interaction with two putative plant SCARECROW-like transcription factors (Huang et al., 2006b). MiMSP16 contributes to M. incognita virulence in several host plants, such as Arabidopsis, grape, and adzuki bean (Huang et al.., 2006a: Yang et al.., 2013; Shivakumara et al., 2016). In addition, species-specific nematode detection and quantification assays by GPCR have been developed using the DNA sequence of the MiMSP16 effector gene (Gorny et al., 2019). Next to the gland-cell specific expression shown by Huang et al. (2003), other studies show no proof of actual transcription of MiMSP16. For example, Shukla et al. (2018) specifically observed the expression of MiMSPs in different parasitic stages of M. incognita, and could not detect MiMSP16. Therefore, the question arises if MiMSP16 is de facto expressed during parasitic phases of root-knot nematodes. We expect 
MiMSP16 to be expressed in low amounts, hence its detection in esophageal gland cells and its lacking detection in more diluted material. This however does not explain the absence of the effector sequence in all the Meloidogyne genomes we analyzed. One possibility is that this gene is not generally found across all Meloidogyne strains, for example by association to ancient conserved haplotypes (Lee et al., 2020; Todesco et al., 2020).

\section{Genes under positive selection}

Genes encoding MiMSP31 and MiMSP32 are under a positive selection as we showed by the log-likelihood ratio tests highly favoring the models that allow for selection (M2a, M3 and M8). This study shows a high degree of positive selection on the MiMSP32 allele in the published M. incognita genome. Interestingly, other effector studies in nematodes have shown that positive selection can be used as a selection criterion to identify virulence factors (Baskaran et al., 2017). In addition to our initial identification of three potential cDNA gene copies of MiMSP32 in M. incognita, the more elaborate search performed on whole genome sequencing projects within the Tylenchoidae superfamily revealed a total of six gene variants in $M$. incognita. The high number of MiMSP32-like genes suggests that this gene family has either developed mutations because it is in a coevolutionary arms race with a host gene, or that it has diversified to adapt new functions.

Two reasons can cause effectors to develop mutations in a coevolutionary arms race; i.e. to avoid recognition by plant receptors or to adapt to changes of a host target gene (Cook et al., 2015). The widely accepted zig-zag model (Jones \& Dangl, 2006) therefore assumes diversifying selection in both host and pathogen genes to achieve or avoid effector-triggered immunity. Likewise, plant genes can also be in an arms race with effectors to avoid binding to so-called susceptibility genes (van Schie \& Takken, 2014; Thordal-Christensen, 2020). This coevolutionary arms race results in the genomic variability of effector genes (Karasov et al., 2014). For example, the Phytophthora infestans RXLR effector AVR2 has a high genetic variation caused by point mutations, deletions, insertions, early-termination, start codon changes, and intragenic recombination, which enables it to evade detection by resistance proteins (Yang et al., 2020).

Effector gene expansion on the other hand can result in the acquisition of new functions by beneficial mutations (Näsvall et al., 2012). In nematodes for example, extensive replication and mutation resulted in the development of glutathione synthetase (GS)-like effectors by neofunctionalization of a housekeeping glutathione synthetase gene (Lilley et al., 2018). A more extreme example for genes participating in a coevolutionary arms race and also acquiring new gene functions is given by the plant pathogenic bacteria of the genus Xanthomonas and their transcription activator-like effectors (TALEs). Out of the in total 53 sequenced TALE genes in Xanthomonas campestris, individual strains can contain highly varying numbers; from zero to more than two dozen (Denancé et al., 2018). Under constant evolutionary pressure, TALEs constantly evolve to remain the capacity to induce susceptibility genes while the host constantly evolves to avoid this process (Hutin et al., 2015). In addition, the same family of effectors has evolved into truncated versions of TALEs that somewhere obtained the ability to interfere with 
resistance genes and neutralize plant resistance (Ji et al., 2016).

Next to genes participating in a coevolutionary arms race or genes acquiring new functions, the copy number of genes in M. incognita can also be used as signatures of adaptive evolution (Castagnone-Sereno et al., 2019). Castagnone-Sereno et al. (2019) show that highly plastic genome regions exist in $M$. incognita, where selection pressure causes more gene duplications and losses than at other regions. Possibly, the genome region where MiMSP32-like genes reside is such a variable region, resulting in a variable number of MiMSP32-like genes. Usually, a high gene copy number translates into a high expression of the gene (Birchler \& Veitia, 2012). However, the interplay of many more mechanisms, such as gene location and promoter elements, mediates the final gene dosing effects (Veitia et al., 2013). In order to study variations in the MiMSP32-like gene repertoire in detail and determine possible gene dosing effects, future studies with sequencing data for individual M. incognita strains or even individual nematodes are necessary. So far, we can argue that based on its adaptive evolution and gene expansion, the acquisition of a new functional diversity is the most likely cause of the occurrence of MiMSP32-like genes.

\section{MiMSP32-like gene clusters}

Remarkably, all root-knot nematode species harboring potential genes with a full coverage of the MiMSP32 protein sequence with a start codon and no pre-mature stop-codon in the expected coding regions are from Meloidogyne group I: M. incognita, M. javanica, M. arenaria, M. Iuci, M. enterolobii and M. floridensis (Álvarez-Ortega et al., 2019). The root-knot nematode species with less conserved potential genes matching the MiMSP32 sequence are either from Meloidogyne group II (M. hapla) or group III (M. graminicola). In contrast to nematodes from Meloidogyne group I, members of Meloidogyne group II and III reproduce sexually (Castagnone-Sereno \& Danchin, 2014). Among asexually reproducing nematodes, we would expect a lower gene conservation, as Castagnone-Sereno et al. (2019) show that the asexually reproducing Meloidogyne contain remarkably diverse genomes. This however contradicts our findings, as the more diverse and thus less conserved gene clusters exist solely in asexual species. Possibly, the mode of reproduction explains the level of sequence conservation. The polyploid nature of genomes from asexual organisms could serve as a buffer against unfavorable mutations (Archetti, 2004: Sattler et al.. 2016). In that case, mutated genes would have additional original copies, thus significantly lowering the chance of the mutation being incorporated in the next generations. The majority of MiMSP32-like potential genes in subgroups A, B and A\&B with high identity to MiMSP32 originated from M. incognita, M. javanica and M. arenaria, which are all members of an asexually reproducing complex known as the $M$. incognita group. The small number of root-knot nematode genomes with a close ortholog of MiMSP32 present suggests a relatively recent innovation of the gene.

The origin of plant parasitism in nematodes has likely evolved by horizontal gene transfer from a variety of sources (Scholl et al., 2003; Haegeman et al., 2011; Bird et al., 2015; Danchin et al., 2016). It has been hypothesized that horizontal gene transfer events have played a key 
role in every one of the at least four phylogenetic clades where plant parasitism has evolved (van Megen et al., 2009; Kikuchi et al., 2017). In specific, horizontal gene transfer from bacteria and fungi is responsible for several cell-wall degrading nematode effectors (Smant et al., 1998; Popeijus et al., 2000; Qin et al.., 2004: Danchin et al., 2010). For example, the pine wood nematode Bursaphelenchus xylophilus contains a family of GHF45 cellulases very similar to those in fungi (Kikuchi et al., 2004). However, the only close hits to MiMSP32 are found within root-knot nematodes. In addition, we did identify resemblance to a hypothetical protein from the budding yeast species Tetrapisispora blattae. As the resemblance is to a hypothetical protein with a very low identity percentage to MiMSP32, MiMSP32 remains a pioneer gene. Therefore, the origin remains unsolved of MiMSP32 as well as many other M. incognita pioneer effectors without a known or predicted function (Bournaud et al.. 2018; Mejias et al., 2019).

\section{MiMSP32 secondary structure}

We expect MiMSP32 to fold into the typical three-layer beta-alpha-beta ( $\beta a \beta)$-sandwich architecture of a Rossmann fold architecture protein, as all templates with similarity to MiMSP32 suggest. The Rossmann fold is one of the five most common super-secondary structures in proteins. Proteins associated with a Rossmann fold often bind with the ADP portion of dinucleotides such as FAD, NAD, and NADP (Hanukoglu, 2015). For example, the Ras-related binding protein C (RRACC) (PDB 3LLU) has a 3D-structure available which is the most homologous to MiMSP32. RRAGC is an essential GTPase that functions in humans as a molecular switch in nutrient-activated rapamycin complex 1 (Long et al., 2016). The second most homologous 3D-structure available is that of imine reductase BCSIRED (PBD 4D3D). BCSIRED is an oxidoreductase from Bacillus cereus BAG3X2 that catalyzes the S-selective reduction of cyclic imine 2-methylpyrroline (Man et al.. 2015). These two proteins with highly varying structure, functions, and origin do not allow for assumptions based on the structural function of MiMSP32. However, an intriguing example of effectors harboring ADP-binding capacities is given by the Pseudomonas syringae effectors HopU1 and HopF2 that covalently attach NAD+-derived ADP-ribose monomers to target proteins to achieve stealthy attacks to the host (Feng et al., 2016). Future studies into protein functioning are necessary to shed light on the subcellular processes and functions of MiMSP32.

\section{Conclusion}

Multiple putative effector characteristics together suggest the pioneer gene MiMSP32 as a bona fide effector. In this chapter, we showed not only an expansion of the MiMSP32-like gene family, but also evidence of positive selection on the gene copies. Based on the adaptive evolution and gene expansion, we hypothesize that MiMSP32 has undergone functional diversification. In combination with the original detection of this putatively secreted protein in the dorsal gland of M. incognita (Huang et al., 2003) and its expression during parasitic stages (Shukla et al.. 2018), MiMSP32 is a high-ranking candidate effector. To check this hypothesis and unravel the molecular working mechanisms, we suggest further studies to identify the host targets of MiMSP32. Therefore, a further characterization of MiMSP32 in planta is necessary to study its potential role in nematode virulence and host plant susceptibility. 


\section{Materials and methods}

\section{Comparative sequence analysis}

The complete mRNA sequences of the known 27 pioneer MiMSP genes (Abad et al., 2008) (Table 1) were used in a nucleotide BLASTN algorithm at the Wormbase Parasite cDNA database, comprising most of the published nematode genomes containing predicted transcripts and splice variants (at parasite.wormbase.org, accessed at May 2020). Hits with a BLASTN score below 100 were regarded as false positives and removed from the dataset. The different genomes wherein hits were identified include the PRJEB8714 dataset for M. arenaria, M. incognita, and M. javanica (Blanc-Mathieu et al., 2017), the PRJNA340324 dataset for M. arenaria, M. enterolobii, M. floridensis, M. incognita, and M. javanica (Szitenberg et al., 2017), the PRJNA438575 dataset for M. arenaria (Sato et al., 2018), the PRJEB6016 dataset version nMf.1.0 from nematodes.org for M. floridensis, and the PRJNA29083 dataset for M. hapla (Opperman et al., 2008).

\section{Preparation of gene clusters}

The Meloidogyne incognita (PRJEB8714) coding sequence (CDS) of the cDNA hits per pioneer gene were aligned using a standard ClustalW cost matrix. We prioritized this genomic dataset above the PRJNA340324 - W1-variant, because the MiMSP-like gene numbers were higher and it thus would allow for more MiMSP-genes to be included in the analysis. If the alignment of a sequence resulted in a frame shift of the whole alignment, sequences were excluded from the analysis. For the resulting gene sequences, a cluster tree was constructed with the Tamura-Nei genetic distance model.

\section{Detection of positive, diversifying selection}

Groups containing at least three genes were used in the CODEML algorithm of PAML 4.7 (phylogenetic analysis by maximum likelihood) (Yang, 1997; Yang \& Bielawski, 2000; Yang, 2007) within EasyCodeML v1.21 (Gao et al., 2019). As input files, we used the aligned CDS nucleotide sequences of the $M$. incognita orthogroups and a Neighbour-Joining tree under the Tamura-Nei genetic distance model. EasyCodeML was run under the Preset mode for nested models, and we used the option for site models to compare different models of evolution.

\section{Protein profiling}

To predict structural and functional features from the MiMSP32 amino acid sequence (AAN52090.1), a structural profiling was performed using several prediction methods, i.e. RaptorX2 (Källberg et al., 2012: Wang et al.., 2016), Scratch (Magnan \& Baldi, 2014), PsiPred4 (Buchan \& Jones, 2019) and Jpred4 (Drozdetskiy et al., 2015) for secondary structure, relative solvent accessibility and intrinsically disordered regions. Identification of structural templates was done in Phyre2 (Kelley et al., 2015) and pblast (Altschul et al., 1990) within the PDB structural database. Post translational modification prediction for $\mathrm{N}-, \mathrm{O}-, \mathrm{C}-$ linked glycosylation was performed using NetNGlyc (Blom et al., 2004), N-GlyDE (Pitti et al., 2019), NetOGlyc (Steentoft et al., 2013), NetCGlyc (Julenius, 2007), GlycoMine (Li et al., 2015), while S-, T-, Y- phosphorylation predictions using MusiteDeep (Wang et al.. 2017), NetPhos (Blom et al.., 1999) and NetPhosPan 
(Fenoy et al., 2019).

\section{WGS analysis}

In order to characterize the MiMSP32 protein, a series of bioinformatic analyses were performed. The amino acid sequence of MiMSP32 was used to perform TBLASTN (Altschul et al., 1990; Gertz et al., 2006) inquiries against the whole-genome shotgun contigs (WCS) database in the Tylenchoidea superfamily, with an E-value threshold of $10^{-5}$ in order to find loci that could potentially encode for MiMSP32 homologues. The results were filtered based on sequence identity, sequence length, coverage of the query sequence and absence of stop codons in the expecting coding regions. The most preserved copies that might potentially encode a MiMSP32/MiMSP31-like protein were further retained for analysis. Protein translation predictions were performed with Augustus (Stanke et al., 2008), FGENESH and homology-based FGENESH+ (Solovyev et al., 2006), using the available nematode species models.

Multiple sequence alignments were generated using the T-Coffee (Notredame et al., 2000), as implemented in Unipro UGENE v34.0 (Okonechnikov et al., 2012). To infer the evolutionary relationship between the sequences, Maximum Likelihood (ML) PhyML 3.0 implementation was used (Guindon et al., 2010). Substitution model selection was performed by SMS (Lefort et al., 2017) with BIC (Bayesian Information Criterion). To assess the robustness of individual nodes in the phylogeny analysis, a bootstrap resampling process of 100 replications was employed. Phylogeny trees figures were generated with TOL v5 (Letunic \& Bork, 2019).

\section{Acknowledgements}

This work was financially supported by the Dutch Research Council (NWO) Domain Applied and Engineering Sciences (AES/TTW) grant 11042. M.G.S. Was supported by NWO domain Applied and Engineering Sciences VENI grant (17282). The authors declare no conflict of interest.

\section{Author contributions}

A.V., E.C.M, A.F-T., P.P., and G.S. conceived the study and designed the experiments. A.V., E.C.M, L.M., and J.J.M.V.S. performed the experiments and analysed the data and A.V., E.C.M. L.M., A.J.P., M.G.S., A.G. and G.S. wrote the paper.

\section{References}

Abad P, Gouzy J, Aury J-M, Castagnone-Sereno P, Danchin EGJ, Deleury E, Perfus-Barbeoch L, Anthouard V, Artiguenave F, Blok VC, et al. 2008. Genome sequence of the metazoan plant-parasitic nematode Meloidogyne incognita. Nature biotechnology 26(8): 909-915.

Abad P, Williamson VM. 2010. Plant nematode interaction: a sophisticated dialogue. Advances in Botanical Research 53 : 147-192.

Altschul SF, Gish W, Miller W, Myers EW, Lipman DJ. 1990. Basic local alignment search tool. Journal of molecular biology 
215(3): 403-410

Álvarez-Ortega S, Brito JA, Subbotin SA. 2019. Multigene phylogeny of root-knot nematodes and molecular characterization of Meloidogyne nataliei Golden, Rose \& Bird, 1981 (Nematoda: Tylenchida). Scientific Reports 9: 11788.

Archetti M. 2004. Loss of complementation and the logic of two-step meiosis. Journal of Evolutionary Biology 17(5): 1098-1105.

Baskaran P, Jaleta TG, Streit A, Rödelsperger C. 2017. Duplications and positive selection drive the evolution of parasitism-associated gene families in the nematode Strongyloides papillosus. Genome Biology and Evolution 9(3): 790-801.

Bebber DP, Holmes T, Gurr SJ. 2014. The global spread of crop pests and pathogens. Global Ecology and Biogeography 23(12): 1398-1407.

Birchler JA, Veitia RA. 2012. Gene balance hypothesis: Connecting issues of dosage sensitivity across biological disciplines. Proc Natl Acad Sci U SA 109(37): 14746

Bird DM, Jones JT, Opperman CH, Kikuchi T, Danchin EGJ. 2015. Signatures of adaptation to plant parasitism in nematode genomes. Parasitology 142: S71-S84.

Blanc-Mathieu R, Perfus-Barbeoch L, Aury J-M, Da Rocha M, Gouzy J, Sallet E, Martin-Jimenez C, Bailly-Bechet M, Castagnone-Sereno P, Flot J-F, et al. 2017. Hybridization and polyploidy enable genomic plasticity without sex in the most devastating plant-parasitic nematodes. PLoS Genetics 13(6): e1006777.

Blom N, Gammeltoft S, Brunak S. 1999. Sequence and structure-based prediction of eukaryotic protein phosphorylation sites. Journal of molecular biology 294(5): 1351-1362.

Blom N, Sicheritz-Pontén T, Gupta R, Gammeltoft S, Brunak S. 2004. Prediction of post-translational glycosylation and phosphorylation of proteins from the amino acid sequence. Proteomics 4(6): 1633-1649.

Booker TR, Jackson BC, Keightley PD. 2017. Detecting positive selection in the genome. BMC biology 15(1): 98.

Bournaud C, Gillet F-X, Murad AM, Bresso E, Albuquerque EVS, Grossi-de-Sá MF. 2018. Meloidogyne incognita PASSE-MURAILLE (MiPM) gene encodes a cell-penetrating protein that interacts with the CSN5 subunit of the COP9 signalosome. Frontiers in plant science $\mathbf{9}(904)$.

Buchan DWA, Jones DT. 2019. The PSIPRED Protein Analysis Workbench: 20 years on. Nucleic acids research 47(W7): W402W407.

Castagnone-Sereno P, Danchin EGJ. 2014. Parasitic success without sex - the nematode experience. Journal of Evolutionary Biology 27(7): 1323-1333.

Castagnone-Sereno P, Mulet K, Danchin EGJ, Koutsovoulos GD, Karaulic M, Da Rocha M, Bailly-Bechet M, Pratx L, Perfus-Barbeoch L, Abad P. 2019. Gene copy number variations as signatures of adaptive evolution in the parthenogenetic, plant-parasitic nematode Meloidogyne incognita. Molecular Ecology 28(10): 2559-2572.

Cook DE, Mesarich $\mathrm{CH}$, Thomma BPHJ. 2015. Understanding plant immunity as a surveillance system to detect invasion. Annual review of phytopathology 53(1): 541-563.

Danchin EG, Arguel M-J, Campan-Fournier A, Perfus-Barbeoch L, Magliano M, Rosso M-N, Da Rocha M, Da Silva C, Nottet N, Labadie K. 2013. Identification of novel target genes for safer and more specific control of root-knot nematodes from a pan-genome mining. PLoS Pathogens.

Danchin EGJ, Guzeeva EA, Mantelin S, Berepiki A, Jones JT. 2016. Horizontal gene transfer from bacteria has enabled the plant-parasitic nematode Clobodera pallida to feed on host-derived sucrose. Molecular biology and evolution 33(6): 15711579 .

Danchin EGJ, Rosso M-N, Vieira P, de Almeida-Engler J, Coutinho PM, Henrissat B, Abad P. 2010. Multiple lateral gene transfers and duplications have promoted plant parasitism ability in nematodes. Proc Nat/ Acad Sci U S A 107(41): 17651.

Denancé N, Szurek B, Doyle EL, Lauber E, Fontaine-Bodin L, Carrère S, Guy E, Hajri A, Cerutti A, Boureau T, et al. 2018. Two ancestral genes shaped the Xanthomonas campestris TAL effector gene repertoire. New Phytologist 219(1): 391-407.

dos Santos de Lima e Souza D, de Souza Junior JDA, Grossi-de-Sá M, Rocha TL, Fragoso RdR, de Deus Barbosa AEA, de Oliveira GR, Nakasu EYT, de Sousa BA, Pires NF, et al. 2011. Ectopic expression of a Meloidogyne incognita dorsal gland protein in tobacco accelerates the formation of the nematode feeding site. Plant Science 180(2): 276-282.

Drozdetskiy A, Cole C, Procter J, Barton GJ. 2015. JPred4: a protein secondary structure prediction server. Nucleic acids research 43(W7): W389-W394

Feng B, Liu C, Shan L, He P. 2016. Protein ADP-ribosylation takes control in plant-bacterium interactions. PLoS Pathogens 12(12): e1005941

Fenoy E, Izarzugaza JMG, Jurtz V, Brunak S, Nielsen M. 2019. A generic deep convolutional neural network framework for prediction of receptor-ligand interactions-NetPhosPan: application to kinase phosphorylation prediction. Bioinformatics 35(7): 1098-1107

Gao F, Chen C, Arab DA, Du Z, He Y, Ho SYW. 2019. EasyCodeML: A visual tool for analysis of selection using CodeML. Ecology and Evolution 9(7): 3891-3898

Gertz EM, Yu Y-K, Agarwala R, Schäffer AA, Altschul SF. 2006. Composition-based statistics and translated nucleotide 
searches: Improving the TBLASTN module of BLAST. BMC biology 4(1): 41

Gorny AM, Wang X, Hay FS, Pethybridge SJ. 2019. Development of a species-specific PCR for detection and quantification of Meloidogyne hapla in soil using the 16D10 root-knot nematode effector gene. Plant Disease 103(8): 1902-1909.

Grossi-de-Sa M, Petitot A-S, Xavier DA, Sá MEL, Mezzalira I, Beneventi MA, Martins NF, Baimey HK, Albuquerque EVS, Grossi-de-Sa MF, et al. 2019. Rice susceptibility to root-knot nematodes is enhanced by the Meloidogyne incognita MSP18 effector gene. Planta 250(4): 1215-1227.

Guindon S, Dufayard J-F, Lefort V, Anisimova M, Hordijk W, Gascuel O. 2010. New algorithms and methods to estimate maximum-likelihood phylogenies: assessing the performance of PhyML 3.0. Systematic Biology 59(3): 307-321.

Haegeman A, Jones JT, Danchin EG. 2011. Horizontal gene transfer in nematodes: a catalyst for plant parasitism? Molecular Plant-Microbe Interactions 24(8): 879-887.

Hanukoglu I. 2015. Proteopedia: Rossmann fold: A beta-alpha-beta fold at dinucleotide binding sites. Biochemistry and Molecular Biology Education 43(3): 206-209.

Huang G, Allen R, Davis EL, Baum TJ, Hussey RS. 2006a. Engineering broad root-knot resistance in transgenic plants by RNAi silencing of a conserved and essential root-knot nematode parasitism gene. Proc Nat/ Acad Sci U S A 103(39): 14302-14306.

Huang G, Dong R, Allen R, Davis EL, Baum TJ, Hussey RS. 2006b. A root-knot nematode secretory peptide functions as a ligand for a plant transcription factor. Molecular Plant-Microbe Interactions 19(5): 463-470.

Huang G, Gao B, Maier T, Allen R, Davis EL, Baum TJ, Hussey RS. 2003. A profile of putative parasitism genes expressed in the esophageal gland cells of the root-knot nematode Meloidogyne incognita. Molecular Plant-Microbe Interactions 16(5): 376-381.

Hussey RS. 1989. Disease-inducing secretions of plant-parasitic nematodes. Annual review of phytopathology 27(1): 123-141.

Hutin M, Pérez-Quintero AL, Lopez C, Szurek B. 2015. MorTAL Kombat: the story of defense against TAL effectors through loss-of-susceptibility. Frontiers in plant science 6(535).

Ji Z, Ji C, Liu B, Zou L, Chen G, Yang B. 2016. Interfering TAL effectors of Xanthomonas oryzae neutralize R-gene-mediated plant disease resistance. Nature Communications 7(1): 13435.

Jones JD, Dangl JL. 2006. The plant immune system. nature 444(7117): 323-329.

Jones JT, Haegeman A, Danchin EG, Gaur HS, Helder J, Jones MG, Kikuchi T, Manzanilla-López R, Palomares-Rius JE, Wesemael WM. 2013. Top 10 plant-parasitic nematodes in molecular plant pathology. Molecular Plant Pathology 14(9): 946-967.

Joshi I, Kumar A, Singh AK, Kohli D, Raman KV, Sirohi A, Chaudhury A, Jain PK. 2019. Development of nematode resistance in Arabidopsis by HD-RNAi-mediated silencing of the effector gene Mi-msp2. Scientific Reports 9(1): 17404.

Julenius K. 2007. NetCGlyc 1.0: prediction of mammalian C-mannosylation sites. Glycobiology 17(8): 868-876.

Källberg M, Wang H, Wang S, Peng J, Wang Z, Lu H, Xu J. 2012. Template-based protein structure modeling using the RaptorX web server. Nature Protocols 7(8): 1511.

Karasov TL, Horton MW, Bergelson J. 2014. Genomic variability as a driver of plant-pathogen coevolution? Current opinion in plant biology 18: 24-30.

Kelley LA, Mezulis S, Yates CM, Wass MN, Sternberg MJE. 2015. The Phyre2 web portal for protein modeling, prediction and analysis. Nature Protocols 10(6): 845-858

Kikuchi T, Eves-van den Akker S, Jones JT. 2017. Genome evolution of plant-parasitic nematodes. Annual review of phytopathology 55(1).

Kikuchi T, Jones JT, Aikawa T, Kosaka H, Ogura N. 2004. A family of glycosyl hydrolase family 45 cellulases from the pine wood nematode Bursaphelenchus xylophilus. FEBS Letters 572(1): 201-205.

Lee D, Zdraljevic S, Stevens L, Wang Y, Tanny RE, Crombie TA, Cook DE, Webster AK, Chirakar R, Baugh LR, et al. 2020. Balancing selection maintains ancient genetic diversity in C. elegans. bioRxiv: 2020.2007.2023.218420.

Lefort V, Longueville J-E, Gascuel O. 2017. SMS: Smart Model Selection in PhyML. Molecular biology and evolution 34(9): 2422-2424.

Letunic I, Bork P. 2019. Interactive Tree Of Life (TOL) V4: recent updates and new developments. Nucleic acids research 47(W1): W256-W259.

Li F, Li C, Wang M, Webb GI, Zhang Y, Whisstock JC, Song J. 2015. GlycoMine: a machine learning-based approach for predicting N-, C- and O-linked glycosylation in the human proteome. Bioinformatics 31(9): 1417-1419.

Lilley CJ, Maqbool A, Wu D, Yusup HB, Jones LM, Birch PR, Banfield MJ, Urwin PE, Eves-van den Akker S. 2018. Effector gene birth in plant parasitic nematodes: Neofunctionalization of a housekeeping glutathione synthetase gene. PLoS Genetics 14(4): e1007310.

Long PA, Zimmermann MT, Kim M, Evans JM, Xu X, Olson TM. 2016. De novo RRAGC mutation activates mTORC1 signaling in syndromic fetal dilated cardiomyopathy. Human Cenetics 135(8): 909-917.

Magnan CN, Baldi P. 2014. SSpro/ACCpro 5: almost perfect prediction of protein secondary structure and relative solvent 
accessibility using profiles, machine learning and structural similarity. Bioinformatics 30(18): 2592-2597.

Man H, Wells E, Hussain S, Leipold F, Hart S, Turkenburg JP, Turner NJ, Grogan G. 2015. Structure, activity and stereoselectivity of NADPH-dependent oxidoreductases catalysing the S-selective reduction of the imine substrate 2-methylpyrroline. ChemBioChem 16(7): 1052-1059.

Mejias J, Truong NM, Abad P, Favery B, Quentin M. 2019. Plant proteins and processes targeted by parasitic nematode effectors. Frontiers in plant science 10: 970-970

Mitchum MG, Hussey RS, Baum TJ, Wang X, Elling AA, Wubben M, Davis EL. 2013. Nematode effector proteins: an emerging paradigm of parasitism. New Phytologist 199(4): 879-894.

Näsvall J, Sun L, Roth JR, Andersson DI. 2012. Real-time evolution of new genes by innovation, amplification, and divergence. Science 338(6105): 384

Nicol JM, Turner SJ, Coyne DL, Nijs Ld, Hockland S, Maafi ZT. 2011. Current nematode threats to world agriculture. In: Jones J, Gheysen G, Fenoll C eds. Genomics and Molecular Genetics of Plant-Nematode Interactions. Dordrecht: Springer Netherlands, 21-43.

Notredame C, Higgins DG, Heringa J. 2000. T-coffee: a novel method for fast and accurate multiple sequence alignment. Journal of molecular biology 302(1): 205-217.

Okonechnikov K, Golosova O, Fursov M, the Ut. 2012. Unipro UGENE: a unified bioinformatics toolkit. Bioinformatics 28(8): $1166-1167$.

Opperman CH, Bird DM, Williamson VM, Rokhsar DS, Burke M, Cohn J, Cromer J, Diener S, Gajan J, Graham S. 2008. Sequence and genetic map of Meloidogyne hapla: A compact nematode genome for plant parasitism. Proc Natl Acad Sci USA 105(39): 14802-14807

Papkou A, Guzella T, Yang W, Koepper S, Pees B, Schalkowski R, Barg M-C, Rosenstiel PC, Teotónio H, Schulenburg H. 2019. The genomic basis of Red Queen dynamics during rapid reciprocal host-pathogen coevolution. Proc Natl Acad Sci U S A 116(3): 923

Patthy L. 2016. Identification and Correction of Erroneous Protein Sequences in Public Databases. In: Carugo O, Eisenhaber F eds. Data Mining Techniques for the Life Sciences. New York, NY: Springer New York, 179-192.

Pitti T, Chen C-T, Lin H-N, Choong W-K, Hsu W-L, Sung T-Y. 2019. N-GlyDE: a two-stage N-linked glycosylation site prediction incorporating gapped dipeptides and pattern-based encoding. Scientific Reports 9(1): 15975.

Popeijus H, Overmars H, Jones J, Blok V, Goverse A, Helder J, Schots A, Bakker J, Smant G. 2000. Enzymology: degradation of plant cell walls by a nematode. nature 406(6791): 36 .

Qin L, Kudla U, Roze EH, Goverse A, Popeijus H, Nieuwland J, Overmars H, Jones JT, Schots A, Smant G. 2004. Plant degradation: a nematode expansin acting on plants. nature 427(6969): 30.

Sato K, Kadota Y, Gan P, Bino T, Uehara T, Yamaguchi K, Ichihashi Y, Maki N, Iwahori H, Suzuki T, et al. 2018. High-quality genome sequence of the root-knot nematode Meloidogyne arenaria genotype A2-O. Genome Announc 6(26).

Sattler MC, Carvalho CR, Clarindo WR. 2016. The polyploidy and its key role in plant breeding. Planta 243(2): 281-296.

Scalzitti N, Jeannin-Girardon A, Collet P, Poch O, Thompson JD. 2020. A benchmark study of ab initio gene prediction methods in diverse eukaryotic organisms. BMC Genomics 21(1): 293.

Scholl EH, Thorne JL, McCarter JP, Bird DM. 2003. Horizontally transferred genes in plant-parasitic nematodes: a high-throughput genomic approach. Genome biology 4(6): R39.

Shi Q, Mao Z, Zhang X, Zhang X, Wang Y, Ling J, Lin R, Li D, Kang X, Sun W. 2018. A Meloidogyne incognita effector MilSE5 suppresses programmed cell death to promote parasitism in host plant. Scientific Reports 8(1): 7256

Shivakumara TN, Chaudhary S, Kamaraju D, Dutta TK, Papolu PK, Banakar P, Sreevathsa R, Singh B, Manjaiah KM, Rao U. 2017. Host-induced silencing of two pharyngeal gland genes conferred transcriptional alteration of cell wall-modifying enzymes of meloidogyne incognita vis-á-vis perturbed nematode infectivity in eggplant. Frontiers in plant science 8.

Shivakumara TN, Papolu PK, Dutta TK, Kamaraju D, Chaudhary S, Rao U. 2016. RNAi-induced silencing of an effector confers transcriptional oscillation in another group of effectors in the root-knot nematode, Meloidogyne incognita. Nematology 18(7): 857-870

Shukla N, Yadav R, Kaur P, Rasmussen S, Goel S, Agarwal M, Jagannath A, Gupta R, Kumar A. 2018. Transcriptome analysis of root-knot nematode (Meloidogyne incognita)-infected tomato (Solanum lycopersicum) roots reveals complex gene expression profiles and metabolic networks of both host and nematode during susceptible and resistance responses. Molecular Plant Pathology 19(3): 615-633.

Smant G, Stokkermans JP, Yan Y, De Boer JM, Baum TJ, Wang X, Hussey RS, Gommers FJ, Henrissat B, Davis EL. 1998.

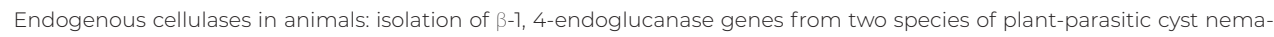
todes. Proc Natl Acad Sci U S A 95(9): 4906-4911

Solovyev V, Kosarev P, Seledsov I, Vorobyev D. 2006. Automatic annotation of eukaryotic genes, pseudogenes and promoters. Genome biology $7(1):$ S10. 
Stanke M, Diekhans M, Baertsch R, Haussler D. 2008. Using native and syntenically mapped cDNA alignments to improve de novo gene finding. Bioinformatics 24(5): 637-644.

Steentoft C, Vakhrushev SY, Joshi HJ, Kong Y, Vester-Christensen MB, Schjoldager KTBG, Lavrsen K, Dabelsteen S, Pedersen NB, Marcos-Silva L, et al. 2013. Precision mapping of the human O-GalNAc glycoproteome through SimpleCell technology. The EMBO journal 32(10): 1478-1488.

Stukenbrock EH. 2013. Evolution, selection and isolation: a genomic view of speciation in fungal plant pathogens. New Phytologist 199(4): 895-907.

Szitenberg A, Salazar-Jaramillo L, Blok VC, Laetsch DR, Joseph S, Williamson VM, Blaxter ML, Lunt DH. 2017. Comparative genomics of apomictic root-knot nematodes: hybridization, ploidy, and dynamic genome change. Genome Biology and Evolution 9(10): 2844-2861.

Thordal-Christensen H. 2020. A holistic view on plant effector-triggered immunity presented as an iceberg model. Cellular and Molecular Life Sciences.

Todesco M, Owens GL, Bercovich N, Légaré J-S, Soudi S, Burge DO, Huang K, Ostevik KL, Drummond EBM, Imerovski I, et al. 2020. Massive haplotypes underlie ecotypic differentiation in sunflowers. nature 584(7822): 602-607.

Trudgill DL, Blok VC. 2001. Apomictic, polyphagous root-knot nematodes: exceptionally successful and damaging biotrophic root pathogens. Annual review of phytopathology 39(7): 53-77.

van Megen H, van den Elsen S, Holterman M, Karssen G, Mooyman P, Bongers T, Holovachov O, Bakker J, Helder J. 2009. A phylogenetic tree of nematodes based on about 1200 full-length small subunit ribosomal DNA sequences. Nematology $11(6):$ 927-950

van Schie CCN, Takken FLW. 2014. Susceptibility genes 101: How to be a good host. Annual review of phytopathology 52(1): 551-581.

Veitia RA, Bottani S, Birchler JA. 2013. Gene dosage effects: nonlinearities, genetic interactions, and dosage compensation. Trends in genetics 29(7): 385-393.

Vieira P, Gleason C. 2019. Plant-parasitic nematode effectors - insights into their diversity and new tools for their identification. Current opinion in plant biology 50: 37-43.

Wang D, Zeng S, Xu C, Qiu W, Liang Y, Joshi T, Xu D. 2017. MusiteDeep: a deep-learning framework for general and kinase-specific phosphorylation site prediction. Bioinformatics 33(24): 3909-3916.

Wang S, Li W, Liu S, Xu J. 2016. RaptorX-Property: a web server for protein structure property prediction. Nucleic acids research 44(W7): W430-W435.

Watson M, Warr A. 2019. Errors in long-read assemblies can critically affect protein prediction. Nature biotechnology 37(2): 124-126.

Xie J, Li S, Mo C, Wang G, Xiao X, Xiao Y. 2016. A novel Meloidogyne incognita effector mispl2 suppresses plant defense response at latter stages of nematode parasitism. Frontiers in plant science 7(JUNE2016).

Xu J, Narabu T, Mizukubo T, Hibi T. 2001. A molecular marker correlated with selected virulence against the tomato resistance gene Mi in Meloidogyne incognita, M. javanica, and M. arenaria. Phytopathology 91(4): 377-382.

Xue B, Hamamouch N, Li C, Huang G, Hussey RS, Baum TJ, Davis EL. 2013. The 8D05 parasitism gene of Meloidogyne incognita is required for successful infection of host roots. Phytopathology 103(2): 175-181.

Yang L-N, Liu H, Duan G-H, Huang Y-M, Liu S, Fang Z-G, Wu EJ, Shang L, Zhan J. 2020. The Phytophthora infestans AVR2 effector escapes R2 recognition through effector disordering. Molecular Plant-Microbe Interactions 33(7): $921-931$.

Yang Y, Jittayasothorn Y, Chronis D, Wang X, Cousins P, Zhong GY. 2013. Molecular characteristics and efficacy of 16D10 siRNAs in inhibiting root-knot nematode infection in transgenic grape hairy roots. PLOS ONE 8(7).

Yang Z. 1997. PAML: a program package for phylogenetic analysis by maximum likelihood. Bioinformatics 13(5): 555-556.

Yang Z. 2007. PAML 4: phylogenetic analysis by maximum likelihood. Molecular biology and evolution 24(8): 1586-1591.

Yang Z, Bielawski JP. 2000. Statistical methods for detecting molecular adaptation. Trends in ecology \& evo/ution 15(12): 496-503.

Zhang L, Davies LJ, Elling AA. 2015. A Meloidogyne incognita effector is imported into the nucleus and exhibits transcriptional activation activity in planta. Molecular Plant Pathology 16(1): 48-60. 


\section{Supplemental information}

Supplemental figures

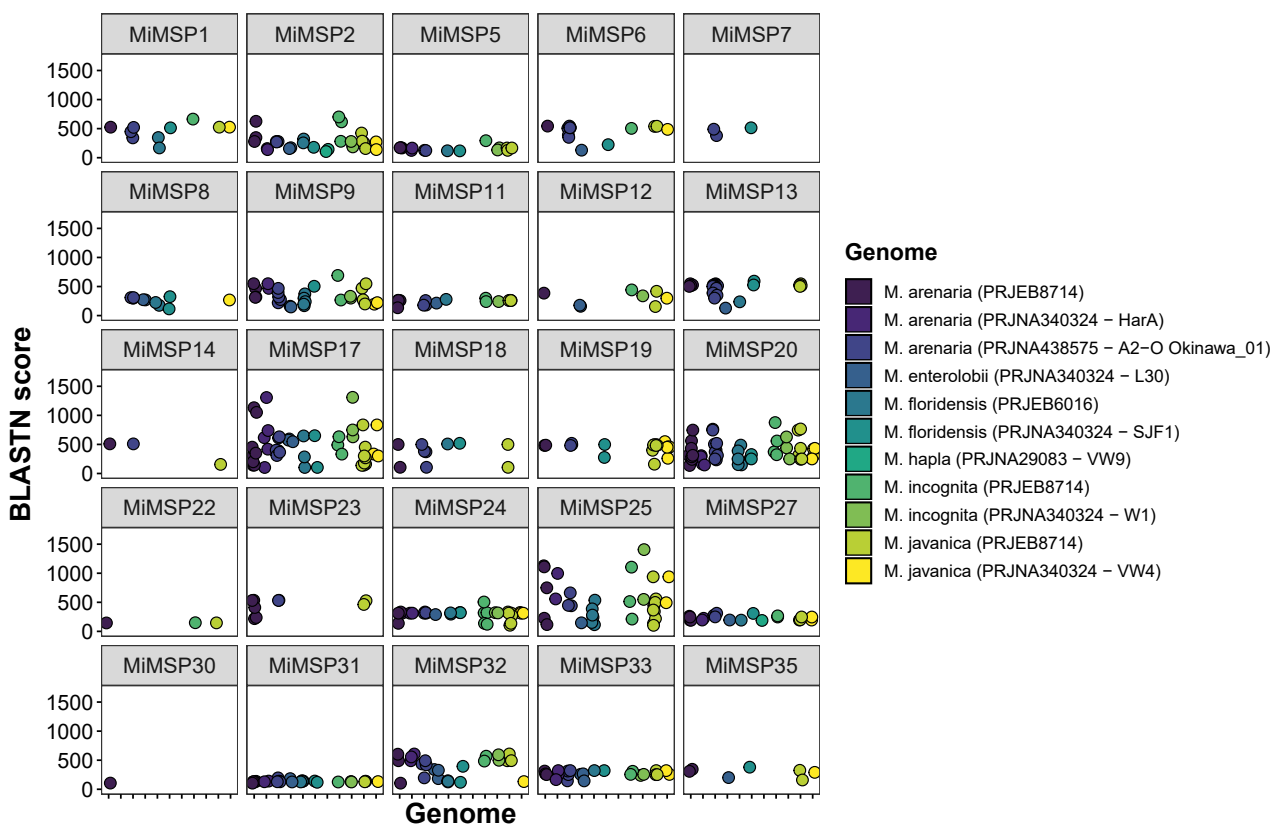

Figure S1. Previously identified M. incognita MiMSP genes and their total unique BLASTN cDNA hits. The BLASTN search was performed within all published nematode genomes containing predicted transcripts and splice variants. Per unique hit, only the highest BLASTN score is shown. We included 25 out of 27 MiMSP genes, as for MiMSP15 and MiMSP16 no unique BLASTN cDNA hits were identified. All MiMSP-hits belong to the root-knot nematode genus (Meloidogyne spp.). 


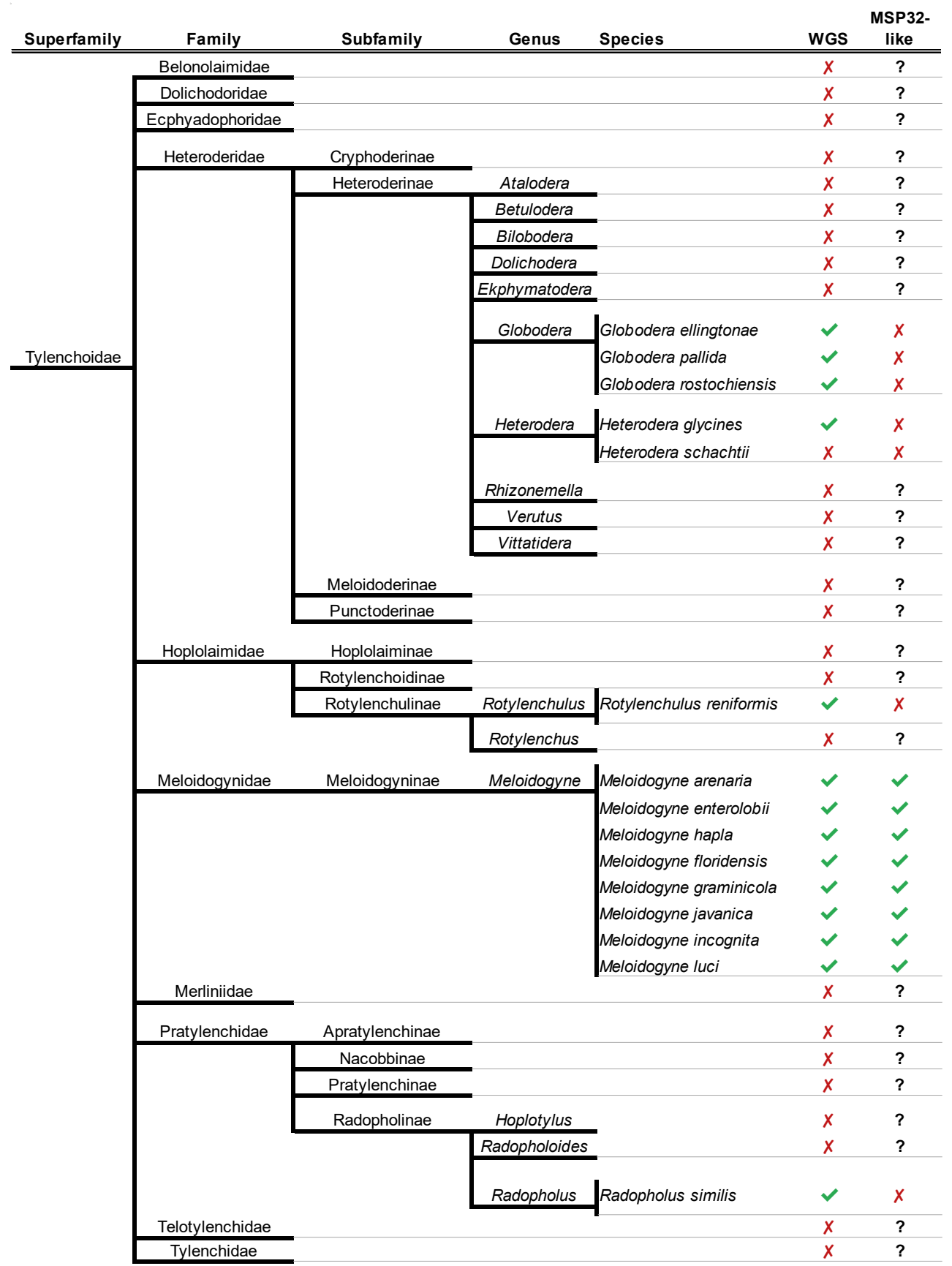

Figure S2. Identification of MiMSP32-like hits within individual Tylenchoidae species. Availability of whole genome sequencing (WCS) projects within the Tylenchoidae superfamily. Similar sequences were identified using TBLASTN, against a whole genome sequencing database, using a threshold of 10-5. 


\section{Supplemental tables}

Table S1. All estimates of parameters for the different models of evolution for the 27 MiMSPs. Only MiMSPs within a gene cluster of at least three coding sequences of the cDNA hits could be included in the analysis. In addition, log-likelihood ratio test values for the complete model comparisons are given.

\begin{tabular}{|c|c|c|c|c|c|c|c|c|c|c|}
\hline \multirow{2}{*}{$\begin{array}{l}\text { Pioneer gene } \\
\text { MiMSP17 }\end{array}$} & \multicolumn{2}{|c|}{ Model } & \multicolumn{6}{|c|}{ Estimates of parameters } & \multirow{2}{*}{$\frac{\text { Comparison }}{\text { MO vs. M3 }}$} & \multirow{2}{*}{$\frac{\text { LRT P-value }}{0.000}$} \\
\hline & \multirow[t]{2}{*}{ M3 } & \multirow[t]{2}{*}{ Discrete } & $\mathrm{p}:$ & 0.318 & $\mathrm{p}:$ & 0.658 & $\mathrm{p}:$ & 0.024 & & \\
\hline & & & $\omega:$ & 0.000 & $\omega:$ & 0.590 & $\omega:$ & 66.194 & & \\
\hline & $\mathrm{MO}$ & One-ratio & $\omega O:$ & 0.516 & & & & & & \\
\hline & \multirow[t]{2}{*}{$\mathrm{M} 2 \mathrm{a}$} & \multirow{2}{*}{$\begin{array}{l}\text { Positive selection } \\
d N / d S>1\end{array}$} & p: & 0.975 & p: & 0.000 & $\mathrm{p}:$ & 0.025 & \multirow[t]{4}{*}{ Mla vs. M2a } & \multirow[t]{4}{*}{0.000} \\
\hline & & & $\omega:$ & 0.387 & $\omega:$ & 1.000 & $\omega:$ & 64.504 & & \\
\hline & \multirow[t]{2}{*}{ Mla } & \multirow{2}{*}{$\begin{array}{l}\text { Nearly-neutral } \\
\text { dN/dS } \leq 1\end{array}$} & $\mathrm{p}:$ & 0.679 & $\mathrm{p}:$ & 0.321 & & & & \\
\hline & & & $\omega:$ & 0.000 & $\omega:$ & 1.000 & & & & \\
\hline & \multirow[t]{2}{*}{ M8 } & \multirow{2}{*}{$\begin{array}{l}\text { Positive selection } \\
\beta+\omega S>1\end{array}$} & pO: & 0.976 & $\mathrm{p}:$ & 0.704 & $\mathrm{q}:$ & 1.041 & \multirow[t]{3}{*}{ M7 vs.M8 } & \multirow[t]{3}{*}{0.000} \\
\hline & & & pl: & 0.024 & $\omega:$ & 66.155 & & & & \\
\hline & M7 & null model; $\beta$ & $\mathrm{p}:$ & 0.008 & q: & 0.022 & & & & \\
\hline & \multirow[t]{2}{*}{ M8a } & \multirow[b]{2}{*}{$\beta+\omega S=1$} & po: & 0.679 & p: & 0.005 & $\mathrm{q}:$ & 32.329 & \multirow[t]{2}{*}{ M8a vs.M8 } & \multirow[t]{2}{*}{0.000} \\
\hline & & & pl: & 0.321 & $\omega:$ & 1.000 & & & & \\
\hline \multirow[t]{12}{*}{ MiMSP2 } & \multirow[t]{2}{*}{ M3 } & \multirow[t]{2}{*}{ Discrete } & $\mathrm{p}:$ & 0.556 & $\mathrm{p}:$ & 0.416 & $\mathrm{p}:$ & 0.028 & \multirow[t]{3}{*}{ MO vs. M3 } & 0.902 \\
\hline & & & $\omega:$ & 0.198 & $\omega:$ & 0.198 & $\omega:$ & 3.260 & & \\
\hline & $\mathrm{MO}$ & One-ratio & $\omega O:$ & 0.258 & & & & & & \\
\hline & $\mathrm{M} 2 \mathrm{a}$ & Positive selection & $\mathrm{p}:$ & 0.972 & $\mathrm{p}:$ & 0.000 & p: & 0.028 & M1a vs. M2a & 0.955 \\
\hline & & dN/dS > 1 & $\omega:$ & 0.198 & $\omega:$ & 1.000 & $\omega:$ & 3.260 & & \\
\hline & Mla & Nearly-neutral & $\mathrm{p}:$ & 0.791 & $\mathrm{p}:$ & 0.209 & & & & \\
\hline & & $\mathrm{dN} / \mathrm{dS} \leq 1$ & $\omega:$ & 0.082 & $\omega:$ & 1.000 & & & & \\
\hline & M8 & Positive selection & pO: & 0.972 & $\mathrm{p}:$ & 24.561 & $\mathrm{q}:$ & 99.000 & M7 vs.M8 & 0.944 \\
\hline & & $\beta+\omega S>1$ & pl: & 0.028 & $\omega:$ & 3.259 & & & & \\
\hline & M7 & null model; $\beta$ & $\mathrm{p}:$ & 0.133 & q: & 0.368 & & & & \\
\hline & M8a & & po: & 0.792 & p: & 9.006 & $q:$ & 99.000 & M8a vs.M8 & 0.761 \\
\hline & & $\beta+\omega S=1$ & pl: & 0.208 & $\omega:$ & 1.000 & & & & \\
\hline MiMSP2O & M3 & Discrete & p: & 0.409 & $\mathrm{p}:$ & 0.494 & $\mathrm{p}:$ & 0.097 & MO vs. M3 & 0.000 \\
\hline & & & $\omega:$ & 0.153 & $\omega:$ & 0.153 & $\omega:$ & 3.259 & & \\
\hline & $\mathrm{MO}$ & One-ratio & $\omega O:$ & 0.332 & & & & & & \\
\hline & $\mathrm{M} 2 \mathrm{a}$ & Positive selection & $\mathrm{p}:$ & 0.903 & $\mathrm{p}:$ & 0.000 & p: & 0.097 & Mla vs. M2a & 0.063 \\
\hline & & $d N / d S>1$ & $\omega:$ & 0.153 & $\omega:$ & 1.000 & $\omega:$ & 3.259 & & \\
\hline & Mla & Nearly-neutral & $\mathrm{p}:$ & 0.690 & $\mathrm{p}:$ & 0.310 & & & & \\
\hline & & $\mathrm{dN} / \mathrm{dS} \leq 1$ & $\omega:$ & 0.016 & $\omega:$ & 1.000 & & & & \\
\hline & M8 & Positive selection & pO: & 0.903 & $\mathrm{p}:$ & 18.043 & $\mathrm{q}:$ & 99.000 & M7 vs.M8 & 0.062 \\
\hline & & $\beta+\omega S>1$ & pl: & 0.097 & $\omega:$ & 3.263 & & & & \\
\hline & M7 & null model; $\beta$ & $\mathrm{p}:$ & 0.014 & q: & 0.016 & & & & \\
\hline & M8a & & po: & 0.689 & $\mathrm{p}:$ & 1.547 & $q:$ & 99.000 & M8a vs.M8 & 0.019 \\
\hline & & $\beta+\omega S=1$ & pl: & 0.311 & $\omega:$ & 1.000 & & & & \\
\hline
\end{tabular}




\begin{tabular}{|c|c|c|c|c|c|c|c|c|c|c|}
\hline \multirow[t]{12}{*}{ MiMSP24 } & \multirow[t]{2}{*}{ M3 } & \multirow[t]{2}{*}{ Discrete } & $\mathrm{p}:$ & 0.758 & $\mathrm{p}:$ & 0.237 & $\mathrm{p}:$ & 0.005 & \multirow[t]{3}{*}{ MO vs. M3 } & \multirow[t]{3}{*}{0.016} \\
\hline & & & $\omega:$ & 0.000 & $\omega:$ & 1.333 & $\omega:$ & 7.440 & & \\
\hline & $\mathrm{MO}$ & One-ratio & $\omega O:$ & 0.276 & & & & & & \\
\hline & \multirow[t]{2}{*}{ M2a } & \multirow{2}{*}{$\begin{array}{l}\text { Positive selection } \\
\mathrm{dN} / \mathrm{dS}>1\end{array}$} & $\mathrm{p}:$ & 0.739 & $\mathrm{p}:$ & 0.216 & $\mathrm{p}:$ & 0.045 & \multirow[t]{4}{*}{ Mla vs. M2a } & \multirow[t]{4}{*}{0.656} \\
\hline & & & $\omega:$ & 0.000 & $\omega:$ & 1.000 & $\omega:$ & 2.933 & & \\
\hline & \multirow[t]{2}{*}{ Mla } & \multirow{2}{*}{$\begin{array}{l}\text { Nearly-neutral } \\
\mathrm{dN} / \mathrm{dS} \leq 1\end{array}$} & $\mathrm{p}:$ & 0.714 & $\mathrm{p}:$ & 0.286 & & & & \\
\hline & & & $\omega:$ & 0.000 & $\omega:$ & 1.000 & & & & \\
\hline & \multirow[t]{2}{*}{ M8 } & \multirow{2}{*}{$\begin{array}{l}\text { Positive selection } \\
\beta+\omega S>1\end{array}$} & po: & 0.836 & p: & 0.060 & $\mathrm{q}:$ & 0.500 & \multirow[t]{3}{*}{ M7 vs.M8 } & \multirow[t]{3}{*}{0.486} \\
\hline & & & pl: & 0.164 & $\omega:$ & 1.838 & & & & \\
\hline & M7 & null model; $\beta$ & $\mathrm{p}:$ & 0.010 & q: & 0.020 & & & & \\
\hline & \multirow[t]{2}{*}{ M8a } & \multirow[b]{2}{*}{$\beta+\omega S=1$} & po: & 0.714 & $\mathrm{p}:$ & 0.005 & $\mathrm{q}:$ & 25.968 & \multirow[t]{2}{*}{ M8a vs.M8 } & \multirow[t]{2}{*}{0.361} \\
\hline & & & pl: & 0.286 & $\omega:$ & 1.000 & & & & \\
\hline \multirow[t]{12}{*}{ MiMSP31 } & \multirow[t]{2}{*}{ M3 } & \multirow[t]{2}{*}{ Discrete } & $\mathrm{p}:$ & 0.532 & $\mathrm{p}:$ & 0.449 & $\mathrm{p}:$ & 0.018 & \multirow[t]{3}{*}{ MO vs. M3 } & \multirow[t]{3}{*}{0.000} \\
\hline & & & $\omega:$ & 0.110 & $\omega:$ & 1.135 & $\omega:$ & 998.994 & & \\
\hline & $\mathrm{MO}$ & One-ratio & $\omega O:$ & 0.467 & & & & & & \\
\hline & \multirow[t]{2}{*}{ M2a } & \multirow{2}{*}{$\begin{array}{l}\text { Positive selection } \\
d \mathrm{~N} / \mathrm{dS}>1\end{array}$} & $\mathrm{p}:$ & 0.457 & $\mathrm{p}:$ & 0.525 & $\mathrm{p}:$ & 0.018 & Mla vs. M2a & 0.000 \\
\hline & & & $\omega:$ & 0.061 & $\omega:$ & 1.000 & $\omega:$ & 998.952 & & \\
\hline & Mla & Nearly-neutral & $\mathrm{p}:$ & 0.516 & $\mathrm{p}:$ & 0.484 & & & & \\
\hline & & $\mathrm{dN} / \mathrm{dS} \leq 1$ & $\omega:$ & 0.079 & $\omega:$ & 1.000 & & & & \\
\hline & M8 & Positive selection & po: & 0.981 & $\mathrm{p}:$ & 0.026 & q: & 0.025 & M7 vs.M8 & 0.000 \\
\hline & & $\beta+\omega S>1$ & pl: & 0.019 & $\omega:$ & 437.944 & & & & \\
\hline & M7 & null model; $\beta$ & $\mathrm{p}:$ & 0.079 & $\mathrm{q}:$ & 0.080 & & & & \\
\hline & M8a & & po: & 0.516 & $\mathrm{p}:$ & 8.698 & q: & 99.000 & M8a vs.M8 & 0.000 \\
\hline & & $\beta+\omega S=1$ & pl: & 0.484 & $\omega:$ & 1.000 & & & & \\
\hline MiMSP32 & M3 & Discrete & $\mathrm{p}:$ & 0.532 & $\mathrm{p}:$ & 0.449 & $\mathrm{p}:$ & 0.018 & MO vs. M3 & 0.000 \\
\hline & & & $\omega:$ & 0.110 & $\omega:$ & 1.135 & $\omega:$ & 728.189 & & \\
\hline & $\mathrm{MO}$ & One-ratio & $\omega O:$ & 0.467 & & & & & & \\
\hline & M2a & Positive selection & $\mathrm{p}:$ & 0.457 & $\mathrm{p}:$ & 0.525 & $\mathrm{p}:$ & 0.018 & Mla vs. M2a & 0.000 \\
\hline & & $\mathrm{dN} / \mathrm{dS}>1$ & $\omega:$ & 0.061 & $\omega:$ & 1.000 & $\omega:$ & 998.956 & & \\
\hline & Mla & Nearly-neutral & $\mathrm{p}:$ & 0.516 & $\mathrm{p}:$ & 0.484 & & & & \\
\hline & & $d N / d S \leq 1$ & $\omega:$ & 0.079 & $\omega:$ & 1.000 & & & & \\
\hline & M8 & Positive selection & po: & 0.981 & $\mathrm{p}:$ & 0.054 & q: & 0.051 & M7 vs.M8 & 0.000 \\
\hline & & $\beta+\omega S>1$ & pl: & 0.019 & $\omega:$ & 475.738 & & & & \\
\hline & M7 & null model; $\beta$ & $\mathrm{p}:$ & 0.078 & $\mathrm{q}:$ & 0.079 & 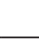 & & & \\
\hline & M8a & & po: & 0.516 & $\mathrm{p}:$ & 8.701 & q: & 99.000 & M8a vs.M8 & 0.000 \\
\hline & & $\beta+\omega S=1$ & pl: & 0.484 & $\omega:$ & 1.000 & & & & \\
\hline
\end{tabular}





\title{
Chapter 3
}

\section{The promiscuous effector MiMSP32 of Meloidogyne incognita contributes to nematode virulence in tomato}

\author{
Ava Verhoeven \\ Debbie R Valkenburg-van Raaij \\ Anna Finkers-Tomczak \\ Koen Varossieau \\ Erik J Slootweg \\ Aska Goverse \\ Geert Smant
}

Laboratory of Nematology, Department of Plant Sciences, Wageningen University \& Research, PO Box 8123, 6700 ES Wageningen, The Netherlands 


\section{Abstract}

The root-knot nematode Meloidogyne incognita causes an annual loss of $\$ 400$ million in damage to crops. This damage is caused by the induction of nematode feeding sites in the roots, a process catalyzed by the secretion of so-called effector proteins. Previously, we identified the putative effector protein MiMSP32 as a member of an expanded gene family produced in the dorsal esophageal gland of M. incognita. Here, we show that the effector MiMSP32 contributes to nematode virulence, as host-induced gene silencing resulted in a lower number of galls in tomato at seven days post inoculation. In addition, we found that MiMSP32 induces susceptibility of tomato plants to M. incognita, because transgenic tomato plants overexpressing MiMSP32 showed an increased number of galls per plant. MiMSP32 proved to be a promiscuous interactor, as we identified six candidate host targets of MiMSP32 by a yeast two-hybrid screening on a library generated from nematode-infected roots of tomato. Moreover, we could confirm the promiscuity of MiMSP32 by further testing its interactions with these candidate host targets in planta using co-immunoprecipitation, co-localization, and FRET-FLIM in leaves of Nicotiana benthamiana. From these results, a model emerges wherein effector MiMSP32 promotes the virulence of $M$. incognita by interacting with multiple tomato host proteins. 


\section{Introduction}

Annually, plant-parasitic nematodes cause for billions of dollars of losses in global food production (Abad et al., 2008; Nicol et al., 2011). A large fraction of these yield losses are induced by root-knot nematodes (Jones et al., 2013). Root-knot nematodes belong to the widely distributed genus Meloidogyne, capable of infecting most vascular plants (Mitchum et al., 2013). The highly polyphagous tropical root-knot nematode Meloidogyne incognita feeds on both monocots and dicots and is thought to be one of the most invasive pathogens worldwide (Trudgill \& Blok, 2001; Jones et al., 2013; Bebber et al., 2014).

Plant invasion starts after second stage juveniles of M. incognita (J2s) hatch from eggs and enter host roots at the transition zone close to the root tip. Next, invasive J2s migrate intercellularly around the endodermis via the columella and quiescent center into the vascular cylinder. Once inside the vascular cylinder, the nematodes induce a permanent feeding structure on which they depend for the rest of their life as sole source of nutrients. The permanent feeding structure of $M$. incognita consists of several enlarged discrete host cells, referred to as giant cells. Giant cells serve as a metabolic sink and actively transport plant assimilates towards the feeding juveniles. While feeding for several weeks on these giant cells, the juveniles lose their locomotory musculature and develop into egg-producing adult females (Gheysen \& Mitchum, 2011; Coverse \& Smant, 2014). Although males occasionally develop, they are believed to play no role in the parthenogenetic reproduction of M. incognita (Abad et al., 2008).

When J2s of M. incognita invade the plant, they secrete a plethora of so-called 'effectors' (Mitchum et al., 2013). Effectors are defined as secreted molecules aiding the infection process by targeting important host molecular pathways (Vieira \& Gleason, 2019). Most effectors are produced in the nematode esophageal glands, which are named after their position in the body of the nematode: subventral or dorsal esophageal gland cells. The subventral glands are active in the initial stages of infection, such as root penetration and migration. The dorsal gland on the other hand increases in activity during later stages, including giant cell initiation and maintenance (Xue et al., 2013). J2s of M. incognita secrete these effectors with their protractible stylet into the apoplast or cytoplasm of host cells (Hussey, 1989; Mejias et al., 2019). The final subcellular destination of M. incognita effectors in plant cells is diverse and likely depends on their function (Shi et al., 2018).

Effectors of $M$. incognita can function in various processes during multiple stages of infection. Probably the best known function of effectors of $M$. incognita is degradation of plant cell walls during nematode invasion (Haegeman et al., 2012). Effectors like MiENG1:4, MiXYL1,3 and MiPEL1:3 degrade celluloses or other sugar polymers such as xylan or pectate (Huang et al., 2004; Huang et al., 2005a; Mitreva-Dautova et al., 2006; Vieira et al., 2011). Other effectors are involved in suppression of plant defense responses. For example, effectors like MiMnSOD1 and MiCST1 protect the nematode by detoxification of harmful substances such as reactive oxygen species (Dubreuil et al., 2007; Molinari \& Rosso, 2014). Defense responses can also be altered by effectors targeting or mimicking plant hormones (Gheysen \& Mitchum, 2019). 
Chorismate mutases MiCM1 and MiCM2 interfere with the production of plant hormones by depleting chorismate precursor levels (Huang et al., 2005b). The role of effectors in feeding site initiation, expansion and maintenance, and in the degradation of plant proteins by the ubiquitination-protease pathway is less well understood (Mitchum et al., 2013).

As genetic transformation of plant-parasitic nematodes is still not possible, functional analysis of effector proteins in M. incognita is dependent on more indirect approaches. For instance, silencing of gene expression in M. incognita can be achieved in early parasitic phases by soaking pre-parasitic juveniles in highly concentrated dsRNA solutions (Fire et al., 1998; Rosso et al., 2005). Alternatively, silencing of gene expression in later parasitic stages of M. incognita can be achieved by host-mediated gene silencing (HICS) (Huang et al., 2006a). Effectors of M. incognita have also been ectopically expressed in various plant species to assess their impacts on plant susceptibility to nematode infections (Huang et al., 2006b). Finally, effector functions have been studied by identifying specific interactions between effectors and possible host targets using for example yeast two-hybrid screens in cDNA libraries of total root proteins (Huang et al., 2006b), or performing in planta immunoprecipitations followed by LC-MS/MS analysis (Zhao et al., 2019).

Previously, we have identified the putative effector MiMSP32 as a member of an expanded gene family under positive selection in root-knot nematodes (Chapter 2). MiMSP32 contains a predicted signal peptide and was previously shown to be expressed in the dorsal esophageal gland of parasitic M. incognita (Huang et al., 2003). In this chapter, we study the biological relevance of the putative effector MiMSP32 for infectivity of M. incognita. We show by host-induced gene silencing on tomato that MiMSP32 contributes to nematode virulence. In addition, we demonstrate by heterologous overexpressing that MiMSP32 regulates the susceptibility of tomato plants to M. incognita. We also identified six possible host targets of MiMSP32 by a yeast two-hybrid screening on a library generated from nematode-infected roots of tomato. We confirmed the physical interaction of MiMSP32 and these six host targets in planta by co-immunoprecipitation, co-localization, and FRET-FLIM following their transient co-expression in leaves of Nicotiana benthamiana. Altogether, our data suggest that MiMSP32 functions as a promiscuous effector targeting a wide range of processes in host cells, such as the proteasome pathway, phytohormone biosynthesis, or plant cell death responses.

\section{Results}

\section{MiMSP32 contributes to virulence of M. incognita}

The putative root-knot nematode specific effector MiMSP32 is under strong positive selection (Chapter 2). To investigate if MiMSP32 contributes to parasitism in the early stages of infection by $M$. incognita in tomato, we used host-induced gene silencing with a hairpin construct targeting nucleotides 313-522 of the MiMSP32 transcript (Figure 1A). To prevent off-target gene silencing, a target sequence fragment was chosen with minimal similarity to any tomato gene (see Material \& Methods). At seven days post inoculation, we observed a significantly lower 

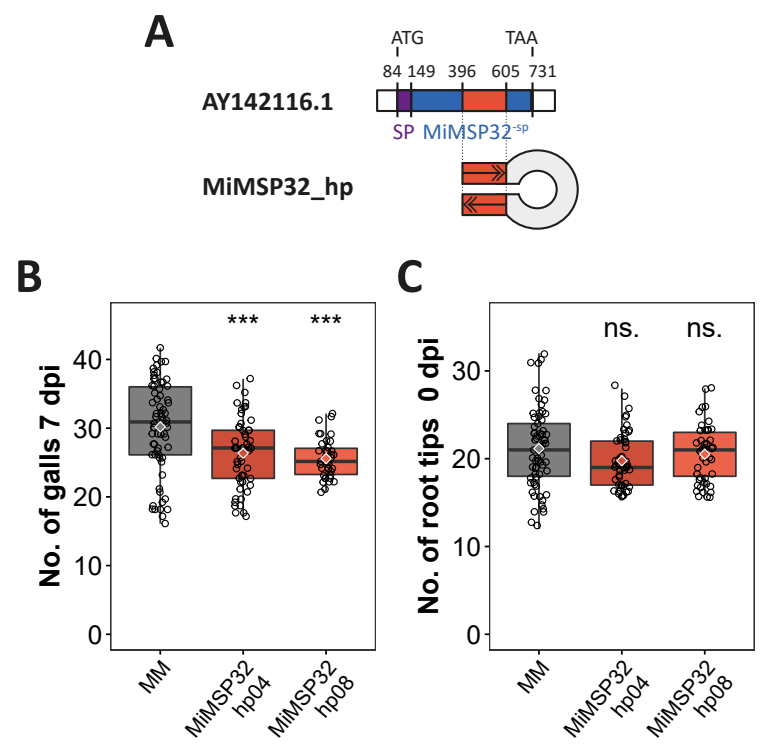

Figure 1. MiMSP32 facilitates M. incognita parasitism in tomato. (A) The target sequence in MiMSP32 for host-induced gene silencing using hairpin construct MiMSP32-SP_hp. (B) Number of galls per plant at seven days post inoculation with $M$. incognita on two independent tomato lines overexpressing MiMSP32-SP_hp (MiMSP32_hp04 and MiMSP32_hp08) and wild-type tomato plants (MM). (C) Number of root tips of tomato seedlings at the time of inoculation. Data were collected in multiple independent experiments and combined for statistical analysis with a one-way ANOVA. Nematode data were batch-corrected. Asterisks indicate significant differences between transgenic lines and wild-type tomato as calculated with an one-way ANOVA using Tukey's HSD (***, P<0.001; ns, not significant).
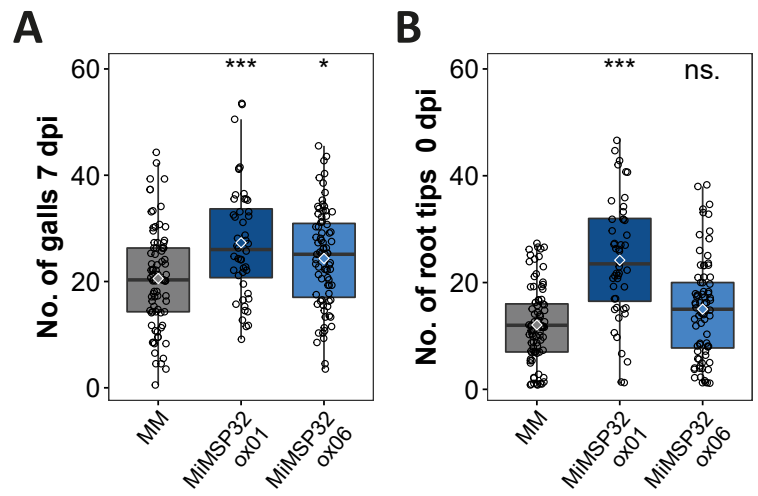

Figure 2. Ectopic overexpression of MiMSP32 without its native protein for secretion alters susceptibility of tomato plants to M. incognita. (A) Number of galls per plant on two independent tomato lines overexpressing MiMSP32-sp (MiMSP32_ox01 and MiMSP32_ox06) and wild-type tomato plants (MM) at seven days post inoculation with M. incognita. (B) Number of root tips per tomato plant for each genotype at the time of inoculation. Data were collected in multiple independent experiments and combined for statistical analysis with a one-way ANOVA. Nematode data were batch-corrected. Asterisks indicate significant differences between transgenic lines and wild-type tomato as calculated with an one-way ANOVA using Tukey's HSD (*, P<0.05; ***, P<0.001; ns, not significant). 
number of nematode-induced galls (13-15\%) for the two independently transformed tomato lines expressing the PSMD:MiMSP32_hp hairpin construct compared to wild-type tomato plants ( $\mathrm{P}<0.001$; one-way ANOVA with Tukey's HSD) (Figure 1B). Plants of the two transgenic lines expressing the hairpin construct and wild-type tomato showed no difference in the number of root tips, which could have otherwise explained the different levels of successfully nitiated galls (Figure 1C). In addition, we did not observe any other morphological effects in the MiMSP32 hairpin expressing lines as compared to wild-type plants. The relative MiMSP32 transcription in M. incognita inside dissected galls on the plants expressing the MiMSP32 hairpin constructs at $23 \mathrm{dpi}$ was lower, although not significantly, compared to those feeding on wild-type tomato plants (Supplemental Figure S1). Nonetheless, we conclude that MiMSP32 most likely contributes to infectivity of $M$. incognita during the early stages of parasitism in roots of tomato plants

\section{MiMSP32 functions as a bona fide effector for M. incognita}

To test if ectopic MiMSP32 alters the susceptibility of tomato plants to M. incognita, we challenged seedlings of two tomato lines stably overexpressing MiMSP32 without its native signal peptide for secretion with infective $\mathrm{J} 2$ in an in vitro bioassay. At seven days post inoculation, we observed a significant $18-33 \%$ increase in the number of galls in roots of two independently transformed tomato lines overexpressing MiMSP32 as compared to wild-type tomato plants ( $\mathrm{P}<0.05$; one-way ANOVA with Tukey's HSD) (Figure 2A). Seedlings of only one MiMSP32 overexpressing

Table 1. A yeast two-hybrid screen identified eleven probable candidate interactors, of which six with high confidence in the interaction. Clobal Predicted Biological Score (PBS) categorizes the interaction to prioritize genuine interactors (Rain et al 2001 .

\begin{tabular}{|c|c|c|c|c|c|}
\hline $\begin{array}{l}\text { Clobal } \\
\text { PBS }\end{array}$ & Cene ID & $\begin{array}{l}\text { Nr. of } \\
\text { clones }\end{array}$ & $\overline{\text { BLAST gene }}$ & $\begin{array}{l}\text { Gene } \\
\text { name }\end{array}$ & Description \\
\hline A & 06g073580.2.1 & 14 & $\begin{array}{l}\text { Solanum lycopersicum } \\
\text { hyoscamine 6-dioxygenase }\end{array}$ & $\mathrm{SIH6D}$ & $\begin{array}{l}\text { 7-aminocyclopropane-I-carboxylate oxidase I (AHRD V1 **--ACCOI_ORYSJ); contains Interpro domain(s) IPR005123 Oxog- } \\
\text { lutarate and iron-dependent oxygenase }\end{array}$ \\
\hline A & 10g074940.1.1. & 11 & $\begin{array}{l}\text { Solanum lycopersicum } \\
\text { phospholipid-transporting ATPase 1-like }\end{array}$ & SIALAT & $\begin{array}{l}\text { Phospholipid-transporting ATPase (AHRD V7 } 7 * * * \text { B6JZB6_SCHJY); contains Interpro domain(s) IPR006539 ATPase, P-type, } \\
\text { phospholipid-translocating, flippase }\end{array}$ \\
\hline A & 129010040.1 .1 & 45 & $\begin{array}{l}\text { Solanum lycopersicum } \\
\text { leucine aminopeptidase }\end{array}$ & SILAPA2 & $\begin{array}{l}\text { Leucyl aminopeptidase (AHRD V V***-D7DWC6_NOSAO); contains Interpro domain(s) IPRo11356 Peptidase M17, leucyl } \\
\text { aminopeptidase IPROo0819 Peptidase M17, leucyl aminopeptidase, C-terminal }\end{array}$ \\
\hline B & Olg103390.2.7 & 6 & $\begin{array}{l}\text { Solanum lycopersicum } \\
\text { 12-oxophytodienoate reductase } 2\end{array}$ & SIOPR2 & $\begin{array}{l}\text { Flavin oxidoreductase/NADH oxidase (AHRD V1 **-_AOYMI2_LYNSP); contains Interpro domain(s) IPRO01155 NADH:flavin } \\
\text { oxidoreductase/NADH oxidase, N-terminal }\end{array}$ \\
\hline B & 03g025610.1.1. & 4 & $\begin{array}{l}\text { Solanum lycopersicum } \\
\text { tripeptidyl-peptidase } 2\end{array}$ & SITPPII & $\begin{array}{l}\text { Subtilisin-like serine protease (AHRD V7 **-- D8IIWO_AMYMU); contains Interpro domain(s) IPR015500 Peptidase S8, } \\
\text { subtilisin-related }\end{array}$ \\
\hline B & 10g081020.1.1. & 4 & $\begin{array}{l}\text { Solanum lycopersicum } \\
\text { transcription elongation factor SPT6-like }\end{array}$ & SISPT6 & $\begin{array}{l}\text { Transcription elongation factor SPT6 (AHRD V1 } 7 * * \text { A8NF94_COPC7); contains Interpro domain(s) IPRO17072 Transcription } \\
\text { elongation factor Spt6 }\end{array}$ \\
\hline c & 049005160.1 .1 & 6 & $\begin{array}{l}\text { Solanum Iycopersicum } \\
\text { 6-phosphogluconate dehydrogenase, decarboxylating } 3\end{array}$ & SI6-PGDH3 & $\begin{array}{l}\text { 6-phosphogluconate dehydrogenase decarboxylating (AHRD VV V*** B9NTWW_POPTR); contains Interpro } \\
\text { domain(s) IPRO06113 6-phosphogluconate dehydrogenase, decarboxylating }\end{array}$ \\
\hline c & 049005610.2 .1 & 7 & $\begin{array}{l}\text { Solanum lycopersicum } \\
\text { NAC domain-containing protein } 2\end{array}$ & SINAP2 & $\begin{array}{l}\text { NAC domain transcription factor (AHRD V1 **** Q5DM36_WHEAT); contains Interpro domain(s) IPR003441 No apical } \\
\text { meristem (NAM) protein }\end{array}$ \\
\hline c & 049074230.2 .1 & 4 & $\begin{array}{l}\text { Solanum lycopersicum } \\
\text { 14-3-3 protein } 7\end{array}$ & TFT7 & $\begin{array}{l}\text { 14-3-3 protein sigma gamma zeta beta/alpha (AHRD V1 **-- Q16QZ7_AEDAE); contains Interpro } \\
\text { domain(s) IPRO00308 14-3-3 protein }\end{array}$ \\
\hline c & 08g082280.2.1 & 3 & $\begin{array}{l}\text { Solanum lycopersicum } \\
\text { long chain acyl-CoA synthetase } 4\end{array}$ & - & $\begin{array}{l}\text { Long-chain-fatty-acid-COA ligase (AHRD VI } 7 * * * \text { B2WS80_ARAHA); contains Interpro domain(s) IPR000873 AMP-depen- } \\
\text { dent synthetase and ligase }\end{array}$ \\
\hline c & 109080440.1 .1 & 3 & $\begin{array}{l}\text { Solanum lycopersicum } \\
\text { TBCC domain-containing protein } 1\end{array}$ & - & $\begin{array}{l}\text { TBCC domain-containing protein } 1 \text { (AHRD V1 } 1 * \text { - TBCCI_XENTR); contains Interpro domain(s) IPRO12945 Tubulin binding } \\
\text { cofactor C }\end{array}$ \\
\hline
\end{tabular}

plant line (named MiMSP32_ox7) also showed a significant 25\% higher number of root tips at the time of inoculation (Figure 2B). We did not observe other morphological effects in the MiMSP32 overexpressing lines as compared to wild-type plants. Both transgenic lines overexpressing MiMSP32 containing the transgene showed high expression levels of MiMSP32 (Supplementa Figure S2). We therefore concluded that MiMSP32 functions as bona fide effector for M. incognita that promotes virulence during the early stages of parasitism in roots of tomato plants.

\section{MiMSP32 interacts with multiple host proteins of tomato}

To identify candidate host targets of MiMSP32 in tomato, we screened a yeast two-hybrid cDNA library constructed of infected tomato roots using MiMSP32 without its native signal peptide as bait. In total, 127 million yeast colonies were analyzed, resulting in the identification of 51 tomato protein fragments possibly interacting with MiMSP32. To separate artefacts from likely specific interactors, we first used a global predicted biological score. Based on this score we selected fifteen probable candidate interactors of MiMSP32, six of which with high confidence (Table 1). The number of unique independent positive yeast clones for each of the probable interactors of MiMSP32 ranged from 4 to 20. Aligning the clone inserts with the best matching predicted full-length proteins in sequence database of tomato genome version SL2.50 enabled us to identify the corresponding gene fragments for 06g073580.2.1 (SIH6D) hyoscamine 6-dioxygenase), 10g074940.1.1 (SIALAT; phospholipid-transporting ATPase 7-like), 12g010040.1.1 (SILAPA2; leucine aminopeptidase), 01g103390.2.1 (SIOPR2; oxophytodienoate reductase 2), 03g025610.1.1 (SITPPII; tripeptidyl-peptidase 2), and 10g081020.1.1 (SISTP6; transcription elongation factor SPT6-like) (Supplemental Table S1). 
Next, the positions of the interacting fragments relative to possible subcellular localization signals and conserved protein domains were determined (Marchler-Bauer et al.., 2016) (Figure 3). For SIOPR2, the minimal interacting fragment contains nine out of fourteen active sites, including substrate binding sites and flavin mononucleotide binding sites. For SISPT6, the interacting fragment contains one of the four nuclear localization sites. For all proteins, the fragment overlapped partly with the main domain or superfamily identified.

Next, we analyzed the predicted physiochemical properties of MiMSP32 and selective interacting domains that could also explain non-specific binding between MiMSP32 and the possible interactors (Table 2). Some general patterns exist within the interacting fragments, such as slight hydrophilic characteristics, translating into soluble proteins inside plant cells (Kyte \& Doolittle, 1982). Additionally, all fragments have an isoelectric point around $\mathrm{pH}=6$, causing them to carry only a minor electrical charge in most plant subcellular conditions (Kurkdjian \& Guern, 1989). We have not found any exceptional features that could cause non-specific binding to MiMSP32.

To independently confirm interactions of MiMSP32 with all six probable host targets, we co-expressed affinity-tagged constructs of the selected interaction domains of the interactors with PBIN:MiMSP32-sp_GFP_HA4 in Nicotiana benthamiana leaves. Co-immunoprecipitation with anti-HA magnetic beads showed that five out of the tested six selected interaction domains also specifically bind to MiMSP32-sp_GFP_HA4 in plant cells (Figure 4). SISPT6 was the only putative interactor not pulled-down by MiMSP32-sp_GFP_HA4. We therefore concluded that fragments of the tomato proteins SIH6D, SIALA1, SILAPA2, SIOPR2 and SITPPII specifically interact with MiMSP32 in plants.

Table 2. Physiochemical protein characteristics as predicted by ExPASy. Values for theoretical pl (isoelectric point), total number of positive and negative residues, extinction coefficient, instability index, aliphatic index and the GRAVY-score (grand average hydropathy).

\begin{tabular}{llllllll}
\hline \hline Gene ID & pl & Residues (-) & Residues (+) & $\begin{array}{l}\text { Extinction } \\
\text { coefficient }\end{array}$ & $\begin{array}{l}\text { Instability } \\
\text { index }\end{array}$ & $\begin{array}{l}\text { Aliphatic } \\
\text { Index }\end{array}$ & $\begin{array}{l}\text { GRAVY } \\
\text { Score }\end{array}$ \\
\hline MiMSP32-sp $^{\text {SP }}$ & 6.44 & 24 & 23 & 18910 & 29.04 & 81.35 & -0.358 \\
\hline SIH6D $^{\text {SID }}$ & 5.18 & 36 & 27 & $31400-31650$ & 38.74 & 88.79 & -0.514 \\
\hline SIALA1 & 5.16 & 32 & 22 & $15930-16055$ & 41.47 & 83.92 & -0.261 \\
\hline SILAPA2 & 5.28 & 13 & 11 & 28990 & 28.08 & 82.83 & -0.095 \\
\hline SIOPR2 & 4.79 & 26 & 18 & 14440 & 26.38 & 90.19 & -0.27 \\
\hline SITPPIIID & 4.78 & 28 & 16 & $18450-18700$ & 37.95 & 95.93 & -0.138 \\
\hline SISPT6SID & 4.73 & 99 & 63 & $46410-46660$ & 63.35 & 65.4 & -0.941 \\
\hline \hline
\end{tabular}

> Figure 3. Overview of the six tomato host proteins. Hyoscamine 6-dioxygenase (SIH6D), phospholipid-transporting ATPase 1-like (SIALA1), leucine aminopeptidase (SILAPA2), 12-oxophytodienoate reductase 2 (SIOPR2), tripeptidyl-peptidase 2 (SITPPII) and transcription elongation factor SPT6-like (SISPT6). For each protein, the selected interaction domains (SIDS), individual and unique interacting clones (A-0:257), localization signals determined by LOCALIZER (such as a nuclear localization signal (NLS)), and conserved domains are visualized. 
$1 \quad \begin{array}{rrrr}50 \\ 1.00\end{array}$

$$
\text { SIH6D_SID }
$$

PLN02639 superfamily
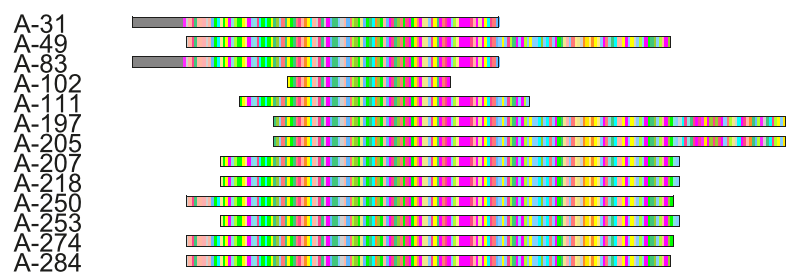

SIALA1
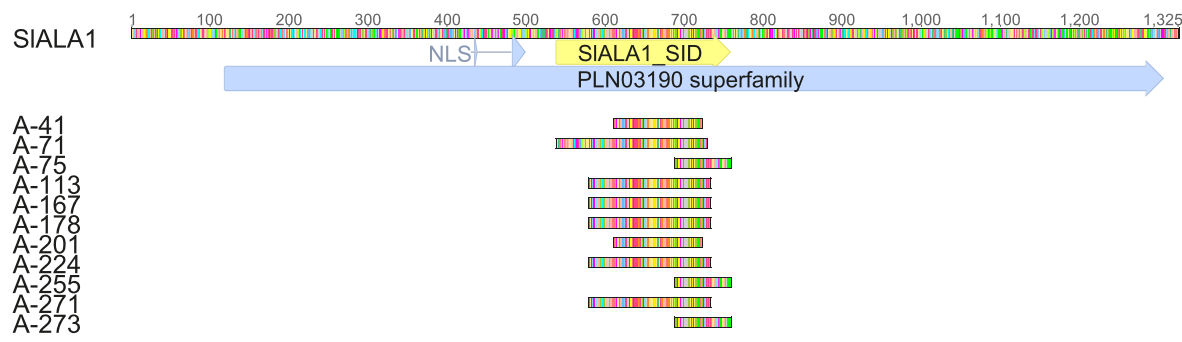

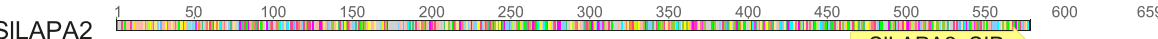

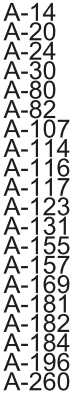

PRK00913 superfamily

SILAPA2_SID

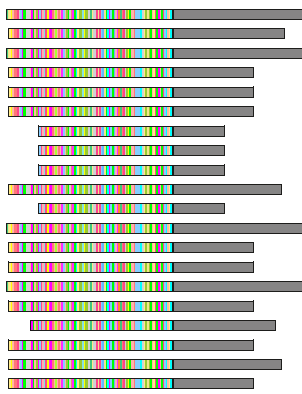

SIOPR

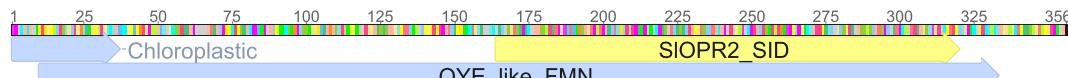

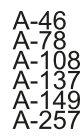

Active site

OYE_like_FMN

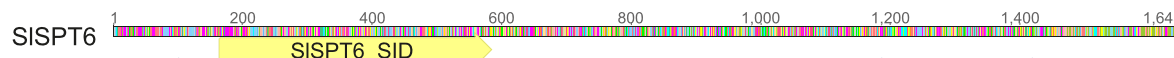

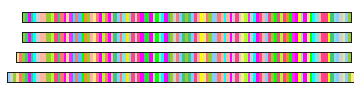

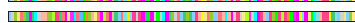
स्म

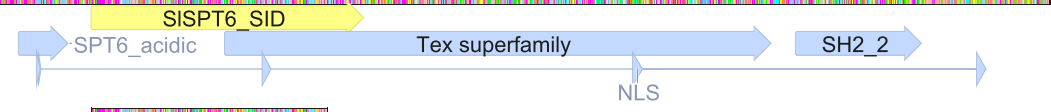

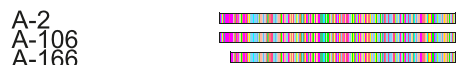

(1)

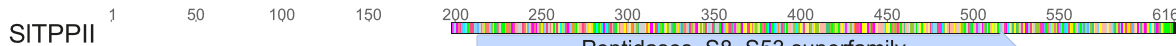
Peptidases S8 S53 superfamily SITPPII_SID

A-81

A-159 


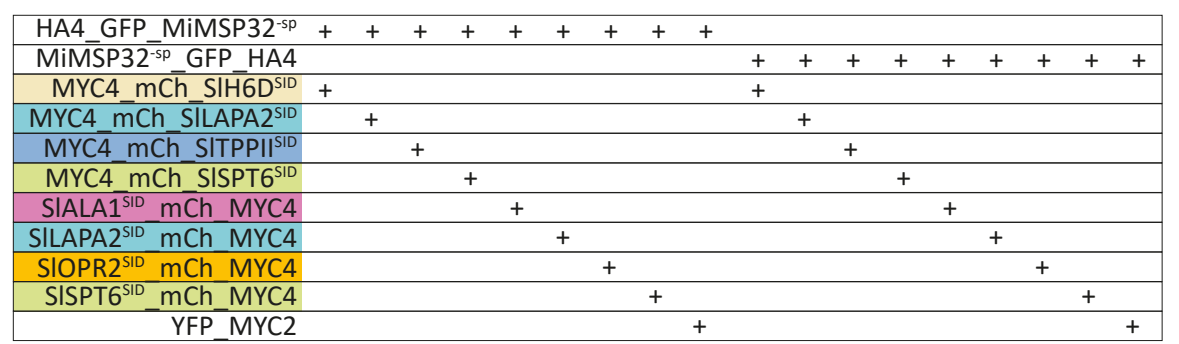
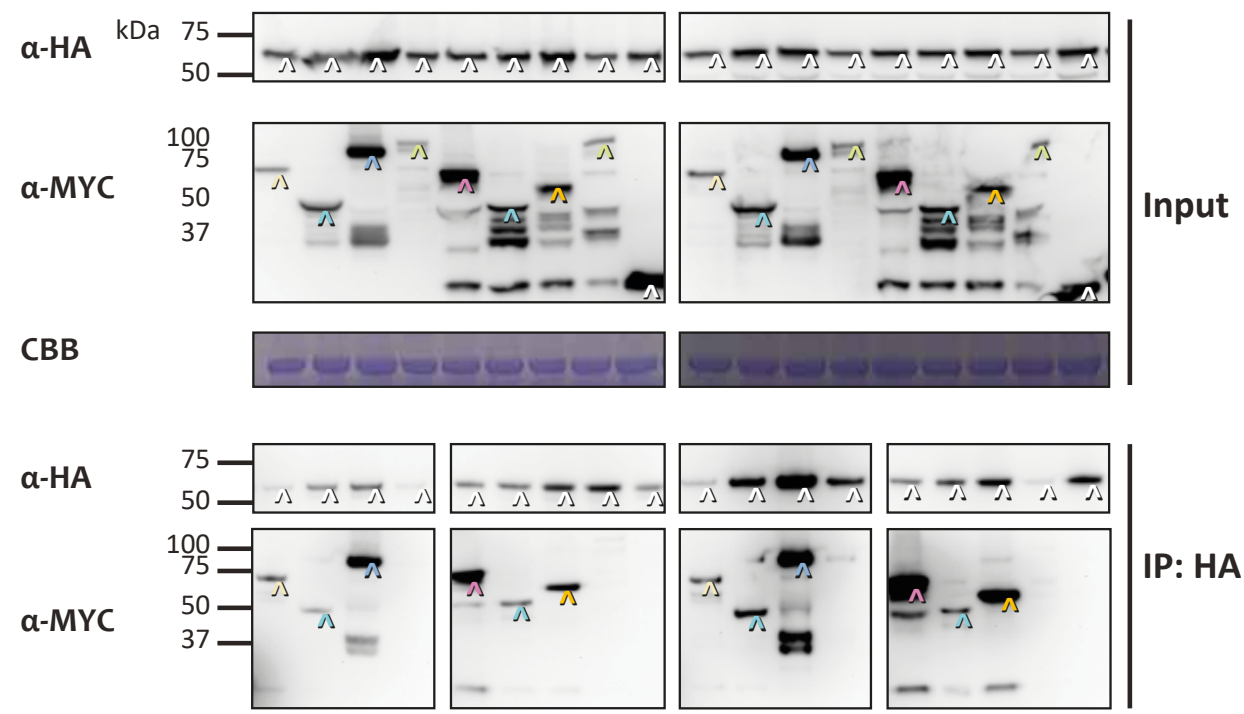

Figure 4. MiMSP32 interacts specifically with at least five host proteins. Co-immunoprecipitation assay of N-and C-terminally HA-tagged MiMSP32 with either N- or C-terminally MYC-tagged potential interacting fragments in tomato. The effector and the selected interaction domains (SIDS) of tomato hyoscamine 6-dioxygenase (SIH6D), phospholipid-transporting ATPase 1-like (SIALA1), leucine aminopeptidase (SILAPA2), 12-oxophytodienoate reductase 2 (SIOPR2), tripeptidyl-peptidase 2 (SITPPII) and transcription elongation factor SPT6-like (SISPT6) were extracted at $48 \mathrm{~h}$ after inoculation in Nicotiana benthamiana. Equal loading is visualized by Coomassie brilliant blue (CBB) staining on total protein extracts.

MiMSP32 co-localizes with host targets in vivo

To investigate the subcellular localization of MiMSP32 without its native signal peptide in planta, we transiently expressed two fluorescently tagged constructs of MiMSP32-sp (i.e., MiMSP32-sp_GFP_HA4 and HA4_GFP_MiMSP32-sp) in Nicotiana benthamiana. Both MiMSP32-sp_GFP_HA4 (Figure 5A) and HA4_GFP_MiMSP32-sp (Supplemental Figure S3) localized to the cytoplasm as well as to the nucleus in mesophyll cells of N. benthamiana. It should be noted that MiMSP32-sp is predicted to be localized in the cytoplasm based on sorting signals, amino acid compositions and functional motifs, although it can likely diffuse into the nucleus due to its small size (Wang \& Brattain, 2007) (Table 3). Additionally, full-length MiMSP32 is also predicted by the machine-learning effector localization program LOCALIZER to reside intracellular, not in the apoplast (Sperschneider et al., 2018). 
A

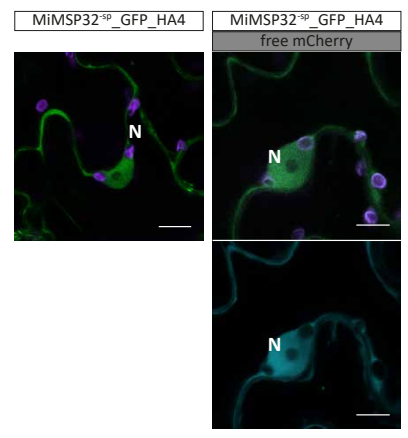

B

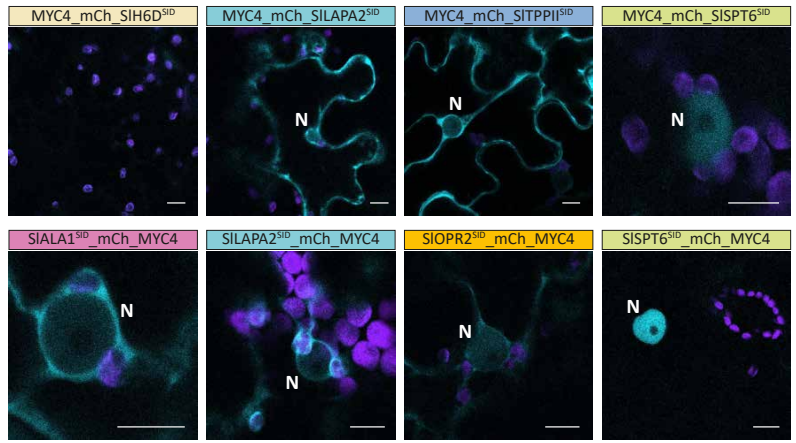

C
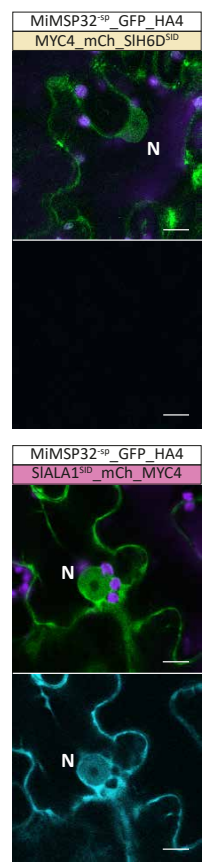

MiMSP32 $32^{-S P}$ GFP_HA4

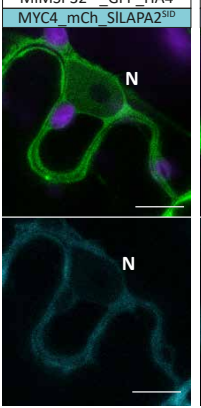

MiMSP32 $2^{\text {sp_GFP_HA4 }}$ SILAPA2 $2^{\text {SI0 }}$ - $\mathrm{CCh}$ - MYC4
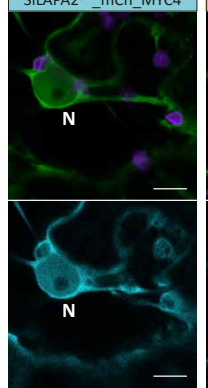
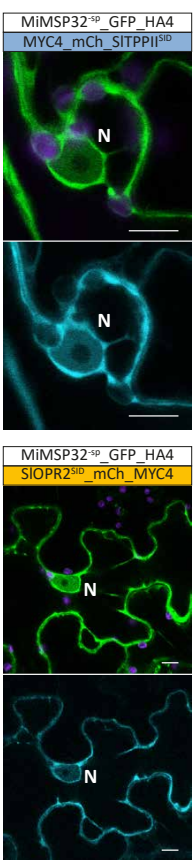

D
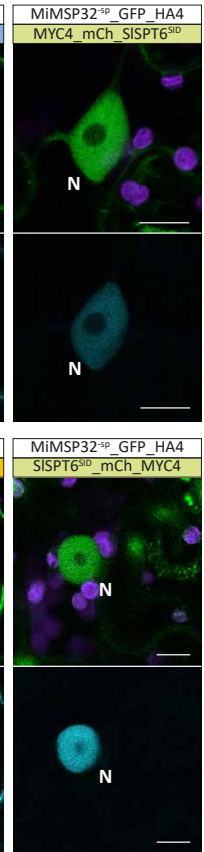

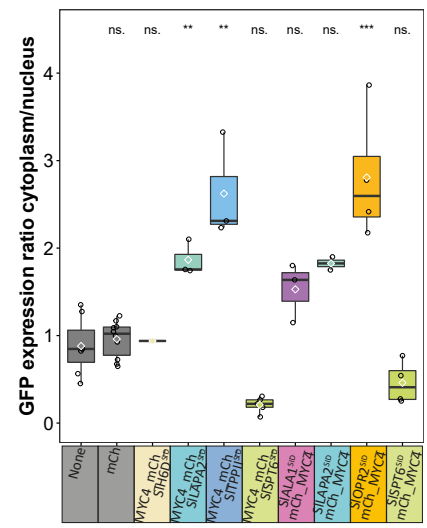

Figure 5. Transiently expressed MiMSP32-sp co-localizes in the cytoplasm or nucleus of Nicotiana benthamiana cells, depending on the host target fragment present. The confocal pictures represent the mCherry channel (cyan) and the combined GFP channel (green) with chloroplasts (purple). (A) Subcellular localization of MiMSP32-sp_GFP_HA4 with and without free mCherry. (B) Subcellular localization of mCherry-tagged host target fragments (SIDs) of tomato Hyoscamine 6-dioxygenase (SIH6D), phospholipid-transporting ATPase 1-like (SIALA1), leucine aminopeptidase (SILAPA2), 12-oxophytodienoate reductase 2 (SIOPR2), tripeptidyl-peptidase 2 (SITPPII) and transcription elongation factor SPT6-like (SISPT6). (C) Subcellular localizations of co-expressed MiMSP32-sp_GFP_HA4 with the mCherry-tagged selected interaction domains as in (B). (D) ImageJ quantification of the GFP expression ratio for cytoplasm versus nucleus. The number of pictures varied between 1 and 14 for which both subcellular locations were represented. Statistical analysis was done with a one-way ANOVA with a Tukey HSD and asterisks indicate significant differences between mCherry-tagged selected interaction domains (SIDS) of tomato host proteins and MiMSP32-sp without any co-expressed construct (**, P<0.01; ***, P<0.001; ns, not significant). All leaf samples were taken at 48 hours after agroinfiltration of the constructs. Bars $=10 \mu \mathrm{m}$. 
Likewise, to determine the subcellular localization of the interactors of MiMSP32, we transiently expressed the constructs MYC4_mCh_SIH6D SID, MYC4_mCh_SILAPA2 ${ }^{S I D}$, MYC4_mCh_SITPPIISID,

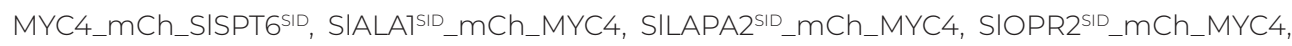

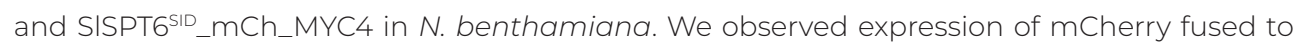
SIALAT ${ }^{S I D}$, SIOPR2 ${ }^{S I D}$, SITPPIISID and SILAPA2 ${ }^{\text {SID }}$ mainly in the cytoplasm, C-terminally tagged SILAPA2 ${ }^{\text {SID }}$ in both cytoplasm and chloroplasts, and SISPT6 ${ }^{\text {IID }}$ in nuclei (Figure 5B). At 48 hours post infiltration, we could not observe MYC4_mCh_SIH6D SID expression. All cytoplasmic localizations of the interacting host protein were in line with our predictions (Table 3). SISPT6SID contains a nuclear localization site and was therefore predicted to be localized in the nucleus. Only C-terminally tagged SILAPA2 ${ }^{\text {SID }}$ did not reside in the predicted subcellular compartment.

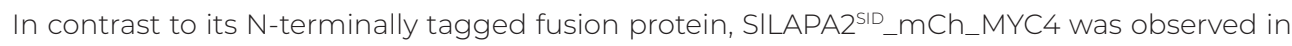
both cytoplasm and chloroplasts instead of only in the cytoplasm.

We reasoned that binding to a probable interactor might shift the subcellular localization of MiMSP32 towards the localization of its interactor. To test this, we transiently co-expressed GFPtagged MiMSP32-sp with the six putative interactor domains fused to mCherry in N. benthamiana (Figure 5C). We noticed a significant shift in localization of MiMSP32-sp_GFP_HA4 to the cytoplasm when it was co-expressed with SILAPA2 $2^{\text {IID }}$, SIOPR2 $2^{\text {SID }}$ or SITPPIISID $(P<0.01$; one-way ANOVA with Tukey's HSD) (Figure 5D). In contrast, the localization of MiMSP32 shifts more to the nucleus when co-expressed with SISPT6 ${ }^{\text {SID }}$. Taking the data of the co-immunoprecipitation experiments and shifts in the subcellular localization together, we conclude that MiMSP32 also interacts in planta with fragments of the tomato proteins phospholipid-transporting ATPase 1-like (SIALAT), leucine aminopeptidase (SILAPA2), oxophytodienoate reductase 2 (SIOPR2), and tripeptidyl-peptidase 2 (SITPPII).

The subcellular localization shift of MiMSP32 in association with transcription elongation factor SPT6-like (SISPT6) contradicts the lack of binding between both proteins in co-immunoprecipitation assays. To find out if nucleic SISPT6SID interacts with MiMSP32 in planta, we used fluorescent lifetime imaging microscopy to measure the Förster resonance energy transfer. We transiently co-expressed the mCherry-tagged SISPT6 ${ }^{\text {SID }}$ and SITPPIIID with MiMSP32-SP_GFP_HA4 in N. benthamiana and measured the average fluorescence lifetime of GFP (Figure 6A). We found a significant decrease in GFP lifetime for co-expressed MiMSP32 with both SISPT6SID and SITPPIISID ( $P<0.05$; Student's t-tests) (Figure 6B), which indicates that the mCherry and GFP-tagged proteins are in close enough proximity for energy transfer to occur. However, we did not observe any significant differences in the GFP lifetime between cytoplasmic or nuclear MiMSP32-sp Co-expressed with SISPT6 ${ }^{\text {ID }}$ (Figure 6C). In contrast, the positive control SITPPII SID resulted in a much lower GFP lifetime in the cytoplasm of cells co-expressing SITPPIIIID when compared to the nucleus of the same cells ( $P<0.001$; t-tests). Based on these observations, we conclude that SISPT6 does interact with MiMSP32 in plant cells and therefore is a genuine host target of MiMSP32. 
Table 3. Expected subcellular localization as predicted by WoLF PSORT. The highest scoring location is highlighted in bold and underlined. Scoring values roughly indicate the number of nearest neighbors to the query which localize to each site. (Nucl; nuclear, cyto; cytosol, chlo; chloroplast, extr; extracellular, mito; mitochondria, cysk; cytoskeleton, golg; Golgi apparatus, pero; peroxisome, plas; plasma membrane, E.R.; endoplasmic reticulum).

\begin{tabular}{|c|c|c|c|c|c|c|c|c|c|c|c|}
\hline & nucl & cyto & chlo & last & extr & mito & cysk & golg & pero & $\begin{array}{l}\text { cysk } \\
\text { plas }\end{array}$ & $\begin{array}{l}\text { cyto } \\
\text { E.R. }\end{array}$ \\
\hline MiMSP32-sp & 1 & $\underline{12.5}$ & & & & & & & & & 7 \\
\hline $\mathrm{SIH} 6 \mathrm{D}^{\mathrm{SID}}$ & 1 & $\underline{7}$ & 1 & 1.5 & 1 & & 2.5 & & & 2.5 & \\
\hline SIALA $]^{S I D}$ & 2 & 3 & 1 & 1 & & & $\underline{6}$ & 1 & & & \\
\hline SILAPA2 ${ }^{\text {SID }}$ & & $\underline{11}$ & 1 & & 2 & & & & & & \\
\hline SIOPR2 $2^{\text {SID }}$ & 2 & $\underline{9}$ & & 2 & & & 1 & & & & \\
\hline SITPPIISID & & $\underline{12}$ & & & & 1 & & & 1 & & \\
\hline SISPT6SID & $\underline{14}$ & & & & & & & & & & \\
\hline
\end{tabular}

A

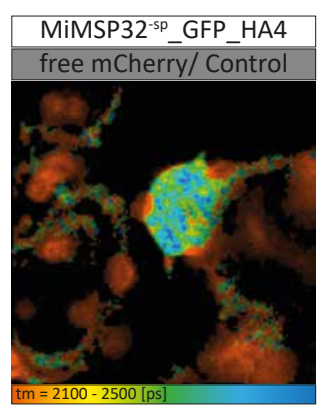

B

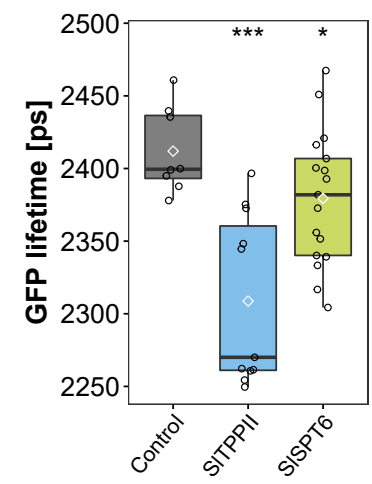

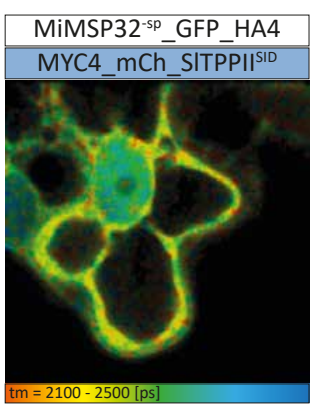

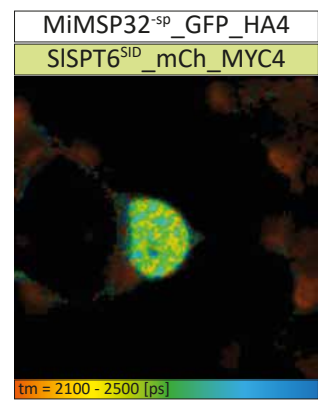

C

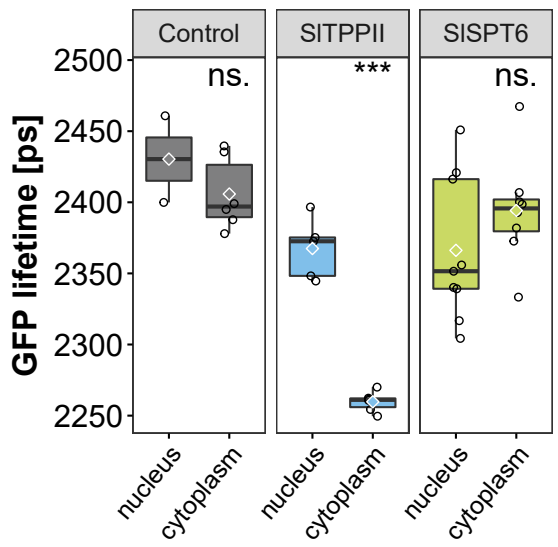

Figure 6. MiMSP32-sp interacts specifically with SITPPIIII and SISPT6 ${ }^{\text {SID }}$ in vivo. (A) Forster resonance energy transfer and fluorescent lifetime imaging microscopy images of MiMSP32-sp_GFP_HA4, when co-expressed with either free mCherry, MYC4_mCh_SITPPIISID or SISPT6SID_mCh_MYC4. (B) Quantification of the average fluorescence lifetime of GFP in picoseconds (ps). (C) Quantification of GFP lifetime per subcellular compartment for nucleus and cytoplasm. GFP lifetime was determined for both subcellular compartment in all 21 pictures if compartments were located within the picture. The experiment was repeated twice with similar results. Asterisks indicate significant differences as tested by t-tests (*, P<0.05; ***, $\mathrm{P}<0.001$; ns, not significant). 


\section{Discussion}

The main objective of this study was to determine if the esophageal gland specific gene MiMSP32 functions as an effector for M. incognita in tomato. First, we found that MiMSP32 contributes to $M$. incognita virulence in the early stages of infection. We also showed that ectopic MiMSP32 makes tomato plants more susceptible to M. incognita, which suggest that it can indeed function as effector for M. incognita. Members of the highly expanded gene family to which MiMSP32 belongs have no sequence similarity to functionally annotated genes currently present in protein sequence databases. We therefore sought to find leads toward its function by a yeast-two-hybrid screen using MiMSP32 as bait. In a series of additional protein-protein interaction studies we identified six unrelated proteins in tomato as possible host targets of MiMSP32 and here we propose a speculative model (Figure 7).

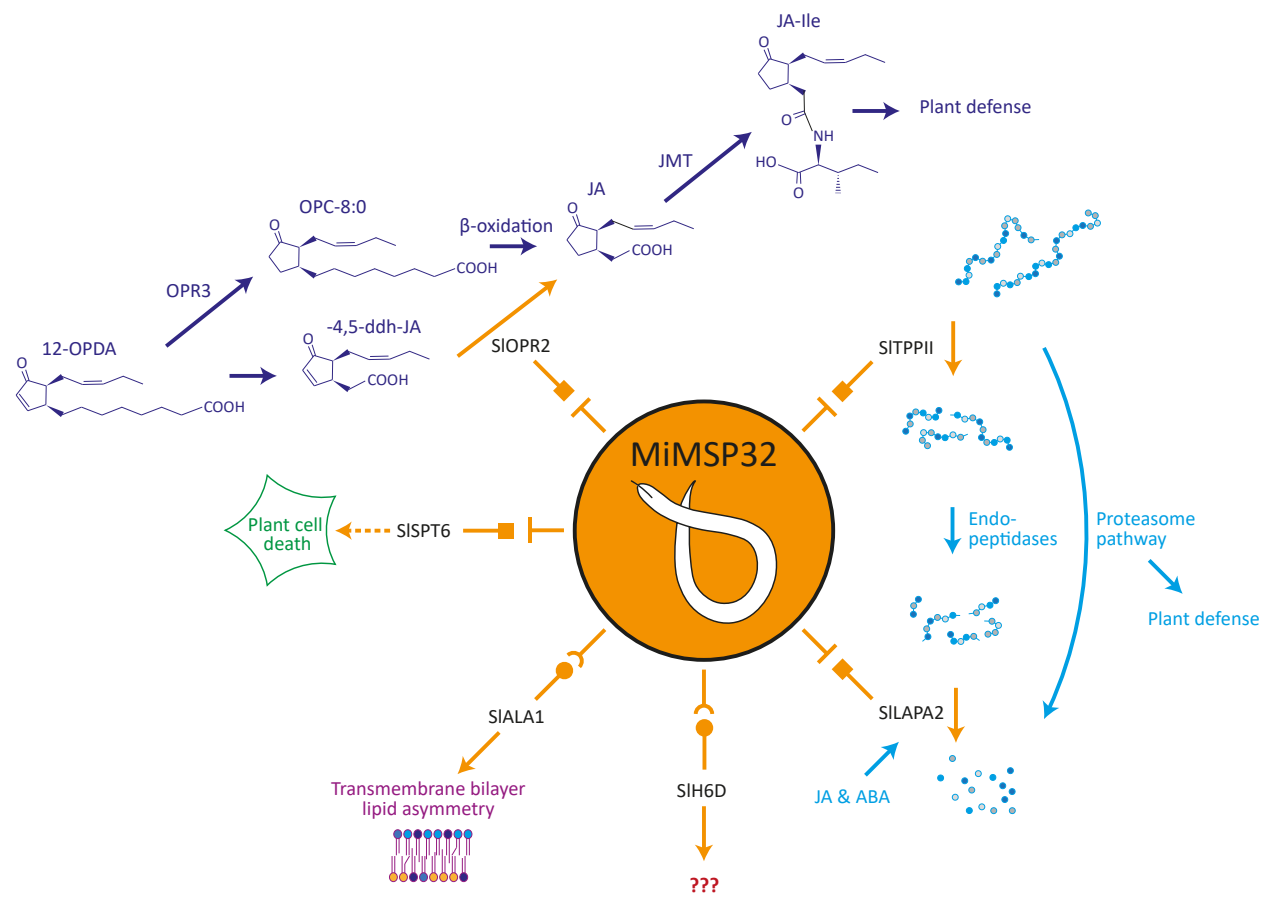

Figure 7. Working model of the effector MiMSP32 and its tomato host targets. MiMSP32 likely induces plant susceptibility by targeting multiple host targets in tomato to suppress plant defenses or induce feeding site formation. 12-oxophytodienoate reductase 2 (SIOPR2) converses 12-oxophytodienoate acid (12-OPDA) to jasmonic acid (JA) via the intermediate 4,5-didehydro-JA (-4,5-ddh-JA), a process that is likely inhibited by MiMSP32 to suppress plant defense. Tripeptidyl peptidase II (SITPPII) cleaves the longer peptide products in the plant defense associated proteasome pathway. In the same pathway, leucine aminopeptidase SILAPA2 degrades the smallest peptides, induced by both abscisic acid (ABA) and jasmonic acid (JA). MiMSP32 is expected to suppress the proteasome pathway to contribute to plant defense. The function of hyoscyamine 6-dioxygenase-like (SIH6D) is so far unknown, and no assumptions can be made whether MiMSP32 induces or suppresses this gene. Usually, phospholipid translocases such as phospholipid-transporting ATPase 1-like SIALA1 mediate the generation and maintenance of the membrane bilayer, a process not linked to plant defense before. The transcription elongation factor SISPT6 is highly expressed when cell death occurs. Therefore, suppression of SISPT6 could regulate transcription of cell-death associated genes. 


\section{MiMSP32 contributes to virulence of $M$. incognita}

Expression of dsRNA matching MiMSP32 reduced the formation of nematode-induced galls in tomato suggesting that this effector contributes to virulence of M. incognita after the initiation of the feeding site. Multiple factors can influence the number of nematode-induced galls, such as the attractiveness of the roots or the number of successful host invasion events. However, host-induced gene silencing is only effective after the nematodes start feeding on host cells. Therefore, we assume that the reduction in number of galls on tomato plant overexpressing dsRNA matching MiMSP32 is caused by an overall smaller number of nematodes capable of successfully initiating and maintaining a feeding site.

We also showed a consistently lower, but not significantly reduced, expression of MiMSP32 in M. incognita located within galls of infected roots of tomato plants overexpressing MiMSP32 dsRNA. There are several reasons that might explain this lack of significant difference in MiMSP32 expression in spite of observing a clear effect on nematode virulence. First, as biological material for the GRT-PCR, we extracted nematode-induced galls, all of which marked successfully established feeding sites of $M$. incognita. In hindsight, our sampling strategy may have selected for virulent individuals that were less affected by HIGS with relatively high MiMSP32 expression. Individual nematodes suffering from strong reduction in MiMSP32 expression by HICS may not have induced galls and would therefore not have been included in our sample of extracted galls. Second, as can also be observed in our data, the variance among biological repeats of nematode-infected root samples in HIGS experiments is notoriously high, which undermines the detection of more subtle effects in the regulation of genes. Third, although Huang et al. (2003) originally identified MiMSP32 as a candidate effector based on its positive in situ hybridization to the dorsal esophageal gland of J3s and older stages of M. incognita, Shukla et al. (2018) concluded that MiMSP32 expression is suppressed at these older stages when compared to the first few days after inoculation. This raises the concern as to whether the expression of MiMSP32 was sufficiently high at $23 \mathrm{dpi}$ to measure a significant downregulation by HIGS in our experiments.

\section{MiMSP32 regulates the susceptibility of tomato plants}

Ectopic expression of MiMSP32 increases susceptibility of tomato plants to M. incognita. In our experiments, we observed an increased number of nematode-induced galls in tomato plants overexpressing MiMSP32. Our data parallels that of several other studies involving the overexpressing of unrelated effectors of M. incognita, such as MiMSP7 (07E12) in N. tabacum (dos Santos de Lima e Souza et al., 2011), MiMSP9 (08D05) in A. thaliana (Xue et al., 2013) and MiMSP16 (16D10) in S. tuberosum (Dinh et al., 2015). As we only have assessed gall-formation at seven days post inoculation, we cannot draw any conclusions regarding the impact of MiMSP32 on either the attractiveness of the roots or the number of successful host invasions. However, as argued above, the processes targeted by MiMSP32 persist until after M. incognita commences feeding.

We also observed a significant increase in number of root tips in one of the overexpression lines, MiMSP32_ox01. Usually, the number of root tips can influence the plant susceptibility to $M$. 
incognita, as $\mathrm{J} 2$ are attracted to root tips. In other studies, it has been shown that overexpression of M. incognita effectors can induce aberrant root phenotypes. For example, overexpression of MiMSP40 (Niu et al. 2016) or MiMSP16 induces root growth (Huang et al., 2006b: Dinh et al. 2015). In contrast, the overexpression of MiPFN3 resulted in dwarf plants (Leelarasamee et al. 2018). In our experiments, only one of the two tomato lines with ectopic overexpression shows an increased number of root tips. Therefore, the most likely explanation of the root growth effects would be an unfavorable position of the transgene in the tomato genome upon plant transformation, disturbing normal gene functioning in plant development.

\section{Identification of six genuine MiMSP32 host targets}

Our yeast-two-hybrid screen for interacting host proteins resulted in a short list of six likely targets of MiMSP32 in infected roots of tomato plants. By using co-immunoprecipitation assays, we independently confirmed the specific interaction of MiMSP32 with five of the six protein fragments in $\mathrm{N}$. benthamiana, suggesting these interactions are robust.

By subcellular localization experiments, we could visually confirm shifts in subcellular localization of MiMSP32 induced by five out of the six tested host protein fragments. In addition to in vitro co-immunoprecipitation on plant protein extracts and a yeast screening, this provides further evidence that MiMSP32 interacts with multiple host proteins in vivo in N. benthamiana cells. Likewise, other studies also validate effector-host protein interactions by localization shifts of the effector. For example, the Arabidopsis host target AtTCP14 (TCP transcription factor) has been found to shift subcellular localization of several pathogen effectors (HopBB1, HaRxL45 and OEC45) (Weßling et al., 2014). We could not confirm the interaction of MiMSP32 with SIH6D ${ }^{\mathrm{SID}}$ using shifts in subcellular localization, as we failed to detect SIH6D ${ }^{\mathrm{SID}}$ in confocal laser scanning microscopy due to unknown reasons. Possibly, some unforeseen folding in the recombinant protein prevented detection of the fluorescent tag. We judged this lack of expression as a technical error and consider SIH6D as a genuine interactor of MiMSP32, based on the co-immunoprecipitation and yeast two-hybrid screening. Likewise, we could not confirm an interaction of MiMSP32 with SISPT6SID by co-immunoprecipitation, although a subcellular localization shift of MiMSP32-sp to the nucleus was visible when co-expressed with SISPT6SID.

As a final test for a specific interaction of MiMSP32-sp and SISPT6, we used FRET-FLIM analyses. The advantage of FRET-FLIM is that it allows the specific detection of mCherry and GFPtagged proteins in close enough proximity for energy transfer to occur, which indicates direct interactions in living plant cells. Other studies also used this technique to confirm if and where pathogen effectors and host proteins interact in planta. For example, the Ralstonia solanacearum effector PopP2 was shown to interact with RRS1-R in the nucleus of living plant cells using FRET-FLIM (Tasset et al.., 2010). For SITPPII, we demonstrated that the cytoplasmic and nuclear located MiMSP32 can associate with SITPPIIID within the plant cytoplasm. For MiMSP32-sp and SISPT6, the apparent GFP fluorescence lifetimes in cytoplasm and nucleus were comparable. Therefore, we conclude that even though expression was mainly observed in the nucleus, interaction between MiMSP32-sp and SISPT6 ${ }^{\text {SID }}$ occurs in both cytoplasm and 
nucleus.

The multiple host targets have led us to question if the physiochemical protein characteristics of MiMSP32-sp might cause a-specific binding or artefacts. Obvious structural reasons underlying genuine effector promiscuity can be the availability of multiple domains or structural motifs, allowing interactions with diverse host targets (Thordal-Christensen et al., 2018). For example, the HopFl effector in Pseudomonas syringae contains two separate subdomains, shaped as the 'head' and the 'stalk' of a mushroom (Singer et al., 2004). A single domain can also cause promiscuity, such as the WY domain structure, which provides plasticity for effectors to bind different host proteins (Franceschetti et al., 2017). For MiMSP32, we could not identify any known domains, and no crystal structure of MiMSP32 is available (Chapter 2: Figure 5). Therefore, we sought for physiochemical protein characteristics such as charged regions or a strong hydrophobicity explaining an exceptional 'stickiness' of MiMSP32-sp or the candidate interactors. However, we could not pinpoint any. On the opposite, the effector and its host targets differ much in individual properties as stability or hydrophobicity. The lack of extreme protein characteristics again suggests that MiMSP32-sp is a promiscuous effector with genuine binding to multiple host targets.

In earlier studies, several nematode effectors have been shown to interact with multiple unrelated host targets. The H. schachtii effector Hs1OAO7 interacts with a plant kinase IPK and the IAA16 transcription factor in the cytoplasm and nucleus, respectively ( Hewezi et al., 2015). Likewise, the effector Hs25AO1 interacts with an Arabidopsis F-box-containing protein, a chalcone synthase and the translation initiation factor elF-2 b subunit (elF-2bs) (Pogorelko et al., 2016). From root-knot nematodes, only the effector MgMO237 of M. graminicola interacts with three unrelated rice endogenous proteins involved in host defense, i.e. 1,3- $\beta$-glucan synthase component (OSCSC), cysteine-rich repeat secretory protein 55 (OsCRRSP55), and pathogenesis-related Betvl family protein (OsBetvl) (Chen et al., 2018).

Although promiscuity is rarely reported in nematode effector studies, other phytopathogen effectors have in many cases been found to associate with multiple host targets (Win et al., 2012). Among all bacterial type III effectors, 32\% has a single host target, 32\% has multiple host targets with a similar molecular function, and 36\% has multiple host targets with different molecular functions (Khan et al., 2018). Likewise, fungal effectors often have multiple host targets (Białas et al., 2018). A possible reason for effectors targeting multiple host proteins is a selection pressure to converge on a relative small set of crucial host proteins at key nodes in defense signal pathways. Presumably, multiple promiscuous effectors have common host targets, thus compensating for the loss of one particular effector. Another reason for promiscuity might be the sequential delivery of effectors, causing a functional effector to bind to different targets in specific phases of the infection (Thordal-Christensen et al., 2018). Possibly, the latter explanation applies to promiscuity of MiMSP32, as MiMSP32 is likely expressed during different nematode infection phases (Huang et al., 2003) (Chapter 2). However, the observation that most phytopathogen effectors are promiscuous suggests a comparable mechanism in 
nematode effectors.

\section{The six host targets in plant-nematode interactions}

To deduce which of the six interacting host proteins could be involved in the enhanced susceptibility of tomato plant overexpressing MiMSP32 to M. incognita, we systematically reviewed the literature for relevant key biological functions.

Although there is no specific biological function assigned to SIH6D yet, the 2OG-Fe(II) oxygenase family to which it belongs is a large enzyme family involved in various responses to biotic and abiotic stresses (Kim et al., 2012). Members of 20G-Fe(II) oxygenase family catalyze different hydroxylation and desaturation steps in the synthesis of a broad range of plant compounds, including several phytohormones. For example, the 2-oxoglutarate-dependent dioxygenases SLC1 and SLC2 play essential roles in salicylic acid biosynthesis in rice (Liu et al., 2019). Jasmonic acid oxidases (JAOS) or jasmonate-induced oxygenases (JOXs) also belong to the same family and catalyze the specific oxidation of jasmonic acid in Arabidopsis to the inactive 12-OH-JA (Caarls et al., 2017). Additionally, tomato plants lacking the 20G-Fe(II) oxygenase DMR6 show disease resistance against a wide variety of pathogens (Paula de Toledo Thomazella et al. 2016). In a similar fashion, alleles of SIH6D may function as susceptibility genes for M. incognita infections, which could explain the loss of susceptibility when MiMSP32 is silenced and unable to target this host. Likewise, the Phytophthora infestans effector PIAVR2 uses BRI7-SUPPRESSORT-like (BLS) family members as susceptibility factors in potato to negatively regulate plant immunity (Turnbull et al., 2019).

In previous studies, aminophospholipid translocases such as SIALAT have not been linked to pathogen invasion before. Phospholipid translocases are usually known as membrane proteins mediating the generation and maintenance of the membrane bilayer (Fan et al., 2018). In Arabidopsis, 11 genes belong to this family. AtALA1 regulates the transmembrane bilayer lipid asymmetry and the adaption of plants to cold stress (Gomès et al., 2000). Transmembrane bilayer lipid asymmetry or aminophospholipid translocases such as SIALA7 have not been shown to play an important role in plant-nematode interactions.

Leucine aminopeptidase ( $L A P A 2)$ belongs to a proteasome pathway, mediating the degradation of peptides and the release of free amino acids (Polge et al., 2009; Boulila-Zoghlami et al. 2011). More specifically, cytosolic leucine aminopeptidases degrade the smallest peptides (3-6 amino acids) (Boulila-Zoghlami et al., 2011). Effectors can interfere with proteasome activity to suppress plant defense (Banfield, 2015). Plant parasitic nematodes secrete protease-like effectors and target host-proteases involved in proteasomal degradation (Hewezi, 2015). Likewise, the proteasome pathway in Arabidopsis has been identified as a hub for plant immunity and a target for Pseudomonas effectors. For example, the type III effector protein HopM1 from Pseudomonas syringae interacts with several E3 ubiquitin ligases and proteasome subunits, leading to inhibition of the proteasome (Üstün et al., 2016). Another interesting fact is that SILAPA2 increases its activity in response to both jasmonic acid and abscisic acid (Fowler et 
al., 2009). Jasmonic acid and abscisic acid are often considered as two positive regulators in the same signaling pathway (Asselbergh et al., 2008). Taken together, its functioning in the proteasome pathway and its regulation by plant phytohormones make SILAPA2 a likely host target of MiMSP32 and an important gene-of-interest for further analyses.

In Arabidopsis, AtTPPII is also involved in proteasomal degradation pathway. However, instead of degrading small peptide products like SILAPA2, SITPPII is likely responsible for cleaving the longer peptide products (>15 amino acids) (Saric et al., 2004). The presence of two proteasome pathway related proteins within the six possible host targets makes both SILAPA2 and AtTPPII interesting candidates for further investigation.

The 12-oxophytodienoate reductase proteins (OPRs) reduce 12-oxophytodienoic acid (OPDA) into jasmonic acid (Strassner et al., 2002). Interestingly, OPDA is known to play a key role in regulating plant susceptibility to M. hapla in A. thaliana (Gleason et al., 2016). Likewise, jasmonic acid has been found to modulate the interaction between $M$. incognita and tomato plants (Seiml-Buchinger et al..2018). A role in the conversion of OPDA to jasmonic acid was shown in particular for OPR3 (Stintzi \& Browse, 2000) and for OPR1 and OPR2 to a lesser extend (Mussig et al., 2000: Schaller et al., 2000). However, a recent in-depth study on the A. thaliana OPRs placed OPR2 in an alternate OPR3-independent JA-biosynthesis pathway. Here, AtOPR2 was found to reduce 4,5-didehydro-JA to JA (Chini et al., 2018). In fact, OPR2 links the two phytohormones OPDA and jasmonic acid, both of which are associated with defense against root-knot nematodes. OPR2 could therefore account for the observed effects of MiMSP32 on virulence of $M$. incognita.

The transcription elongation factor SPT6 can stimulate the transcription elongation rate of RNA polymerase II by modulating the chromatin structure of transcribed genes (Grasser, 2005). In Arabidopsis, the histone chaperone AtSPT6 has a similar function. Interestingly, AtSPT6 is highly expressed during senescence and in plants with the necrotrophic fungus Alternaria brassicicola (Tripathi et al., 2015). The potential characteristic of AtSPT6 controlling cell death particularly makes it a promising candidate for further studies.

Given that our experiments suggest that all six interacting host proteins are likely effector targets of M. incognita, we have developed a speculative model that accommodates as many of their known biological functions as possible (Figure 7). As explained above, SIOPR2, SILAPA2 and SITPPII can be easily linked to plant-nematode interactions. SISPT6 can play a role in controlling plant cell death, but a more direct connection to the survival of host cells in unclear. For SIH6D, not enough is known yet to draw any conclusions and for SIALA1, there is no further support to expect it to function in plant-nematode interactions. 


\section{Conclusion}

In conclusion, our results suggest that the promiscuous M. incognita effector MiMSP32 contributes to virulence by interacting with several host targets in tomato plants. A further characterization of host target functioning in plant-nematode interactions is necessary to study how exactly MiMSP32 influences plant defense responses. One option is to generate deletion mutants in tomato which can then be screened for loss or gain of susceptibility to M. incognita. However, creating deletion mutants in tomato for six interacting host proteins is a very time-consuming process. An alternative option is to screen existing T-DNA mutants of homologs of the six host targets in A. thaliana, as M. incognita is also capable of infecting Arabidopsis (Chapter 4). Alternatively, genome-wide association (CWA) can also be used to link quantitative variation in plant susceptibility to $M$. incognita to allelic variants of the six interacting host proteins (Chapter 5 ).

\section{Materials and Methods}

\section{Nematode infection assays}

Meloidogyne incognita eggs (strain 'Morelos' from INRA, Sophia Antipolis, France) were obtained from infected tomato plants (Solanum lycopersicum L. cV. MoneyMaker). Eggs were extracted by incubating roots in $0.05 \%(\mathrm{~V} / \mathrm{V}$ ) bleach for 3 minutes followed by sieving (Hussey \& Barker, 1973). Eggs were surface-sterilized with $2.4 \mathrm{mM}$ sodium azide $\left(\mathrm{NaN}_{3}\right)$ for 20 minutes and washed thoroughly with tap water. Hatching took place at room temperature in the dark on a $25 \mu \mathrm{m}$ mesh hatching sieve with $1.5 \mathrm{mg} / \mathrm{ml}$ gentamycin and $0.05 \mathrm{mg} / \mathrm{ml}$ nystatin. After four days, freshly hatched J2s were collected by centrifugation on a 70\% sucrose column and subsequently surface-sterilized by incubating for 10 minutes in $0.002 \%$ (v/V) Triton X-100, $0.004 \%(\mathrm{w} / \mathrm{V}) \mathrm{NaN}_{3}$ and $0.004 \%(\mathrm{~W} / \mathrm{V}) \mathrm{HgCl}_{2}$. Next, the $\mathrm{J} 2 \mathrm{~s}$ were rinsed in sterile tap water three times and transferred to a $0.7 \%$ Gelrite solution (Duchefa Biochemie, Haarlem) before being used as inoculum (Warmerdam et al., 2018).

For in vitro infection assays, tomato seeds (Solanum lycopersicum L. CV. MoneyMaker) were first incubated for three days in tap water at $4^{\circ} \mathrm{C}$ in the dark. Thereafter, the seeds were briefly washed with 70\% ethanol and 2.5\% ( V/V) bleach and incubated three times for 10 minutes in sterile tap water. Batches of seeds were sowed on square plates of $10 \mathrm{~cm}$ containing $1 / 2$ MS20 medium (2.35 g/L Murashige and Skoog (MS) with vitamins (Duchefa Biochemie), 20 $\mathrm{g} / \mathrm{L}$ sucrose, $\mathrm{pH}$ 6.4, 7.0 g/L Gelrite (Duchefa Biochemie)). After incubating for four days at 24 ${ }^{\circ} \mathrm{C}$ in $16 \mathrm{~h}$ light and $8 \mathrm{~h}$ darkness, germinated plants were transferred to fresh square plates containing $1 / 2$ MS2O medium. The transferred plants were allowed to grow for an additional six days under the same conditions, after which they were inoculated with 120 infective J2s per plant. The number of root tips was counted for each plant at the time of inoculation. Plants were kept horizontally in the dark for two days at $24^{\circ} \mathrm{C}$, after which they were placed diagonally in $16 \mathrm{~h}$ light and $8 \mathrm{~h}$ dark conditions again. To reduce the direct exposure of the roots to light, the bottom $8 \mathrm{~cm}$ of the plates were covered with paper sleeves. Seven days post inoculation, 
the number of galls formed in the roots was counted by visually inspecting the roots with a dissection microscope. Data was collected in at least three independent experiments and pooled for statistical analysis and visualization in $\mathrm{R}$ version 3.6.1 x64. As absolute numbers differed in between independent experiments, all gall counts were batch corrected. Therefore, the average of the different batches was used with a subtraction method to obtain an equal average per batch. Data outside of 1.5 times the interquartile range was regarded as an outlier and removed (Vinutha et al., 2018). Statistical analysis to compare different plant lines with the wild type was done using the package ggplot2 (Wickham, 2016) and a one-way ANOVA with Tukey's HSD.

\section{Construction of MiMSP32-derived plasmids MiMSP32 hairpin construct for stable transformation}

To generate transgenic tomato plants for host-delivered RNA interference of MiMSP32 in parasitic stages of M. incognita, a hairpin construct was synthesized. The online SGN VICS Tool was used with the Meloidogyne incognita PRJEA28837 database to find the optimal target fragment and with the Solanum Iycopersicum ITAC V3.2 database to avoid off-target silencing (Fernandez-Pozo et al., 2015). Using this information, a hairpin was designed containing both the sense and corresponding antisense fragment of MiMSP32 (nucleotides 396 to 605 in GenBank accession AY142116.1) separated by a 462 bp stuffer fragment of the beta-glucuronidase gene (GeneArt by Life Technologies). Restriction/digestion with Xbal and Sacl and subsequent ligation was used to transfer the synthesized hairpin construct to pSUPERMD-RNAi (pSMD), a modified version of the pSuperRNAi vector (Lee et al., 2008) to form pSMD:MiMSP32_hp.

\section{MiMSP32-sp overexpression construct for stable transformation}

To generate tomato plants stably overexpressing the coding sequence of MiMSP32 without its native signal peptide for secretion, the coding sequence of MiMSP32 minus signal peptide was cloned from the synthetic plasmid PMKRQ:MiMSP32-sp into Gateway destination vector pSOL2092 to form PSOL2092:MiMSP32-sp. This vector is a Gateway-compatible pBIN derivative (Zhang et al., 2013), which contains the CaMV 35S. Therefore, the entry vector pMK-RQ:MiMSP32-sp (Life Technologies, Carlsbad) was used in Gateway cloning with LR Clonase enzyme mix (Invitrogen, Carlsbad).

\section{$\mathrm{N}$-terminally tagged MiMSP32-sp for transient expression}

For the N-terminally tagged HA4_GFP_MiMSP32-sp, MiMSP32-sp was amplified from the synthetic gene PMKRQ:MiMSP32-sp as a template. In the amplification, a Nhel site at the start and a Kpnl at the end of the gene were included (using forward and reverse primers CTTACAgctagcCAGTCTGGCAGTAGC and GCGGACggtacCTTAAATTTCTGGAATAT). The PCR product was subcloned into $\mathrm{PCR}{ }^{\mathrm{TM}}$ 2.1-TOPO ${ }^{\circledR}$ TA vector using a TOPO ${ }^{\otimes}$ TA Cloning ${ }^{\circledR}$ Kit for Subcloning (Invitrogen). Restriction enzyme digestion with Nhel and Kpnl resulted in the MiMSP32-sp gene. Likewise, an enhanced GFP-reporter gene (Yang et al., 1996) was subcloned by Ncol and Nhel digestion. Both fragments were ligated in a Ncol and Nhel digested pRAP35S backbone 
containing a multimeric hemagglutin (YPYDVPDYA) tag (HA4) (Schouten et al., 1997) to obtain pRAP35S:HA4_GFP_MiMSP32-sp:tnos.

\section{C-terminally tagged MiMSP32-sp for transient expression}

For the C-terminally tagged MiMSP32_CFP_HA4, MiMSP32-sp was amplified without stop codon using the synthetic gene PMKRQ:MiMSP32-sp as a template. In the amplification, Ncol sites were included at the start and end of the gene (using forward and reverse primers CTTACAccatggttCACTCTGGCAGTAG and GCGGACccatggaAATTTCTCGAATAT). The PCR product was subcloned into $\mathrm{PCR}{ }^{\mathrm{TM}}$ 2.1-TOPO ${ }^{\circledR}$ TA vector using a TOPO ${ }^{\circledR}$ TA Cloning ${ }^{\circledR}$ Kit for Subcloning (Invitrogen). Restriction enzyme digestion with $\mathrm{Ncol}$ resulted in the MiMSP32-sp gene without a stop codon. Likewise, an enhanced GFP-reporter gene (Yang et al.., 1996) was subcloned by $\mathrm{Ncol}$ and Nhel digestion. Both fragments were ligated in a Ncol and Nhel digested pRAP35S backbone containing a multimeric hemagglutin (YPYDVPDYA) tag (HA4) (Schouten et al.. 1997) to obtain PRAP35S:MiMSP32-sp_GFP_HA4:tnos.

After construction of MiMSP32-derived plasmids, all inserts were checked by sequencing (Macrogen Europe, Amsterdam).

\section{Transformation of tomato plants}

To generate transgenic tomato plants, sectioned cotyledons were used from germinated tomato seeds (Solanum lycopersicum L. cv. MoneyMaker) 11 days after sowing (Ellul et al., 2003). Small cotyledon explants were precultured abaxial side up while covered with two filter paper discs on shoot-inducing medium (SIM) plates ( $4.3 \mathrm{~g} / \mathrm{L}$ Murashige and Skoog (MS) (Duchefa Biochemie), $108.73 \mathrm{mg} / \mathrm{L}$ Nitsch vitamin mixture (Duchefa Biochemie), $30 \mathrm{~g} / \mathrm{L}$ glucose, $\mathrm{pH}=5.8,8$ $\mathrm{g} / \mathrm{L}$ micro agar, $1.5 \mathrm{mg} / \mathrm{L}$ filter-sterilized zeatine riboside, $0.2 \mathrm{mg} / \mathrm{L}$ filter sterilized 3-Indoleacetic acid). After two days of pre-culturing in the light at $24^{\circ} \mathrm{C}$, the filter paper discs were flipped together with the explant (adaxial side up) and transferred to be co-cultured. Co-culturing was done without filter papers for 15 minutes together with A. tumefaciens strain AGL1 containing PSMD:MiMSP32_hp or pSOL2092:MiMSP32-sp at an OD600 of 0.4 in liquid MS30 medium (4.4 $\mathrm{g} / \mathrm{L}$ Murashige and Skoog (MS) with vitamins (Duchefa Biochemie), $30 \mathrm{~g} / \mathrm{L}$ glucose, $\mathrm{pH}=5.2$ ) with $100 \mu \mathrm{M}$ acetosyringone. Excess bacteria were removed by blotting on sterile filer paper, and explants were placed back on the pre-culturing plates. After another two days in light conditions at $24^{\circ} \mathrm{C}$, the explants were transferred to fresh SIM including $50 \mathrm{mg} / \mathrm{L}$ kanamycin and $250 \mathrm{mg} / \mathrm{L}$ cefotaxime. Medium was refreshed every three weeks. After two months, regenerated shoots were selected in MS30 medium supplemented with $50 \mathrm{mg} / \mathrm{L}$ kanamycin and $300 \mathrm{mg} / \mathrm{L}$ timetin. Transformants were transferred to the greenhouse for seed production. After selfing, heterozygous Fl seeds acquired from one independently transformed plant were considered as one line.

\section{Yeast-two-hybrid screen}

A yeast-two-hybrid ( $\mathrm{Y} 2 \mathrm{H}$ ) screen was performed as a custom service using full-length MiMSP32 minus the signal peptide as bait and a library of infected tomato roots (Solanum lycopersicum 
L. CV. M82) as prey (Hybrigenics Services, Evry). The final cDNA library was constructed with mRNA from an equal mixture of tomato root tissue infected with Ralstonia solanacaerarum, root tissue infected with Meloidogyne incognita, and uninfected roots and is available as 'Tomato Roots Infected_RP1' (Hybrigenics Services). Hybrigenics performed their optimized ULTImate $\mathrm{Y} 2 \mathrm{H}^{\mathrm{TM}}$ technique and provided information to separate artefacts from specific interactions by the global Predicted Biological Score (PBS), which is based on a statistical model (Rain et al., 2001). Alignments of individual clone sequences described with both a forward and reverse sequence were made in Geneious 8.1.9 (Biomatters, Auckland).

For physiochemical characterization of MiMSP32 and the tomato interactor fragments, theoretical pl (isoelectric point), total number of positive and negative residues, extinction coefficient, instability index, aliphatic index (Ikai, 1980)) and GRAVY (grand average hydropathy) were computed using the Expasy's ProtParam server (https://web.expasy.org/protparam/) for proteins (Gasteiger et al., 2005) (Table 2).

\section{Construction of plasmids encoding host protein fragments}

Interacting domains of six genes were selected for further analyses based on probability scores in the $\mathrm{Y} 2 \mathrm{H}$ screen. Of all selected interaction domains (Supplemental Table S1) DNA constructs were synthesized (GeneArt by Life Technologies), starting with ccATGgtt to include a start codon and a Ncol restriction site, and ending with gtcatgatgTAAggtacc to include a BspHI restriction site, followed by a stop codon and an additional Kpnl restriction site. After construction of MiMSP32-derived plasmids, all inserts were checked by sequencing (Macrogen Europe, Amsterdam).

\section{$\mathrm{N}$-terminally tagged interactor constructs}

For the N-terminally tagged MYC4_mCH_SID constructs, restriction enzyme digestion on the plasmids harboring the synthetic DNA fragments was done with $\mathrm{Ncol}$ and Kpnl to generate fragments including a stop codon. Likewise, a mCherry reporter gene (Shaner et al., 2004) without a stop codon was obtained by $\mathrm{Ncol}$ and BspHI digestion. Both fragments were ligated in a Ncol and Kpnl digested pRAP35S backbone containing a multimeric c-myc (EQKLISEEDL) tag (MYC4) (대outen et al., 1997) to obtain pRAP35S:MYC4_mCh_SID:tnos.

\section{C-terminally tagged interactor constructs}

For the C-terminally tagged SID_mCh_MYC4 constructs, restriction enzyme digestion on the plasmids harboring the synthetic DNA fragments was done with $\mathrm{Ncol}$ and $\mathrm{BspHI}$ to generate fragments without a stop codon. Likewise, a mCherry reporter gene (Shaner et al., 2004) without a stop codon was obtained by $\mathrm{Ncol}$ and Nhel digestion. Both fragments were ligated in a Ncol and Nhel digested pRAP35S backbone containing a multimeric c-myc (EQKLISEEDL) tag (MYC4) (ㄷhouten et al., 1997) to obtain PRAP35S:SID_mCh_MYC4:tnos. 


\section{Transient expression assays}

For transient expression in N. benthamiana, constructs were subcloned into the $\mathrm{pBIN}+$ plasmid with restriction and ligation reactions using the Ascl and Pacl sites (van Engelen et al., 1995). Plasmids were subsequently introduced by electroporation (Neumann et al., 1982) into Agrobacterium tumefaciens GV3101 cells already harboring the pSOUP helper plasmid. Transient expression in Nicotiana benthamiana leaves was achieved by first culturing A. tumefaciens in LB medium (10 g/L peptone, $5 \mathrm{~g} / \mathrm{L}$ yeast extract, $10 \mathrm{~g} / \mathrm{L} \mathrm{NaCl}$ ) with $20 \mu \mathrm{M}$ acetosyringone, $50 \mathrm{mg} / \mathrm{L}$ kanamycin and $20 \mathrm{mg} / \mathrm{L}$ rifampicin for 16 hours at $28^{\circ} \mathrm{C}$. Bacteria were pelleted by centrifugation and resuspended in MMAi infiltration medium (5 g/L Murashi-Skoog salts, 1.95 g/L 2-(N-morpholino)ethanesulfonic acid (MES), $20 \mathrm{~g} / \mathrm{L}$ sucrose at pH 5.6 and including 200 $\mu \mathrm{M}$ acetosyringone) and incubated at room temperature for $1-2$ hours. The leaf infiltration procedure was done with bacterial suspensions set at an optical density (OD600) of 0.5. Bacterial suspensions were infiltrated in the apoplast of a $\mathrm{N}$. benthamiana leaf using a $1 \mathrm{ml}$ syringe without needle. Leaves were harvested at 48 hours post infiltration.

\section{Quantitative PCR}

Reaction volumes of quantitative PCR reactions was set to $15 \mu$ l containing $1 \mu$ l of template (c) DNA, $0.6 \mu$ l of each primer and $7.5 \mu$ l of Absolute SYBR Green Fluorescein Mix (Thermo Fisher, Waltham). Primer pairs for each test were selected based on their efficiency and stability. The following quantitative PCR protocol was used: 15 minutes at $95^{\circ} \mathrm{C}$, followed by 40 cycles of 30 seconds at $95^{\circ} \mathrm{C}, 30$ seconds at $60^{\circ} \mathrm{C}, 30$ seconds at $72^{\circ} \mathrm{C}$, followed by 5 minutes at $72^{\circ} \mathrm{C}$. To generate a melting curve for the PCR product, 75 cycles of 15 seconds at $60^{\circ} \mathrm{C}$ were used with steps of $+0.5^{\circ} \mathrm{C}$ until a maximum of $97.5^{\circ} \mathrm{C}$. Statistical analysis and visualization were done in $\mathrm{R}$ version $3.6 .1 \times 64$ using dplyr and ggplot2 and a nonparametric Kruskall-Wallis $\mathrm{H}$ test with pairwise Benjamini-Hochberg corrected Wilcoxon rank sum tests.

\section{Transgene presence in tomato overexpression lines}

Transgenic tomato lines generated to overexpress MiMSP32 were tested for presence of MiMSP32 transgene in a GPCR. Therefore, gene presence of the endogenous single copy vacuolar invertase gene (using forward and reverse primers CTCGCTCAAGTTCAAACGCAAC and CATTTTCTGGTCCGGTCCAA) was compared with the transgene (using forward and reverse primers TGCAGTCTGGCAGTAGCAAA and ACGCATTGGCAAAGACACTG), using the insertion comparison method $2^{\mathrm{ct} \text { ref }} / 2^{\mathrm{ct} \text { tra }}$ (German et al., 2003). To this purpose, genomic DNA was isolated from individual plants (Holterman et al., 2006) and used in GPCR with the above mentioned qPCR protocol.

\section{Transgene expression in tomato overexpression lines}

Expression levels of the MiMSP32 transgene in tomato seedlings were checked by comparing mRNA levels of MiMSP32 and a constitutively expressed ubiquitin gene (GenBank accession TC193502). Bulk samples were generated of root systems of six plants and immediately snap-frozen in liquid nitrogen after which they were homogenized using a TissueLyser (Qiagen, Hilden). Extraction of total RNA was performed using the Maxwell 16 LEV-plant RNA kit 
(Promega, Madison) following the manufacturers protocol. Samples were reverse transcribed into cDNA using GoScript Reverse Transcriptase for use in quantitative RT-PCR with tomato ubiquitin (using the primers GGACGGACGTACTCTAGCTGAT and AGCTTTCGACCTCAAGGGTA) ( $\underline{\varnothing \vee v d a l ~ \& ~ L i l l o, ~ 2009}$ ) and MiMSP32, using the earlier mentioned MiMSP32 primers. The relative expression for the gene of interest as a ratio of the reference gene was calculated (Pfaffl, 2001).

\section{MiMSP32 expression in parasitic M. incognita}

Effective silencing in M. incognita feeding on tomato hairpin plants was checked by comparing nematode gene expression levels while feeding. Galls (with nematodes inside) were harvested by cutting visible galls from the roots of infected hairpin and MM plants at 23 dpi growing on MS2O plates. Samples were immediately snap-frozen in liquid nitrogen. RNA extraction and cDNA synthesis were performed as mentioned above. The relative expression for the gene of interest as a ratio of the reference gene was calculated (Pfaffl, 2001). Expression of the nematode household gene actin (GenBank accession BE225475) (using the primers CGAACGTGAGATGTCCGTCA and GATGACTTCACCGTCAGGCA) was compared with MiMSP32 expression, using the earlier mentioned MiMSP32 primers.

\section{Co-immunoprecipitation assays}

Total protein was extracted from $100 \mathrm{mg}$ agroinfiltrated leaves collected from different plants and homogenized using a TissueLyser (Qiagen). After subsequent homogenization in $1.5 \mathrm{ml}$ ice-cold extraction buffer $(150 \mathrm{mM} \mathrm{NaCl}, 50 \mathrm{mM}$ Tris- $\mathrm{HCl}, \mathrm{pH}$ 7.5, 1 mM ethylenediaminetetraacetic acid, 10\% glycerol, $10 \mathrm{mM}$ dithiothreitol, 2\% polyclar-AT polyvinylpolypyrrolidone (Serva, Heidelberg) and $0.5 \mathrm{mg} / \mathrm{ml}$ pefabloc SC protease inhibitor (Hoffmann-La Roche, Bazel)) and spinning down the cell debris, the supernatant was purified by passing over a Sephadex G-25 column (GE Healthcare, Chicago). Protein extract was cleared by mixing with $50 \mu \mathrm{l}$ rabbit-IgC agarose (Sigma-Aldrich, Saint Louis) and subsequently incubating with $50 \mu \mathrm{l}$ anti-HA microbeads. For co-immunoprecipitation, the anti-HA microbeads were pulled down using the MMACS Epitope Tag Protein isolation kit (Miltenyi Biotec, Bergisch Gladbach). Soluble fractions were analyzed by SDS-PAGE separation on a 12\% Bis-Tris gel (Invitrogen) and proteins were subsequently transferred to a PVDF membrane for Western blotting (Thermo Fisher). Protein bands on the blots were visualized with either a horseradish peroxidase-conjugated rat anti-HA antibody (Hoffmann-La Roche) or with a primary goat anti-MYC antibody (Abcam, Cambridge) and a horseradish peroxidase-conjugated secondary antibody of donkey antigoat (Jackson ImmunoResearch, Ely). SuperSignal West 1:1 Femto-Dura substrate (Thermo Fisher) was used to detect horseradish peroxidase-conjugated antibodies in the G:BOX Chemi System (Syngene, Bangalore). Total protein extracts were confirmed for equal loading with Coomassie brilliant blue (CBB) staining.

\section{Subcellular localization}

Subcellular localization in plants was predicted by WoLF PSORT (https://wolfpsort.hgc.jp/) using sorting signals, amino acid compositions and functional motifs (Horton et al., 2007) (Table 3). To assess the subcellular localization of MiMSP32-sp with and without its putative 
interacting host protein fragments in plant cells, the proteins were transiently expressed in $N$. benthamiana epidermal cells. Agroinfiltrated leaves expressing either HA4_GFP_MiMSP32-sp or MiMSP32-sp_GFP_HA4 in combination with the interacting domain of possible interactors (SID) in MYC4_mCh_SID, SID_mCh_MYC4, free mCherry were collected for microscopic observations with a Zeiss LSM 510 confocal microscope (Carl Zeiss). For imaging of constructs carrying a GFP tag, the $488 \mathrm{~nm}$ line of an argon-ion laser was used for excitation excitation and GFP emission was selected through a band-pass filter of 505-530 nm for detection. For constructs carrying a mCherry tag, imaging was done using a $543 \mathrm{~nm}$ HeNe laser for excitation and mCherry emission was selected by a 600-650 nm band-pass filter. Chlorophyll emission was detected using a $650 \mathrm{~nm}$ long-pass filter. Images were equally enhanced in brightness for publication in print.

To quantify differences in subcellular localization, the ratios in fluorescence intensity between cytoplasm and nucleus were calculated in ImageJ. Statistical analysis and numerical visualizations were done in R version 3.6.1 using ggplot2 and a one-way ANOVA with Tukey's HSD.

\section{Fluorescence lifetime imaging microscopy}

To test the physical association of MiMSP32-sp with SISPT6 ${ }^{\text {IID }}$ and SITPPIISID, Förster resonance energy transfer was measured by fluorescence lifetime imaging microscopy. After harvesting the $N$. benthamiana leaves transiently expressing PBIN+:MiMSP32-sp_GFP_HA4 constructs co-expressed with either free mCherry, PBIN+:MYC4_mCh_SITPPIISID or SISPT6SID_mCh_MYC4, leaves were immediately transferred to a Leica SP5X-SMD CLSM (Leica, Wetzlar) equipped for fluorescence lifetime imaging. Fluorescence lifetime and emission of GFP was measured by a HYD SMD detector using a supercontinuum tunable white light laser with pulsed excitation and time correlated single photon counting detection. Acquisition time was 80 s for all measurements and the time-correlated single-photon counting (TCSPC) was performed using a Becker \& HickI FLIM system. Analysis was done using SPCImage NG software (Becker \& Hickl $\mathrm{GmbH}$, Berlin), and the average lifetime of GFP emission was acquired in the nuclear area and cytoplasm of every picture. Statistical analysis and numerical visualizations were done in R version 3.6.1 using ggplot2 and Student's t-tests.

\section{Acknowledgements}

This work was financially supported by the Dutch Research Council (NOW) Domain Applied and Engineering Sciences (AES/TTW) project 11042. The authors would like to thank the Wageningen Microspectroscopy Research Facility, for access to the equipment and technical support. We would also like to thank Mark G. Sterken for his valuable feedback. Additionally, we would like to thank Unifarm of Wageningen University and Research for support with plant material and the laboratory of Plant Breeding for support with plant transformations. The authors declare no conflict of interest. 


\section{Author contributions}

A.V., A.F-T. and G.S. conceived and designed the experiments. A.V., D.R.V.-V.R., A.F-T., K.V. and E.J.S. performed the experiments. A.V. analysed the data and A.V., A.G. and G.S. wrote the paper. All authors edited and approved the final chapter.

\section{References}

Abad P, Gouzy J, Aury J-M, Castagnone-Sereno P, Danchin EGJ, Deleury E, Perfus-Barbeoch L, Anthouard V, Artiguenave F, Blok VC, et al. 2008. Genome sequence of the metazoan plant-parasitic nematode Meloidogyne incognita. Nature biotechnology 26(8): 909-915.

Asselbergh B, De Vleesschauwer D, Höfte M. 2008. Global Switches and Fine-Tuning-ABA Modulates Plant Pathogen Defense. Molecular Plant-Microbe Interactions 21(6): 709-719.

Banfield MJ. 2015. Perturbation of host ubiquitin systems by plant pathogen/pest effector proteins. Cellular Microbiology 17(1): 18-25.

Bebber DP, Holmes T, Gurr SJ. 2014. The global spread of crop pests and pathogens. Global Ecology and Biogeography 23(12): 1398-1407.

Białas A, Zess EK, De la Concepcion JC, Franceschetti M, Pennington HG, Yoshida K, Upson JL, Chanclud E, Wu C-H, Langner T, et al. 2018. Lessons in effector and NLR biology of plant-microbe systems. Molecular Plant-Microbe Interactions 31(1): 34-45.

Boulila-Zoghlami L, Gallusci P, Holzer FM, Basset GJ, Djebali W, Chaïbi W, Walling LL, Brouquisse R. 2011. Up-regulation of leucine aminopeptidase-A in cadmium-treated tomato roots. Planta 234(4): 857

Caarls L, Elberse J, Awwanah M, Ludwig NR, de Vries M, Zeilmaker T, Van Wees SCM, Schuurink RC, Van den Ackerveken G. 2017. Arabidopsis JASMONATE-INDUCED OXYGENASES down-regulate plant immunity by hydroxylation and inactivation of the hormone jasmonic acid. Proc Nat/ Acad Sci U S A 114(24): 6388.

Chen J, Hu L, Sun L, Lin B, Huang K, Zhuo K, Liao J. 2018. A novel Meloidogyne graminicola effector, MgMO237, interacts with multiple host defence-related proteins to manipulate plant basal immunity and promote parasitism. Molecular Plant Pathology 19(8): 1942-1955.

Chini A, Monte I, Zamarreño AM, Hamberg M, Lassueur S, Reymond P, Weiss S, Stintzi A, Schaller A, Porzel A, et al. 2018. An OPR3-independent pathway uses 4,5-didehydrojasmonate for jasmonate synthesis. Nature Chemical Biology 14: 171.

Dinh PTY, Zhang L, Mojtahedi H, Brown CR, Elling AA. 2015. Broad Meloidogyne resistance in potato based on RNA interference of effector gene 16D10. Journal of nematology 47(1): 71-78.

dos Santos de Lima e Souza D, de Souza Junior JDA, Grossi-de-Sá M, Rocha TL, Fragoso RdR, de Deus Barbosa AEA, de Oliveira GR, Nakasu EYT, de Sousa BA, Pires NF, et al. 2011. Ectopic expression of a Meloidogyne incognita dorsal gland protein in tobacco accelerates the formation of the nematode feeding site. Plant Science 180(2): 276-282.

Dubreuil G, Magliano M, Deleury E, Abad P, Rosso M. 2007. Transcriptome analysis of root-knot nematode functions induced in the early stages of parasitism. New Phytologist 176(2): 426-436.

Ellul P, Garcia-Sogo B, Pineda B, Rios G, Roig L, Moreno V. 2003. The ploidy level of transgenic plants in Agrobacterium-mediated transformation of tomato cotyledons (Lycopersicon esculentum L. Mill.) is genotype and procedure dependent. Theoretical and Applied Genetics 106(2): 231-238.

Fan J, Wang X, Sun Z, Zhou X. 2018. Membrane asymmetry and phospholipid translocases in eukaryotic cells. In: Cao Y ed. Advances in Membrane Proteins: Part l: Mass Processing and Transportation. Singapore: Springer Singapore, 47-76.

Fernandez-Pozo N, Rosli Hernan G, Martin Gregory B, Mueller Lukas A. 2015. The SGN VIGS Tool: User-Friendly Software to Design Virus-Induced Gene Silencing (VIGS) Constructs for Functional Genomics. Molecular plant 8(3): 486-488.

Fire A, Xu S, Montgomery MK, Kostas SA, Driver SE, Mello CC. 1998. Potent and specific genetic interference by double-stranded RNA in Caenorhabditis elegans. nature 391(6669): 806-811.

Fowler JH, Narváez-Vásquez J, Aromdee DN, Pautot V, Holzer FM, Walling LL. 2009. Leucine aminopeptidase regulates defense and wound signaling in tomato downstream of jasmonic acid. The Plant Ce// 21(4): 1239-1251.

Franceschetti M, Maqbool A, Jiménez-Dalmaroni MJ, Pennington HG, Kamoun S, Banfield MJ. 2017. Effectors of Filamentous Plant Pathogens: Commonalities amid Diversity. Microbiology and Molecular Biology Reviews 81(2): e00066-00016.

Gasteiger E, Hoogland C, Gattiker A, Wilkins MR, Appel RD, Bairoch A. 2005. Protein identification and analysis tools on the ExPASy server. The proteomics protocols handbook: Springer, 571-607.

German MA, Kandel-Kfir M, Swarzberg D, Matsevitz T, Granot D. 2003. A rapid method for the analysis of zygosity in trans- 
genic plants. Plant Science 164(2): 183-187.

Gheysen G, Mitchum MG. 2011. How nematodes manipulate plant development pathways for infection. Current opinion in plant biology 14(4): 415-421.

Gheysen G, Mitchum MG. 2019. Phytoparasitic nematode control of plant hormone pathways. Plant Physiology. pp.01067.02018.

Gleason C, Leelarasamee N, Meldau D, Feussner I. 2016. OPDA has key role in regulating plant susceptibility to the root-knot nematode Meloidogyne hapla in Arabidopsis. Frontiers in plant science 7(1565).

Gomès E, Jakobsen MK, Axelsen KB, Geisler M, Palmgren MG. 2000. Chilling tolerance in Arabidopsis involves ALAT, a member of a new family of putative aminophospholipid translocases. The Plant Cel/ 12(12): 2441-2453.

Goverse A, Smant G. 2014. The activation and suppression of plant innate immunity by parasitic nematodes. Annual review of phytopathology 52: 243-265.

Grasser KD. 2005. Emerging role for transcript elongation in plant development. Trends in Plant Science 10(10): 484-490.

Haegeman A, Mantelin S, Jones JT, Gheysen G. 2012. Functional roles of effectors of plant-parasitic nematodes. Gene 492(1): 19-31.

Hewezi T. 2015. Cellular Signaling Pathways and Posttranslational Modifications Mediated by Nematode Effector Proteins. Plant Physiology 169(2): 1018.

Hewezi T, Juvale PS, Piya S, Maier TR, Rambani A, Rice JH, Mitchum MG, Davis EL, Hussey RS, Baum TJ. 2015. The cyst nematode effector protein 10A07 targets and recruits host posttranslational machinery to mediate its nuclear trafficking and to promote parasitism in arabidopsis. The Plant Cel/ 27(3): 891-907.

Holterman M, van der Wurff A, van den Elsen S, van Megen H, Bongers T, Holovachov O, Bakker J, Helder J. 2006. Phylum-wide analysis of SSU rDNA reveals deep phylogenetic relationships among nematodes and accelerated evolution toward crown clades. Molecular biology and evolution 23(9): 1792-1800.

Horton P, Park K-J, Obayashi T, Fujita N, Harada H, Adams-Collier C, Nakai K. 2007. WoLF PSORT: protein localization predictor. Nucleic acids research 35(suppl_2): W585-W587.

Huang G, Allen R, Davis EL, Baum TJ, Hussey RS. 2006a. Engineering broad root-knot resistance in transgenic plants by RNAi silencing of a conserved and essential root-knot nematode parasitism gene. Proc Natl Acad Sci U S A 103(39): 14302-14306.

Huang G, Dong R, Allen R, Davis EL, Baum TJ, Hussey RS. 2005a. Developmental expression and molecular analysis of two Meloidogyne incognita pectate lyase genes. International journal for parasitology 35(6): 685-692.

Huang G, Dong R, Allen R, Davis EL, Baum TJ, Hussey RS. 2005b. Two chorismate mutase genes from the root-knot nematode Meloidogyne incognita. Molecular Plant Pathology 6(1): 23-30.

Huang G, Dong R, Allen R, Davis EL, Baum TJ, Hussey RS. 2006b. A root-knot nematode secretory peptide functions as a ligand for a plant transcription factor. Molecular Plant-Microbe Interactions 19(5): 463-470.

Huang G, Dong R, Maier T, Allen R, Davis EL, Baum TJ, Hussey RS. 2004. Use of solid-phase subtractive hybridization for the identification of parasitism gene candidates from the root-knot nematode Meloidogyne incognita. Molecular Plant Pathology 5(3): 217-222.

Huang G, Gao B, Maier T, Allen R, Davis EL, Baum TJ, Hussey RS. 2003. A profile of putative parasitism genes expressed in the esophageal gland cells of the root-knot nematode Meloidogyne incognita. Molecular Plant-Microbe Interactions 16(5): 376-381.

Hussey RS. 1989. Disease-inducing secretions of plant-parasitic nematodes. Annual review of phytopathology 27(1): 123-141.

Hussey RS, Barker KR. 1973. Comparison of methods of collecting inocula of Meloidogyne spp., including a new technique. Plant disease reporter.

Ikai A. 1980. Thermostability and aliphatic index of globular proteins. The Journal of Biochemistry 88(6): 1895-1898.

Jones JT, Haegeman A, Danchin EG, Gaur HS, Helder J, Jones MG, Kikuchi T, Manzanilla-López R, Palomares-Rius JE, Wesemael WM. 2013. Top 10 plant-parasitic nematodes in molecular plant pathology. Molecular Plant Pathology 14(9): 946-967

Khan M, Seto D, Subramaniam R, Desveaux D. 2018. Oh, the places they'll go! A survey of phytopathogen effectors and their host targets. The Plant Journal 93(4): 651-663.

Kim DY, Hong MJ, Jang JH, Seo YW. 2012. cDNA-AFLP analysis reveals differential gene expression in response to salt stress in Brachypodium distachyon. Genes \& Genomics 34(5): 475-484.

Kurkdjian A, Guern J. 1989. Intracellular pH: measurement and importance in cell activity. Annual review of plant biology 40(1): 271-303.

Kyte J, Doolittle RF. 1982. A simple method for displaying the hydropathic character of a protein. Journal of molecular biology 157(1): 105-132.

Lee L-Y, E Kononov M, Bassüner B, R Frame B, Wang K, Gelvin S. 2008. Novel Plant Transformation Vectors Containing the Superpromoter. Plant Physiology: 1294-1300.

Leelarasamee N, Zhang L, Gleason C. 2018. The root-knot nematode effector MiPFN3 disrupts plant actin filaments and 
promotes parasitism. PLoS Pathogens 14(3): el006947.

Liu X, Cai W-J, Yin X, Yang D, Dong T, Feng Y-Q, Wu Y. 2019. Two dioxygenases, SLC1 and SLC2, play essential roles in shoot development of rice. Journal of experimental botany.

Løvdal T, Lillo C. 2009. Reference gene selection for quantitative real-time PCR normalization in tomato subjected to nitrogen, cold, and light stress. Analytical Biochemistry 387(2): 238-242.

Marchler-Bauer A, Bo Y, Han L, He J, Lanczycki CJ, Lu S, Chitsaz F, Derbyshire MK, Geer RC, Gonzales NR, et al. 2016. CDD/ SPARCLE: functional classification of proteins via subfamily domain architectures. Nucleic acids research 45(D1): D200-D203.

Mejias J, Truong NM, Abad P, Favery B, Quentin M. 2019. Plant proteins and processes targeted by parasitic nematode effectors. Frontiers in plant science 10: 970-970.

Mitchum MG, Hussey RS, Baum TJ, Wang X, Elling AA, Wubben M, Davis EL. 2013. Nematode effector proteins: an emerging paradigm of parasitism. New Phytologist 199(4): 879-894

Mitreva-Dautova M, Roze E, Overmars H, de Graaff L, Schots A, Helder J, Goverse A, Bakker J, Smant G. 2006. A symbiont-independent endo-7, 4- $\beta$-xylanase from the plant-parasitic nematode Meloidogyne incognita. Molecular Plant-Microbe Interactions 19(5): 521-529.

Molinari S, Rosso L. 2014. Manganese superoxide dismutase in Meloidogyne incognita isolates selected for virulence on Mi-7-carrying tomato: gene expression and enzyme activity. Nematology 16(3): 249.

Mussig C, Biesgen C, Lisso J, Uwer U, Weiler EW, Altmann T. 2000. A novel stress-inducible 12-oxophytodienoate reductase from Arabidopsis thaliana provides a potential link between brassinosteroid-action and jasmonic-acid synthesis. Journal of plant physiology 157(2): 143-152.

Neumann E, Schaefer-Ridder M, Wang Y, Hofschneider PH. 1982. Gene transfer into mouse lyoma cells by electroporation in high electric fields. The EMBO journal 1(7): 841-845.

Nicol JM, Turner SJ, Coyne DL, Nijs Ld, Hockland S, Maafi ZT. 2011. Current nematode threats to world agriculture. In: Jones J, Gheysen G, Fenoll C eds. Genomics and Molecular Genetics of Plant-Nematode Interactions. Dordrecht: Springer Netherlands, 27-43.

Niu J, Liu P, Liu Q, Chen C, Guo Q, Yin J, Yang G, Jian H. 2016. Msp40 effector of root-knot nematode manipulates plant immunity to facilitate parasitism. Scientific Reports 6: 19443.

Paula de Toledo Thomazella D, Brail Q, Dahlbeck D, Staskawicz B. 2016. CRISPR-Cas9 mediated mutagenesis of a DMR6 ortholog in tomato confers broad-spectrum disease resistance. bioRxiv: 064824

Pfaffl MW. 2001. A new mathematical model for relative quantification in real-time RT-PCR. Nucleic acids research 29(9): e45-e45.

Pogorelko G, Juvale PS, Rutter WB, Hewezi T, Hussey R, Davis EL, Mitchum MG, Baum TJ. 2016. A cyst nematode effector binds to diverse plant proteins, increases nematode susceptibility and affects root morphology. Molecular Plant Pathology 17(6): 832-844.

Polge C, Jaquinod M, Holzer F, Bourguignon J, Walling L, Brouquisse R. 2009. Evidence for the Existence in Arabidopsis thaliana of the Proteasome Proteolytic Pathway: ACTIVATION IN RESPONSE TO CADMIUM. Journal of Biological Chemistry 284(51): 35412-35424.

Rain J-C, Selig L, De Reuse H, Battaglia V, Reverdy C, Simon S, Lenzen G, Petel F, Wojcik J, Schachter V, et al. 2001. The protein-protein interaction map of Helicobacter pylori. nature 409(6817): 217-215.

Rosso M-N, Dubrana MP, Cimbolini N, Jaubert S, Abad P. 2005. Application of RNA interference to root-knot nematode genes encoding esophageal gland proteins. Molecular Plant-Microbe Interactions 18(7): 615-620.

Saric T, Graef Cl, Goldberg AL. 2004. Pathway for degradation of peptides generated by proteasomes: a key role for thimet oligopeptidase and other metallopeptidases. Journal of Biological Chemistry 279(45): 46723-46732.

Schaller F, Biesgen C, Müssig C, Altmann T, Weiler EW. 2000. 12-Oxophytodienoate reductase 3 (OPR3) is the isoenzyme involved in jasmonate biosynthesis. Planta 210(6): 979-984

Schouten A, Roosien J, de Boer JM, Wilmink A, Rosso M-N, Bosch D, Stiekema WJ, Gommers FJ, Bakker J, Schots A. 1997. Improving SCFV antibody expression levels in the plant cytosol 1. FEBS Letters 415(2): 235-241.

Seiml-Buchinger VV, Zinovieva SV, Udalova ZV, Matveeva EM. 2018. Jasmonic acid modulates Meloidogyne incognitatomato plant interactions. Brill.

Shaner NC, Campbell RE, Steinbach PA, Giepmans BNG, Palmer AE, Tsien RY. 2004. Improved monomeric red, orange and yellow fluorescent proteins derived from Discosoma sp. red fluorescent protein. Nature biotechnology 22(12): 1567-1572.

Shi Q, Mao Z, Zhang X, Ling J, Lin R, Zhang X, Liu R, Wang Y, Yang Y, Cheng X, et al. 2018. The novel secreted Meloidogyne incognita effector MilSE6 targets the host nucleus and facilitates parasitism in Arabidopsis. Frontiers in plant science 9(252).

Shukla N, Yadav R, Kaur P, Rasmussen S, Goel S, Agarwal M, Jagannath A, Gupta R, Kumar A. 2018. Transcriptome analysis of root-knot nematode (Meloidogyne incognita)-infected tomato (Solanum lycopersicum) roots reveals complex gene expression profiles and metabolic networks of both host and nematode during susceptible and resistance responses. Molecular 
Plant Pathology 19(3): 615-633

Singer AU, Desveaux D, Betts L, Chang JH, Nimchuk Z, Grant SR, DangI JL, Sondek J. 2004. Crystal structures of the type III effector protein AvrPphF and its chaperone reveal residues required for plant pathogenesis. Structure (London, England: 1993) 12(9): 1669-1681.

Sperschneider J, Dodds PN, Singh KB, Taylor JM. 2018. ApoplastP: prediction of effectors and plant proteins in the apoplast using machine learning. New Phytologist 217(4): 1764-1778

Stintzi A, Browse J. 2000. The Arabidopsis male-sterile mutant, opr3, lacks the 12-oxophytodienoic acid reductase required for jasmonate synthesis. Proc Natl Acad Sci U S A 97(19): 10625.

Strassner J, Schaller F, Frick UB, Howe GA, Weiler EW, Amrhein N, Macheroux P, Schaller A. 2002. Characterization and CDNA-microarray expression analysis of 12-oxophytodienoate reductases reveals differential roles for octadecanoid biosynthesis in the local versus the systemic wound response. The Plant Journal 32(4): 585-601.

Tasset C, Bernoux M, Jauneau A, Pouzet C, Brière C, Kieffer-Jacquinod S, Rivas S, Marco Y, Deslandes L. 2010. Autoacetylation of the Ralstonia solanacearum Effector PopP2 Targets a Lysine Residue Essential for RRS1-R-Mediated Immunity in Arabidopsis. PLoS Pathogens 6(11): el001202.

Thordal-Christensen H, Birch PRJ, Spanu PD, Panstruga R. 2018. Why did filamentous plant pathogens evolve the potential to secrete hundreds of effectors to enable disease? Molecular Plant Pathology 19(4): 781-785.

Tripathi AK, Singh K, Pareek A, Singla-Pareek SL. 2015. Histone chaperones in Arabidopsis and rice: Genome-wide identification, phylogeny, architecture and transcriptional regulation. BMC Plant Biology 15(1).

Trudgill DL, Blok VC. 2001. Apomictic, polyphagous root-knot nematodes: exceptionally successful and damaging biotrophic root pathogens. Annual review of phytopathology 39(1): 53-77.

Turnbull D, Wang H, Breen S, Malec M, Naqvi S, Yang L, Welsh L, Hemsley P, Zhendong T, Brunner F, et al. 2019. AVR2 targets BSL family members, which act as susceptibility factors to suppress host immunity. Plant Physiology 180(1): 571.

Üstün S, Sheikh A, Gimenez-Ibanez S, Jones A, Ntoukakis V, Börnke F. 2016. The Proteasome Acts as a Hub for Plant Immunity and Is Targeted by Pseudomonas Type III Effectors. Plant Physiology 172(3): 1941-1958.

van Engelen FA, Molthoff JW, Conner AJ, Nap J-P, Pereira A, Stiekema WJ. 1995. pBINPLUS: an improved plant transformation vector based on pBIN19. Transgenic Research 4(4): 288-290.

Vieira P, Danchin EGJ, Neveu C, Crozat C, Jaubert S, Hussey RS, Engler G, Abad P, de Almeida-Engler J, Castagnone-Sereno $P$, et al. 2011. The plant apoplasm is an important recipient compartment for nematode secreted proteins. Journal of experimental botany 62(3): 1241-1253.

Vieira P, Gleason C. 2019. Plant-parasitic nematode effectors - insights into their diversity and new tools for their identification. Current opinion in plant biology 50: 37-43.

Vinutha HP, Poornima B, Sagar BM. 2018. Detection of outliers using interquartile range technique from intrusion dataset. In Satapathy SC, Tavares JMRS, Bhateja V, Mohanty JR. Information and Decision Sciences. Singapore: Springer Singapore. 511-518.

Wang R, Brattain MG. 2007. The maximal size of protein to diffuse through the nuclear pore is larger than $60 \mathrm{kDa}$. FEBS Letters 581(17): 3164-3170.

Warmerdam S, Sterken MG, van Schaik C, Oortwijn ME, Sukarta OC, Lozano-Torres JL, Dicke M, Helder J, Kammenga JE, Goverse A. 2018. Genome-wide association mapping of the architecture of susceptibility to the root-knot nematode Meloidogyne incognita in Arabidopsis thaliana. New Phytologist 218(2): 724-737.

Weßling R, Epple P, Altmann S, He Y, Yang L, Henz Stefan R, McDonald N, Wiley K, Bader Kai C, Gläßer C, et al. 2014. Convergent targeting of a common host protein-network by pathogen effectors from three kingdoms of life. Cell Host \& Microbe 16(3): 364-375.

Wickham H. 2016. ggplot2: elegant graphics for data analysis. New York: Springer-Verlag

Win J, Chaparro-Garcia A, Belhaj K, Saunders DGO, Yoshida K, Dong S, Schornack S, Zipfel C, Robatzek S, Hogenhout SA, et al. 2012. Effector Biology of Plant-Associated Organisms: Concepts and Perspectives. Cold Spring Harbor Symposia on Quantitative Biology 77: 235-247.

Xue B, Hamamouch N, Li C, Huang G, Hussey RS, Baum TJ, Davis EL. 2013. The 8D05 parasitism gene of Meloidogyne incognita is required for successful infection of host roots. Phytopathology 103(2): 175-181.

Yang T-T, Cheng L, Kain SR. 1996. Optimized Codon Usage and Chromophore Mutations Provide Enhanced Sensitivity with the Green Fluorescent Protein. Nucleic acids research 24(22): 4592-4593.

Zhang Z, Fradin E, de Jonge R, van Esse HP, Smit P, Liu C-M, Thomma BP. 2013. Optimized agroinfiltration and virus-induced gene silencing to study Vel-mediated Verticillium resistance in tobacco. Molecular Plant-Microbe Interactions 26(2): 182-190.

Zhao J, Li L, Liu Q, Liu P, Li S, Yang D, Chen Y, Pagnotta S, Favery B, Abad P, et al. 2019. A MIF-like effector suppresses plant immunity and facilitates nematode parasitism by interacting with plant annexins. Journal of experimental botany $70(20)$ : 5943-5958. 


\section{Supplemental information}

Supplemental figures

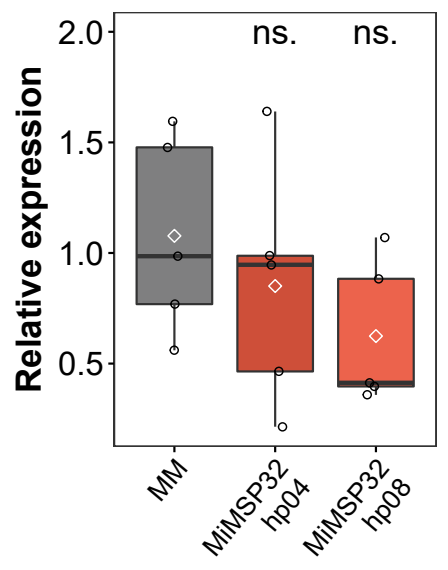

Figure S1. Relative expression of MiMSP32. Expression was measured in relation to M. incognita household gene actin for two independent tomato lines overexpressing MiMSP32-SP_hp (MiMSP32_hp04 and MiMSP32_hp08) and wild-type tomato plants (MM). Expression data were statistically tested using pairwise Benjamini-Hochberg corrected Wilcoxon rank sum tests (ns, not significant).

A

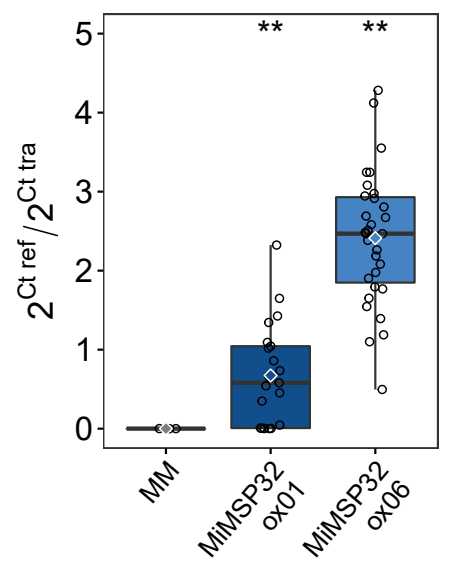

B

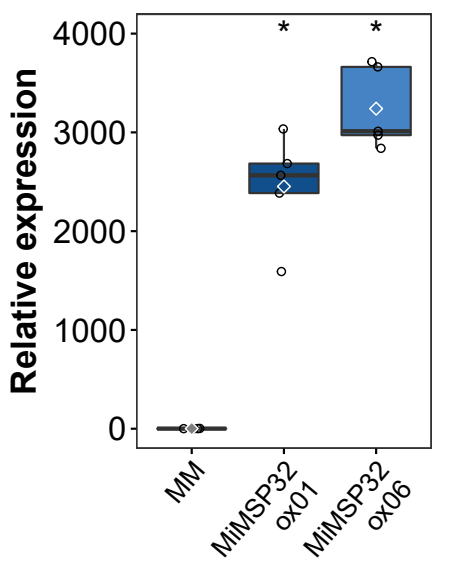

Figure S2. Seedlings of the stable overexpression lines MiMSP_ox01 and MiMSP_ox06 show abundance of the construct in DNA and in transcriptome. (A) Presence of MiMSP32 construct in the genome of transgenic tomato lines and wild-type tomato as determined by quantitative PCR relative to the abundance of the endogenous single copy vacuolar invertase gene. (B) Relative expression of MiMSP32_ox compared to tomato ubiquitin as determined by quantitative PCR. Expression data were statistically tested using pairwise Benjamini-Hochberg corrected Wilcoxon rank sum tests (*, P<0.05; **, P<0.01). 

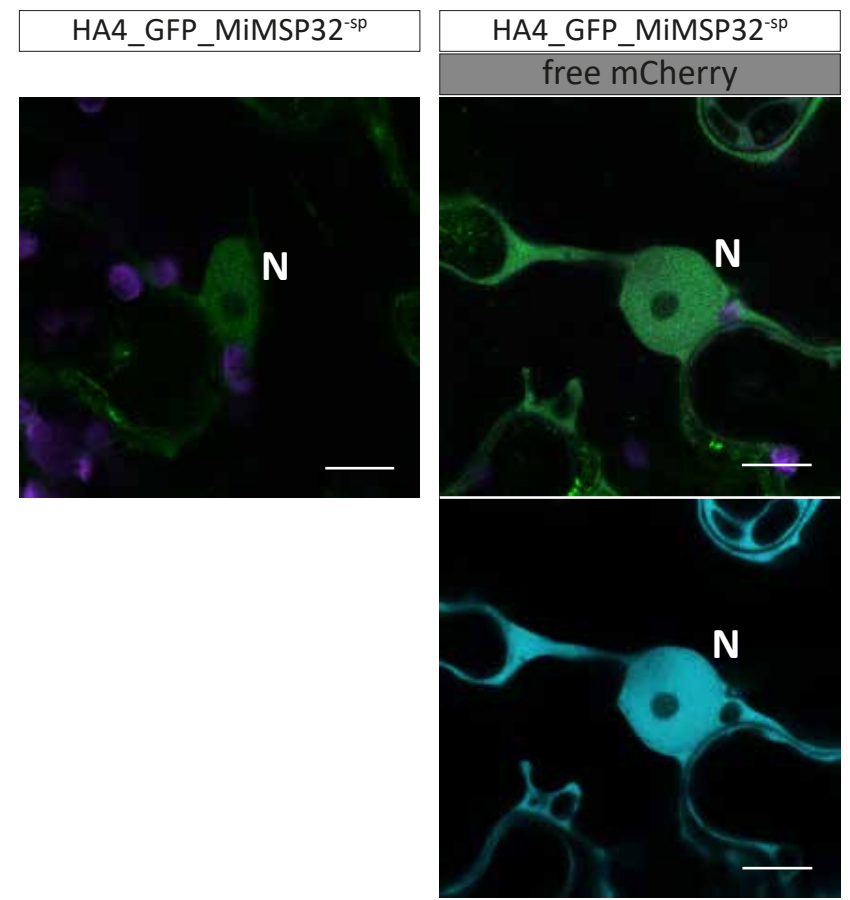

Figure S3. Subcellular localization of HA4_GFP_MiMSP32-sp with and without free mCherry. All leaf samples were taken at 48 hours after agroinfiltration of the constructs. Bars $=10 \mu \mathrm{m}$.

\section{Supplemental tables}

Table S1. Overview of the six tomato host proteins. The selected interaction domains (SIDs) of the six proteins with the lowest chance of being false-positives based on probability scores in the yeast two-hybrid screen.

\begin{tabular}{llll}
\hline \hline Cene & Name & Start & Stop \\
\hline Solyc06g073580.2.1 & SIH6D & 1 & 214 \\
\hline Solyc10g074940.1.1 & SIALA7 $^{\text {SID }}$ & 538 & 759 \\
\hline Solyc12.010040.1.1 & SILAPA2 $^{\text {SID }}$ & 465 & 578 \\
\hline Solyc01g103390.2.1 & SIOPR2 $^{\text {IID }}$ & 164 & 320 \\
\hline Solyc03g025610.1.1 & SITPPIISID $^{\text {SID }}$ & 1 & 189 \\
\hline Solyc10g081020.1.1 & SISPT6 $^{\text {SID }}$ & 164 & 585 \\
\hline \hline
\end{tabular}





\title{
Chapter 4
}

\section{The effector target AtOPR2 regulates susceptibility of Arabidopsis thaliana to Meloidogyne incognita}

\author{
Ava Verhoeven \\ Mark G Sterken \\ Joris JM van Steenbrugge \\ Aska Goverse \\ Geert Smant
}

Laboratory of Nematology, Department of Plant Sciences, Wageningen University \& Research, PO Box 8123, 6700 ES Wageningen, The Netherlands 


\section{Abstract}

Recently, the 12-oxophytodienoate reductase 2 (SIOPR2) was identified as a host target of the M. incognita effector MiMSP32 in tomato, but its role in susceptibility is not well understood. Here, we show that the closest homolog of SIOPR2 in Arabidopsis (AtOPR2) is also targeted by MiMSP32. We found that Arabidopsis knock-out opr2-7 mutants are significantly more susceptible to M. incognita than wild-type Arabidopsis plants, suggesting that AtOPR2 may function in plant defense. However, the Arabidopsis opr2-7 mutants do not respond differently than wild-type Arabidopsis plants to the bacterial elicitor of basal plant defense responses flg22. In addition, the Arabidopsis knock-out opr2-7 mutants also showed no significant changes in susceptibility to the beet cyst nematode Heterodera schachtii. From this, we postulate that AtOPR2 is specifically involved in mediating host susceptibility to root-knot nematodes independent from PAMP or DAMP triggered immunity. AtOPR2 is thought to take part in an alternative jasmonic acid (JA) biosynthesis pathway downstream of 12-oxo-phytodienoic acid (OPDA) in the conversion of 4,5-didehydrojasmonate (4,5-ddh-JA) to JA. We found that the root-growth inhibition response to exogenous application of OPDA in the opr2-7 mutant is different from wild-type Arabidopsis plants, suggesting a role of AtOPR2 in root development. However, our transcriptome analysis of nematode-infected roots of the opr2-7 mutant revealed no significant alterations in components of JA biosynthesis and signaling pathways. The responses of opr2-7 mutant plants to exogenous application of OPDA, and not JA, suggest that the conversion of this precursor of JA is altered and that an accumulation of 4,5-ddh-JA may be causal to the increased susceptibility of this mutant to M. incognita. 


\section{Introduction}

Meloidogyne incognita is an obligate sedentary plant parasite from the genus of root-knot nematodes. Root-knot nematodes are responsible for the majority of the estimated \$157 billion in agricultural losses by plant-parasitic nematodes every year Abad et al. (2008); (Jones et al., 2013). The tropical root-knot nematode Meloidogyne incognita is arguably one of the most invasive of all pathogens and pests worldwide (Trudgill \& Blok, 2001; Jones et al.., 2013; Bebber et al., 2014). This highly polyphagous parasite feeds on both monocots and dicots, including the model plant Arabidopsis (Sijmons et al.. 1991). After entering host roots, infective second stage juveniles (J2) of M. incognita use their stealthy and nondestructive intercellular migration to infiltrate the host vascular cylinder and start the formation of four to eight feeding cells (Wyss \& Grundler, 1992; Williamson \& Gleason, 2003; Abad \& Williamson, 2010). These so-called giant cells are multinucleate and hypertrophied and can reach a size up to 100-times the size of a normal parenchyma cell (Kyndt et al., 2013). Juveniles feed during six weeks from metabolites provided by the giant cells. Mature females of $M$. incognita reproduce parthenogenetically and deposit their eggs into a gelatinous mass (Gheysen \& Mitchum, 2019).

During infection, juveniles of $M$. incognita secrete effectors into the apoplast and cytoplasm of plant cells (Gheysen \& Mitchum, 2011). Once inside the host plant, effectors target host proteins to increase susceptibility. Genes encoding host targets of plant parasitic nematodes can function as susceptibility genes, because variation in these genes can translate into differences in plant susceptibility (van Schie \& Takken, 2014). Typical host processes targeted by effectors include the degradation of plant cell walls to allow pathogen invasion, or the suppression of plant defenses (Haegeman et al., 2012). For example, the M. incognita effector MiMSP16 (16D10) targets two SCARECROW-like transcription factors to stimulate giant cell induction by intervening in downstream root cell proliferation (Huang et al., 2006). However, the host targets are known for only a few of the currently identified effectors of $M$. incognita (Chapter 1). For example, host targets of the plant defense suppression associated effectors MilSE5 and MilSE6 have not been identified (Shi et al., 2018a; Shi et al., 2018b). Additionally, many host targets of effectors are expected within plant phytohormonal pathways to suppress plant defense responses (Gheysen \& Mitchum, 2019).

The phytohormone jasmonic acid (JA) remodels cellular functions and plant behavior (Zander et al., 2020) and plays an important role in plant defense (Bhattarai et al., 2008; SeimlBuchinger et al., 2018; Zhou et al., 2019). The importance of JA in root-knot nematode infection has been found in several studies. For example, JA biosynthesis plays a pivotal role in rice defense against root-knot nematodes (Nahar et al., 2011). Likewise, several rice JA biosynthesis genes are suppressed in giant cells compared to uninfected vascular root cells (i et al., 2013). Although the jasmonic acid precursor 12-oxo-phytodienoic acid (OPDA) is also regulating plant development, it has a distinct signaling role from jasmonic acid (Dave \& Graham, 2012; Monte et al., 2020). For example, OPDA and not JA activates the AtPHO1; $\mathrm{H1O}$ gene which is responsive to biotic and abiotic stresses in Arabidopsis (Ribot et al., 2008). Furthermore, OPDA plays a key role in regulating plant susceptibility to the root-knot nematode M. hapla (Gleason et al., 2016). 
As Gleason et al. (2016) show, Arabidopsis plants mutated upstream of OPDA are hypersusceptible to M. hapla, while mutations downstream of OPDA result in a loss of hyper-susceptibility.

So far, root-knot nematode effectors that target components of the JA-biosynthesis pathway have not yet been described. Here, we demonstrate that the M. incognita effector MiMSP32 Chapter 3) targets the 12-oxophytodienoate reductase AtOPR2 to regulate susceptibility of Arabidopsis. AtOPR2 functions in the conversion of 4,5-didehydro-jasmonate, a derivative of 2-oxophytodienoic acid (OPDA), to JA (Chini et al., 2018). However, it is thought that most JA biosynthesis occurs via a parallel pathway which involves 12-oxo-phytodienoate reductase AtOPR3. AtOPR3 reduces OPDA to 3-oxo-2(29[Z]-pentenyl)-cyclopentane-7-octanoic acid (OPC:8) (Mussig et al., 2000: Schaller et al., 2000: Stintzi \& Browse, 2000). To resolve the molecular mechanisms underlying the AtOPR2-mediated plant responses to M. incognita, we conducted a whole transcriptome analysis of opr2-7 plants during early stages of nematode infection. Furthermore, we aimed to investigate if AtOPR2 is involved in a PAMP-triggered immunity response. Additionally, we compared if hyper susceptibility of the opr2-7 line is specific for $M$ incognita by testing the susceptibility to the beet cyst nematode Heterodera schachtii. Together, our data provides evidence that AtOPR2 regulates susceptibility of Arabidopsis to M. incognita independent from basal plant immune responses by conversion of the signaling molecule 4,5-ddh-JA.

\section{Results}

Orthologs of host targets of MiMSP32 in Arabidopsis

Previously, we showed that the effector MiMSP32 of M. incognita physically interacts with a diverse set of six tomato proteins, i.e. SIH6D, SIALA1, SILAPA2, SIOPR2, SITPPII, and SISPT6 (Chapter 3). M. incognita is also capable of infecting Arabidopsis, a model plant system with many tools available allowing for efficient mutant screening with plant-parasitic nematodes (Siimons et al. 1991). To identify orthologs of these possible host-targets of $\mathrm{M}$. incognita in Arabidopsis, we used a nucleotide BLAST algorithm to query the Arabidopsis genome using the full-length coding sequences of the tomato genes. We identified orthologs with a similar function for SIALA1, SIOPR2, SITPPII, and SISPT6 (Table 1). These four genes have very diverse biological functions. Aminophospholipid translocase AtALAT is a membrane protein mediating the generation and maintenance of the membrane bilayer (Fan et al., 2018). The second gene, 12-oxophytodienoate reductase protein 2 (AtOPR2), reduces 4,5-didehydro-JA to JA (Chini et al.. 2018). The third gene, AtTPPII, is likely responsible for cleavage of peptide products (>15 amino acids) in the proteasome pathway (Saric et al.. 2004). The fourth gene, transcription elongation factor AtSPT6, can stimulate the transcription elongation rate of RNA polymerase II by modulating the chromatin structure of transcribed genes (Grasser 2005). In addition, we compared the obtained Arabidopsis protein sequences with the tomato proteins using EMBOSS Water from EMBL-EBI (Madeira et al., 2019). For these four Arabidopsis genes, protein similarity to the tomato genes ranged from $69.3 \%$ to $87.6 \%$. For the other two possible effector targets, SILAPA2 and SIH6D, we could not identify an ortholog in Arabidopsis. SILAPA2 is a stress-induced acidic leucine aminopeptidase thus far only found in a subset of the Solanaceae (Scranton et al.. 2012). Likewise, the hyoscyamine 6-dioxygenase SIH6D is produced in the roots of several Solanaceous plants to catalyze the hydroxylation of hyoscyamine transformation to scopolamine (Matsuda et al., 1991).

Table 1. Summary of the six tomato host target genes together with their orthologs in Arabidopsis. For

\begin{tabular}{|c|c|c|c|c|c|c|c|c|c|}
\hline Tomato gene & $\begin{array}{l}\text { Tomato } \\
\text { gene ref }\end{array}$ & Blastn & $\begin{array}{l}\text { Arabidopsis } \\
\text { gene }\end{array}$ & $\begin{array}{l}\text { Arabidopsis } \\
\text { gene ref }\end{array}$ & T-DNA mutants & 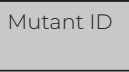 & Arabidopsis gene description & $\begin{array}{l}\text { Whole protein } \\
\text { similarity }\end{array}$ & $\begin{array}{l}\text { Whole protein } \\
\text { identity }\end{array}$ \\
\hline Solyc06g 073580.2.1 & $\mathrm{SIH} 6 \mathrm{D}$ & hyoscyamine 6-dioxygenase & & & & & & & \\
\hline Solyclog074940.1.1. & SIALAT & phospholipid-transporting ATPase 7-like & At5g04930 & AtALAT & $\begin{array}{l}\text { SALK_002106C, } \\
\text { SALK_056947C }\end{array}$ & $\begin{array}{l}\text { alal-1, } \\
\text { alat-2 }\end{array}$ & ALAl aminophospholipid ATPase 1 & 0.704 & 0.545 \\
\hline Solyc12g010040.1.1. & SILAPA2 & leucine aminopeptidase 2 (LAPA2) & & & & & & & \\
\hline Solyc01g103390.2.1 & SIOPR2 & 12-oxophytodienoate reductase 2 (opr2) & Atlg76690 & AtOPR2 & SALK_116381C & opr2-1 & OPR2 12-oxophytodienoate reductase 2 & 0.693 & 0.509 \\
\hline Solyc03g025610.1.1. & SITPPII & tripeptidyl-peptidase 2 (TPPII) & At4g20850 & AtTPPII & SALK_085776C & tppll-2 & TPP2 tripeptidyl peptidase ii & 0.876 & 0.778 \\
\hline Solyclog081020.1.1. & SISPT6 & transcription elongation factor SPT6-like & Attg63210 & AtSPT6 & SALK_131654C & spt6-1 & Transcription elongation factor Spt6 & 0.782 & 0.63 \\
\hline
\end{tabular}




\section{AtOPR2 regulates susceptibility of Arabidopsis to $M$. incognita}

To test if the Arabidopsis orthologs of four possible host targets of MiMSP32 play a role in plant susceptibility to root-knot nematodes, we performed an Arabidopsis mutant screen. We therefore challenged five T-DNA mutant lines - ala7-7, ala7-2, opr2-7, tpp/l-2, and spt6-7 -and wild-type Col-O (Figure 1A) with infective juveniles of M. incognita. All five insertions are located in gene exons and the lines were confirmed for homozygosity of the insertion (Supplemental Figure S1). Only opr2-7 mutant plants lacking a functional AtOPR2 gene harbored a significantly higher number of nematodes per plant at seven days post inoculation than wild-type Col-O plants ( $P<0.05$; one-way ANOVA with Tukey's HSD) (Figure 1B). At seven days post inoculation, juveniles have established feeding sites and formed galls. We could not observe any visual aberrations in gall formation or nematode development in the mutant plants as compared to the wild-type control. Since M. incognita invades Arabidopsis at root tips, we also counted the number of root tips per plant at the stage of inoculation as this can influence the infection rate. The number of root tips of opr2-7 plants were not significantly different from wild-type Col-0 plants, confirming the increased susceptibility of this genotype (Figure 1C). Although spt6-7 and tpp/l-2 plants contained significantly more root tips at this stage of inoculation, none of the T-DNA mutant lines showed an significantly altered infection ratio of $M$. incognita juveniles per root tip (Supplemental Figure S2). Taken together, our bioassays suggested that AtOPR2 may indeed be a genuine host target of $M$. incognita, and we therefore focused our analyses further on this protein.

\section{MiMSP32 specifically interacts with full-length AtOPR2}

To assess whether MiMSP32 also physically interacts with Arabidopsis AtOPR2, we transiently co-expressed affinity-tagged constructs encoding the full-length AtOPR2 protein and MiMSP32 without its native signal peptide for secretion in Nicotiana benthamiana leaves by agroinfiltration. Therefore, we transiently expressed MiMSP32-sp fused to GFP- and 4XHA-tags on either the $\mathrm{N}$ - or $\mathrm{C}$-terminus of the protein and AtOPR2 carrying mCherry- and 4XMYCtags. Indeed, MiMSP32-sp pulled down AtOPR2 in a co-immunoprecipitation assay (Figure 2). AtOPR2 shows a specific protein pattern suggesting protein cleavage, although after precipitation, only the full-length protein resides. Western blotting with anti-HA antibodies detected MiMSP32-sp in all input and pull-down material as expected and anti-MYC antibodies detected AtOPR2. MYC-tagged YFP was used as control and did not precipitate along with MiMSP32. Our data thus showed that full-length AtOPR2 specifically interacts with MiMSP32-sp

\section{Transcriptional differences in opr2-7 mutant not associated with JA biosynthesis}

To further investigate the pathways underlying the enhanced susceptibility of the Arabidopsis opr2-7 mutant to $M$. incognita, we analyzed differential expression patterns in nematode-infected roots of mutant opr2-7 and wild-type Col-0 plants at 0, 1, 4, and 7 days after inoculation using RNA-Seq. In total we analyzed 1,624,950,228 reads, of which $95.31 \%$ mapped to the TAIR10 A. thaliana genome (Lamesch et al., 2011) (Supplemental Table S2). Importantly, the mutation in AtOPR2 explained less than 1.9\% of the total observed variation in Arabidopsis gene expression in either mock infected or in M. incognita infected samples 
A

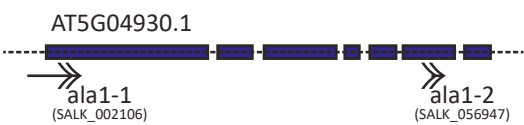

AT4G20850.1

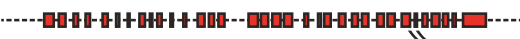

$\operatorname{tp}_{\text {tSALK } 285776)}$

B

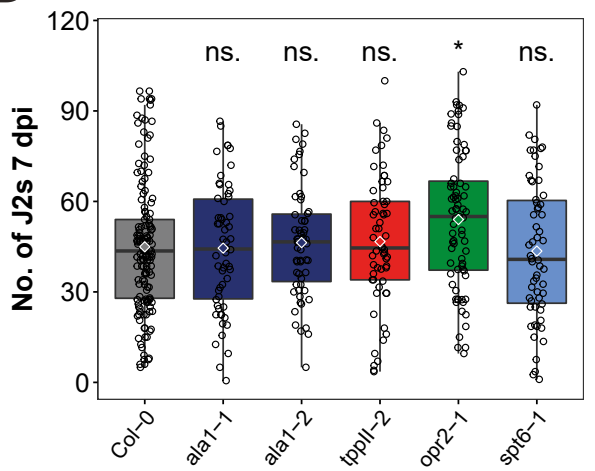

AT1G76690.1

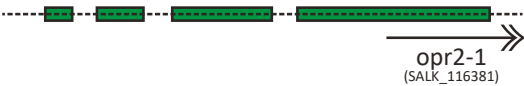

AT1G63210.1

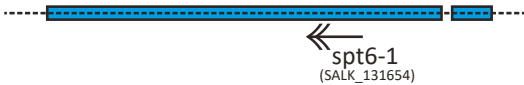

C

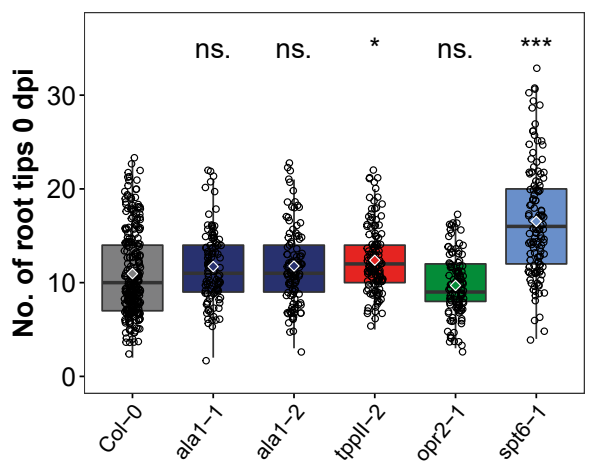

Figure 1. Susceptibility to $M$. incognita is affected by the opr2-7 mutant. (A) Detailed locations of the T-DNA insertions (arrows) at the Arabidopsis gene loci. (B) Boxplot of the number of stained M. incognita juveniles (J2s) in mutant and wild-type plant roots at seven days after inoculation. (C) Boxplot of the number of root tips for the different Arabidopsis lines at the day of inoculation. Data was collected in at least three independent experiments with $n \geq 16$ and all data was combined. Asterisks indicate significant differences between T-DNA lines and wild-type Col-0 Arabidopsis plants (***, P<0.001; *, P<0.05; ns, not significant).

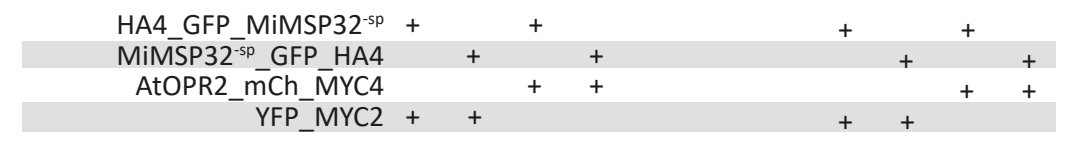

WB: $\alpha-\mathrm{HA}$

kDa

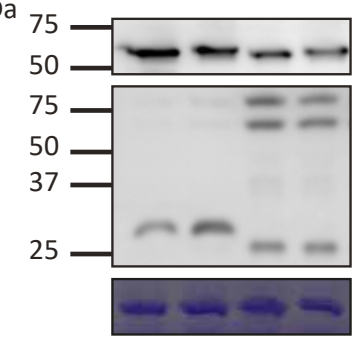

Input

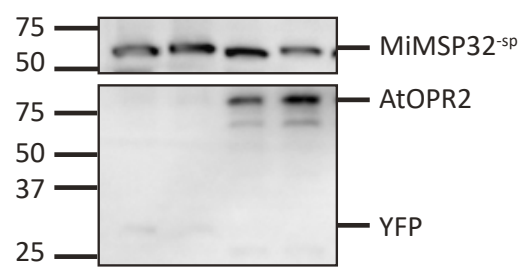

IP: $\alpha-H A$

Figure 2. Full-length AtOPR2 specifically interacts with MiMSP32-sp in transiently expressed Nicotiana benthamiana leaves. Co-immunoprecipitation in N. benthamiana leaves by pulling down MiMSP32-sp using anti-HA magnetic beads and anti-MYC detection of AtOPR2. Proteins were extracted from a combination of two plants and leaves at $48 \mathrm{~h}$ after inoculation. Equal loading is visualized by Coomassie brilliant blue (CBB) staining on total protein extracts. 
A

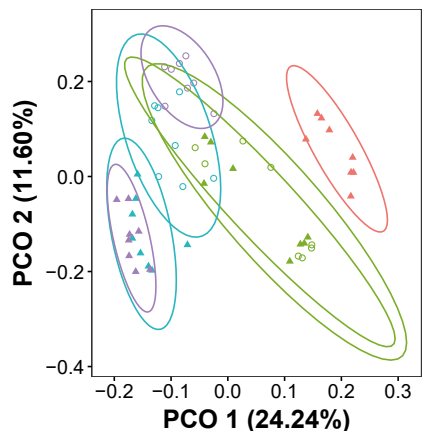

B

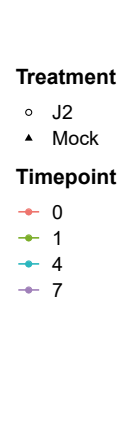

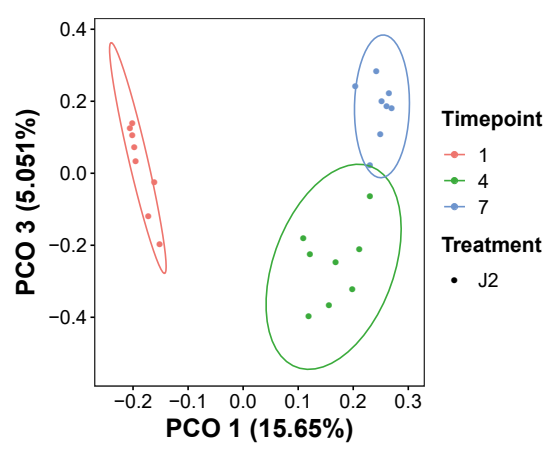

Figure 3. Distribution of transcripts is mainly regulated by time. (A) Principal component analysis visualizing a distribution of $A$. thaliana transcripts from all 56 samples categorized by timepoint and treatment (inoculation with M. incognita J2 or mock). (B) Principal component analysis visualizing a distribution of M. incognita transcripts from all 24 samples categorized by timepoint and treatment (inoculation with $M$. incognita J2). Ellipses are based on a confidence level of $95 \%$.
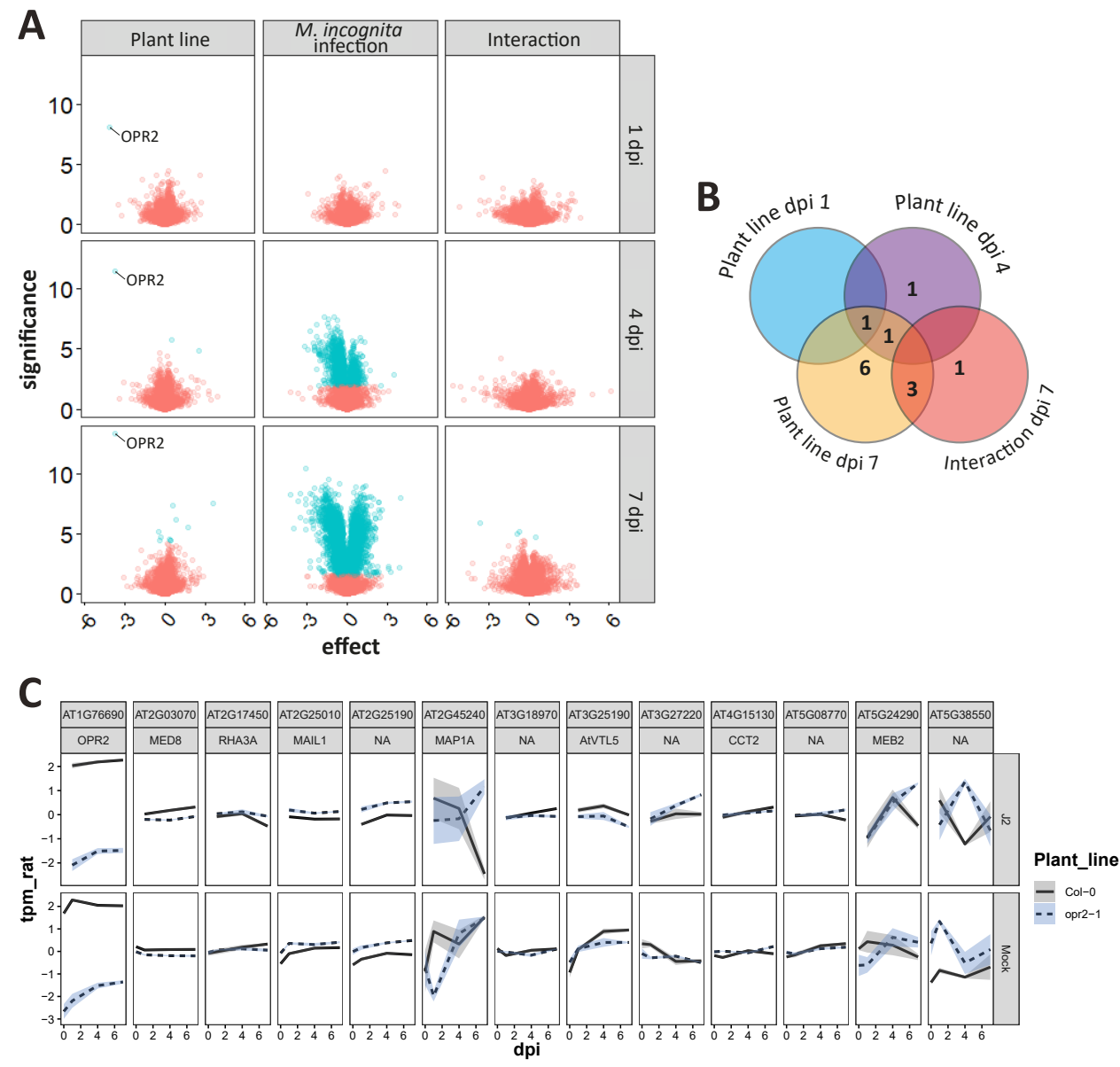
(Supplemental Figure S3). In contrast, the first principle component explaining 24\% of the variance in expression in the 9483 genes in the Arabidopsis roots was related to the number of days since the time of inoculation, likely caused by root development (Figure 3A). The second principle component, explaining almost $12 \%$ of the variance in expression of Arabidopsis genes across all samples was related to the presence of an infection by $M$. incognita. Furthermore, the different samples showed a clear separation in gene expression for nematode-infected root samples versus mock-infected samples at late timepoints.

Of all analyzed reads, only $0.20 \%$ mapped to the PRJEB8714 M. incognita genome (BlancMathieu et al., 2017) (Supplemental Table S2). Similar as in Arabidopsis, the variance in gene expression among the $15426 \mathrm{M}$. incognita genes was also mainly related to time (principal component 1, 16\%; Figure 3B). We attempted to analyse gene expression of the effector MiMSP32 in wild-type plants compared to the opr2-7 mutant, but the sequencing coverage was not sufficient to make this comparison. Most of the differences in gene expression in the nematodes occurred between $1 \mathrm{~d}$ pi and later timepoints, consistent with progression through different life stages.

Next, we analyzed the RNA-Seq dataset to specifically identify differentially regulated genes in the Arabidopsis opr2-7 mutant during nematode infection. To include genes affected by the mutation on separate days or in interaction with nematode infection, we used an interaction model for plant genotype and M. incognita infection on 1, 4, and 7 days after inoculation (Figure $4 \mathrm{~A}$ ). We found a total of thirteen genes which were differentially regulated in roots of the opr2-7 mutant lines versus wild-type Col-O (Figure 4B). As expected, the most downregulated gene in the opr2-7 mutant at all three timepoints in both infected and non-infected roots was AtOPR2. Several other putative susceptibility regulating genes show deviating expression patterns in the opr2-7 mutant when compared to the wild-type Col-O line (Figure 4C, Table 2). Most of the other twelve differentially expressed genes were upregulated in the absence of a functional AtOPR2 gene.

AtOPR2 reduces 4,5-didehydrojasmonate (4,5-ddh-JA) to JA in the JA biosynthesis pathway (Chini et al.. 2018). As JA also plays an important role in the defense against root-knot nematodes, we aimed to study any potential effects of AtOPR2 on the regulation of other JA biosynthesis genes. Therefore, we also analyzed the relative expression of all genes included in KEGC module M00113 (Jasmonic acid biosynthesis). As several of the genes were removed from the

< Figure 4. Differentially regulated A. thaliana genes in opr2-7 plants compared to wild-type plants during $M$. incognita infection. (A) Volcano plot of the used interaction model for opr2-7 and wild-type plants on 1, 4, and 7 days post inoculation (dpi) with $M$. incognita juveniles or mock-inoculated. Differentially regulated genes (false discovery rate, fdr<0.05) are colored in blue, non-significant differences are colored in red. (B) Venn diagram with the differentially regulated genes, organized by significant factors from the interaction model. (C) Relative expression as the ratio of transcripts per kilobase million (tpm_rat) of the 13 differentially regulated genes at 0, 1, 4, or 7 days post inoculation (dpi) with $M$. incognita juveniles (J2) or mock-treatment for the opr2-7 mutant or Col-0 wild-type plants. 
dataset during filtering for high and consistently detected expression, we chose to observe gene expression without filtering for this analysis. Hereby, we observed a downregulation of the main OPDA reductase AtOPR3 in nematode-infected roots of the opr2-7 mutant compared to wild-type plants at 1 and 4 days after inoculation (Figure 5 ). The transcriptional regulation of the other jasmonic acid biosynthesis associated genes was similar for opr2-7 mutants and wildtype Col-O plants, as would be expected from a singular gene mutation. Hence, we conclude that AtOPR2 had no detectable influence on other JA-biosynthesis genes.

Table 2. The 13 differentially regulated genes between opr2-1 mutant plants and Col-0 wild-type plants. Differences were determined using an interaction model for time and $M$. incognita infection. For every gene, it is mentioned whether the gene is up- or downregulated in mutant plants.

\begin{tabular}{|c|c|c|c|}
\hline Gene & opr2-1 & Short & Details \\
\hline AT1G76690 & Down & OPR2 & Encodes one of the closely related 12-oxophytodienoic acid reductases. \\
\hline AT2G03070 & Down & MED8 & $\begin{array}{l}\text { Encodes a subunit of the Mediator complex - Regulates plant defense to fungus and } \\
\text { flowering. }\end{array}$ \\
\hline AT2G17450 & $\begin{array}{l}\text { Up/ } \\
\text { down }\end{array}$ & RHA3A & Encodes a putative RING-H2 finger protein RHA3a. \\
\hline AT2G25010 & Up & MAIL1 & $\begin{array}{l}\text { Essential for maintaining correct cell division and differentiation. Involved in an alternative } \\
\text { silencing pathway. }\end{array}$ \\
\hline AT2G25190 & Up & NA & $\begin{array}{l}\text { PPPDE - Putative thiol peptidase family protein. One of the brassinosteroid-regulated } \\
\text { putative genes. }\end{array}$ \\
\hline AT2G 45240 & $\begin{array}{l}\text { Down/ } \\
\text { up }\end{array}$ & MAPIA & $\begin{array}{l}\text { Encodes a cytoplasmic MAP1 like methionine aminopeptidase which is involved in } \\
\text { removing the N-terminal methionine from proteins. }\end{array}$ \\
\hline AT3G18970 & $\begin{array}{l}\text { Down/ } \\
\text { up }\end{array}$ & MEF2O & $\begin{array}{l}\text { Encodes a pentatricopeptide repeat protein (PPR) protein involved in mitochondrial mRNA } \\
\text { editing. Responsive to several abiotic stresses. }\end{array}$ \\
\hline AT3G25190 & $\begin{array}{l}\text { Up/ } \\
\text { down }\end{array}$ & VTL5 & $\begin{array}{l}\text { Vacuolar Iron Transporter-Like } 5 \text { / Nodulin-like21 / - Catalyzes Fe transport into vacuoles } \\
\text { and thus contribute to the regulation of Fe homeostasis. Downregulated in roots with iron } \\
\text { deficiency and also in roots with ACC-induced inhibition of root cell elongation. }\end{array}$ \\
\hline AT3G27220 & $\begin{array}{l}\text { Down/ } \\
\text { up }\end{array}$ & NA & Galactose oxidase/kelch repeat superfamily protein - anaerobic respiration. \\
\hline AT4G15130 & Up & $\mathrm{CCT} 2$ & phosphorylcholine cytidylyltransferase2. \\
\hline AT5G08770 & Up & NA & topoisomerase I damage affected-like protein. \\
\hline AT5G24290 & $\begin{array}{l}\text { Down/ } \\
\text { up }\end{array}$ & MEB2 & Vacuolar iron transporter (VIT) family protein. \\
\hline AT5C38550 & Up & NA & Jacalin lectin family protein gene. \\
\hline
\end{tabular}

> Figure 6. Opr2-1 mutant plants are not inhibited in root growth by exogenous OPDA. (A) Proposed conversion of 12-oxophytodienoic acid into jasmonoyl-isoleucine by AtOPR3 and AtOPR2 (adapted from Chini (2018)). (B) Quantification of root length at three days after transplanting of the single mutant opr2-1 or opr3-3, double mutant opr2-7/opr3-3 or wild-type Col-0 plants to medium containing 0.5 uM methyl jasmonate (MeJA), 0.5 uM 12-oxophytodienoic acid (OPDA), or control medium (EtOH). Representative pictures are shown for each subgroup after three days. Data was collected in two independent experiments with a total $n \geq 27$ and combined for statistical analysis with a one-way ANOVA using Tukey's HSD. Asterisks indicate significant differences for supplemented media within one plant line when compared with the EtOH control (***, $\mathrm{P}<0.001 ;{ }^{* *}, \mathrm{P}<0.01$; ns, not significant) 

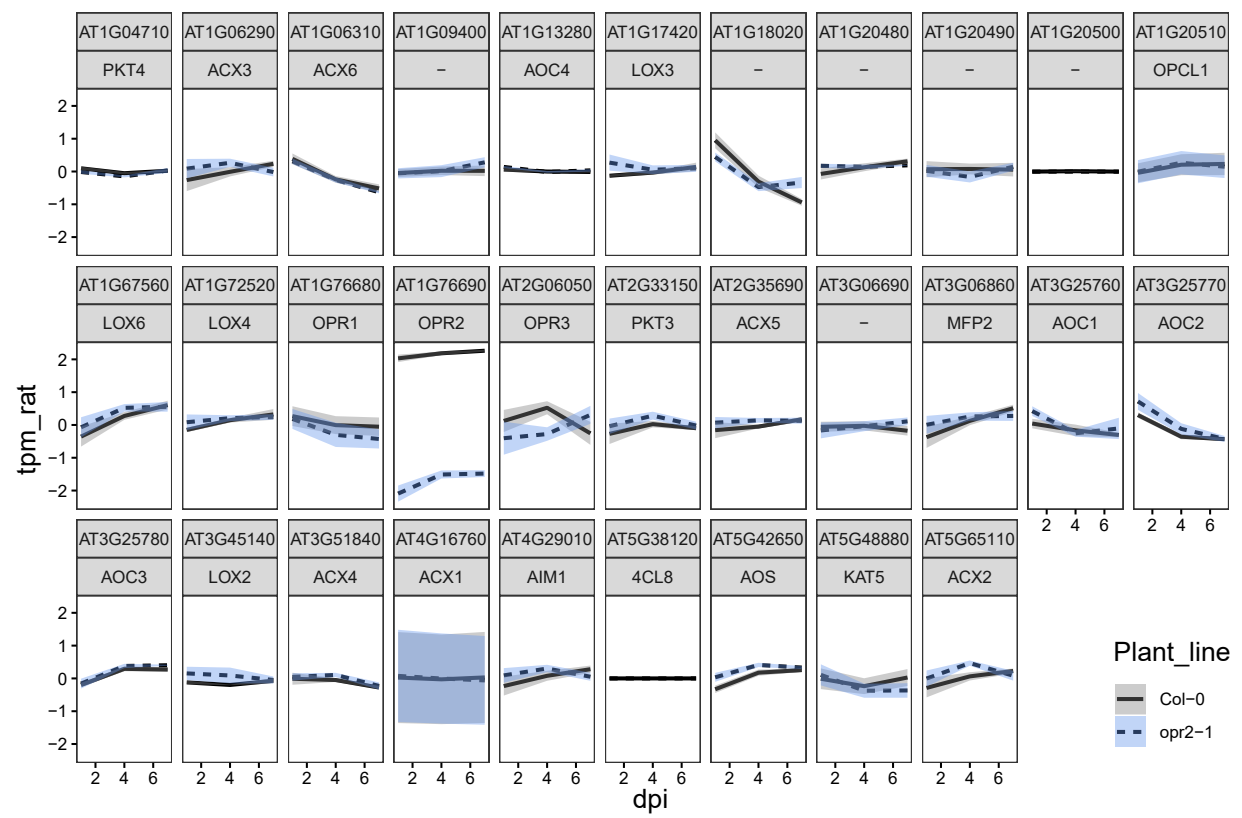

Figure 5. Expression of Arabidopsis genes associated with jasmonic acid biosynthesis. Jasmonic acid biosynthesis associated genes (KEGG module M00113) in nematode-infected roots of the opr2-7 mutant and Col-O plants over time. Gene expression was unfiltered, and samples were taken at 1, 4 and 7 days post inoculation (dpi) with M. incognita.

A

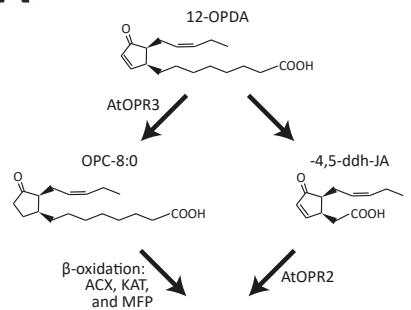

$\overbrace{\text { CooH }}^{\mathrm{JA}}$

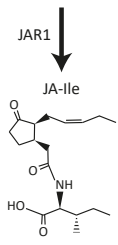

B

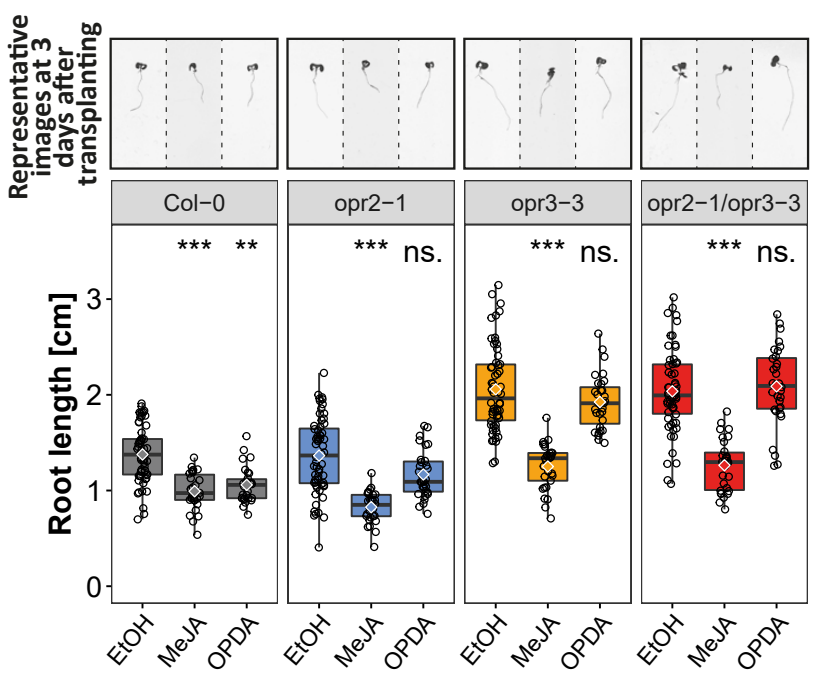


A

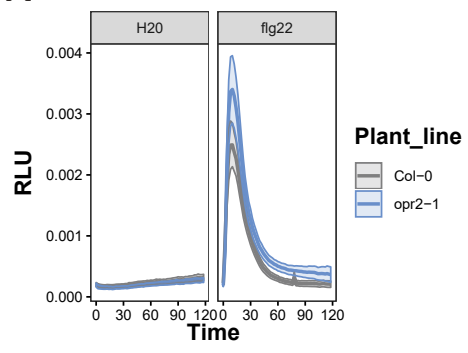

B

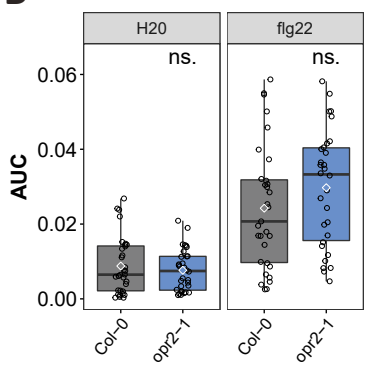

C

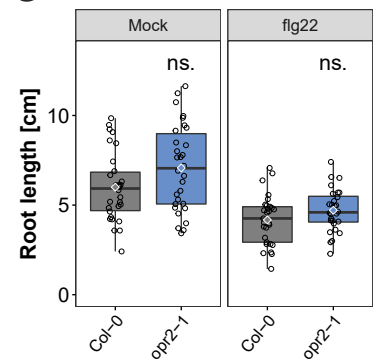

Figure 7. Opr2-1 mutants are not impaired in flg22-triggered immunity. (A) Leaf disks from six weeks-old wild-type plants or opr2-7 mutant plants were treated with the bacterial pathogen associated molecular pattern flg22 or autoclaved tap water as a control. Reactive oxygen species (ROS) burst was measured in relative light units (RLU) using a L-012 based assay from 0 to $120 \mathrm{~min}$. Results of three independent experiments were combined in the analysis and the (B) area under the curve (AUC) was calculated. (C) Total root length of opr2-7 and wild-type plants grown for three days on medium treated with 0.5 uM flg22 or tap water with $n=30$ each. Root length and AUC of opr2-7 and wildtype plants were compared using Student's t-tests (ns, not significant).

A

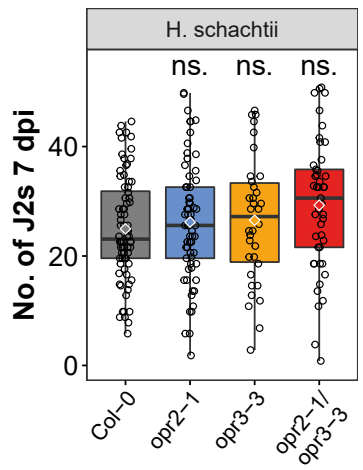

B

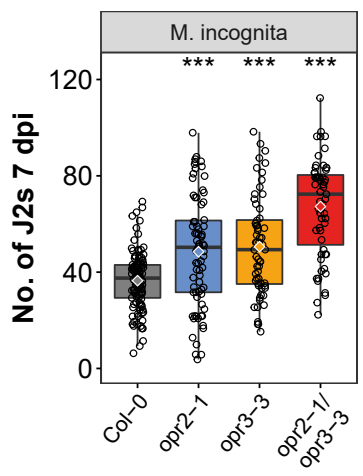

C

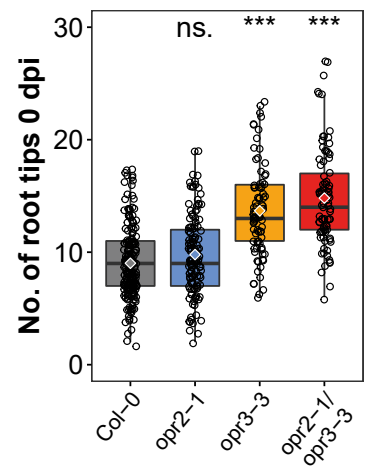

Figure 8. Arabidopsis OPR proteins AtOPR2 and AtOPR3 affect root-knot nematode virulence, but not cyst nematodes. (A) Number of stained M. incognita juveniles (J2s) in wild-type, opr2-7, opr3-3 or opr2-7/ opr3-3 mutant plants at seven days post inoculation (dpi). (B) Number of stained M. incognita juveniles in wild-type, opr2-7, opr3-3 or opr2-7/opr3-3 mutant plants at seven days post inoculation. (C) Number of root tips at the day of inoculation. Data was collected in at least two independent experiments with $n \geq 16$ and combined for statistical analysis. Asterisks indicate significant differences between mutant plants and wild-type Col-O plants as calculated with an one-way ANOVA using Tukey's HSD (***, P<0.001; ns, not significant). 
From the twelve differentially regulated genes in the Arabidopsis opr2-7 mutant during nematode infection, AtMED8 is the only gene that has been associated with JA-dependent defense responses (Kidd et al., 2009). Therefore, we focused further on the characterization of a functional med8 mutant line (MT; AT2G03070) from Kooke et al. (2019). AtMED8 is a subunit of the Mediator complex and the only gene down regulated in the absence of AtOPR2 in nematode-infected Arabidopsis roots. To test if AtMED8 also plays a role in the early stages of M. incognita infection, we challenged med8 knock-out lines with infective J2s. Notably, med8 knock-out plants did not show an altered susceptibility to $M$. incognita compared to wild-type Col-O plants at 7 dpi (Supplemental Figure S4). It is therefore not likely that the AtOPR2-dependent regulation of susceptibility to $M$. incognita in Arabidopsis involves AtMED8.

\section{opr2-7 mutant plants are not inhibited in root growth by exogenous OPDA}

AtOPR2 regulates an AtOPR3-independent pathway in the synthesis of jasmonates (Figure 6A; (Chini et al., 2018)), which can inhibit root growth of seedlings of Arabidopsis at elevated levels. We reasoned that if OPR2 contributes to the conversion of OPDA into jasmonates, the opr2-7 mutant may also show a weaker root-growth inhibition upon exogenous application of OPDA than wild-type Arabidopsis plants. To test this hypothesis, we analyzed the root growth of the single mutants opr2-7 and opr3-3, and the double mutant opr2-7/opr3-3 in the presence of either the enzymatic substrate OPDA or the product methyl jasmonate (MeJA), an elicitor derived from JA (Figure 6B). While wild-type Arabidopsis plants showed a significant reduction in root growth upon exogenous application with OPDA $(P<0.01$; one-way ANOVA with Tukey's HSD), no significant root-growth inhibition was observed for the opr2-7 and opr3-3 single mutants and the opr2-7/opr3-3 double mutant. In contrast, the opr2-7, opr3-3, and opr2-7/opr3-3 mutants as well as the wild-type Col-0 plants all showed significant root growth inhibition upon treatment with MeJA ( $\mathrm{P}<0.001$; one-way ANOVA with Tukey's HSD). Our data suggests that the altered susceptibility of the opr2-7 mutant to M. incognita may involve the inability of this mutant to convert OPDA into JA.

\section{opr2-7 mutant plants not impaired in PTI}

Plant phytohormones like JA function in downstream immune responses, after the initial pathogen detection by PAMP-triggered immunity (PTI) has taken place (Zhang et al., 2017). To test if the phenotype associated with the mutant opr2-7 can be explained by alterations in PTI, we exposed the opr2-7 mutant and wild-type plants to the bacterial elicitor peptide flg22 (Felix et al., 1999). After addition of flg22 to Arabidopsis leaf disks in vitro, we measured a similar intensity (Figure 7A) and a comparable total amount of reactive oxygen species being released from leaf disks of opr2-7 mutant and wild-type Arabidopsis plants in the first two hours ( $P>0.05$; Student's t-tests) (Figure 7B). Additionally, we used root growth inhibition assays with flg22 to test if slower, cumulative effects of a PTI-response occur. After six days of growth on media

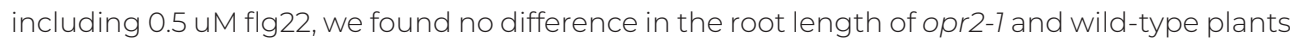
( $P>0.05$; Student's t-tests) (Figure 7C). These results suggest that the PTI response induced by the bacterial elicitor flg22 occurs independently of AtOPR2 in Arabidopsis plants, and supports 
the observation that susceptibility is induced by the downstream immune responses. AtOPR2 and AtOPR3 specifically regulate susceptibility to root-knot nematodes To test if the observed susceptibility increase of AtOPR-mutants is specific for $M$. incognita, we also challenged the opr2-7, opr3-3, and opr2-7/opr3-3 mutants with infective juveniles of the beet cyst nematode Heterodera schachtii. Surprisingly, none of the mutant lines showed a significantly altered susceptibility to $H$. schachtii at seven days after inoculation (Figure 8A). In contrast, the opr2-7 and opr3-3 single mutants and the opr2-7/opr3-3 double mutant showed a significant increase in susceptibility to $M$. incognita ( $\mathrm{P}<0.001$; one-way ANOVA with Tukey's HSD) (Figure 8B). The number of root tips at the time of inoculation was also significantly higher in the opr3-3 mutant and the double mutant, which may have contributed to the increase in susceptibility to M. incognita of these genotypes (Figure $8 \mathrm{C}$ ). The additive effect of opr2-7 and opr3-3 in the opr2-7/opr3-3 double mutant further suggests that both genes alter susceptibility to M. incognita, at least to some extent, via independent pathways. The alterations in plant susceptibility may involve the inability of this mutant to convert OPDA into JA. Taken together, we expect that AtOPR2 and AtOPR3 regulate plant susceptibility to M. incognita and not $H$. schachtii by conversion of the JA precursors OPDA and 4,5-ddh-JA.

\section{Discussion}

Previously, we searched the genome of M. incognita for gene families under positive selection, one of which includes the esophageal gland specific gene MiMSP32 (Chapter 2) (Huang et al., 2003). MiMSP32 contributes to virulence of M. incognita in tomato and was shown to interact with several tomato proteins (Chapter 3). In this chapter, our main goal was to assess which of these interacting proteins functions as a host target for M. incognita. Therefore, we used the model plant Arabidopsis, which is susceptible to M. incognita and has many tools available for efficient mutant screening with plant-parasitic nematodes (Sijmons et al., 1991). For four of the MiMSP32-interacting tomato proteins, we found orthologs in Arabidopsis for which T-DNA knockout lines were also available. Our bioassays showed that only Arabidopsis 12-oxophytodeinoate reductase-2 mutant plants are more susceptible to M. incognita. AtOPR2 is thought to take part in an alternative jasmonic acid (JA) biosynthesis pathway downstream of 12-oxo-phytodienoic acid (OPDA) in the conversion of 4,5-didehydrojasmonate (4,5-ddh-JA) to JA. Importantly, like SIOPR2, AtOPR2 specifically interacted with the effector MiMSP32 in a co-immunoprecipitation assay. Our transcriptomic analyses further showed that 13 genes are differentially regulated in association with AtOPR2 in nematode-infected roots of Arabidopsis, none of which is thought to be in JA biosynthesis. However, the responses of opr2-7 mutant plants to exogenous application of OPDA, and not JA, suggest that the conversion of this precursor of JA is altered and that an accumulation of OPDA may be causal to the increased susceptibility of this mutant to M. incognita (Figure 9).

The increased susceptibility of opr2-7 mutant Arabidopsis plants to M. incognita at seven days after inoculation likely reflects the role of AtOPR2 as a host target of MiMSP32. Although we focused on AtOPR2 as a likely host target of MiMSP32 in Arabidopsis, we cannot exclude the 
interaction of MiMSP32 with the other tomato host targets to contribute to nematode virulence. The orthologs - AtALAT, AtTPPII, and AtSPT6 - do not show a phenotypic difference in plant susceptibility to M. incognita at seven days after inoculation. However, the host-target genes could very well still be associated with plant susceptibility to root-knot nematodes at a different timepoint or plant host background.

In our earlier work, we observed a similar susceptibility increase of MiMSP32 overexpression on tomato (Chapter 3) as we now observed in Arabidopsis mutant line opr2-7. It should be noted that we counted juveniles in the roots of Arabidopsis instead of galls in tomato roots. However, the observation that MiMSP32 overexpression affects gall formation at $7 \mathrm{dpi}$ in a similar way as the opr2-7 mutant affects nematode numbers suggests a direct causal relationship between those traits. Together, the direct binding of MiMSP32 with AtOPR2, and the opr2-7 mutant plants in Arabidopsis 'phenocopying' MiMSP32 overexpressing tomato plants leads us to believe that MiMSP32 might increase plant susceptibility by binding to the host protein OPR2.

Both the effect of time and nematode infection had a larger impact than the opr2-7 mutation on the transcriptional regulation of Arabidopsis roots, pointing to a relatively similar overall transcriptional regulation of opr2-7 mutant plants compared to wild-type Arabidopsis. This finding can be interpreted by two potential explanations. First, the altered susceptibility of opr2-7 mutant plants can be caused by changes on a protein level rather than on a gene transcription level. A known flaw of transcriptomics datasets is the low correlation with actual protein concentrations, which is usually about 40\% (Vogel \& Marcotte, 2012). As we also observed protein degradation in our blots, this could potentially point to post-transcriptional modifications. Second, the sampling of whole roots could have led to a dilution effect, causing local changes at nematode infection sites of expression in opr2-7 mutant plants to remain small and unnoticed. To prevent a dilution effect, we suggest future sampling of gall-enriched material instead of whole-root samples.

Potentially meaningful candidate genes likely reside within the twelve identified differentially regulated genes during nematode infection in opr2-7 plants. Therefore, the identified genes should be investigated in further mutant studies for their potential role in Arabidopsis susceptibility to M. incognita. For example, MAIL1 (At2925010) is essential for maintaining correct cell division and the differentiation of cells (Ühlken et al., 2014). It can thus be reasonably hypothesized that MAIL7 might contribute to plant susceptibility to nematodes by regulating feeding site formation by cell division and differentiation. However, further investigations to compare plant susceptibilty to M. incognita of Arabidopsis mutant lines of these genes are necessary to see which differentially regulated genes play a role in plant-nematode interactions.

As a first attempt to identify genes associated with plant susceptibility to $M$. incognita, we picked AtMED8 as the most likely candidate from the thirteen differentially regulated genes in nematode-infected roots of the opr2-7 mutant lines versus wild-type Col-0. AtMED 8 encodes a subunit of the Mediator complex involved in JA-dependent immune responses (Kidd et al., 
2009; Zhang et al., 2012; Li et al., 2018). However, the nematode numbers in med8 mutants at seven days after inoculation were comparable to those in wild-type plants. Therefore, our results suggest that AtMED 8 is not involved in plant susceptibility to $M$. incognita at $7 \mathrm{dpi}$. An alternative explanation of the results is that AtMED8 is involved in Arabidopsis susceptibility at a later timepoint than the measured $7 \mathrm{dpi}$.

Our observation that root growth of the opr2-7, opr3-3, and op2-7/opr3-3 mutants responds to JA treatment, but not to OPDA treatment, suggest that both AtOPR2 and AtOPR3 are most likely involved in the conversion of OPDA to JA. Treatment with JA inhibits the growth of primary roots of Arabidopsis, while exogenous application of OPDA only has a growth inhibiting effect when it can be converted to JA or one of its metabolites (Zhang \& Turner. 2008). AtOPR2 and AtOPR3 functioning in the conversion of OPDA to JA is consistent with the biochemical analyses done by Chini et al. (2018). The function of the remaining Arabidopsis OPR-protein AtOPR1 has so far not been revealed, and thus might also involve a conversion of OPDA. We included the opr2-7/opr3-3 double mutant, because it is deficient in the synthesis of all compounds downstream of OPDA (Schulze et al.. 2019). Additionally, opr7-7/opr2-7/opr3-3 triple mutants were unavailable, as they cannot be obtained by crossing due to AtOPR1 and AtOPR2 being contiguous genes (Chini et al., 2018). Taken together, the altered susceptibility of the opr2-7 mutant plants to M. incognita may involve an accumulation of the JA precursor 4,5-ddh-JA, hereby disrupting local jasmonate biosynthesis in nematode-infected roots.

Our data further showed that AtOPR2 and AtOPR3 non-redundantly alter Arabidopsis susceptibility to M. incognita. Mutations in either AtOPR2 or AtOPR3 cause a similar increase of susceptibility to M. incognita at seven days post inoculation. We also observed a significantly larger increase in susceptibility for the opr2/opr3 double mutant than for either of the single mutants. These results suggest an additive effect of the AtOPRs in Arabidopsis susceptibility to M. incognita, possibly by higher levels of 4,5-ddh-JA in the opr2-7 mutant or higher levels of OPDA in de opr3-3 mutant.

In contrast, Arabidopsis opr3-7 mutant plants did not differ in their susceptibility to the rootknot nematode M. hapla at 14 days post inoculation (Gleason et al. 2016). However, there are ample reasons in experimental conditions to explain the seemingly contrasting results. First, it is impossible to directly compare plant susceptibility to M. hapla and M. incognita. For example, the resistance genes $\mathrm{Mi}-7$ in tomato and $\mathrm{MeT}, \mathrm{Me} 3$, and $\mathrm{N}$ in pepper are functional against M. incognita, but not against M. hapla (Hallmann \& Meressa, 2018). Second, Gleason et al. (2016) used a different timepoint and method by quantifying M. hapla galls at 14 dpi, while we stained the M. incognita juveniles at $7 \mathrm{dpi}$. Additionally, their use of the conditional opr3-7 mutant line in Wassilewskija background has been found to produce full-length AtOPR3 transcripts under certain conditions (Chehab et al., 2011).

In Arabidopsis plants, the PAMP-triggered immunity (PTI) response induced by the bacterial elicitor flg22 occurs independently of AtOPR2. We found that both flg22-induced ROS-pro- 
duction in leaves and root-growth inhibition was not affected in the opr2-7 mutant. PTI can be triggered via activation of surface-localized pattern recognition receptors by recognition of either pathogen- or damage-associated molecular patterns (Macho \& Zipfel, 2014: Mott et al., 2017). For example, plant elicitors as oligogalacturonides (OGs) can induce similar signaling pathways as flg22, even though they are detected by different receptors (Denoux et al., 2008). (Mendy et al., 2017). In contrast to our results, silencing of StOPR3 in potato resulted in a highly reduced accumulation of reactive oxygen species by PAMP-triggered immunity (PTI) (Halim et al., 2009). However, the observation that opr2-7 mutant and wild type Arabidopsis plants responded similarly to flg22 suggests that AtOPR2 is most likely not involved in immune signaling directly up- or downstream of pattern-recognition receptors.

In our experiments at seven days post inoculation, we found that opr2-7, opr3-3, and the opr2-7/opr3-3 double mutant plants harbored a significantly higher number of juveniles of M. incognita, but not of $\mathrm{H}$. schachtii, when compared to wild-type Arabidopsis plants. As this shows the specificity of the response and a role of AtOPR2 in Arabidopsis susceptibility to $M$. incognita, we expect AtOPR2 functioning in one of the three main plant-associated nematode life phases where cyst and root-knot nematodes differ, i.e. host attraction, host invasion, and/ or feeding site formation.

First, root-knot nematodes prefer different plant exudates than cyst nematodes to identify a suitable host plant, and the AtOPRs could therefore affect the attraction of $M$. incognita and not H. schachtii. For example, M. incognita 32 were repelled by root exudates and root extracts of three different host plants, while they were attracted to root tips of the same plant species (Wang et al..2018). In the same study, Wang et al. (2018) show that the cyst nematode $H$. glycines was attracted to the whole root exudates and extracts of all three plant species. The main phytohormone influencing $H$. schachtii attraction in Arabidopsis roots is ethylene, while MeJA addition has no significant effect on nematode attraction (Kammerhofer et al., 2015). For M. incognita, MeJA has a direct nematicidal effect (Schouteden et al., 2017) as well as an indirect effect by inducing resistance (Fujimoto et al., 2011). A potential cause of less root attraction could lie in plant-derived ascarosides (Manohar et al., 2020). The nematode-derived version of ascarosides functions as a root-knot nematode pheromone and can be recognized in plants as nematode-associated molecular patterns (Manosalva et al., 2015). Similar to the AtOPR2-independent biosynthesis of JA, the production of active plant-derived ascarosides is dependent on $\beta$-oxidation enzymes such as ACX (Dave \& Graham, 2012; Manohar et al., 2020). Therefore, one hypothesis would be that $M$. incognita reduces plant ascaroside metabolism by blocking the AtOPR2-dependent pathway and funneling all JA-biosynthesis via AtOPR3 and $\beta$-oxidation (Figure 9). Possibly, H. schachtii has a different tactic than M. incognita to reduce plant ascaroside metabolism, which would explain the observed plant susceptibility differences. Taken together, we expect an altered host attraction to be a viable cause of the increased susceptibility to $M$. incognita but not $H$. schachtii.

Whereas root-knot nematodes exhibit a stealthy and nondestructive intercellular migration 
(Wyss \& Grundler, 1992; Williamson \& Gleason, 2003; Abad \& Williamson, 2010), cyst nematodes migrate intracellular (Marhavý et al., 2019). Jasmonates play an important role in regulating plant responses to damage in nematode-infected roots of Arabidopsis (Zhou et al., 2019). We therefore reasoned that the increase in susceptibility of the opr2-7 mutant to $M$. incognita may be caused by reduced damage-triggered host defenses. Because of this additional damage by $H$. schachtii, we expected the OPR-mutants to be hypersusceptible to this species if opr2-7 is indeed involved in DAMP-triggered immunity. However, as the AtOPR-mutants do not show any altered susceptibility to $H$. schachtii, this hypothesis is not likely to be true. Interestingly, the hormonal regulation of plant defenses in Arabidopsis roots infected with $\mathrm{H}$. schachtii is structurally different from M. incognita infected roots. Infections by M. incognita involve the downregulation of both SA- and JA-associated genes, while infections by H. schachtii mainly involve alterations in SA signaling (Hamamouch et al., 2011). Likewise, expression of the Arabidopsis cell wall receptor protein PGIP during migratory phases is induced near the head of H. schachtii, but not of M. incognita (Shah et al., 2017). Host invasion by M. incognita is much more affected by defects in Casparian strips compared to H. schachtii (Holbein et al., 2019).

Another major difference between the M. incognita and $H$. schachtii life cycles is feeding site formation, where root-knot nematodes transform four to eight cells to giant cells by repeated rounds of nuclear division and cell growth without cytokinesis. Cyst nematodes select only one cell to transform to a syncytium by the breakdown of plant cell walls and subsequent fusion of adjacent protoplasts (Kyndt et al., 2013). We suspect that feeding site formation is not necessary applicable to our observed $7 \mathrm{dpi}$ increase in nematode numbers in the AtOPR mutants, as this number does not yet depend on feeding site initiation. Taken together, we propose a model based on two possible scenario's (Figure 9). In the most obvious main scenario, opr2-7 mutants contain altered levels of 4,5-ddh-JA, JA and JA-lle which likely makes Arabidopsis roots more attractive or easier to invade. In an alternative indirect scenario, absence of the AtOPR2-pathway forces JA-biosynthesis to go exclusively via AtOPR3 and $\beta$-oxidation, thereby lowering the availability of $\beta$-oxidation in other plant processes, such as plant metabolism of ascarosides.

\section{Conclusion}

In conclusion, our results suggest that the effector target AtOPR2 regulates susceptibility of Arabidopsis to Meloidogyne incognita. Next to binding the tomato host target SIOPR2 (Chapter 2), the effector MiMSP32 likely inhibits Arabidopsis AtOPR2 to increase host plant susceptibility (Figure 9). AtOPR2 is responsible for an alternative conversion of OPDA into JA by a reduction of 4,5-ddh-JA, while AtOPR3 regulates the dominant JA biosynthesis by a reduction of OPDA. However, if the dominant JA biosynthesis by AtOPR3 remains intact, plant susceptibility is significantly altered by mutation of the alternative AtOPR2-dependent pathway. We expect the opr2-7 mutation to result in an accumulation of the JA precursor 4,5-ddh-JA, as represented by the model we propose. Therefore, it is possible that the increased susceptibility of opr2-7 mutant plants is caused by elevated levels of 4,5-ddh-JA, suggesting a new role for 4,5-ddh-JA in Arabidopsis susceptibility to M. incognita. 


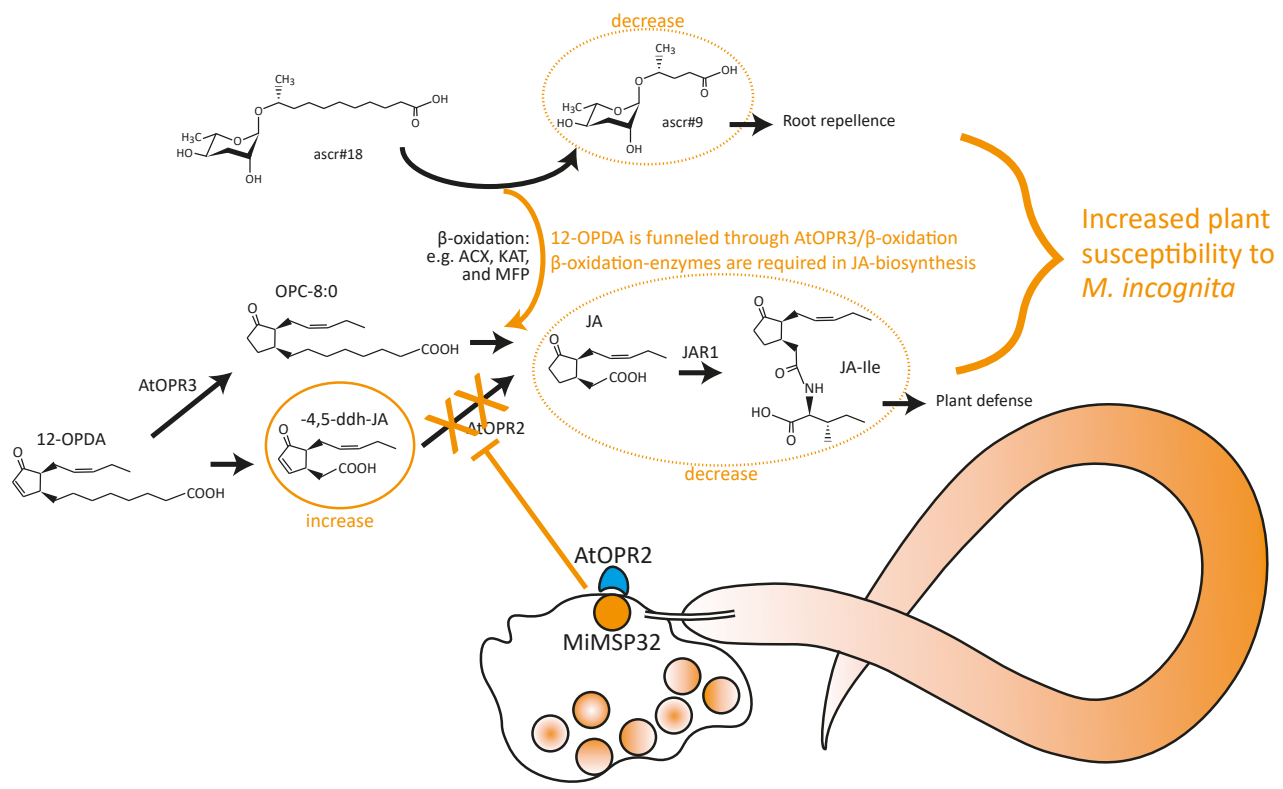

Figure 9. Hypothetical model showing how M. incognita uses the effector MiMSP32 to inhibit the host target AtOPR2 and increase host plant susceptibility. In wild-type Arabidopsis plants, AtOPR2 functions in the conversion of -4,5-ddh-JA to JA and JA-Ile. The inhibition of AtOPR2 likely results in an accumulation of -4,5-ddh-JA and decreases the concentration of JA and JA-Ile, resulting in an increased plant susceptibility to $M$. incognita. In an alternative indirect scenario, absence of the AtOPR2-pathway forces JA-biosynthesis to go exclusively via AtOPR3 and $\beta$-oxidation, thereby lowering the availability of $\beta$-oxidation for ascaroside metabolism, resulting in a higher root attraction to M. incognita.

\section{Material and Methods}

\section{Nematode surface sterilization}

Meloidogyne incognita eggs (strain 'Morelos' from INRA, Sophia Antipolis, France) were obtained from infected tomato plants (Solanum lycopersicum L. CV. MoneyMaker) as described previously (Warmerdam et al., 2018). In short, roots of infected tomato plants were rinsed in water to remove sand particles ten weeks after inoculation and eggs were extracted by incubation in 0.05\% (V/V) bleach for 3 min followed by sieving (Hussey \& Barker, 1973). Cysts of Heterodera schachtii (Woensdrecht population from IRS, the Netherlands) were obtained from infected rapeseed plants (various susceptible cultivars of Brassica napus) and extracted by sieving. Eggs and cysts were disinfected using $0.02 \%$ sodium azide $\left(\mathrm{NaN}_{3}\right)$ for 20 min and washed thoroughly with tap water. Hatching took place at room temperature in the dark on a $25 \mathrm{~mm}$ hatching sieve with $1.5 \mathrm{mg} / \mathrm{ml}$ gentamycin and $0.05 \mathrm{mg} / \mathrm{ml}$ nystatin. For H. schachtii, $3 \mathrm{mM}$ zinc chloride was added to the hatching solution. After four days, J2s were collected by separation on a $70 \%$ sucrose column and sterilized by incubation for $10 \mathrm{~min}$ in $0.002 \%(\mathrm{~V} / \mathrm{V})$ Triton $\mathrm{X}-100,0.004 \%(\mathrm{w} / \mathrm{V}) \mathrm{NaN}_{3}$ and $0.004 \%$ (w/V) mercury chloride. After surface sterilization, nematodes were rinsed in sterile tap water three times before use and transferred to a $0.7 \%$ (w/v) Gelrite solution (Duchefa Biochemie, Haarlem). 


\section{Arabidopsis}

Arabidopsis seeds were obtained from T-DNA mutant lines of the following genes: At5g04930; SALK_002106C (ala7-7), SALK_056947C (ala7-2), At7g76690C; SALK_116381C (opr2-7), At4920850; SALK_085776C (tppll-2), Atlg63210; SALK_131654C (spt6-7) from the European Arabidopsis Stock (Alonso et al., 2003). Additionally, seeds from a functional med8 mutant line were obtained (M7; AT2C03070) from Kooke et al. (2019). The Saskatoon insertion line opr3-3 (SK24765) (Robinson et al. 2009) and opr2-7/opr3-3 double mutants were provided by Chini et al. (2018). All above-mentioned plant lines are in the same Col-O (N60000) genetic background, which was also used as a wild-type Arabidopsis line. Seeds were propagated by selfing and MeJA addition for the opr3-3 and opr2-7/opr3-3 mutant lines as described (Chini et al., 2018). Homozygosity of selected T-DNA insertion lines was confirmed by PCR (Supplemental Figure S1) using primer pairs WT1:M5 (Supplemental Table S1). Homozygosity of opr2-7, opr3-3 and opr2-7/opr3-3 insertion lines without cross-contamination was likewise confirmed by PCR (Supplemental Figure S5), by using both primer combinations for an insertion at the opr3-3 and opr2-7 position for the single and double mutant (see primer pairs WT3, M3, WT6 \& M6 in Supplemental Table S1). All plant lines contained the correct insertions, although a non-specific by-product slightly smaller than the expected PCR-product was visible in all samples for the opr3-3 insertion check.

All Arabidopsis seeds were vapor-sterilized for four hours in $0.7 \mathrm{M}$ sodium hypochlorite and 1\% hydrogen chloride before sowing in plates containing the appropriate medium. Seed were stratified for at least three days at $4{ }^{\circ} \mathrm{C}$.

\section{Susceptibility to nematodes}

Arabidopsis seeds were stimulated to germinate at $24^{\circ} \mathrm{C}$ under a $16 \mathrm{~h}$ light, $8 \mathrm{~h}$ dark regime on MS20 medium (4.7 g/L Murashige and Skoog (MS) with vitamins (Duchefa Biochemie), 20 g/L sucrose, pH 6.4, 0.7\% Gelrite (Duchefa Biochemie)). After six days, individual plants were transferred to fresh six-well culture plates and allowed to grow and settle for an additional seven days, after which they were inoculated with 180 infective J2s of M. incognita per plant (Warmerdam et al.. 2018). The root tips were counted at the day of inoculation to compare root architecture. Nematode-containing 6 -well plates were incubated at $24^{\circ} \mathrm{C}$ under dark conditions for the duration of the bioassay.

To assess susceptibility of mutant lines to cyst nematodes, Arabidopsis seeds were germinated on KNOP-medium (Sijmons et al., 1991) at $21{ }^{\circ} \mathrm{C}$ under a $16 \mathrm{~h}$ light, $8 \mathrm{~h}$ dark regime for five days. Next, young seedlings were transferred to individual wells of fresh twelve-well culture plates. Individual plants were allowed to grow and settle for an additional seven days, after which they were inoculated with 250 infective $\mathrm{H}$. schachtii juveniles per plant. Plates were kept at $21^{\circ} \mathrm{C}$ under a $16 \mathrm{~h}$ light, $8 \mathrm{~h}$ dark regime during the bioassay.

The number of nematodes inside the roots was counted at seven days after inoculation by means of acid fuchsin staining on the whole root system. Therefore, clean roots were incubated 
for 5 min in 2.5\% household bleach followed by rinsing for 10 min in tap water. Next, roots were incubated in fuchsin staining solution (0.2 M acid fuchsin and $0.8 \%$ glacial acetic acid in tap water) for 30 seconds in a microwave oven at maximum power. Finally, roots were transferred to $40 \%$ glycerol and nematodes could be counted visually using a dissection microscope.

Counting data was collected in at least two independent experiments with $n \geq 16$ and combined for statistical analysis and visualization. To correct for possible fluctuations of nematode virulence throughout the year, the number of nematodes per independent experiment was normalized. Therefore, the number of nematodes was corrected based on average of the Col-O control line in an independent experiment against the total average over all Col-O measurements using

$$
T_{\text {norm }}=T_{i}-\left(\bar{T}_{i, \text { Col-o }}-\bar{T}_{\text {total }, \text { Col-o }}\right)
$$

where $T_{\text {norm }}$ is the normalized number of nematodes, $i$ is the individual experiment and $\bar{T}$ is the averaged number.

\section{Data analysis of plant traits}

Trait data for nematode numbers, root tip numbers, relative light units and root length was analyzed in $\mathrm{R}$ version 3.6.1. $\times 64$ Extreme outliers in the dataset outside the interquartile range of 1.5 were removed (Vinutha et al., 2018). Normality was checked using qq-plots from the ggpubr package and statistical comparison was done using either an ANOVA analysis with Tukey's HSD or Students t-tests, depending on the number of treatments or plant lines. Data visualization was done using the ggplot2 package (Wickham, 2016).

\section{Plasmid construction}

Arabidopsis thaliana Col-O plants of four weeks old were harvested and immediately snap-frozen in liquid nitrogen. Extraction of RNA was performed using the Maxwell 16 LEV-plant RNA kit (Promega, Madison) following the manufacturer's protocol. Samples were converted to cDNA using GoScript Reverse Transcriptase and the AtOPR2 transcript without a stop codon was amplified with HiFi PCR Premix (Takara Bio, Kusatsu) according to manufacturer's protocols with primer pair AtOPR2_FL (Supplemental Table S1). Likewise, the mCherry-reporter gene (mCh) (Shaner et al., 2004) was amplified with primer pair mCh_FL (Supplemental Table S1). The genes were first subcloned into PCR ${ }^{\mathrm{TM}}$ 2.1-TOPO ${ }^{\circledR}$ TA vector using a TOPO ${ }^{\circledR}$ TA Cloning ${ }^{\circledR}$ Kit for Subcloning (Invitrogen, Carlsbad). Both fragments were fused using recombinant In-Fusion cloning (Takara Bio) (Park et al., 2015) and ligated into the restriction sites Ncol and Nhel of pRAP35S:_MYC4:tnos backbone (Schouten et al., 1997) to obtain pRAP35S:AtOPR2_mCh MYC4:tnos. The 35S:AtOPR2_mCh_MYC4:tnos insert was subsequently subcloned by using Ascl and Pacl restriction sites into the pBIN+ vector (van Engelen et al., 1995). Binary plasmids were introduced by electroporation (Neumann et al., 1982) in Agrobacterium tumefaciens GV3101 cells (harboring the pSOUP helper plasmid).

\section{Agrobacterium tumefaciens leaf infiltration}

Transient expression in Nicotiana benthamiana was done by culturing Agrobacterium tume- 
faciens in LB medium (10 g/L peptone, $5 \mathrm{~g} / \mathrm{L}$ yeast, $10 \mathrm{~g} / \mathrm{L} \mathrm{NaCl}$ ) with $50 \mathrm{mg} / \mathrm{L}$ kanamycin and $20 \mathrm{mg} / \mathrm{L}$ rifampicin for 16 hours at $28^{\circ} \mathrm{C}$ (Wilbers et al., 2017). Bacteria were pelleted by centrifugation and resuspended in MMAi infiltration medium (5 g/L Murashi-Skoog salts, $1.95 \mathrm{~g} / \mathrm{L}$ MES, $20 \mathrm{~g} / \mathrm{L}$ sucrose, $\mathrm{pH}$ 5.6, $200 \mu \mathrm{M}$ acetosyringone) and incubated at room temperature for 1-2 hours. Agroinfiltration was done with the bacterial suspensions having an optical density (OD600) set at 0.5 for each construct. Bacterial suspensions were infiltrated in the apoplast of a N. benthamiana leaf using a $1 \mathrm{ml}$ syringe without needle. Leaves were harvested at 48 hours post inoculation.

\section{Protein extraction and co-immunoprecipitation}

Leaf material from different plants was frozen in liquid nitrogen and grinded using a $5.6 \mathrm{~mm}$ metal ball in a Tissuelyzer II for two times 1 min at $15 \mathrm{~Hz}$ (Qiagen, Hilden). Total protein was extracted from $100 \mathrm{mg}$ of leaf material by homogenizing it with ice-cold extraction buffer (150 mM NaCl, 50 mM Tris- $\mathrm{HCl}, \mathrm{pH}$ 7.5, 1 mM ethylenediaminetetraacetic acid, 10\% glycerol, 10 mM dithiothreitol, 2\% polyclar-AT polyvinylpolypyrrolidone (Serva, Heidelberg), and 0.5 mg/ $\mathrm{ml}$ pefabloc SC protease inhibitor (Hoffmann-La Roche, Bazel)). After spinning down the cell debris, the supernatant was desalted by passing over a Sephadex G-25 column (GE Healthcare, Chicago). Protein extract was first mixed with $50 \mu \mathrm{l}$ rabbit-lgG agarose (Sigma-Aldrich, Saint Louis) and incubated with $50 \mu \mathrm{l}$ anti-HA microbeads. Co-immunoprecipitation was done with separation columns from $\mu$ MACS Epitope Tag Protein isolation kit (Miltenyi Biotec, Bergisch Gladbach) according to manufacturer's instructions. Soluble fractions were analyzed by SDS-PAGE on a 12\% Bis-Tris gel (Invitrogen) and proteins were subsequently transferred to a PVDF membrane for Western blotting (Thermo Fisher, Waltham). Protein bands were visualized with either horseradish peroxidase-conjugated rat anti-HA antibody (Hoffmann-La Roche) or with a primary goat anti-MYC antibody (Abcam, Cambridge) and a horseradish peroxidase-conjugated secondary antibody of donkey anti-goat (Jackson ImmunoResearch, Ely). SuperSignal West 1:1 Femto-Dura substrate (Thermo Fisher) was used to detect horseradish peroxidase-conjugated antibodies in the G:BOX Chemi System (Syngene, Bangalore). To confirm equal protein loading, membranes were stained with Coomassie Brilliant Blue (CBB).

\section{Whole transcriptome analysis by RNA-Seq}

Four replicates, each consisting of six individual opr2-7 mutant or wild-type Col-0 root systems were sampled at $0,1,4$, and 7 days after inoculation with $M$. incognita or mock inoculation. Whole root systems were carefully removed from MS2O medium containing culture plates and immediately snap-frozen in liquid nitrogen. Extraction of RNA was performed using the Maxwell 16 LEV-plant RNA kit (Promega) following the manufacturers protocol. RNA-Seq and quality filtering was done using BGISEQ-500 at BGI TECH SOLUTIONS (Hongkong), providing at least 40 million clean paired-end reads of 100 bp per sample. The reads from all 56 samples were mapped onto the annotated genome sequences of both $M$. incognita (PRJEB8714) (Blanc-Mathieu et al.. 2017) and A. thaliana (TAIR10) (Lamesch et al.. 2011) using HISAT2 v2.2.0 in downstream-transcriptome-assembly mode (Kim et al., 2019). Gene expression for M. incognita and A. thaliana was quantified and TPM-normalized by assembling RNA-Seq alignments 
into transcripts, guided by reference annotations using StringTie v2.1.2 (Pertea et al., 2015). Before analysis, the TPM values were filtered and transformed. First, the Arabidopsis gene-expression was filtered for read detection of $\log _{2}>1.3$ in all samples This filter resulted in 9483 detected genes (out of 27655 protein coding genes in the assembly). For M. incognita, gene-expression was filtered for read detection in at least $50 \%$ of the 24 infected samples. This filter resulted in 15426 detected genes (out of 43718 protein coding genes in the assembly). This more relaxed threshold was chosen because of the low-coverage of $M$. incognita reads. subsequently, the TPM values were transformed by

$$
T P M_{\text {log, }, i j}=\log _{2}\left(T P M_{i j}+1\right)
$$

where $T P M_{\text {log }}$ was the $\log _{2}$-normalized TPM value of gene $i$ (one out of 9483 for Arabidopsis and 15426 for M. incognita) and sample j (one out of 56 samples for Arabidopsis and 24 for $M$. incognita).

For principal component and correlation analysis, a ratio was also calculated with the mean of the TPM, by

$$
T P M_{\text {ratio }, i j}=\log _{2}\left(\frac{T P M_{i j}}{T P M_{i,}}\right)
$$

where TPM ratio was the $\log _{2}$ of the TPM value of gene $i$ (one out of 9483 for Arabidopsis and 15426 for M. incognita) and sample $j$ (one out of 56 samples for Arabidopsis and 24 for $M$. incognita), divided by the average TPM value over all samples for gene $i$. To understand the sources of variance in the expression data, principal component analyses were made with the

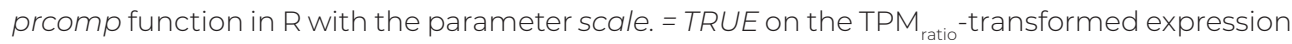
data (both for Arabidopsis and M. incognita). Likewise, correlation matrices were made on the TPM $_{\text {ratio }}$-transformed expression data (both for Arabidopsis and M. incognita) with cor and the heatmap function in $\mathrm{R}$.

Statistical analysis was done in $\mathrm{R}$ version 3.6.1. x64 using the $\log _{2}$-normalized TPM values in an interaction model ran for dpi 1, 4 and 7 separately with plant genotype and $M$. incognita infection as variables, using the formula

$$
T P M_{\text {log }, i}=T_{j}+I_{j}+T_{j} \times I_{j}
$$

in a linear model. Where the gene-expression $T P M_{\text {log }}$ of gene $i$ was explained over time $T$ and infection status $/$ and the interaction $T \times /$ of sample $j$. The obtained significances were corrected using a Benjamini-Hochberg adjustment for multiple testing (provided by the prcomp function).

\section{Release of reactive oxygen species (ROS)}

Non-sterile Arabidopsis seeds were sown $5 \times 5 \mathrm{~cm}$ square pots containing soil and incubated for four weeks at $21{ }^{\circ} \mathrm{C}$ under a $16 \mathrm{~h}$ light and $8 \mathrm{~h}$ dark regime. Leaf disks of $6 \mathrm{~mm}$ in diameter were collected from the Arabidopsis plants with metal cork bore and incubated individually with the abaxial surface in $100 \mu$ sterile tap water in a white 96-wells plate. After 16 hours, water was removed a sample solution of $100 \mu \mathrm{l}$ tap water containing $0.5 \mathrm{mM}$ 8-Amino-5-chloro-2,3-dihy- 
dro-7-phenyl-pyrido[3,4-d] pyridazine sodium salt (L-012, FUJIFILM Wako Chemicals Europe $\mathrm{GmbH}$, Neuss), $10 \mathrm{mg} \mathrm{ml}^{-1}$ horseradish peroxidase and $100 \mu \mathrm{M}$ of the synthetic flg22 peptide (QRLSTGSRINSAKDDAAGLQIA) or a water control was added to the individual wells shortly before measuring the luminescence. Relative light units were measured in a CLARIOstar Plus plate reader (BMG labtech, Ortenberg) over $120 \mathrm{~min}$.

\section{Root growth inhibition}

Arabidopsis seeds were stimulated to germinate on MS-medium for four days at $21^{\circ} \mathrm{C}$ under a $16 \mathrm{~h}$ light and $8 \mathrm{~h}$ dark regime. Seedling were transferred to square Petri dishes containing 24 $\mathrm{mL}$ of MS2O medium supplemented with filter-sterilized components. For the phytohormone treatments, either $0.5 \mu \mathrm{M}$ methyl jasmonate (MeJA; Sigma-Aldrich), 0.5 MM 12-oxophytodienoic acid (OPDA; Cayman Chemical Company, Ann Arbor), or the dissolvent 96\% ethanol was supplemented. For the flg22 treatments, either $0.5 \mu \mathrm{M}$ flg22, or sterile MQ was supplemented. On every square Petri dish, three individual plants of all four plant genotypes opr2-7, opr3-3, opr2-7/opr3-3 and wild-type Col-O were added to diminish any plate-effects. After three days of vertical growing on the plates with supplemented media, the root systems were analyzed using root scans and WinRHIZO software (Regent Instruments, Québec).

\section{Acknowledgements}

This work was financially supported by the Dutch Research Council (NWO) Domain Applied and Engineering Sciences (AES/TTW) grant 11042. M.G.S. was supported by NWO domain Applied and Engineering Sciences VENI grant (17282). The authors would like to thank Unifarm of Wageningen University and Research for support with plant material. We are also grateful for the technical assistance from C. van Schaik, H. Overmars, T. Neefjes, S. Put, S. Blom, Y. Yang, T. Wesselink, and W. Tacken. We wish to thank R. Solano and A. Chini for the opr3-3 and opr2-7/ opr3-3 seeds and J. Keurentjes and F. Becker for the med8 seeds. The authors declare no conflict of interest.

\section{Author contributions}

A.V. and G.S. conceived and designed the experiments. A.V. performed the experiments. A.V, M.G.S. \& J.V.S. analysed the data and A.V., M.G.S., A.G. and G.S. wrote the paper. All authors edited and approved the final chapter.

\section{References}

Abad P, Gouzy J, Aury J-M, Castagnone-Sereno P, Danchin EGJ, Deleury E, Perfus-Barbeoch L, Anthouard V, Artiguenave F, Blok VC, et al. 2008. Genome sequence of the metazoan plant-parasitic nematode Meloidogyne incognita. Nature biotechnology 26(8): 909-915.

Abad P, Williamson VM. 2010. Plant nematode interaction: a sophisticated dialogue. Advances in Botanical Research 53 : 147-192.

Alonso JM, Stepanova AN, Leisse TJ, Kim CJ, Chen H, Shinn P, Stevenson DK, Zimmerman J, Barajas P, Cheuk R, et al. 2003. 
Genome-wide insertional mutagenesis of Arabidopsis thaliana. Science 301(5633): 653-657.

Bebber DP, Holmes T, Gurr SJ. 2014. The global spread of crop pests and pathogens. Global Ecology and Biogeography 23(12): 1398-1407.

Bhattarai KK, Xie Q-G, Mantelin S, Bishnoi U, Girke T, Navarre DA, Kaloshian I. 2008. Tomato susceptibility to root-knot nematodes requires an intact jasmonic acid signaling pathway. Molecular Plant-Microbe Interactions 21(9): 1205-1214.

Blanc-Mathieu R, Perfus-Barbeoch L, Aury J-M, Da Rocha M, Gouzy J, Sallet E, Martin-Jimenez C, Bailly-Bechet M, Castagnone-Sereno P, Flot J-F, et al. 2017. Hybridization and polyploidy enable genomic plasticity without sex in the most devastating plant-parasitic nematodes. PLoS Genetics 13(6): el006777.

Chehab EW, Kim S, Savchenko T, Kliebenstein D, Dehesh K, Braam J. 2011. Intronic T-DNA insertion renders Arabidopsis opr3 a conditional jasmonic acid-producing mutant. Plant Physiology 156(2): 770-778.

Chini A, Monte I, Zamarreño AM, Hamberg M, Lassueur S, Reymond P, Weiss S, Stintzi A, Schaller A, Porzel A, et al. 2018. An OPR3-independent pathway uses 4,5-didehydrojasmonate for jasmonate synthesis. Nature Chemical Biology 14: 171.

Dave A, Graham I. 2012. Oxylipin signaling: A distinct role for the jasmonic acid precursor cis-(+)-12-oxo-phytodienoic acid (cis-OPDA). Frontiers in plant science 3(42).

Denoux C, Galletti R, Mammarella N, Gopalan S, Werck D, De Lorenzo G, Ferrari S, Ausubel FM, Dewdney J. 2008. Activation of defense response pathways by OGs and flg22 elicitors in Arabidopsis seedlings. Molecular plant 1(3): 423-445.

Fan J, Wang X, Sun Z, Zhou X. 2018. Membrane asymmetry and phospholipid translocases in eukaryotic cells. In: Cao Y ed. Advances in Membrane Proteins: Part l: Mass Processing and Transportation. Singapore: Springer Singapore, 47-76.

Felix G, Duran JD, Volko S, Boller T. 1999. Plants have a sensitive perception system for the most conserved domain of bacterial flagellin. The Plant Journa/ 18(3): 265-276.

Fujimoto T, Tomitaka Y, Abe H, Tsuda S, Futai K, Mizukubo T. 2011. Expression profile of jasmonic acid-induced genes and the induced resistance against the root-knot nematode (Meloidogyne incognita) in tomato plants (Solanum lycopersicum) after foliar treatment with methyl jasmonate. Journal of plant physiology 168(10): 1084-1097.

Gheysen G, Mitchum MG. 2011. How nematodes manipulate plant development pathways for infection. Current opinion in plant biology 14(4): 415-421.

Gheysen G, Mitchum MG. 2019. Phytoparasitic nematode control of plant hormone pathways. Plant Physiology. pp.01067.02018.

Gleason C, Leelarasamee N, Meldau D, Feussner I. 2016. OPDA has key role in regulating plant susceptibility to the root-knot nematode Meloidogyne hapla in Arabidopsis. Frontiers in plant science 7(1565).

Grasser KD. 2005. Emerging role for transcript elongation in plant development. Trends in Plant Science 10(10): 484-490.

Haegeman A, Mantelin S, Jones JT, Gheysen G. 2012. Functional roles of effectors of plant-parasitic nematodes. Gene 492(1): 19-31.

Halim VA, Altmann S, Ellinger D, Eschen-Lippold L, Miersch O, Scheel D, RosahI S. 2009. PAMP-induced defense responses in potato require both salicylic acid and jasmonic acid. The Plant Journa/ 57(2): 230-242.

Hallmann J, Meressa BH. 2018. Nematode parasites of vegetables. In: Sikora RA, Coyne D, Hallmann J, Timper P eds. Plant Parasitic Nematodes in Subtropical and Tropical Agriculture, 346.

Hamamouch N, Li C, Seo PJ, PARK CM, Davis EL. 2011. Expression of Arabidopsis pathogenesis-related genes during nematode infection. Molecular Plant Pathology 12(4): 355-364

Holbein J, Franke RB, Marhavý P, Fujita S, Górecka M, Sobczak M, Geldner N, Schreiber L, Grundler FMW, Siddique S. 2019. Root endodermal barrier system contributes to defence against plant-parasitic cyst and root-knot nematodes. The Plant Journal 100(2): 221-236.

Huang G, Dong R, Allen R, Davis EL, Baum TJ, Hussey RS. 2006. A root-knot nematode secretory peptide functions as a ligand for a plant transcription factor. Molecular Plant-Microbe Interactions 19(5): 463-470.

Huang G, Gao B, Maier T, Allen R, Davis EL, Baum TJ, Hussey RS. 2003. A profile of putative parasitism genes expressed in the esophageal gland cells of the root-knot nematode Meloidogyne incognita. Molecular Plant-Microbe Interactions 16(5): 376-381.

Hussey RS, Barker KR. 1973. Comparison of methods of collecting inocula of Meloidogyne spp., including a new technique. Plant disease reporter.

Ji H, Gheysen G, Denil S, Lindsey K, Topping JF, Nahar K, Haegeman A, De Vos WH, Trooskens G, Van Criekinge W. 2013. Transcriptional analysis through RNA sequencing of giant cells induced by Meloidogyne graminicola in rice roots. Journal of experimental botany 64(12): 3885-3898.

Jones JT, Haegeman A, Danchin EG, Gaur HS, Helder J, Jones MG, Kikuchi T, Manzanilla-López R, Palomares-Rius JE, Wesemael WM. 2013. Top 10 plant-parasitic nematodes in molecular plant pathology. Molecular Plant Pathology 14(9): 946-961.

Kammerhofer N, Radakovic Z, Regis J, Dobrev P, Vankova R, Grundler FM, Siddique S, Hofmann J, Wieczorek K. 2015. Role of stress-related hormones in plant defence during early infection of the cyst nematode Heterodera schachtii in Arabidopsis. 
New Phytologist 207(3): 778-789.

Kidd BN, Edgar Cl, Kumar KK, Aitken EA, Schenk PM, Manners JM, Kazan K. 2009. The mediator complex subunit PFT1 is a key regulator of jasmonate-dependent defense in Arabidopsis. The Plant Ce// 21(8): 2237-2252.

Kim D, Paggi JM, Park C, Bennett C, Salzberg SL. 2019. Graph-based genome alignment and genotyping with HISAT2 and HISAT-genotype. Nature biotechnology 37(8): 907-915.

Kooke R, Morgado L, Becker F, van Eekelen H, Hazarika R, Zheng Q, de Vos RCH, Johannes F, Keurentjes JJB. 2019. Epigenetic mapping of the Arabidopsis metabolome reveals mediators of the epigenotype-phenotype map. Genome research 29 96-106.

Kyndt T, Vieira P, Gheysen G, de Almeida-Engler J. 2013. Nematode feeding sites: unique organs in plant roots. Planta 238(5): 807-818

Lamesch P, Berardini TZ, Li D, Swarbreck D, Wilks C, Sasidharan R, Muller R, Dreher K, Alexander DL, Garcia-Hernandez M, et al. 2011. The Arabidopsis Information Resource (TAIR): improved gene annotation and new tools. Nucleic acids research 40(D1): D1202-D1210.

Li X, Yang R, Chen H. 2018. The Arabidopsis thaliana Mediator subunit MED8 regulates plant immunity to Botrytis Cinerea through interacting with the basic helix-loop-helix (bHLH) transcription factor FAMA. PLOS ONE 13(3): e0193458.

Macho Alberto P, Zipfel C. 2014. Plant PRRs and the activation of innate immune signaling. Molecular Cel/ 54(2): $263-272$.

Madeira F, Park YM, Lee J, Buso N, Gur T, Madhusoodanan N, Basutkar P, Tivey ARN, Potter SC, Finn RD, et al. 2019. The EMBL-EBI search and sequence analysis tools APIs in 2019. Nucleic acids research 47(W1): W636-W641.

Manohar M, Tenjo-Castano F, Chen S, Zhang YK, Kumari A, Williamson VM, Wang X, Klessig DF, Schroeder FC. 2020. Plant metabolism of nematode pheromones mediates plant-nematode interactions. Nature Communications 11(1): 208

Manosalva P, Manohar M, von Reuss SH, Chen S, Koch A, Kaplan F, Choe A, Micikas RJ, Wang X, Kogel K-H, et al. 2015. Conserved nematode signalling molecules elicit plant defenses and pathogen resistance. Nature Communications 6: 7795.

Marhavý P, Kurenda A, Siddique S, Dénervaud Tendon V, Zhou F, Holbein J, Hasan MS, Grundler FMW, Farmer EE, Geldner N. 2019. Single-cell damage elicits regional, nematode-restricting ethylene responses in roots. The EMBO journal 38(10): el00972.

Matsuda J, Okabe S, Hashimoto T, Yamada Y. 1991. Molecular cloning of hyoscyamine 6 beta-hydroxylase, a 2-oxoglutarate-dependent dioxygenase, from cultured roots of Hyoscyamus niger. Journal of Biological Chemistry 266(15): 9460-9464.

Mendy B, Wang'ombe MW, Radakovic ZS, Holbein J, llyas M, Chopra D, Holton N, Zipfel C, Grundler FM, Siddique S. 2017. Arabidopsis leucine-rich repeat receptor-like kinase NILRT is required for induction of innate immunity to parasitic nematodes. PLoS Pathogens 13(4): e1006284.

Monte I, Kneeshaw S, Franco-Zorrilla JM, Chini A, Zamarreño AM, García-Mina JM, Solano R. 2020. An ancient COI7-independent function for reactive electrophilic oxylipins in thermotolerance. Current Biology(30): 1-10.

Mott GA, Guttman DS, Desveaux D. 2017. The study of pattern-triggered immunity in Arabidopsis. Canadian Journal of Plant Pathology 39(3): 275-281.

Mussig C, Biesgen C, Lisso J, Uwer U, Weiler EW, Altmann T. 2000. A novel stress-inducible 12-oxophytodienoate reductase from Arabidopsis thaliana provides a potential link between brassinosteroid-action and jasmonic-acid synthesis. Journal of plant physiology 157(2): 143-152.

Nahar K, Kyndt T, de Vleesschauwer D, Höfte M, Gheysen G. 2011. The jasmonate pathway is a key player in systemically induced defense against root knot nematodes in rice. Plant Physiology 157(1): 305-316.

Neumann E, Schaefer-Ridder M, Wang Y, Hofschneider PH. 1982. Gene transfer into mouse lyoma cells by electroporation in high electric fields. The EMBO journal 1(7): 841-845.

Park J, Throop AL, LaBaer J. 2015. Site-specific recombinational cloning using Gateway and In-Fusion cloning schemes. Current Protocols in Molecular Biology 110(1): 3.20.21-23.20.23

Pertea M, Pertea GM, Antonescu CM, Chang T-C, Mendell JT, Salzberg SL. 2015. StringTie enables improved reconstruction of a transcriptome from RNA-seq reads. Nature biotechnology 33(3): 290-295.

Ribot C, Zimmerli C, Farmer EE, Reymond P, Poirier Y. 2008. Induction of the Arabidopsis PHO1 gene by 12-oxo-phytodienoic acid but not jasmonic acid via a CORONATINE INSENSITIVET-dependent pathway. Plant Physiology 147(2): 696

Robinson SJ, Tang LH, Mooney BAG, McKay SJ, Clarke WE, Links MG, Karcz S, Regan S, Wu Y-Y, Gruber MY, et al. 2009. An archived activation tagged population of Arabidopsis thaliana to facilitate forward genetics approaches. BMC Plant Biology 9: 101 .

Saric T, Graef Cl, Goldberg AL. 2004. Pathway for degradation of peptides generated by proteasomes: a key role for thimet oligopeptidase and other metallopeptidases. Journal of Biological Chemistry 279(45): 46723-46732.

Schaller F, Biesgen C, Müssig C, Altmann T, Weiler EW. 2000. 12-Oxophytodienoate reductase 3 (OPR3) is the isoenzyme involved in jasmonate biosynthesis. Planta 210(6): 979-984

Schouteden N, Lemmens E, Stuer N, Curtis R, Panis B, De Waele D. 2017. Direct nematicidal effects of methyl jasmonate and 
acibenzolar-S-methyl against Meloidogyne incognita. Natural Product Research 31(10): 1219-1222.

Schouten A, Roosien J, de Boer JM, Wilmink A, Rosso M-N, Bosch D, Stiekema WJ, Gommers FJ, Bakker J, Schots A. 1997. Improving scFv antibody expression levels in the plant cytosol 1. FEBS Letters 415(2): 235-241.

Schulze A, Zimmer M, Mielke S, Stellmach H, Melnyk CW, Hause B, Gasperini D. 2019. Wound-induced shoot-to-root relocation of JA-Ile precursors coordinates Arabidopsis growth. Molecular plant 12(10): 1383-1394

Scranton MA, Yee A, Park S-Y, Walling LL. 2012. Plant leucine aminopeptidases moonlight as molecular chaperones to alleviate stress-induced damage. Journal of Biological Chemistry 287(22): 18408-18417.

Seiml-Buchinger VV, Zinovieva SV, Udalova ZV, Matveeva EM. 2018. Jasmonic acid modulates Meloidogyne incognitatomato plant interactions. Brill.

Shah SJ, Anjam MS, Mendy B, Anwer MA, Habash SS, Lozano-Torres JL, Grundler FM, Siddique S. 2017. Damage-associated responses of the host contribute to defence against cyst nematodes but not root-knot nematodes. Journal of experimental botany 68(27-22): 5949-5960.

Shaner NC, Campbell RE, Steinbach PA, Giepmans BNG, Palmer AE, Tsien RY. 2004. Improved monomeric red, orange and yellow fluorescent proteins derived from Discosoma sp. red fluorescent protein. Nature biotechnology 22(12): 1567-1572.

Shi Q, Mao Z, Zhang X, Ling J, Lin R, Zhang X, Liu R, Wang Y, Yang Y, Cheng X, et al. 2018a. The novel secreted Meloidogyne incognita effector MilSE6 targets the host nucleus and facilitates parasitism in Arabidopsis. Frontiers in plant science 9(252).

Shi Q, Mao Z, Zhang X, Zhang X, Wang Y, Ling J, Lin R, Li D, Kang X, Sun W. 2018b. A Meloidogyne incognita effector MilSE5 suppresses programmed cell death to promote parasitism in host plant. Scientific Reports 8(7): 7256

Sijmons PC, Grundler FMW, von Mende N, Burrows PR, Wyss U. 1991. Arabidopsis thaliana as a new model host for plant-parasitic nematodes. The Plant Journal 1(2): 245-254

Stintzi A, Browse J. 2000. The Arabidopsis male-sterile mutant, opr3, lacks the 12-oxophytodienoic acid reductase required for jasmonate synthesis. Proc Natl Acad Sci U S A 97(19): 10625.

Trudgill DL, Blok VC. 2001. Apomictic, polyphagous root-knot nematodes: exceptionally successful and damaging biotrophic root pathogens. Annual review of phytopathology 39(7): 53-77.

Ühlken C, Horvath B, Stadler R, Sauer N, Weingartner M. 2014. MAIN-LIKE 1 is a crucial factor for correct cell division and differentiation in Arabidopsis thaliana. The Plant Journal 78(1): 107-120.

van Engelen FA, Molthoff JW, Conner AJ, Nap J-P, Pereira A, Stiekema WJ. 1995. pBINPLUS: an improved plant transformation vector based on pBIN19. Transgenic Research 4(4): 288-290.

van Schie CCN, Takken FLW. 2014. Susceptibility genes 101: How to be a good host. Annual review of phytopathology 52(1): 551-581.

Vinutha HP, Poornima B, Sagar BM. 2018. Detection of outliers using interquartile range technique from intrusion dataset. In Satapathy SC, Tavares JMRS, Bhateja V, Mohanty JR. Information and Decision Sciences. Singapore: Springer Singapore. 511-518.

Vogel C, Marcotte EM. 2012. Insights into the regulation of protein abundance from proteomic and transcriptomic analyses. Nature Reviews Genetics 13(4): 227-232

Wang C, Masler EP, Rogers ST. 2018. Responses of Heterodera glycines and Meloidogyne incognita infective juveniles to root tissues, root exudates, and root extracts from three plant species. Plant Disease 102(9): 1733-1740.

Warmerdam S, Sterken MG, van Schaik C, Oortwijn ME, Sukarta OC, Lozano-Torres JL, Dicke M, Helder J, Kammenga JE, Goverse A. 2018. Genome-wide association mapping of the architecture of susceptibility to the root-knot nematode Meloidogyne incognita in Arabidopsis thaliana. New Phytologist 218(2): 724-737.

Wickham H. 2016. ggplot2: elegant graphics for data analysis. New York: Springer-Verlag.

Wilbers RH, Westerhof LB, Van Noort K, Obieglo K, Driessen NN, Everts B, Gringhuis SI, Schramm G, Goverse A, Smant G. 2017. Production and glyco-engineering of immunomodulatory helminth glycoproteins in plants. Scientific Reports 7: 45910.

Williamson VM, Gleason CA. 2003. Plant-nematode interactions. Current opinion in plant biology 6(4): 327-333.

Wyss U, Grundler F. 1992. Feeding behavior of sedentary plant parasitic nematodes. Netherlands Journal of Plant Pathology 98(2): 165-173.

Zander M, Lewsey MG, Clark NM, Yin L, Bartlett A, Saldierna Guzmán JP, Hann E, Langford AE, Jow B, Wise A, et al. 2020. Integrated multi-omics framework of the plant response to jasmonic acid. Nature Plants 6(3): 290-302.

Zhang W, Corwin JA, Copeland D, Feusier J, Eshbaugh R, Chen F, Atwell S, Kliebenstein DJ. 2017. Plastic transcriptomes stabilize immunity to pathogen diversity: the jasmonic acid and salicylic acid networks within the Arabidopsis/Botrytis pathosystem. The Plant Cell 29(17): 2727.

Zhang X, Wang C, Zhang Y, Sun Y, Mou Z. 2012. The Arabidopsis mediator complex subunit16 positively regulates salicylate-mediated systemic acquired resistance and jasmonate/ethylene-induced defense pathways. The Plant Cell 24(10): 4294-4309.

Zhang Y, Turner JG. 2008. Wound-induced endogenous jasmonates stunt plant growth by inhibiting mitosis. PLOS ONE 3(11): 
Chapter 4

e3699.

Zhou W, Lozano-Torres JL, Blilou I, Zhang X, Zhai Q, Smant G, Li C, Scheres B. 2019. A jasmonate signaling network activates root stem cells and promotes regeneration. Cell 177(4): 942-956.e914. 


\section{Supplemental Information}

Supplemental figures
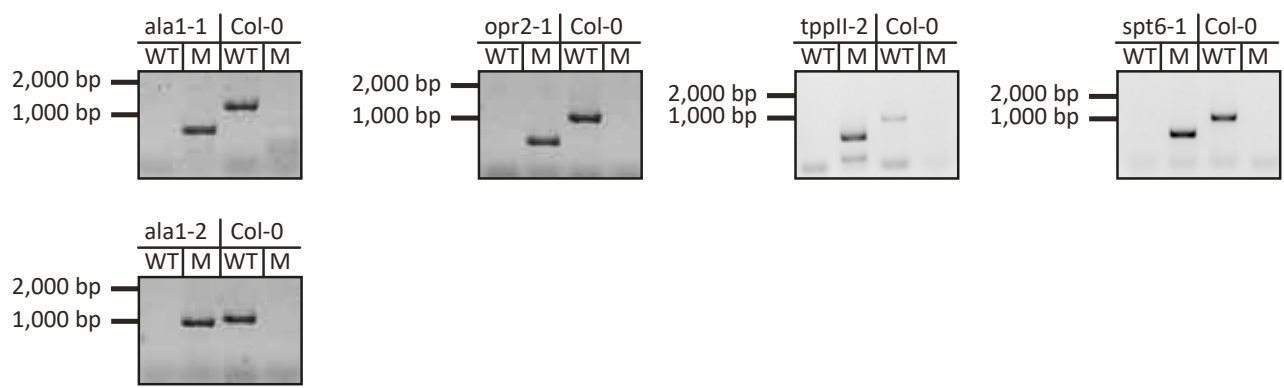

Figure S1. Confirmation of homozygous Arabidopsis t-DNA insertion lines. Every line was tested for fragment amplification with two different primerpairs, WT (wild type) to identify lines containing no insertion at the gene, and $\mathrm{M}$ (mutant) to identify lines containing the insert. Col-O was used as a negative control for all primerpairs.

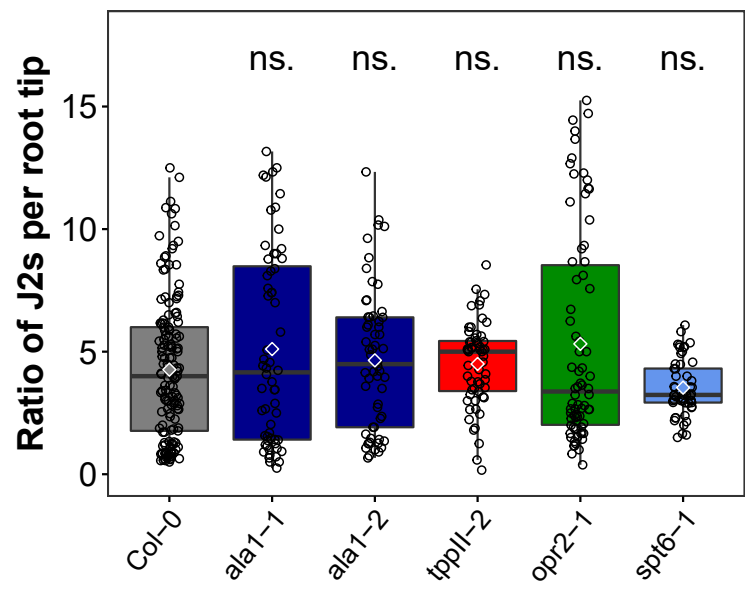

Figure S2. The ratio of stained M. incognita juveniles (J2s) in mutant and wild-type plant roots at seven days post inoculation per root tip at the day of inoculation. Data was collected in at least three independent experiments with $n \geq 16$ and all data was combined. Asterisks indicate significant differences between Arabidopsis T-DNA lines and wild-type Col-0 plants (*, P<0.05; ns, not significant). 
A
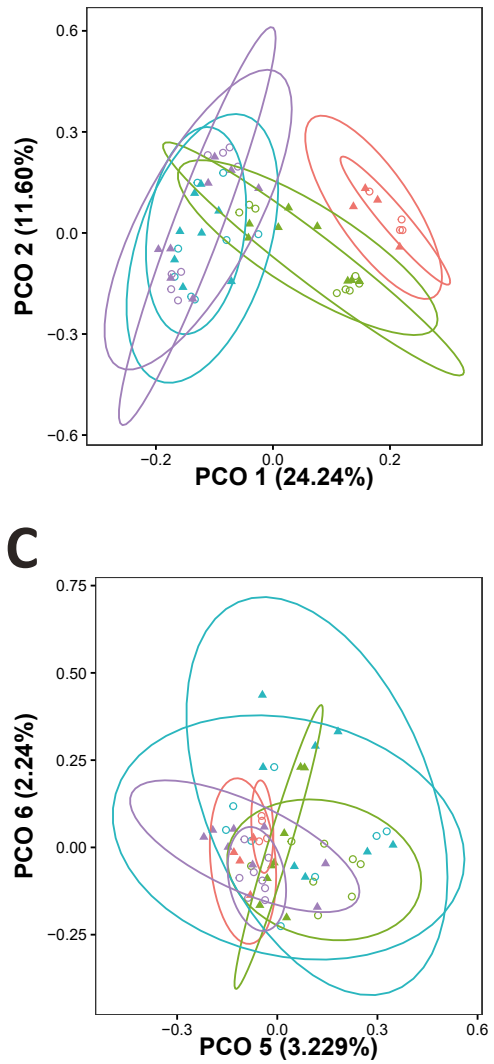

B

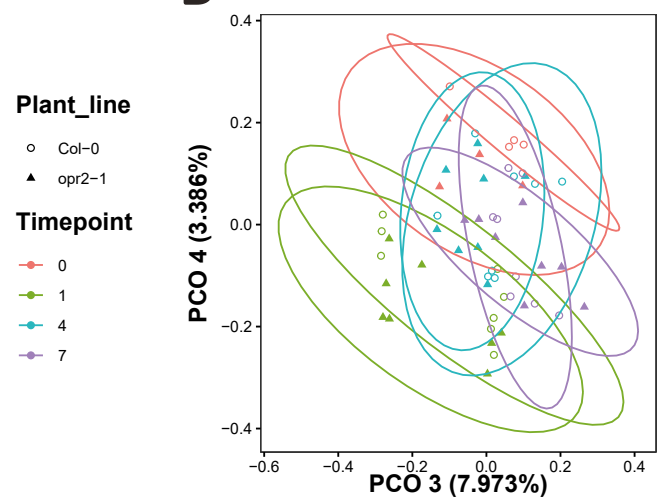

Plant_line

- Col-0

- opr2-1

Timepoint

$\rightarrow 0$

$\rightarrow-1$

$\rightarrow 4$
D

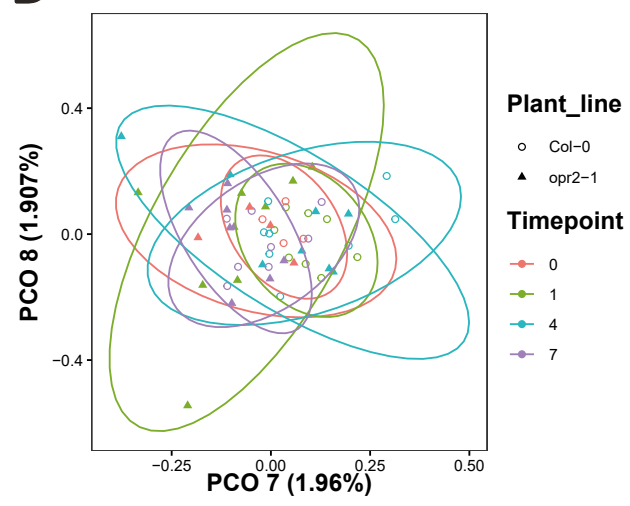

Figure S3. AtOPR2 mutation has only a minor effect on A. thaliana gene expression. Principal component analyses visualizing a distribution of transcripts from all 56 samples categorized by plant line (opr2-7 mutant or wild-type Col-O plants) and timepoint in days post inoculation. The eight largest principal components explained almost 57\% of the variation in expression of Arabidopsis genes across all samples. Ellipses are based on a confidence level of $95 \%$.

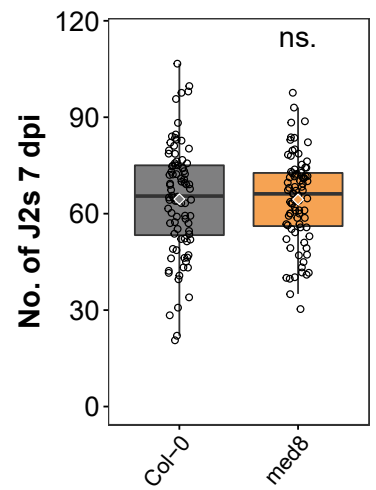

Figure S4. Number of stained M. incognita juveniles (J2) in Atmed8 (At2G03070) knock-out plants and wild-type Col-O plants at seven days after inoculation. Data was collected in three independent experiments with $n \geq 22$ and combined for statistical analysis using Student's t-test (ns, not significant). 


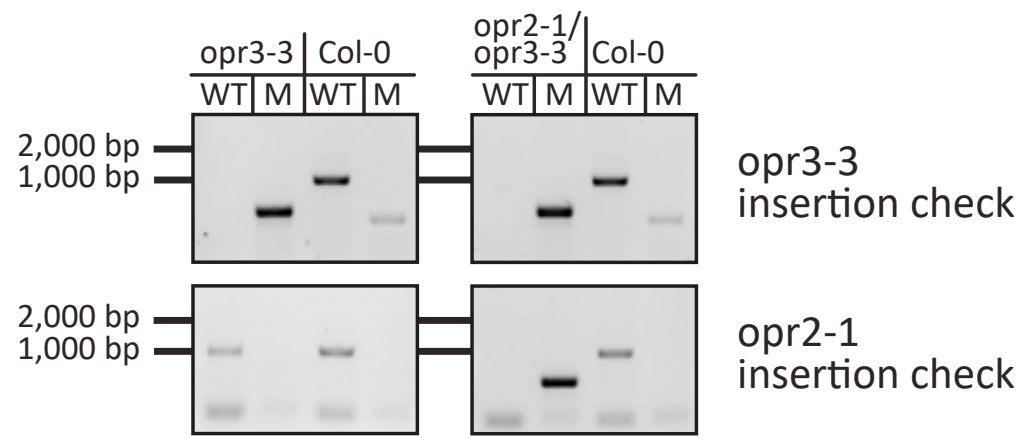

Figure S5. Confirmation of homozygous Arabidopsis T-DNA insertion lines. Every line was tested for fragment amplification with two different primer pairs, WT (wild type) to identify lines containing no insertion at the gene, and $\mathrm{M}$ (mutant) to identify lines containing the insert. Col-O was used as a negative control for all primerpairs.

\section{Supplemental tables}

Table S1. Primer pairs used in this study.

\begin{tabular}{|c|c|c|c|}
\hline Ref. & Target gene & Forward & Reverse \\
\hline WT1 & Atalal-1 wild type & ССTTTATCCCGATTTAGTAATTGTG & CGAGCATCTTCGTCTTTTGATC \\
\hline M1 & Atalal-7 t-DNA insert & ATTTTCCCGATTTCGGAAC & CGAGCATCTTCGTCTTTCATC \\
\hline WT2 & Atalal-2 wild type & GCCATTGGTGATGGTAATGAC & ACCACAACATCCATCTCTTGC \\
\hline M2 & Atalal-2 t-DNA insert & ATTTTCCCGATTTCGGAAC & ACCACAACATCCATCTCTTGC \\
\hline WT3 & Atopr2-1 wild type & GTGGGTTATTGCTGATCATCC & AGCTGTTCATTCAAGGGAAGG \\
\hline M3 & Atopr2-7 t-DNA insert & ATTTTCCCGATTTCGGAAC & AGCTGTTCATTCAAGGGAAGG \\
\hline WT4 & Attppll-2 wild type & ATTGAGGAACTCAGCAAATGC & AGAAGTCTCCTAGTTTCCCGC \\
\hline M4 & Attppll-2 t-DNA insert & ATTTTGCCGATTTCGGAAC & AGAAGTCTGCTAGTTTCCCGC \\
\hline WT5 & Atspt6-1 wild type & GATCCTCGAAGGTTTCATTCC & AAAGCTGCATCTTTGCAGAAG \\
\hline M5 & Atspt6-1 t-DNA insert & ATTTTGCCGATTTCGGAAC & AAAGCTGCATCTTTTGCAGAAG \\
\hline WT6 & Atopr3-3 wild type & AATCCGTGTAGCCAACAACTC & CAGCCACATTCAAAGAAAAGG \\
\hline M6 & Atopr3-3 t-DNA insert & GCTTTCGCCTATAAATACGACGGATCGT & CAGCCACATTCAAAGAAAAGG \\
\hline AtOPR2_FL & AtOPR2_full length & $\begin{array}{l}\text { ПTCAAATACTTCCACCATGGTTATGGAAAT- } \\
\text { GGTAAACGCAGAAGC }\end{array}$ & $\begin{array}{l}\text { CCTTCCTCACGGTACCAGCTGTT- } \\
\text { GATTCAAGGGAAGGG }\end{array}$ \\
\hline mCh_FL & mCherry_gene & AGCTGGTACCGTGAGCAAGGGCGAGGAGG & $\begin{array}{l}\text { AATGAGCTTTTGCTCGCTAG- } \\
\text { CAACTGACTTGTAGAGCTCGTCC }\end{array}$ \\
\hline
\end{tabular}


Table S2. RNA-Seq mapping statistics. For every sample, the sampling conditions are mentioned, along with the number of reads, the number and percentage of reads mapped to the Arabidopsis TAIR10 genome and the number and percentage of reads mapped to the M. incognita PRJEB8714 genome.

\begin{tabular}{|c|c|c|c|c|c|c|c|}
\hline Sample & Treatment & Plant_line & Fw\&RV combined & Mapped TAIR & Mapped MINC & TAIR10\% & PRJEB8714\% \\
\hline 1 & Mock & Col-O & $33,930,141$ & $31,795,995$ & 265 & 93.71 & 0 \\
\hline 2 & Mock & Col-O & $33,447,622$ & $32,209,199$ & 1,156 & 96.3 & 0 \\
\hline 3 & Mock & Col-O & $31,299,777$ & $30,109,077$ & 1,034 & 96.2 & 0 \\
\hline 4 & Mock & $\mathrm{Col}-\mathrm{O}$ & $33,293,747$ & $26,910,564$ & 926 & 80.83 & 0 \\
\hline 5 & Mock & opr2-1 & $31,413,952$ & $30,202,746$ & 225 & 96.14 & 0 \\
\hline 6 & Mock & opr2-1 & $29,500,395$ & $28,311,519$ & 263 & 95.97 & 0 \\
\hline 7 & Mock & opr2-1 & $30,155,272$ & $28,984,956$ & 223 & 96.12 & 0 \\
\hline 8 & Mock & opr2-1 & $30,440,554$ & $29,323,331$ & 1,191 & 96.33 & 0 \\
\hline 13 & Mock & Col-O & $28,936,794$ & $27,637,717$ & 113 & 95.51 & 0 \\
\hline 14 & Mock & Col-O & $27,675,819$ & $26,532,410$ & 911 & 95.87 & 0 \\
\hline 15 & Mock & Col-O & $33,428,662$ & $32,149,146$ & 902 & 96.17 & 0 \\
\hline 16 & Mock & Col-O & $26,656,859$ & $25,514,373$ & 158 & 95.71 & 0 \\
\hline 17 & $\mathrm{~J} 2$ & Col-O & $29,807,640$ & $28,495,412$ & 25,043 & 95.6 & 0.08 \\
\hline 18 & 32 & Col-O & $30,414,302$ & $29,240,124$ & 42,364 & 96.14 & 0.14 \\
\hline 19 & $\mathrm{~J} 2$ & Col-O & $29,532,245$ & $28,373,218$ & 72,507 & 96.08 & 0.25 \\
\hline 20 & 32 & Col-O & $28,827,471$ & $27,756,498$ & 56,654 & 96.28 & 0.2 \\
\hline 21 & Mock & opr2-7 & $27,838,993$ & $26,779,661$ & 216 & 96.19 & 0 \\
\hline 22 & Mock & opr2-1 & $29,914,102$ & $28,699,147$ & 179 & 95.94 & 0 \\
\hline 23 & Mock & opr2-1 & $26,988,650$ & $26,016,836$ & 1,433 & 96.4 & 0.01 \\
\hline 24 & Mock & opr2-1 & $28,605,651$ & $27,582,333$ & 877 & 96.42 & 0 \\
\hline 25 & 32 & opr2-1 & $26,598,893$ & $25,575,487$ & 26,820 & 96.15 & 0.1 \\
\hline 26 & $\mathrm{~J} 2$ & opr2-1 & $29,728,779$ & $28,556,290$ & 15,966 & 96.06 & 0.05 \\
\hline 27 & $\mathrm{~J} 2$ & opr2-1 & $28,912,952$ & $27,474,403$ & 70,027 & 95.02 & 0.24 \\
\hline 28 & $\mathrm{~J} 2$ & opr2-1 & $25,281,103$ & $23,878,138$ & 30,432 & 94.45 & 0.12 \\
\hline 29 & Mock & Col-O & $27,576,034$ & $26,496,735$ & 134 & 96.09 & 0 \\
\hline 30 & Mock & Col-O & $29,958,672$ & $28,852,452$ & 737 & 96.31 & 0 \\
\hline 31 & Mock & Col-O & $24,039,320$ & $22,153,054$ & 260 & 92.15 & 0 \\
\hline 32 & Mock & Col-O & $26,971,586$ & $25,923,056$ & 175 & 96.11 & 0 \\
\hline 33 & $\mathrm{~J} 2$ & Col-O & $25,064,827$ & $23,935,265$ & 184,750 & 95.49 & 0.74 \\
\hline 34 & 32 & Col-O & $27,467,319$ & $26,214,607$ & 208,633 & 95.44 & 0.76 \\
\hline 35 & $\mathrm{~J} 2$ & Col-O & $26,570,161$ & $25,398,158$ & 163,172 & 95.59 & 0.61 \\
\hline 36 & 32 & Col-O & $30,930,163$ & $29,505,159$ & 172,477 & 95.39 & 0.56 \\
\hline 37 & Mock & opr2-1 & $27,436,771$ & $26,386,562$ & 302 & 96.17 & 0 \\
\hline 38 & Mock & opr2-1 & $28,082,691$ & $26,892,346$ & 200 & 95.76 & 0 \\
\hline 39 & Mock & opr2-1 & $28,996,622$ & $27,840,253$ & 308 & 96.01 & 0 \\
\hline 40 & Mock & opr2-1 & $24,980,467$ & $23,976,066$ & 254 & 95.98 & 0 \\
\hline 41 & $\mathrm{J2}$ & opr2-1 & $29,517,856$ & $28,271,302$ & 90,378 & 95.78 & 0.31 \\
\hline 42 & $\mathrm{~J} 2$ & opr2-1 & $29,245,225$ & $27,918,497$ & 105,051 & 95.46 & 0.36 \\
\hline 43 & $\mathrm{~J} 2$ & opr2-1 & $33,171,558$ & $31,668,960$ & 154,662 & 95.47 & 0.47 \\
\hline 44 & $\mathrm{~J} 2$ & opr2-1 & $27,552,934$ & $25,687,398$ & 145,830 & 93.23 & 0.53 \\
\hline 45 & Mock & Col-O & $29,726,432$ & $28,487,858$ & 290 & 95.83 & 0 \\
\hline 46 & Mock & Col-O & $28,971,570$ & $27,843,171$ & 814 & 96.11 & 0 \\
\hline
\end{tabular}




\begin{tabular}{|c|c|c|c|c|c|c|c|}
\hline Sample & Treatment & Plant_line & Fw\&RV combined & Mapped TAIR & Mapped MINC & TAIR10\% & PRJEB8714\% \\
\hline 47 & Mock & Col-O & $26,492,685$ & $25,385,601$ & 257 & 95.82 & 0 \\
\hline 48 & Mock & Col-O & $29,771,684$ & $28,559,138$ & 397 & 95.93 & 0 \\
\hline 49 & $\mathrm{~J} 2$ & Col-O & $28,169,067$ & $26,783,406$ & 142,865 & 95.08 & 0.51 \\
\hline 50 & $\mathrm{~J} 2$ & Col-O & $28,265,591$ & $26,931,087$ & 171,347 & 95.28 & 0.61 \\
\hline 51 & $\mathrm{~J} 2$ & Col-O & $29,859,988$ & $28,375,097$ & 252,106 & 95.03 & 0.84 \\
\hline 52 & $\mathrm{~J} 2$ & Col-O & $29,776,873$ & $28,292,576$ & 232,190 & 95.02 & 0.78 \\
\hline 53 & Mock & opr2-1 & $26,623,470$ & $25,634,916$ & 351 & 96.29 & 0 \\
\hline 54 & Mock & opr2-1 & $30,247,261$ & $29,017,233$ & 268 & 95.93 & 0 \\
\hline 55 & Mock & opr2-1 & $29,004,142$ & $27,819,763$ & 292 & 95.92 & 0 \\
\hline 56 & Mock & opr2-1 & $28,890,775$ & $27,742,859$ & 331 & 96.03 & 0 \\
\hline 57 & $\mathrm{~J} 2$ & opr2-1 & $29,844,929$ & $28,394,135$ & 242,527 & 95.14 & 0.81 \\
\hline 58 & $\mathrm{~J} 2$ & opr2-1 & $28,243,736$ & $26,876,613$ & 193,525 & 95.16 & 0.69 \\
\hline 59 & $\mathrm{~J} 2$ & opr2-1 & $29,702,084$ & $28,283,542$ & 214,953 & 95.22 & 0.72 \\
\hline \multirow[t]{2}{*}{60} & $\mathrm{~J} 2$ & opr2-1 & $31,167,360$ & $29,055,769$ & 237,650 & 93.22 & 0.76 \\
\hline & & & $1,624,950,228$ & $1,548,711,214$ & $3,267,371$ & 95.31 & 0.2 \\
\hline
\end{tabular}




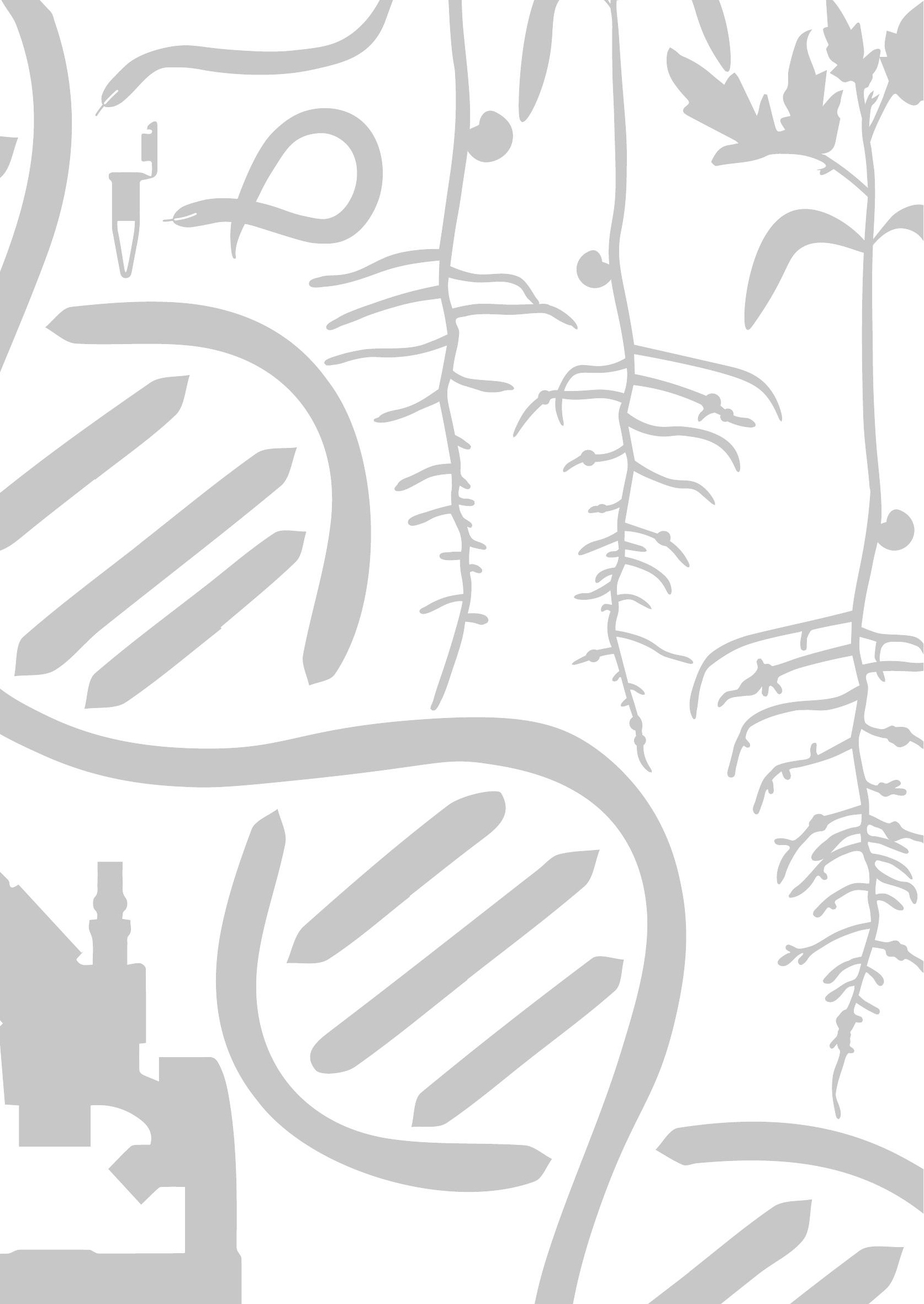




\title{
Chapter 5
}

\section{$R$-gene independent variation in susceptibil- ity of Solanum lycopersicum to Meloidogyne incognita}

\author{
Mark G Sterken \\ Ava Verhoeven \\ Sonja Warmerdam \\ Nina Guaneri \\ Joris JM van Steenbrugge \\ Casper C van Schaik \\ Misghina G Teklu \\ Marian Oortwijn \\ Jose Lozano Torres \\ Aska Goverse \\ Geert Smant
}

Laboratory of Nematology, Department of Plant Sciences, Wageningen University \& Research, Wageningen, The Netherlands 


\section{Abstract}

Plant parasitic root-knot nematodes such as Meloidogyne incognita cause major agronomical problems in tomato (Solanum lycopersicum) by the formation of galls surrounding the nematode feeding sites and thereby disrupting host plant physiology. Yet, for control of $M$. incognita in tomato cultivation the only currently exploited genetic source is the Mi-7.2 resistance-gene (R-gene). Recently, $R$-gene independent natural quantitative variation in $A$. thaliana was identified for the susceptibility to $M$. incognita. This finding raises the question if there is a genetic basis for variation in susceptibility to $M$. incognita parasitism in tomato beyond the Mi-7.2 gene. In this study, we used a collection of 178 domesticated tomato lines lacking the Mi-7.2 gene to identify quantitative variation in tomato susceptibility to M. incognita and link this trait to genomic regions of 156 of these tomato accessions using genome-wide association (CWA) mapping. We identified 380 genes associated with quantitative variation among domesticated tomato accessions. Moreover, this R-gene independent variation contains significant narrow-sense heritability. Additionally, we used RNA-Seq to observe differences in the transcriptomic regulation associated with these particular regions in ten tomato accessions with varying susceptibility. Our findings highlight a total of 37 high priority candidate genes for use in future studies and breeding applications. These high-priority genes are enriched for varying functions, of which several are associated with plant stress. 


\section{Introduction}

Most of the annual $\$ 100$ billion of agricultural damage by plant-parasitic nematodes is caused by members of the genus Meloidogyne (Jones et al., 2013; Mitchum et al., 2013). Of the more than 90 individual species within Meloidogyne (Hunt \& Handoo, 2009), the tropical root-knot nematode Meloidogyne incognita is globally the most invasive (Bebber et al., 2014). The agronomical problems with $M$. incognita are mainly caused by the disruption of host plant physiology, resulting in various symptoms like stunting, lack of vigor, and wilting under drought stress. These symptoms are specially detrimental in plants with succulent roots, such as tomato, because these plants are highly susceptible to galling (Moens et al., 2009). M. incognita control in tomato cultivation is usually based on the only exploited genetic source at present; the Mi-1.2 resistance-gene from S. peruvianum (Barbary et al., 2015). As an alternative, the S. chilense Ty-7 (or Mi-J) homolog of Mi-7.2 confers resistance to tomato yellow leaf curl virus and has an intermediate level of resistance to M. incognita (Hoogstraten et al., 2014). However, the Mi-7.2 and Mi-J genes are tightly linked, and their close proximity causes problems with the introgression of the two (Bhavana et al., 2019). In addition, a growing number of resistance-breaking populations has been detected worldwide (Kaloshian et al., 1996; Iberkleid et al., 2014; Guan et al., 2017). Therefore, there is a clear demand for new forms of nematode resistance that are not based on one single R-gene, but instead on the complex array of plant genes responsible for nematode susceptibility.

To successfully parasitize its host plant, M. incognita needs to enter the plant and establish a permanent feeding site to gain access to the flow of assimilates inside the vascular cylinder. Second stage juveniles (J2s) of M. incognita start the infection process by finding the host plant and entering the root at the elongation zone. Thereafter, they migrate intercellularly through the cortex in the direction of the root apical meristem (Kyndt et al., 2013). After arriving at the root meristem, J2s make an U-turn and move upward into the vascular cylinder (Wyss \& Grundler, 1992). Inside the vascular cylinder, the juveniles induce the differentiation and growth of vascular cells into giant cells. Usually, one feeding site consists of 4-10 multinucleate and enlarged giant cells (Abad \& Williamson, 2010; Bartlem et al., 2013). Cells surrounding the giant cells become hyperplastic, leading to the formation a large gall. The giant cells act as a nutrient sink, maintained by active unloading of plant assimilates from neighboring phloem cells. These development of galls surrounding the giant cells induces major physiological changes. During the course of several weeks, sedentary stages of $M$. incognita take up their nutrients from the giant cells, whilst developing into adult females. The adult females produce offspring via mitotic parthenogenesis, which is deposed at the root surface as a mass of eggs held together by a gelatinous matrix. From the eggs, second stage juveniles emerge, ready for another infection cycle. The act of establishing a permanent nutrient sink requires extensive reprogramming of genes and manipulation of molecular and cellular processes in the host by the nematode (Hewezi \& Baum, 2013; Mitchum et al., 2013).

The complex manipulation of the host plant by M. incognita stipulates that its susceptibility is a complex trait involving multiple genes (Barcala et al., 2010; Kyndt et al., 2012; Favery et al.. 
2016). One way to study the genetics of complex traits is the use of quantitative trait locus (QTL) mapping. For example, genome-wide association (CWA) allows for the analysis of many segregating polymorphic loci within a population. CWA can identify associations between variants of different individuals (usually single nucleotide polymorphisms; SNPs) and the associated trait of interest (Bush \& Moore, 2012). Recently, GWA was used to identify genes associated with resistance to root-knot nematodes in soybean (Glycine max), sweet potato (Ipomoea batatas), and rice (Oryza sativa) (Dimkpa et al., 2015; Passianotto et al., 2017; Sasai et al., 2019). In addition, Warmerdam et al. (2018; 2019) used GWA to show the existence of large $R$-gene independent natural quantitative variation in $A$. thaliana for the susceptibility to $M$. incognita. The availability of such quantitative variation in populations without $R$-genes, can be of interest for nematode management in tomato.

The requirement of the complex manipulation of a plethora of plant genes juxtaposed with control strategies based on a single R-gene raises the question if there is a genetic basis for variation in susceptibility to $M$. incognita parasitism in tomato beyond the Mi-7.2 gene. To expand on the findings of Warmerdam et al. $(2018,2019)$ in A. thaliana, we quantified susceptibility to M. incognita infection in 178 tomato accessions lacking the Mi-7.2 gene by measuring the number of galls at ten days post inoculation. At this point in the infection cycle, major physiological changes have occurred in the host by the development of galls surrounding the nematode feeding sites. Within the 178 S. Iycopersicum accessions, we quantified R-gene independent variation in both the normalized number of galls per plant and the number of galls per root tip per plant. Furthermore, we located significant heritability of $M$. incognita susceptibility among the 156 sequenced tomato accessions. In a CWA analysis, we identified a total of 380 candidate genes associated with S. Iycopersicum susceptibility to M. incognita. Additional transcriptome analysis on galls of ten S. Iycopersicum accessions resulted in 37 high priority candidate genes for use in future studies and breeding applications.

\section{Results}

\section{Quantitative variation in susceptibility of S. Iycopersicum to M. incognita}

We performed a large-scale phenotype screen of 178 tomato accessions using nematode bioassays to assess quantitative variation in susceptibility to $M$. incognita (Supplementary

Table S1). These accessions were previously tested for the absence of the Mi-7.2 resistance gene using PCR based markers (Seah et al., 2007). Several of the accessions were tested in multiple batches of the in total 25 batches, and every batch included the Arlyco RZ F7-Hybrid (referred to as accession ' $F \mathrm{l}^{\prime}$ ) as a reference (Supplementary Table S2). Per accession, we scored on average 12.9 plants (excluding F1; median of 12). At the time of inoculation with M. incognita juveniles (day 0), we counted the number of root tips per plant. This is a relevant parameter as M. incognita uses root tips to enter plant roots. Subsequently, at ten days post inoculation (dpi), we counted the number of galls per plant. Together, we determined three parameters per plant: (i) the number of root tips at $\mathrm{O} \mathrm{dpi}$, (ii) the number of galls at $10 \mathrm{dpi}$, and (iii) the number of galls per root tip. To optimize the genetic signal and reduce batch effects, we normalized 
both the number of galls and the number of root tips to the Fl reference line (see Materials and methods).

The data showed clear phenotypic differences in susceptibility among the 178 accessions based on the normalized number of galls at $10 \mathrm{dpi}$ as well as the number of galls per root tip (Figure 1; Supplementary Table S3). To enable further characterization of the variation in trait levels, we calculated for each of the parameters several summary statistics per accession. These summary statistics were subsequently used to analyze both heritability and GWA. Furthermore, they allowed us to determine how the summary statistics of the different traits were correlated, like the mean number of galls per root tip (Supplementary Figure S1).

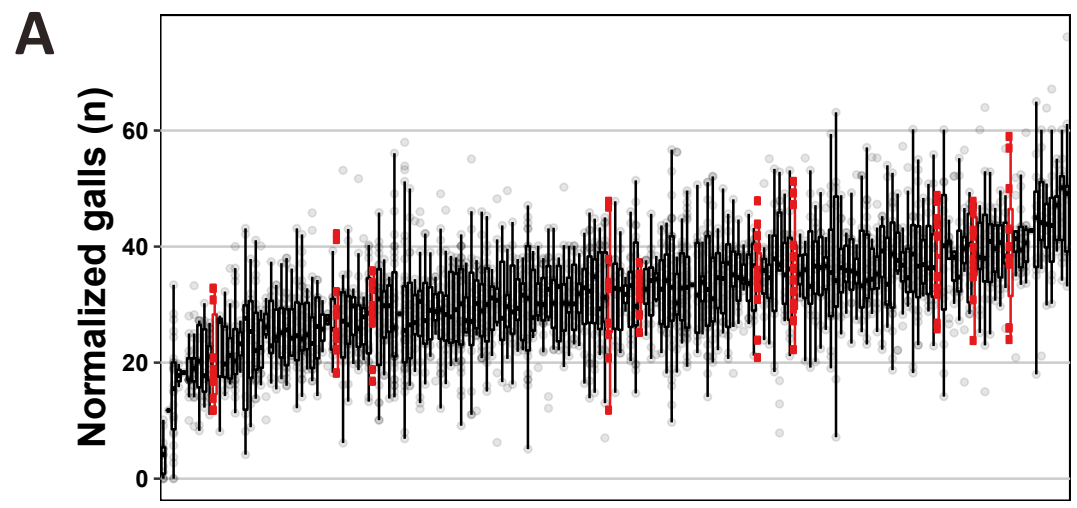

Accession

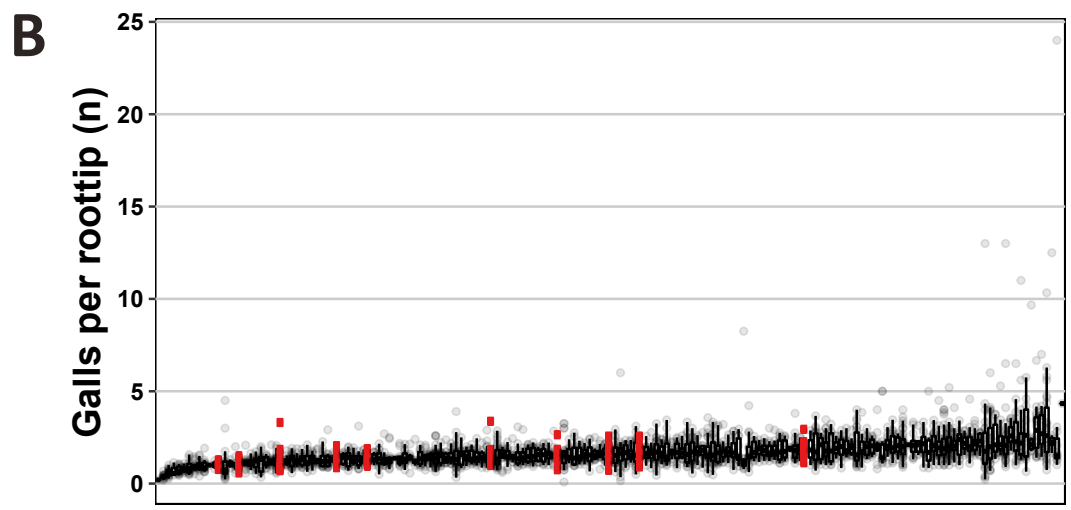

\section{Accession}

Figure 1. Quantitative variation in susceptibility over 178 accessions of S. lycopersicum. (A) A boxplot of the normalized number of galls per seedling at ten days post inoculation (dpi) with infective juveniles of M. incognita for all 178 accessions. The accessions are ranked on the $X$-axis according to the means. The number of galls per seedling is normalized for batch effects using data of the Fl hybrid as a reference genotype for each batch. Each box represents data of at least ten seedlings. The red boxplots indicate ten accessions that were later used for transcriptomics. (B) As in (A), but then for the number of galls per seedling at $10 \mathrm{dpi}$ corrected for the number of root tips present at the time of inoculation. 


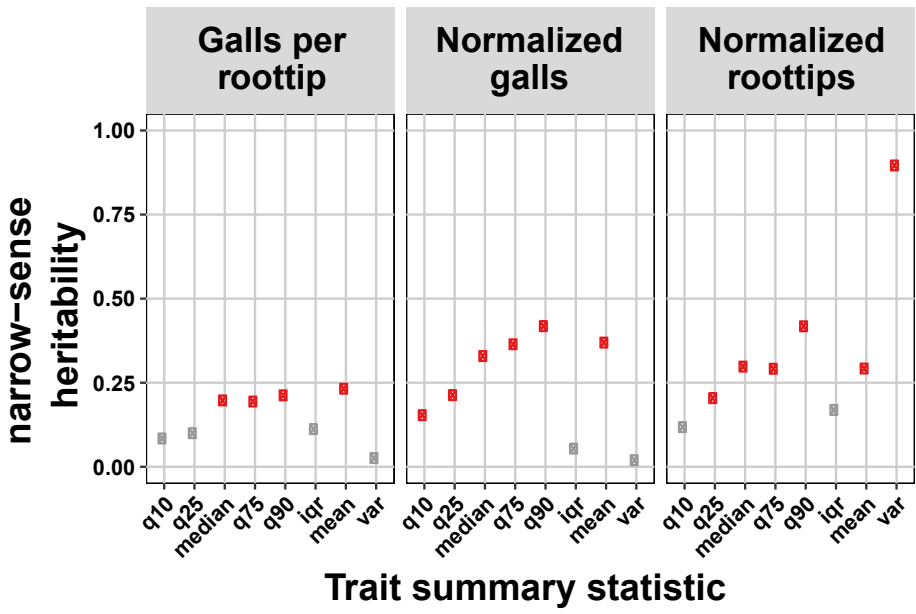

Figure 2. The calculated narrow sense heritability per trait summary statistic. On the $x$-axis the summary statistics are shown (q, quantile; iqr, inter quartile range; var, variance), for the quantiles the numbers indicate the percentage (e.g. q10 is the 10\% quantile). The three panels represent the main traits measured. The $y$-axis represents the narrow-sense heritability as calculated using REML. The red dots indicate significant heritability (permutation, FDR < 0.05).

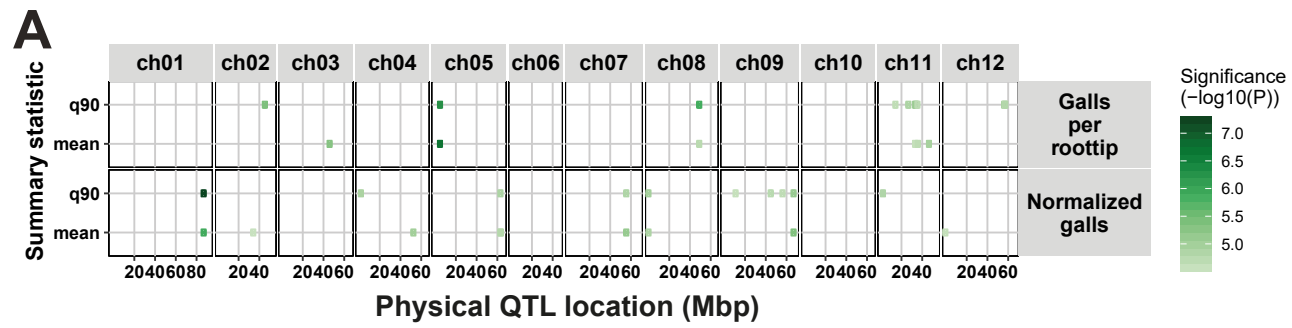

B

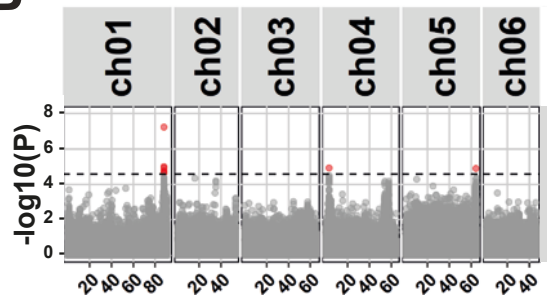

Normalized galls (q90)

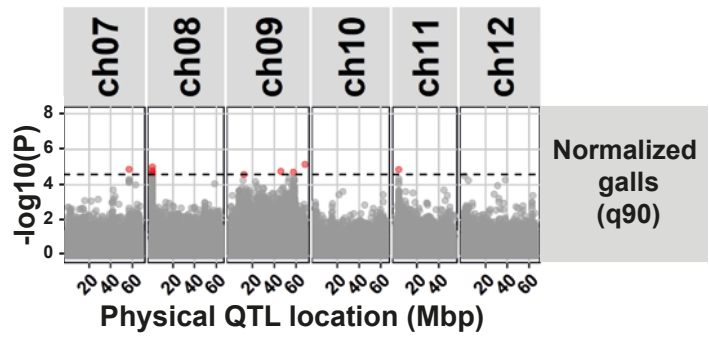

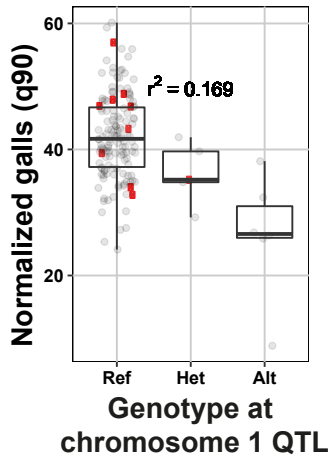

chromosome 1 QTL 


\section{Heritable variation in M. incognita susceptibility}

Next, we assessed the role of genetic variation in the variance of the number of galls per root tip, the normalized number of galls, and the normalized number of root tips. To infer a kinship matrix, we constructed a genetic map for 156 out of 178 accessions. We re-sequenced 120 accessions to complement the previously generated genome sequence data of the accessions (The 100 Tomato Cenome Sequencing Consortium et al., 2014) to generate a genetic map based on 489,119 segregating polymorphic loci (see Materials and methods; Supplementary Table S4, Supplementary Figure S2). Second, based on the kinship matrix, we calculated narrow-sense heritability ( $h^{2}$; the variance explained by additive genetic variation) for all summary traits. We found significant narrow-sense heritability for summary statistics of all three traits (FDR < 0.05). For two of the summary statistics, i.e. the mean and the 90\% quantile, we found a consistently high $h^{2}$ (Figure 2 ). Therefore, we took these two statistics for all three traits for further GWA analysis.

GWA analysis identified 25 loci in S. Iycopersicum associated with susceptibility to M. incognita

To identify loci associated with susceptibility in the genome of S. lycopersicum, we conducted a CWA analysis on the normalized number of galls, the normalized number of root tips, and the number of galls per root tip of 156 tomato accessions. We used the mean and $90 \%$ quantile summary statistics of these traits since these showed the highest narrow sense heritability $\left(h^{2}\right.$ $=0.21-0.42)$. Using the genetic map, we identified 51 distinct QTL above the Bonferroni-corrected threshold $\left(-\log _{10}(P)>4.57\right.$; see Materials and methods); 14 distinct QTL for normalized number of galls, 23 distinct QTL for the normalized number of root tips, and 14 distinct QTL for the number of galls per root tip. To determine whether the QTL were independent, we calculated the pairwise linkage disequilibrium between each of the peak variants. In total, we identified 45 independent QTL $\left(r^{2}<0.8\right)$, of which 25 were related to M. incognita susceptibility (Figure 3A). For example, for the $90 \%$ quantile of galls, we identified ten QTL, on chromosome $1,4,5,7,8,9$, and 11 (Figure 3B).

To further characterize the QTL associated with susceptibility to M. incognita, we investigated the direction of the effect and the distribution of the accessions under the QTL. For example, for the strongest QTL associated with 90\% quantile of galls - $16.9 \%$ of the variance was explained by the QTL (full ANOVA model; Figure 3C). Furthermore, we found that for 16 out

< Figure 3. Outcomes of GWA analysis of susceptibility of S. lycopersicum to M. incognita. (A) An overview of all the QTL mapped by GWA. The x-axis shows the genomic location, the $y$-axis the summary statistic used for mapping (split out over the two susceptibility-related traits). Colors indicate significance of the association. (B) The QTL profile for $90 \%$ quantile of the normalized number of galls. On the $x$-axis the genomic location is shown (in million base pairs; Mbp), split out over the 12 chromosomes. On the $y$-axis the significance of the association in $-\log _{10}(p)$ is shown. The dashed line indicates the Bonferroni-corrected significance threshold and all significant QTL are colored red. (C) Boxplot of the normalized number of galls 90\% quantile trait summary values over the genotypes at the major chromosome 1 QTL. The $r^{2}$ is based on an additive ANOVA model over all peaks (see Materials and methods). The red dots indicate ten accessions used in transcriptome analysis. 
of 25 independent QTL, presence of the alternative allele showed increased susceptibility. To affect susceptibility, the causal genes could carry loss- or gain-of-function mutations or the expression levels could be affected. To determine likely causal variants, we considered genes within the linkage disequilibrium distance of the peak. Based on the linkage disequilibrium in the genetic map, we determined a 95\%-confidence interval of 81,150 bases around the peaks for identifying causal variants. For example, the confidence interval region of the normalized number of galls 90\% quantile trait at the major QTL encompassed 2,340 variants. Within the confidence interval region, we identified 36 annotated genes. In total, this approach resulted in a list of 380 unique genes for 24 out of 25 independent susceptibility-associated QTL, for which 233 harbored associated polymorphisms as determined by re-sequencing.

Variation in gene expression associated with susceptibility of S. Iycopersicum to M. incognita To test whether differential expression of genes could account for variation in susceptibility to M. incognita, we investigated the whole transcriptome in dissected nematode-induced galls from a subset of ten accessions at six different time points after inoculation. At 1, 2, 3, 4, 7, and 10 days after inoculation, nematode-induced galls or similar non-infected root fragments were dissected for the different accessions (Materials and methods). The ten chosen accessions (RFO4, RF05, RF08, RF22, RF23, RF29, RF32, RF36, RF41, and RF96) represent the diversity in susceptibility observed in the entire GWA panel. The goal of this experiment was to characterize differences in local transcriptional response to M. incognita infection.

First, we investigated the factors explaining variance in the mapped reads of the RNA-sequencing for gene expression in tomato and in M. incognita. For tomato (SI4.0; ITAC4.0), principal component analysis showed that $32.5 \%$ of variance was associated with time and $18.7 \%$ of variance with nematode infection, where infection became more distinguishable over time (Figure 4A). Next, we used linear models to explain tomato gene expression over time and infection. We found 8,401 genes were significantly differentially expressed over time, 693 genes were differentially expressed for infection (Figure 4B), and 939 were significantly affected by time and infection (Figure 4C) (Bonferroni-corrected $\mathrm{p}<0.05$ ). These genes were enriched for various processes, including oxidative stress, oxidation-reduction, and trehalose biosynthesis (Supplementary Table S5). Moreover, 19/693 and 12/939 genes were among the 380 genes identified within susceptibility-associated QTL identified by GWA (Figure 4D). As these genes are implicated in the infection process, they constitute high-priority candidates for further analyses.

As the ten accessions included in this analysis reflect a gradient in the number of galls per plant and the number of galls per root tip (Figure 1), we used these values in a linear model to find variance in gene-expression correlated with these traits. Using this approach, we identified 1,198 unique genes that were associated with susceptibility of an accession (false discovery rate, $q<0.05$ ). These genes were enriched for various processes, including oxidation-reduction, cellulose biosynthesis, and carbohydrate binding (Supplementary Table S6). Furthermore, 19/1,198 were among the 380 susceptibility-associated QTL genes identified by GWA (Figure 4D). Hence, also these genes constitute high-priority candidates for further analysis as these 
are associated with variance in susceptibility, adding to a total of 37 high-priority candidate genes.

A

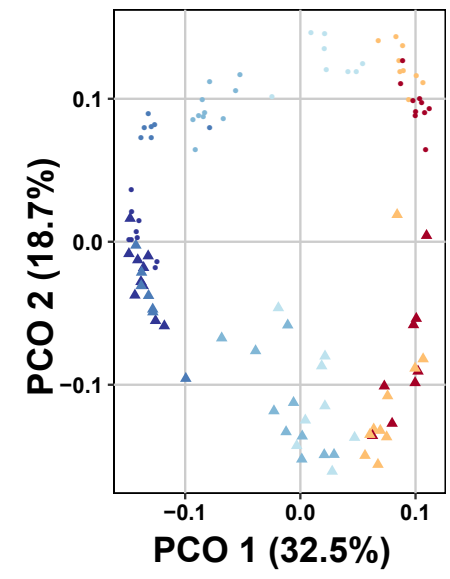

C

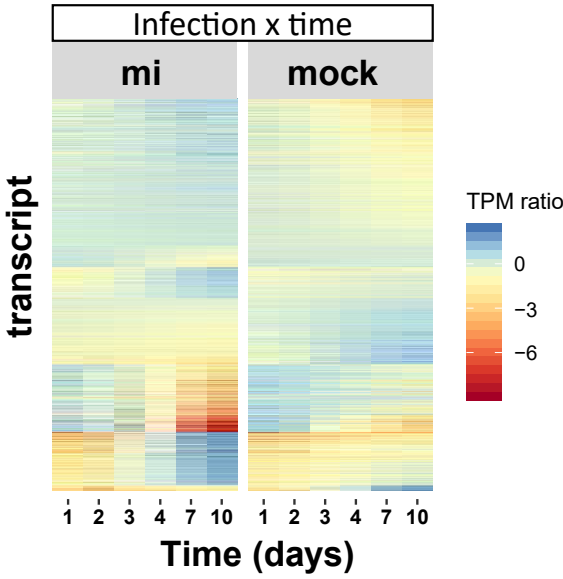

Infection

- $\mathrm{mi}$

- mock

$=10.0$

5.5

2.5

2.5
B

Time (days)

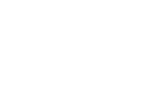

D
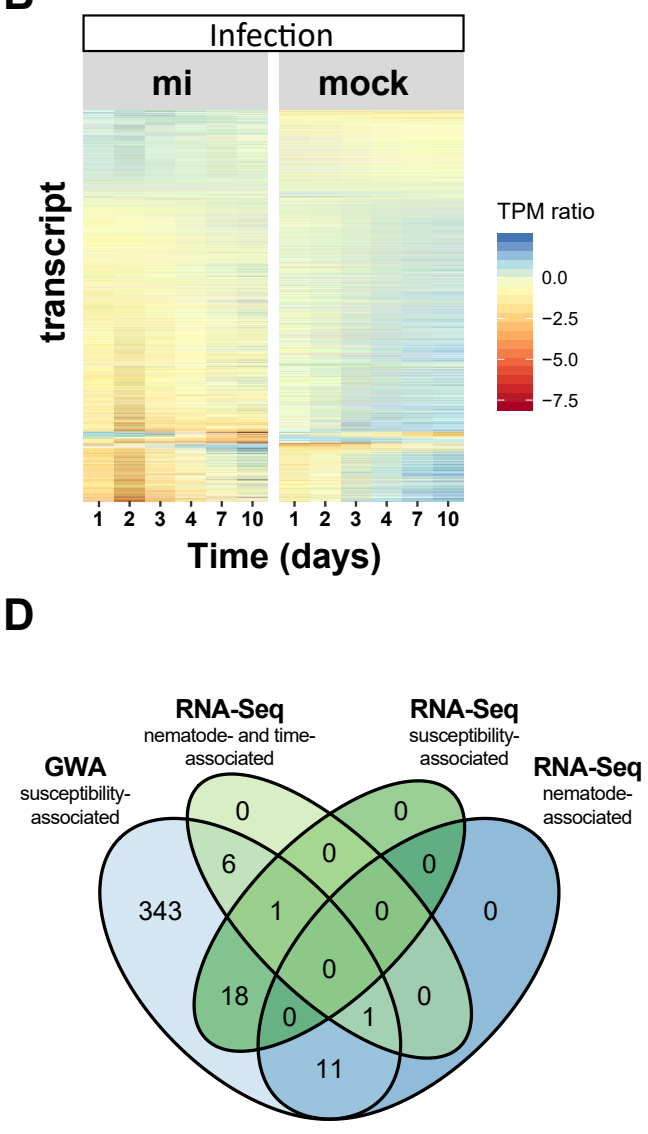

Figure 4. Differential gene expression in S. Iycopersicum over time and between galls and non-infected root segments. (A) A plot of the first two principal components (PCO) of gene expression in tomato. The first PCO explains 32.5\% of variance and aligns with time after the start of the experiment that the sample was taken, shown by a blue-red color gradient. The second PCO (18.7\%) aligns with whether a sample was inoculated with Meloidogyne incognita (mi; dots) or not (mock; triangles). (B) A heatmap of the gene expression of the 693 genes affected by M. incognita infection, averaged per timepoint over the ten accessions. For visualization genes were organized in four clusters by k-means clustering. (C) A heatmap of the gene expression of the 939 genes affected by M. incognita infection and time, averaged per timepoint over the ten accessions. For visualization genes were organized in four clusters by k-means clustering. (D) Venn diagram representing the 37 high-priority genes within the 380 susceptibility-associated QTL genes identified by GWA. These high-priority genes are overlapping with the differentially regulated genes over time, between galls and non-infected root segments, and/or with genes of which expression was associated with susceptibility of an accession. 


\section{Discussion}

Extensive heritable genetic variation related to $M$. incognita feeding site formation In this chapter, we show the existence of heritable genetic variation in the susceptibility to root-knot nematodes in tomato and mapped it to various QTL. Importantly, the population used did not contain the classical R-genes like Mi-7.2. We noticed that the genetic structure of our tomato accession subset was very distinct from that in wild species, as was expected because of our choice for cultivated tomato lines (Bergougnoux, 2014: The 100 Tomato Genome Sequencing Consortium et al., 2014: Sul et al.., 2018). A negative effect of this narrow genetic structure compared with a wild population such as A. thaliana (Warmerdam et al., 2018; 2019), would be the absence of equally distributed variation throughout the genome due to years of selection. The advantage for the analysis was that there was no clear population structure in the population, therefore accounting for identity by kinship was sufficient, taking away this potentially confounding factor (Sul et al., 2018).

The trait we mapped (susceptibility) is molecularly complex - both from the nematode and the plant perspective - and also phenotypically complex (Mukhtar et al., 2017). Namely, several measurable variables together determine plant susceptibility to nematodes, including feeding site formation and nematode reproduction (Mukhtar et al., 2017). For example, feeding site formation depends on host attraction, host invasion, and the selection of a suitable host cell. Once established, feeding sites should ensure an uninterrupted supply of nutrients, allowing the nematode to develop and in ultimo leads to reproduction: the deposition of eggs (Abad et al.. 2009). However, the quality or the number of feeding cells can determine important traits such as female development or the reproduction rate. Hence, there are many traits related to susceptibility that can be measured. Here, we measured the successful establishment of a feeding site by root-knot nematodes, as these result in the formation of galls. It should be noted that some plants can appear to be hypersusceptible, resulting in heavy galling, yet still show a suppressed nematode reproduction due to poor quality for the feeding nematode (Anwar \& McKenry, 2010). Therefore, our GWA identifies QTL responsible for variation in susceptibility of tomato plants to gall induction, and not necessarily related to lower nematode reproduction.

We first established that there was significant heritable variation in susceptibility $\left(h^{2}=0.21\right.$ 0.42), this indicated that there was ample additive genetic variation segregating within the population tested. This was at the lower boundary of what we previously found in A. thaliana (Warmerdam et al., 2018). Still, we consider this a relatively high heritability, given that a substantial part of the genetic variation that exists in the wild was not included in our population panel (The 100 Tomato Genome Sequencing Consortium et al., 2014). In addition, no classical $R$-genes were present in the population, which was the case in most GWA studies with rootknot nematodes (Dimkpa et al., 2015; Passianotto et al., 2017; Sasai et al., 2019). For example, studies on M. incognita resistance in sweet potato and soybean in the context of (almost) complete cultivars, report major QTL explaining 37-40\% of total variance (Passianotto et al.., 2017; Sasai et al., 2019). In that perspective, it is interesting to note that the total of additive genetic effect segregating within a tomato population without any resistance surmounts to 
the same potential effect.

\section{GWA for tomato susceptibility to nematodes identified 25 QTL}

To identify genes associated with susceptibility, we constructed a genetic map for 156 tomato accessions by mining data from 36 previously sequenced accessions and re-sequencing of 120 accessions. For GWA, we constructed a map of almost 500,000 markers forming a fully informative representation of almost 3.15 million polymorphisms.

Using CWA, we mapped the variation in galling to 25 independent QTL related to susceptibility. To take into account the true number of tests given the existence of linkage disequilibrium within chromosomes, we used an eigenvalue-based multiple-testing correction for the CWA (Li \& Ji, 2005). Initially, we identified 28 QTL regions harboring one or multiple associated polymorphisms, by aggregating the polymorphisms based on linkage disequilibrium. Thereafter, we found that a total of five loci showed linkage disequilibrium over a larger distance $\left(r^{2}>0.8\right)$, forming a group of two and three QTL. As these were not considered independent, this led to 25 independent QTL. The contribution to variance explained by the QTL was typically low. The largest effect-size of a QTL for the number of galls formed explained almost $17 \%$ of variance, which meant a reduction of 16 galls per plant or $40 \%$ related to the alternative allele.

The $40 \%$ reduction of $M$. incognita induced galls caused by the alternative allele of the major QTL on chromosome 1, can be compared with other studies done to lower plant susceptibility to M. incognita. Three main methods have been studied, i.e. R-genes, S-genes, and gene silencing in nematodes. The $40 \%$ reduction of galls does not match the potentially extremely high percentages obtained by major R-genes. The Mi-7.2 resistance gene for example, affects M. incognita infection by decreasing egg mass formation for $84 \%$ on the resistant tomato cultivar Caramba (de Carvalho et al., 2015) when compared to egg formation on the susceptible cultivar Roma (Verdejo-Lucas et al., 2012). Although the efficiency of Mi-7.2 can be high under such controlled conditions, efficacy varies still with root-knot nematode species, population, tomato cultivar, and particularly soil temperature (Devran et al., 2010; de Carvalho et al., 2015).

S-genes are usually responsible for a lower efficiency in decreasing plant susceptibility to nematode infection. In an earlier A. thaliana CWA without major R-genes, we used the exact same M. incognita population to identify eight SNPs with significant associations to the number of egg masses after six weeks (Warmerdam et al., 2018). For these eight SNPS, we linked $22 \%$ of the total variation to plant susceptibility to root-knot nematodes. A T-DNA mutant line of one of these major SNPS, bzr7-1D, showed a $20 \%$ reduction of the number of juveniles at $7 \mathrm{dpi}$ and a similar reduction of the number of egg masses at six weeks after inoculation. The current study in tomato shows potential for an even higher gene-specific effect.

Additional studies to reduce M. incognita damage in tomatoes are based on silencing either nematode effector genes or other essential nematode genes (El-Sappah et al., 2019). For example, Niu et al. (2012) knocked down the M. incognita Rpn7 gene essential for the $26 \mathrm{~S}$ 
proteasome pathway by soaking preparasitic J2s in dsRNA, and hereby achieved a reduction of $\sim 60 \%$ fewer nematodes in tomato roots at 36 hours post inoculation. Likewise, Dutta et al. (2015) measured a $55 \%$ reduced number of galls in tomato plants conferring host-induced gene silencing using another $M$. incognita-specific protease gene, e.g. cathepsin $L$ cysteine proteinase ( $\mathrm{Mi}-\mathrm{cpl}-7$ ). This magnitude of percentages suggests similar effects for $\mathrm{M}$. incognita specific gene silencing as for the $40 \%$ decrease in galls we observed for alternative alleles at the QTL on chromosome 1. Future validation with the highest SNPs should be done to confirm this potential effect. Validation can be done with complementation assays or allele swaps in tomato. Other, technically less challenging methods that can be used for gene validation are CRISPR mutants in tomato or even mutants of homologous genes in A. thaliana.

\section{Candidate gene prioritization by linking polymorphisms and gene expression}

Based on linkage disequilibrium, we found the 25 independent susceptibility QTL to contain 380 candidate genes. We aimed to further reduce the number of candidate genes using additional steps. First, we stipulate that for a gene to be involved, it should either be (i) polymorphic, (ii) differentially expressed upon infection, or (iii) show expression related to the phenotypic plant variation of nematode susceptibility (here represented as the number of galls formed).

To test the first stipulation, we used our re-sequencing data to identify that out of 380 genes, 233 harbored polymorphisms as identified by re-sequencing. Although potentially informative, as many causal polymorphisms have been associated with changes in coding sequences (Roux \& Bergelson, 2016; Seung et al., 2020), it does not formally exclude the genes not associated with polymorphisms. Firstly, our re-sequencing method cannot identify larger structural variants (insertions, deletions, or inversions), which have been associated with functional polymorphisms (Hahnel et al., 2018). Secondly, regulatory polymorphisms could affect expression, and these can be located far-away from the regulated gene (Qiu et al., 2016). Therefore, we conclude here that associated polymorphisms present a mechanism and can be potentially informative, but are not essential for the identification of tomato genes associated with the susceptibility to M. incognita.

To test the second stipulation, we performed transcriptomic analysis on ten different tomato accessions over a time-course of ten days. Here, we identified a total of 693 genes differentially expressed for infection and 939 were significantly affected by time and infection. As these represent genes reacting to infection, we screened for the presence of the 380 genes among them, finding 12/693 and 8/939 genes. Some overlap is typically expected, and a similar approach has been reported for M. graminicola in rice, but then on a single rice genotype (Kyndt et al., 2012; Dimkpa et al., 2015). The 20 overlapping genes are enriched for various processes, such as oxidative stress, oxidation-reduction, and trehalose biosynthesis. Several of these processes (such as oxidative stress and trehalose biosynthesis) are associated with stress conditions in tomato plants (Bai et al., 2018: Maclntyre et al..2020), which would again highlight these genes as high-priority candidates for further analyses. 
The third stipulation could be tested because of our approach of the RNA-Seq experiment. Using ten accessions, allowed us to correlate the number of galls formed per accession to gene-expression measured in the accession. This approach resulted in identifying 1,198 genes associated with susceptibility and of these 19 were among the 380 genes within the QTL. Usually, gene expression Quantitative Trait Locus (eQTL) mapping is done because it provides unprecedentedly rich, allele-specific expression data (Sun \& Hu, 2013; Lutz et al., 2019). Our RNA-Seq based experimental approach differs from the standard eQTL because of the integration of genomic data, phenotypic data and transcriptomic data of ten different tomato accessions. One of the caveats of this analysis could be that causal polymorphisms do not need to be transcriptionally reactive. Transcriptionally reactive polymorphisms in the promotor sequences on the other hand can be highly overrepresented. Therefore, future studies could integrate a motif analysis to include possible common promoter elements represented in the gene set. Altogether, the identified overlapping genes of the transcriptomic analysis and the cWA likely contain potential targets for future use in breeding.

\section{Conclusion}

In conclusion, our results suggest that tomato harbors a quantitative variation in susceptibility to $M$. incognita, which is independent of major R-genes. The significant narrow-sense heritability highlights the role of genetic variation in the variance of nematode-induced galls. Among the 156 sequenced tomato accessions, we identified a R-gene independent susceptibility associated with 25 loci, encompassing a total of 380 genes. Additionally, we were able to study variation in gene expression of the genes associated with susceptibility of S. Iycopersicum to M. incognita. We have now pinpointed 37 high priority candidate susceptibility-associated genes, although their role in plant parasitism by M. incognita and applicational use as leads for resistance breeding remains to be studied.

\section{Materials and methods}

\section{Bioassays}

\section{Nematodes}

Eggs of Meloidogyne incognita (strain 'Morelos' from INRA, Sophia Antipolis, France) were harvested from infected tomato plants grown on silver sand. First, the roots were rinsed in water to remove sand particles extracted eggs by incubation with $0.05 \%(\mathrm{v} / \mathrm{v})$ bleach for $3 \mathrm{~min}$ followed by sieving (Hussey \& Barker, 1973). Extracted eggs were stored for a maximum of two weeks at $17{ }^{\circ} \mathrm{C}$.

Four days before inoculation, the eggs were surface-sterilized by incubation in $0.02 \%(\mathrm{~W} / \mathrm{V})$ sodium azide for 20 min and washed thoroughly with tap water. Egg hatching was stimulated in dark conditions on a $25 \mu \mathrm{m}$ hatching sieve with $1.5 \mathrm{mg} / \mathrm{ml}$ gentamycin and $0.05 \mathrm{mg} / \mathrm{ml}$ nystatin. Shortly before inoculation, second stage juveniles (J2s) were collected on a $70 \%(\mathrm{~W} / \mathrm{V})$ sucrose column by centrifugation and surface-sterilized by incubating for 10 min in $0.002 \%$ 
( $/ \mathrm{V}$ ) Triton X-100, $0.004 \%(\mathrm{~W} / \mathrm{V})$ sodium azide, and $0.004 \%(\mathrm{~W} / \mathrm{V})$ mercuric chloride. Next, the J2s were washed in sterile tap water three times and transferred to a $0.7 \%(\mathrm{~W} / \mathrm{V})$ Gelrite solution (Duchefa Biochemie, Haarlem) for inoculation (Warmerdam et al., 2018).

\section{Quantifying susceptibility of tomato accessions to M. incognita}

First, leaf material of all tomato accessions was checked by PCR for presence of the Mi-7.2 resistance gene (Solyc06g008450) as described by Seah et al. (2007) with the primers Mi23F (TGGAAAAATCTTCAATTTCTTTTG) and Mi23R (GCATACTATATGGCTTGTTTACCC). For GWA analysis, 178 tomato accessions of S. Iycopersicum without the Mi-7.2 resistance gene were assayed for their susceptibility to M. incognita using in vitro infection assays (Supplementary Table S1).

To obtain plants, tomato seeds were incubated for three days in tap water at $4{ }^{\circ} \mathrm{C}$ in dark conditions before being washed with 70\% ( $/ / \mathrm{v})$ ethanol and sterilized in 2.5\% ( $/ \mathrm{v})$ bleach. Afterwards, seeds were washed three times for 10 minutes in sterile tap water and transferred to square plates containing $1 / 2$ MS2O medium (2.35 g/L Murashige and Skoog (MS) with vitamins (Duchefa Biochemie), $20 \mathrm{~g} / \mathrm{L}$ sucrose, $\mathrm{pH}$ 6.4, 0.7\% (w/v) Gelrite (Duchefa Biochemie)). After incubating for four days at $24^{\circ} \mathrm{C}$ under a $16 \mathrm{~h}$ light, $8 \mathrm{~h}$ dark regime, seedlings were transferred to $1 / 2$ MS2O square plates with only one plant per plate. Next, plants were allowed to grow for an additional six days. Thereafter, the plants were inoculated with $120 \mathrm{~J} 2 \mathrm{~s}$ of M. incognita. The number of root tips was counted shortly before inoculation to observe genotype specific aberrances in root architecture. Plates with the inoculated plants were kept horizontally in dark conditions for two days, after which they were placed diagonally at $24^{\circ} \mathrm{C}$ under a $16 \mathrm{~h}$ light, 8 h dark regime. Plates were covered by dark cardboard surrounding each plate it to simulate dark soil conditions, while the top was left exposed to light. Ten days after nematode inoculation, the number of galls formed in the roots was counted by visually inspecting the roots with a dissection microscope. The tomato accessions were screened in 25 batches with varying numbers of replications per batch and a combined minimum of 10 replications per accession (Supplementary Table S1). Each batch included a standard hybrid tomato line as a reference to allow for normalizing batch effects.

\section{Collecting galls induced by $M$. incognita for whole transcriptome analysis}

To correlate differences in gene-expression in nematode-infected roots with the genotype of tomato line, we collected galls from ten tomato accessions (i.e. RF004, RF005, RFO08, RF022, RF023, RFO29, RF032, RF036, RF041, and RF096) at different time point post inoculation. At 10 days after sowing plants were inoculated with either 0 or $120 \mathrm{~J} 2 \mathrm{~s}$ of $\mathrm{M}$. incognita as described above. At 1, 2, 3, 4, 7, and 10 days post inoculation, 50 - 90 galls per genotype were dissected from the roots and subsequently pooled for RNA sequencing. To enable the dissection of similar uninfected root segments, the position of the root tips was marked on the plates at the time of inoculation. At each of the specific time points after inoculation, the root segments located at the marker site were dissected to yield similar uninfected root segments. 


\section{Data analysis}

All analyses unless indicated otherwise were conducted in R (v. 3.5 .3 x64). For data filtering, organization, and plotting the tidyverse packages ggplot2, dplyr, tidyr, and broom were used. For some analyses specialized packages were used, which were listed in the relevant sections.

\section{Tomato genetic map}

The KeyGene Whole Genome Variant Discovery pipeline was used to identify SNPs and small INDELS of tomato samples using the Solanum lycopersicum version 4.0 reference genome (Hosmani et al., 2019).The pipeline supports the Genalice gaMap (mapping of high quality reads) and gaPopulation (variant calling of high quality variants) using the Genalice software version 2.4.14. In total, 43,926,971,902 reads were processed belonging to 156 tomato accessions of which on average $89.4125 \%$ mapped to the SL4.0 genome (Supplementary Table S4).

\section{Read pre-processing}

The raw sequencing data has been trimmed and filtered on sequence quality. The reads have been trimmed on minimum base quality phred score of 17, allowing a maximum of 10 base-quality misses. After trimming the minimum read length has been set to 75 bases and the maximum number of undetermined nucleotide per read has been set to 5 .

\section{Genome reference mapping}

Read pairs that pass the filtering have been mapped to the genome reference: 'SL4.0.fasta'. The genome consists of 13 chromosomes with a total size of 782,520,033 bases and an N50 contig index of 6 and N50 contig length of 65,269,487 bases. The reads with a mapping quality score of a least 60 have been used for variation detection. Duplicate reads have been marked based by gaMap CIGAR string filtering to be ignored in the genotyping step. The reference index has been performed with galndex, repeat k-size 96 .

\section{Variant calling}

Variants such as SNPs and INDELs have been identified using gaPopulation. The variants have been stored in a single Variant Call Format (*.vcf) file. These variants have been filtered on allele quality, sample quality and allele depth. A minimum allele quality of 30, minimum sample quality of 20 and minimum allele coverage depth of $7 X$ were used for filtering. Furthermore SNPS found in all samples that are identical have been discarded. Other filters have been turned off. Finally the filtered variants have been annotated using the public gene models with SNPeff.

After variant calling, variants of the 156 tomato accessions were filtered according to the following criteria: (i) the site was called in $>90 \%$ of the accessions, (ii) the minimum allele frequency was $5 \%$, (iii) the percentage of heterozygous accessions was $<50 \%$. Variants were filtered using the 'filterVcf' function in the ' $R$ ' (x64, v. 3.5.3) Bioconductor package VariantAnnotation (v. 3.10) (Obenchain et al., 2014). This resulted in a set of $3,149,679$ variants that were used for construction of a genetic map. 
The 3,149,679 variants over 156 tomato accessions were called as reference $86.5 \%$ of the cases, as alternative $10.5 \%$ of the cases, and heterozygous $2.5 \%$ of the cases. The remaining variant calls $(0.5 \%)$ were either missing or called as a second alternative allele, these were ignored in construction of the genetic map. To reduce the map-size, we filtered variants in perfect linkage by calculating the linkage between adjacent variants within a sliding-window of 1,000 variants. A block of linked variants was represented in the genetic map by the first occurring marker, reducing the map size to 489,119 variants.

\section{Construction of genetic map in tomato for GWA}

Based on the 489,119 variants in the genetic map, a kinship matrix was constructed, using the 'A.mat' function in the 'R' (x64, v. 3.5.3) package rrBLUP (v. 4.6.1) (Endelman, 2011). The population structure was analyzed using principal component analysis (prcomp function). To supplement the genetic map, we also determined the extent of linkage based on the 3,149,679 variant map, which was taken in account after GWA analysis.

To get an estimate of the linkage disequilibrium within the population, we determined the $95 \%$ distance interval of absolute linkage over the genome. This interval was 81,150 bases on a genome-wide level.

\section{Genome wide association analysis Bioassay data processing}

Before use in genome wide association analysis, the trait data was normalized to remove batch effects. The plants were scored over 25 batches in the period November 2016 to June 2017 for the three traits: (i) number of galls, (ii) the number of root tips, and (iii) the number of galls per tip. In each batch the Arlyco RZ Fl-Hybrid accession was included (referred to as ' Fl'), and was used to normalize against. Each trait value was batch-corrected based on the batch average of the Fl against the total average over all Fl measurements using

$$
T_{\text {norm }}=T_{i j}-\left(\bar{T}_{i, F]}-\bar{T}_{\text {total }, F]}\right)
$$

where $T_{\text {norm }}$ is the normalized trait (either number of galls, the number of root tips, or the number of galls per tip), $i$ is the batch $(1,2, \ldots, 25), j$ is the accession (one of 178 ; Supplementary Table S1), and $\bar{T}$ are the averaged trait values for the $\mathrm{Fl}$ accession.

We tested the effectiveness of the normalization by ANOVA (model: Trait = Batch + Accession). This showed that the normalization method reduced the amount of variance explained by batch from $30.0 \%$ to $11.2 \%$ for number of galls, from $25.5 \%$ to $16.4 \%$ for number of root tips. However, it increased the amount of variance explained by batch for the number of galls per root tip, from $7.7 \%$ to $13.5 \%$. Therefore, we continued with the normalized values for the number of galls, the normalized values for the number of root tips, and the raw values for the number of galls per root tip (Supplementary Table S2).

For further analysis, the three trait values were summarized per accession by eight statistics: 
the mean, the variance, five quantiles (10\%, 25\%, 50\%; median, 75\%, and 90\%), and the interquartile range. These can be found in Supplementary Table S3.

\section{Heritability analysis}

For all eight trait statistics determined per trait per accession, we determined the amount of additive genetic variation explaining trait variance. The narrow-sense heritability $\left(h^{2}\right)$ was calculated using a REML-based approach as implemented in the R package heritability (Gilmour et al., 1995; Kruijer et al., 2015). To determine whether the estimated $h^{2}$ was significant, we relied on a permutation approach. We permutated the data by randomly assigning the accession codes to the summary statistic and ran the algorithm. This was repeated 1,000 times, thereafter the $50^{\text {th }}$ highest $h^{2}$ value was taken as the boundary for $F D R=0.05$.

\section{Genome wide association mapping}

To identify variants associated with variance in traits over the tomato accessions, we used CWA mapping, as implemented in the 'R' (x64, v. 3.5.3) package rrBLUP (v. 4.6.1) (Endelman, 2011). We used the genetic map of 489,119 markers as variants and corrected for population structure using the kinship matrix. In this way, we mapped the $90 \%$ quantile and the mean for normalized number of galls, normalized number of root tips, and the number of galls per root tip.

To correct for multiple-testing, we first calculated the number of independent tests conducted using the genetic map. This was done by eigenvalue decomposition on the correlation matrix of the genetic map per chromosome. The correlation matrix measured linkage of markers, making the GWA mapping per marker non-independent. The correlation matrix was calculated using the cor function and the eigenvalues were calculated using the eigs_sym function in 'R' (x64, v. 3.5.3) of the Rspectra package (Li \& Ji, 2005). We calculated the 1,000 largest values. Eigenvalues larger than 1 were set to one, and the sum of the eigenvalue matrix was taken. We calculated these values per chromosome, under the assumption no (significant) linkage was present between chromosomes. This led to an estimation of 1,860 independent tests conducted by GWA analysis; which led to a Bonferroni-corrected multiple testing threshold of $-\log _{10}(p)=4.57$.

The confidence interval around the QTL was based on the previously determined 95\% distance interval of linkage. Per significant variant, we considered variants with overlapping linkage intervals as a single QTL. Thereafter, we took the leftmost and rightmost variant still significantly associated with the trait variance and $+/-81,150$ bases determined the confidence interval of the peak.

\section{Characterization of GWA QTL}

We performed several checks to determine independence and variance explained of found QTL. To test for independence, we calculated the pairwise correlation between markers und QTL identified for the same trait by GWA using cor in 'R' (x64, v. 3.5.3). QTL were considered unlinked when $r^{2}<0.8$. Furthermore, we also determined the linkage within the confidence 
region with the peak marker for each QTL.

The amount of variance explained by QTL was tested by running an additive ANOVA model on all the QTL found for a single trait summary statistic, by the model

$$
T_{i} \sim X_{1}+X_{2}+\ldots+X_{n}
$$

where $T$ is the trait summary statistic of $i$ (one of six, the mean and $90 \%$ quantile of: normalized number of galls, normalized number of root tips, and the raw number of galls per root tip) explained over the peak-markers $X$ ( $n$ depending on trait summary statistic).

\section{RNA-Seq tomato}

\section{Library preparation and sequencing}

Gall-enriched tomato root samples were snap-frozen in liquid nitrogen and homogenized using a Tissuelyzer (Qiagen, Hilden). Total RNA was isolated with the Maxwell Plant RNA kit (Promega, Madison) using the Maxwell 16 Robot (Promega) according to manufacturer's protocol. After isolation, 107 samples passed the RNA quality control done with a ND-1000 spectrophotometer (Isogen Life Science, Utrecht). The thirteen failing samples were: RF005 day 2 mock-infected, RFO08 day 4 mock-infected, RF008 day 4 infected, RF022 day 2 mock-infected, RFO22 day 2 infected, RF023 day 2 mock-infected, RFO23 day 2 infected, RF032 day 10 mock-infected, RF032 day 2 infected, RF036 day 4 mock-infected, RF036 day 4 infected, RF041 day 7 infected, RFO96 day 10 mock-infected. General RNA (transcriptome) sequencing and quality filtering was done using BGISEQ-50O at BGI TECH SOLUTIONS (Hongkong), providing at least 40 million clean paired-end reads of 100 bp per sample.

\section{RNA-Seq data mapping, quantification and normalization}

The reads from all 107 samples were mapped to the reference genome sequence of both the tomato SL4.0 genome, with the ITAG4.0 annotation obtained from Sol Genomics Network (Hosmani et al., 2019) and M. incognita (PRJEB8714)(Blanc-Mathieu et al., 2017) and A. thaliana (TAIR10)(Lamesch et al.. 2011) using HISAT2 v2.2.0 in downstream-transcriptome-assembly mode (Kim et al.. 2019). The detection of M. incognita expression was more challenging than expression in tomato because of the overrepresentation of tomato cells in the sequenced material. Nonetheless, we were able to quantify expression of $M$. incognita genes. Gene expression for M. incognita and A. thaliana was quantified and TPM-normalized by assembling RNA-Seq alignments into transcripts, guided by reference annotations using StringTie v2.1.2 (Pertea et al., 2015).

Before analysis, we filtered and transformed the TPM values. First, we filtered the tomato gene-expression for read detection in all samples, this left us with 18,791 detected genes (out of 34,075 protein coding genes in the assembly). For M. incognita, we filtered gene-expression for read detection in at least 50\% of the infected samples (27 / 54), this left us with 9,915 detected genes (out of 43,718 protein coding genes in the assembly). This more relaxed threshold was chosen because of the low coverage of M. incognita reads. Subsequently, the TPM values were transformed by 


$$
T P M_{\text {log, } i j}=\log _{2}\left(T P M_{i j}+1\right)
$$

where TPM $M_{\log }$ was the $\log _{2}$-normalized TPM value of gene $i$ (one out of 18,791 for tomato and 9,915 for M. incognita) and sample $j$ (one out of 107 samples for tomato and 54 for $M$. incognita).

For principal component and correlation analysis, we also calculated a ratio with the mean of the TPM, by

$$
T P M_{\text {ratio, }, j}=\log _{2}\left(\frac{T P M_{i, j}}{\overline{T P M_{i}}}\right)
$$

where TPM ${ }_{\text {ratio }}$ was the $\log _{2}$ of the TPM value of gene $i$ (one out of 18,791 for tomato and 9,915 for M. incognita) and sample $j$ (one out of 107 samples for tomato and 54 for M. incognita), divided by the average TPM value over all samples for gene $i$.

\section{Principal component analysis}

To understand the sources of variance in the expression data, principal component analysis was used. We used the prcomp function in 'R' with the parameter scale. = TRUE on the TPM ra-

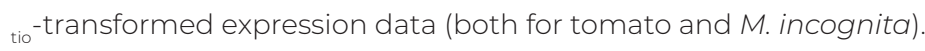

\section{RNA-Seq linear models}

To identify differentially expressed genes, we used two sets of linear models for the tomato gene-expression data.

The first linear model helped us identify genes that were differentially expressed over time and related to infection, fitting the data to the model

$$
T P M_{\text {log }, i j}=T_{j}+I_{j}+T_{j}+I_{j}
$$

where TPM $M_{\text {log }}$ of gene $i$ (one out of 18,791) and sample $j$ (one out of 107 samples for tomato) was explained over time $T$ (1, 2, 3, 4, 7, and 10 days post inoculation), inoculation status I (M. incognita or mock) and the interaction between the two terms. This model sought to identify the overall effect of $M$. incognita infection on local gene expression, regardless of the tomato accession that was infected. On this model we used a strict method of multiple-testing correction to prevent effects from differential expression among the ten strains to affect the genes we found. Hence, we Bonferroni-corrected the obtained p-values to come to differentially expressed genes $\mathrm{p}_{\text {bonf }}<0.05$ as implemented in the p.adjust function.

The second linear model helped to identify genes of which the expression was related to the susceptibility of the accessions to infection with M. incognita by explaining expression using

$$
T P M_{\log , i j}=T_{j}+G_{j}
$$

where TPM $M_{\text {log }}$ of gene $i$ (one out of 18,791) and sample $j$ (one out of 54 infected samples for tomato) was explained over time $T$ (1, 2, 3, 4, 7, and 10 days post inoculation), susceptibility measurement $G$ (the mean or 990 of normalized number of galls or galls per tip). As we were looking for genes expressed differentially per se the interaction term was dropped from this model. Hence, the model sought to identify gene expression linked to the susceptibility of 
tomato accessions. Given that genotypic variation was taken into account in this model, we were less strict in the application of multiple-testing correction using a false discovery rate $(q<$ 0.05) as implemented in the p.adjust function.

\section{Visualizing gene expression data}

To visualize the gene expression differences, we used k-means clustering to arrange the genes in clusters with similar expression patterns. To this end 1-20 clusters were explored using kclust, based on the drop in variance explained, 4 clusters were chosen as optimal for visualizing the data.

\section{Enrichment analysis}

Gene enrichment analyses were conducted using the GO annotations provided by ITAC 4.O. TO connect the GO-ID numbers to descriptions we used the Go.db package from Bioconductor.

\section{Acknowledgements}

This project receives financial support from the Topsector Horticulture and Starting Materials. Businesses, knowledge institutes and government work together in the top sector to develop innovations in the sustainable production of healthy and safe food and contribute to a healthy, green environment. Contributions from Rijk Zwaan and KeyGene are gratefully acknowledged. M.G.S. was supported by NWO domain Applied and Engineering Sciences VENI grant (17282). The authors would like to thank Unifarm of Wageningen University and Research for support with the plant materials. The authors declare that they have no competing interests.

\section{Author contributions}

G.S. and A.G. conceived the study. S.W., N.G., C.C.S., M.O. and J.L.T. conducted the experiments. M.G.S., A.V. and J.V.S. analyzed and interpreted the data and M.G.S., A.V., A.G. and G.S. wrote the chapter.

\section{References}

Abad P, Castagnone-Sereno P, Rosso MN, Engler JdA, Favery B. 2009. Invasion, feeding and development. In: Perry RN, Moens M, Starr JL eds. Root-knot nematodes. Wallingford: CABI, 163-181.

Abad P, Williamson VM. 2010. Plant nematode interaction: a sophisticated dialogue. Advances in Botanical Research 53 : 147-192.

Anwar SA, McKenry MV. 2010. Incidence and reproduction of Meloidogyne incognita on vegetable crop genotypes. Pakistan Journal of Zoology 42(2).

Bai Y, Kissoudis C, Yan Z, Visser RGF, van der Linden G. 2018. Plant behaviour under combined stress: tomato responses to combined salinity and pathogen stress. The Plant Journal 93(4): 787-793.

Barbary A, Djian-Caporalino C, Palloix A, Castagnone-Sereno P. 2015. Host genetic resistance to root-knot nematodes, Meloidogyne spp., in Solanaceae: from genes to the field. Pest Management Science 71(12): 1591-1598.

Barcala M, García A, Cabrera J, Casson S, Lindsey K, Favery B, García-Casado G, Solano R, Fenoll C, Escobar C. 2010. Early transcriptomic events in microdissected Arabidopsis nematode-induced giant cells. The Plant Journal 61(4): 698-712. 
Bartlem DG, Jones MG, Hammes UZ. 2013. Vascularization and nutrient delivery at root-knot nematode feeding sites in host roots. Journal of experimental botany: ert475.

Bebber DP, Holmes T, Gurr SJ. 2014. The global spread of crop pests and pathogens. Global Ecology and Biogeography 23(12): 1398-1407.

Bergougnoux V. 2014. The history of tomato: From domestication to biopharming. Biotechnology Advances 32(1): 170-189.

Blanc-Mathieu R, Perfus-Barbeoch L, Aury J-M, Da Rocha M, Gouzy J, Sallet E, Martin-Jimenez C, Bailly-Bechet M, Castagnone-Sereno P, Flot J-F, et al. 2017. Hybridization and polyploidy enable genomic plasticity without sex in the most devastating plant-parasitic nematodes. PLoS Genetics 13(6): el006777.

Bush WS, Moore JH. 2012. Chapter 11: Genome-Wide Association Studies. PLOS Computational Biology: Public Library of Science. e1002822.

de Carvalho LM, Benda ND, Vaughan MM, Cabrera AR, Hung K, Cox T, Abdo Z, Allen LH, Teal PE. 2015. Mi-7-mediated nematode resistance in tomatoes is broken by short-term heat stress but recovers over time. Journal of nematology 47(2): 133.

Devran Z, Söğüt MA, Mutlu Nm. 2010. Response of tomato rootstocks with the Mi resistance gene to Meloidogyne incognita race 2 at different soil temperatures. Phytopathologia Mediterranea 49(1): 11-17.

Dimkpa SON, Lahari Z, Shrestha R, Douglas A, Gheysen G, Price AH. 2015. A genome-wide association study of a global rice panel reveals resistance in Oryza sativa to root-knot nematodes. Journal of experimental botany 67(4): 1191-1200.

Dutta TK, Papolu PK, Banakar P, Choudhary D, Sirohi A, Rao U. 2015. Tomato transgenic plants expressing hairpin construct of a nematode protease gene conferred enhanced resistance to root-knot nematodes. Frontiers in Microbiology 6(APR).

El-Sappah AH, M M I, H El-Awady H, Yan S, Qi S, Liu J, Cheng G-T, Liang Y. 2019. Tomato natural resistance genes in controlling the root-knot nematode. Genes 10(11): 925

Endelman JB. 2011. Ridge regression and other kernels for genomic selection with R package rrBLUP. The Plant Genome 4(3): 250-255.

Favery B, Quentin M, Jaubert-Possamai S, Abad P. 2016. Gall-forming root-knot nematodes hijack key plant cellular functions to induce multinucleate and hypertrophied feeding cells. Journal of Insect Physiology 84: 60-69.

Gilmour AR, Thompson R, Cullis BR. 1995. Average information REML: An efficient algorithm for variance parameter estimation in linear mixed models. Biometrics 51(4): 1440-1450.

Guan T, Shen J, Fa Y, Su Y, Wang X, Li H. 2017. Resistance-breaking population of Meloidogyne incognita utilizes plant peroxidase to scavenge reactive oxygen species, thereby promoting parasitism on tomato carrying Mi-7 gene. Biochemical and Biophysical Research Communications 482(1): 1-7.

Hahnel SR, Zdraljevic S, Rodriguez BC, Zhao Y, McGrath PT, Andersen EC. 2018. Extreme allelic heterogeneity at a Caenorhabditis elegans beta-tubulin locus explains natural resistance to benzimidazoles. PLoS Pathogens 14(10): el007226.

Hewezi T, Baum TJ. 2013. Manipulation of plant cells by cyst and root-knot nematode effectors. Molecular Plant-Microbe Interactions 26(7): 9-16.

Hosmani PS, Flores-Gonzalez M, van de Geest H, Maumus F, Bakker LV, Schijlen E, van Haarst J, Cordewener J, Sanchez-Perez G, Peters S, et al. 2019. An improved de novo assembly and annotation of the tomato reference genome using single-molecule sequencing, Hi-C proximity ligation and optical maps. bioRxiv: 767764.

Hunt DJ, Handoo ZA. 2009. Taxonomy, identification and principal species. In: Perry RN ed. Root-knot nematodes, 55-88.

Hussey RS, Barker KR. 1973. Comparison of methods of collecting inocula of Meloidogyne spp., including a new technique. Plant disease reporter.

Iberkleid I, Ozalvo R, Feldman L, Elbaz M, Patricia B, Horowitz SB. 2014. Responses of tomato genotypes to avirulent and Mi-virulent Meloidogyne javanica isolates occurring in Israel. Phytopathology 104(5): 484-496.

Jones JT, Haegeman A, Danchin EG, Gaur HS, Helder J, Jones MG, Kikuchi T, Manzanilla-López R, Palomares-Rius JE, Wesemael WM. 2013. Top 10 plant-parasitic nematodes in molecular plant pathology. Molecular Plant Pathology 14(9): 946-967.

Kaloshian I, Williamson VM, Miyao G, Lawn DA, WesterdahI BB. 1996. "Resistance-breaking" nematodes identified in California tomatoes. California Agriculture 50(6): 18-19.

Kim D, Paggi JM, Park C, Bennett C, Salzberg SL. 2019. Graph-based genome alignment and genotyping with HISAT2 and HISAT-genotype. Nature biotechnology 37(8): 907-915.

Kruijer W, Boer MP, Malosetti M, Flood PJ, Engel B, Kooke R, Keurentjes JJB, van Eeuwijk FA. 2015. Marker-based estimation of heritability in immortal populations. Genetics 199(2): 379

Kyndt T, Denil S, Haegeman A, Trooskens G, Bauters L, Van Criekinge W, De Meyer T, Gheysen G. 2012. Transcriptional reprogramming by root knot and migratory nematode infection in rice. New Phytologist 196(3): 887-900.

Kyndt T, Vieira P, Gheysen G, de Almeida-Engler J. 2013. Nematode feeding sites: unique organs in plant roots. Planta 238(5): 807-818. 
Lamesch P, Berardini TZ, Li D, Swarbreck D, Wilks C, Sasidharan R, Muller R, Dreher K, Alexander DL, Garcia-Hernandez M, et al. 2011. The Arabidopsis Information Resource (TAIR): improved gene annotation and new tools. Nucleic acids research 40(D1): D1202-D1210.

Li J, Ji L. 2005. Adjusting multiple testing in multilocus analyses using the eigenvalues of a correlation matrix. Heredity 95(3): 221-227.

Lutz SM, Thwing A, Fingerlin T. 2019. eQTL mapping of rare variant associations using RNA-seq data: An evaluation of approaches. PLOS ONE 14(10): e0223273.

MacIntyre AM, Barth JX, Pellitteri Hahn MC, Scarlett CO, Genin S, Allen C. 2020. Trehalose synthesis contributes to osmotic stress tolerance and virulence of the bacterial wilt pathogen Ralstonia solanacearum. Molecular plant-microbe interactions: MPM/ 33(3): 462-473.

Mitchum MG, Hussey RS, Baum TJ, Wang X, Elling AA, Wubben M, Davis EL. 2013. Nematode effector proteins: an emerging paradigm of parasitism. New Phytologist 199(4): 879-894

Moens M, Perry RN, Starr JL. 2009. Meloidogyne species-a diverse group of novel and important plant parasites. Root-knot nematodes, 1-17.

Mukhtar T, Arooj M, Ashfaq M, Gulzar A. 2017. Resistance evaluation and host status of selected green gram germplasm against Meloidogyne incognita. Crop protection 92: 198-202.

Niu J, Jian H, Xu J, Chen C, Guo Q, Liu Q, Guo Y. 2012. RNAi silencing of the Meloidogyne incognita Rpn7 gene reduces nematode parasitic success. European Journal of Plant Pathology 134(1): 131-144

Obenchain V, Lawrence M, Carey V, Gogarten S, Shannon P, Morgan M. 2014. VariantAnnotation : a Bioconductor package for exploration and annotation of genetic variants. Bioinformatics 30(14): 2076-2078.

Passianotto ALdL, Sonah H, Dias WP, Marcelino-Guimarães FC, Belzile F, Abdelnoor RV. 2017. Genome-wide association study for resistance to the southern root-knot nematode (Meloidogyne incognita) in soybean. Molecular Breeding 37(12): 148.

Pertea M, Pertea GM, Antonescu CM, Chang T-C, Mendell JT, Salzberg SL. 2015. StringTie enables improved reconstruction of a transcriptome from RNA-seq reads. Nature biotechnology 33(3): 290-295.

Qiu Z, Li R, Zhang S, Wang K, Xu M, Li J, Du Y, Yu H, Cui X. 2016. Identification of regulatory DNA elements using genome-wide mapping of DNase I hypersensitive sites during tomato fruit development. Molecular Plant 9(8): 1168-1182.

Roux F, Bergelson J. 2016. Chapter Four - The genetics underlying natural variation in the biotic interactions of Arabidopsis thaliana: The challenges of linking evolutionary genetics and community ecology. In: Orgogozo $\vee$ ed. Current Topics in Developmental Biology: Academic Press, 111-156

Sasai R, Tabuchi H, Shirasawa K, Kishimoto K, Sato S, Okada Y, Kuramoto A, Kobayashi A, Isobe S, Tahara M, et al. 2019. Development of molecular markers associated with resistance to Meloidogyne incognita by performing quantitative trait locus analysis and genome-wide association study in sweetpotato. DNA Research 26(5): 399-409.

Seah S, Williamson VM, Garcia BE, Mejia L, Salus MS, Martin CT, Maxwell DP. 2007. Evaluation of a co-dominant SCAR marker for detection of the Mi-7 locus for resistance to root-knot nematode in tomato germplasm. Tomato Genetic Cooperative Report(57): 37-40.

Seung D, Echevarría-Poza A, Steuernagel B, Smith AM. 2020. Natural polymorphisms in Arabidopsis result in wide variation or loss of the amylose component of starch. Plant Physiology 182(2): 870 .

Sul JH, Martin LS, Eskin E. 2018. Population structure in genetic studies: Confounding factors and mixed models. PLOS Genetics 14(12): e1007309.

Sun W, Hu Y. 2013. eQTL mapping using RNA-seq data. Statistics in biosciences 5(1): 198-219.

The 100 Tomato Genome Sequencing Consortium, Aflitos S, Schijlen E, de Jong H, de Ridder D, Smit S, Finkers R, Wang J, Zhang G, Li N, et al. 2014. Exploring genetic variation in the tomato (Solanum section Lycopersicon) clade by whole-genome sequencing. The Plant Journal 80 (1): 136-148.

Verdejo-Lucas S, Talavera M, Andrés MF. 2012. Virulence response to the Mi.1 gene of Meloidogyne populations from tomato in greenhouses. Crop protection 39: 97-105.

Warmerdam S, Sterken MG, van Schaik C, Oortwijn ME, Sukarta OC, Lozano-Torres JL, Dicke M, Helder J, Kammenga JE, Goverse A. 2018. Genome-wide association mapping of the architecture of susceptibility to the root-knot nematode Meloidogyne incognita in Arabidopsis thaliana. New Phytologist 218(2): 724-737.

Warmerdam S, Sterken MG, Van Schaik C, Oortwijn MEP, Lozano-Torres JL, Bakker J, Goverse A, Smant G. 2019. Mediator of tolerance to abiotic stress ERF6 regulates susceptibility of Arabidopsis to Meloidogyne incognita. Molecular Plant Pathology 20(1): 137-152.

Wyss U, Grundler F. 1992. Feeding behavior of sedentary plant parasitic nematodes. Netherlands Journal of Plant Pathology 98(2): 165-173. 


\section{Supplemental information}

Supplemental figures

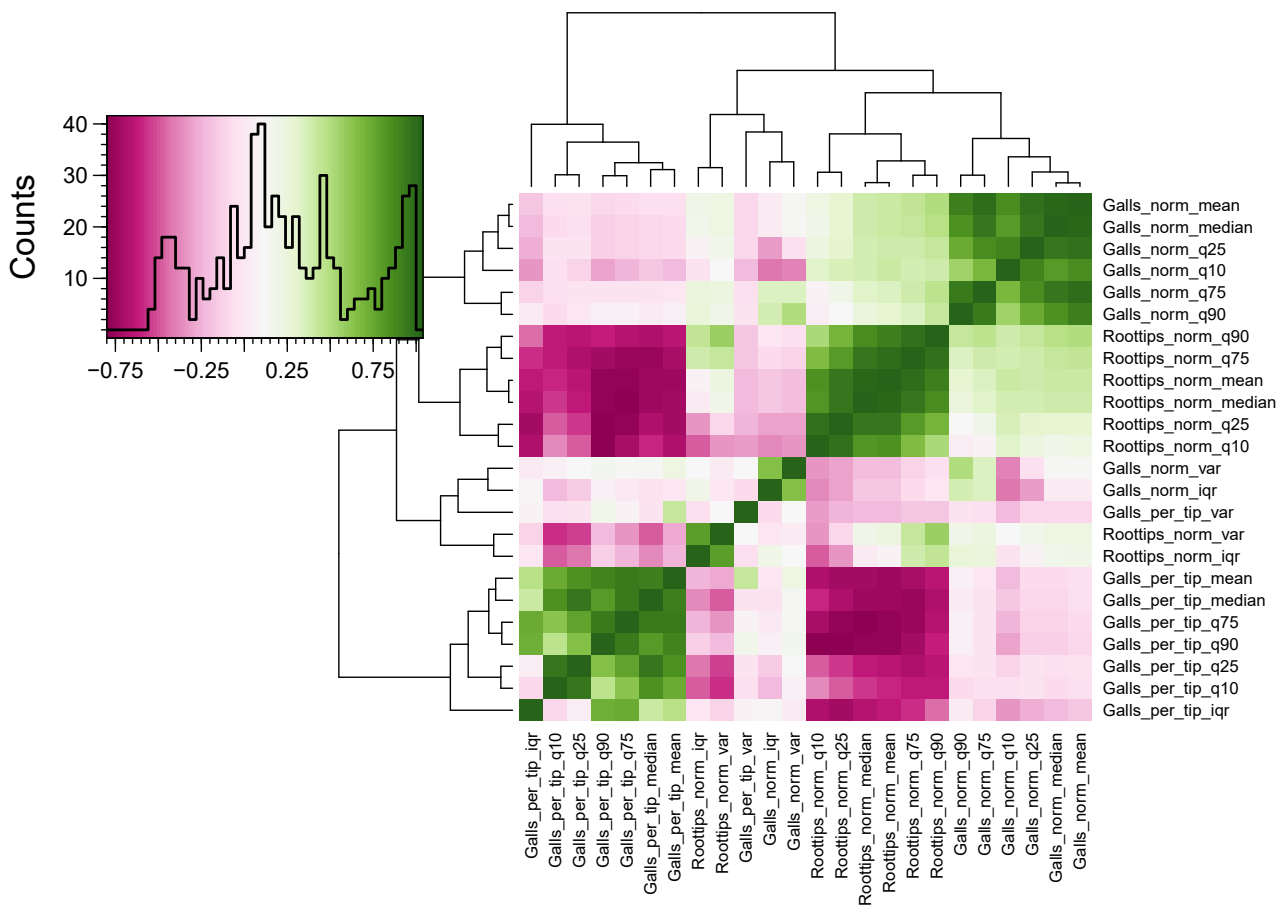

Supplemental Figure S1: Pearson correlation between the summary statistics for the three traits measured in the tomato accessions. Note that the diagonal is the autocorrelation. The colour scale indicates the strength of the correlation (negative: purple, positive: green). 
A

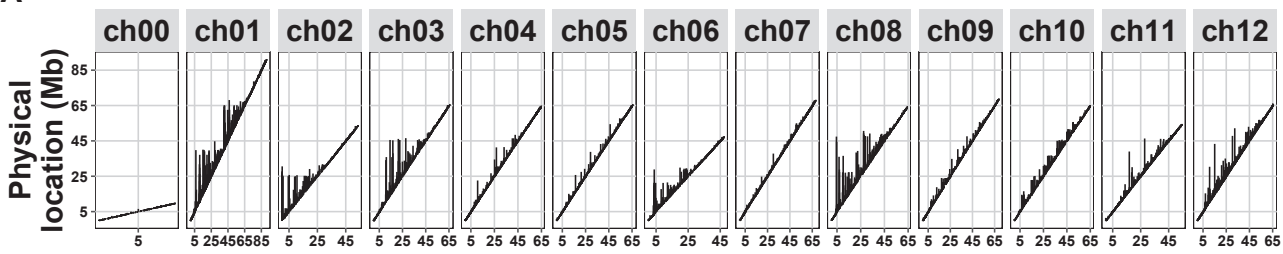

Physical location (Mb)

B
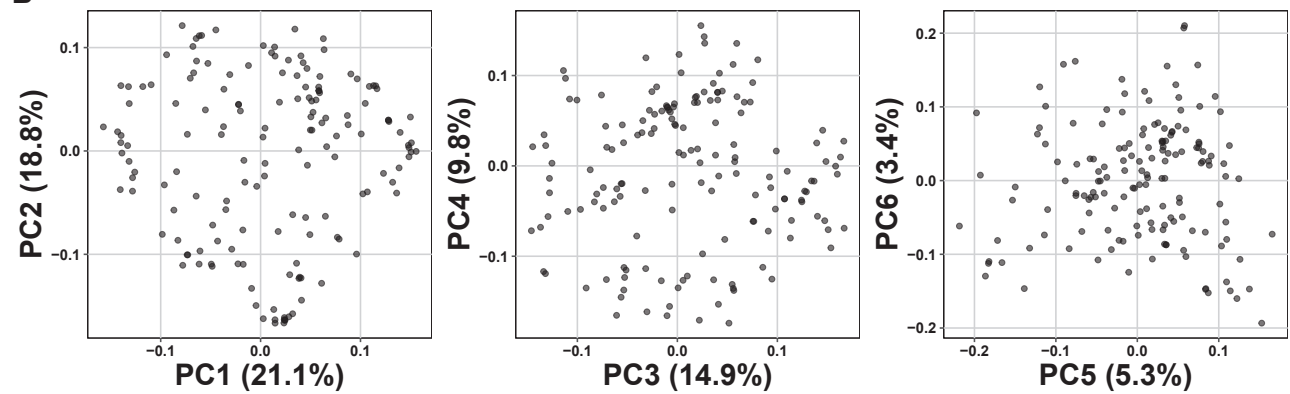

Supplemental Figure S2: The structure of the genetic map of the 156 tomato accessions used for GWA mapping. (A) the extend of linkage over the physical map per chromosome. Each line indicates linkage between variants from most proximal variant ( $\mathrm{x}$-axis) to the most distal variant ( $\mathrm{y}$-axis). (B) principal component analysis of the kinship matrix. The first six principal component axes are shown. As there is no clear clustering or separation into sub-populations visible ( $>3.4 \%$ of variance) we concluded there is little population structure in the used accessions.

\section{Supplemental tables}

Only the head and tail of the supplemental tables are depicted here. The full tables are deposited at: shorturl.at/aoxOT

Supplemental Table S1. List of 178 tomato accessions where also the batches of the GWA experiment are indicated.

\begin{tabular}{|c|c|c|c|c|c|c|c|}
\hline Nr. & Accession & $\begin{array}{l}\text { Sequence } \\
\text { data }\end{array}$ & Source & Species_name & $\begin{array}{l}\text { Acces- } \\
\text { sion_name }\end{array}$ & $\begin{array}{l}\text { Accesion_ } \\
\text { EUSOL_ID }\end{array}$ & Batches \\
\hline 1 & $\mathrm{Fl}$ & Yes & RZ & S. Iycopersicum & $\begin{array}{l}\text { Arlyco RZ } \\
\text { Fl-Hybrid }\end{array}$ & 72-385 RZ & $\begin{array}{l}1 ; 2 ; 3 ; 4 ; 5 ; 6 ; 7 ; 8 ; 9 ; 10 ; 17 ; 12 ; 13 ; \\
14 ; 15 ; 16 ; 17 ; 18 ; 19 ; 20 ; 21 ; 22 ; 2 \\
3 ; 24 ; 25\end{array}$ \\
\hline 2 & MM & Yes & WUR & S. Iycopersicum & $\begin{array}{l}\text { MoneyMaker } \\
\text { 'Pieter Pik' }\end{array}$ & & $1 ; 2 ; 3$ \\
\hline 3 & RFO02 & Yes & CGN & S. Iycopersicum & Ailsa Craig & several & 4 \\
\hline 4 & RFO03 & Yes & CGN & S. Iycopersicum & $\begin{array}{l}\text { Garderners } \\
\text { Delight }\end{array}$ & EA06086 & 21 \\
\hline 5 & RFOO4 & Yes & $\mathrm{CGN}$ & S. Iycopersicum & Rutgers & EA00465 & 21 \\
\hline \multicolumn{8}{|l|}{$\ldots$} \\
\hline 176 & WiD11F12_6562 & Yes & VCO & S. Iycopersicum & 692-HZ-088 & & 24 \\
\hline 177 & WiD11F12_6566 & Yes & VCO & S. Iycopersicum & 692-HZ-092 & & 22 \\
\hline 178 & WiD11F12_6567 & Yes & VCO & S. Iycopersicum & $\begin{array}{l}\text { 692-HZ-093- } \\
\text { CATIE-30 }\end{array}$ & & 22 \\
\hline
\end{tabular}


Supplemental Table S2. Trait measurements for normalized galls, normalized number of root tips and galls per root tip as used as basis for heritability and GWA analysis.

\begin{tabular}{llllll}
\hline \hline Nr. & Batch & Accession & Galls_norm & Roottips_norm & Galls_per_tip \\
\hline 1 & 1 & Fl & 33.23 & 15.50 & 2.00 \\
\hline 2 & 1 & Fl & 31.23 & 15.50 & 1.90 \\
\hline 3 & 1 & F7 & 41.23 & 33.50 & 1.26 \\
\hline 4 & 1 & Fl & 59.23 & 70.50 & 0.88 \\
\hline 5 & 1 & Fl & 23.23 & 16.50 & 1.43 \\
\hline$\ldots$ & & & & 2.60 \\
\hline 2598 & 25 & WiD11F12_6547 & 30.24 & 12.46 & 1.44 \\
\hline 2599 & 25 & WiD11F12_6547 & 30.24 & 24.46 & 2.95 \\
\hline 2600 & 25 & WiD11F12_6547 & 50.24 & 17.46 & \\
\hline \hline
\end{tabular}

Supplemental Table S3. Trait value summary statistics per accession for normalized galls, normalized number of root tips and galls per root tip.

\begin{tabular}{|c|c|c|c|c|c|c|}
\hline $\mathrm{Nr}$. & Accession & plants_n & $\begin{array}{l}\text { Summary } \\
\text { statistic }\end{array}$ & Galls_norm & Roottips_norm & Galls_per_tip \\
\hline 1 & $\mathrm{Fl}$ & 308 & Mean & 40.590 & 32.363 & 1.408 \\
\hline 2 & $\mathrm{Fl}$ & 308 & Var & 67.293 & 104.273 & 0.410 \\
\hline 3 & $\mathrm{Fl}$ & 308 & IQR & 9.806 & 10.164 & 0.572 \\
\hline 4 & $\mathrm{Fl}$ & 308 & Median & 41.461 & 31.888 & 1.319 \\
\hline 5 & $\mathrm{Fl}$ & 308 & $\mathrm{q} 10$ & 30.506 & 27.126 & 0.822 \\
\hline \multicolumn{7}{|l|}{$\ldots$} \\
\hline 1422 & WiD11F12_6567 & 10 & q25 & 37.107 & 20.957 & 1.430 \\
\hline 1423 & WiDI1F12_6567 & 10 & q75 & 44.107 & 29.457 & 2.192 \\
\hline 1424 & WiD11F12_6567 & 10 & q90 & 49.657 & 31.457 & 2.826 \\
\hline
\end{tabular}

Supplemental Table S4. Overview of the reads mapped to SL4.0 for the tomato genetic map. In total, reads of 156 tomato accessions were processed.

\begin{tabular}{llllllll}
\hline \hline Nr. & Sample & Raw reads & Filtered reads & Mapped reads & $\begin{array}{l}\text { Duplicated } \\
\text { reads }\end{array}$ & $\begin{array}{l}\text { \% of filtered } \\
\text { reads }\end{array}$ & $\begin{array}{l}\text { \% of mapped } \\
\text { reads }\end{array}$ \\
\hline 1 & F1 & 204666006 & 204521668 & 182557774 & 17742775 & 99.93 & 89.2 \\
\hline 2 & MM & 206732248 & 206730495 & 189478449 & 16307552 & 100 & 91.65 \\
\hline 3 & RFO02 & 361403404 & 360622946 & 324196030 & 12594341 & 99.78 & 89.7 \\
\hline 4 & RFO03 & 373210924 & 368850914 & 317578274 & 14337596 & 98.83 & 85.09 \\
\hline 5 & RF004 & 379457578 & 374971610 & 336114888 & 14715491 & 98.82 & 88.58 \\
\hline$\ldots$ & & & & & & 90.35 \\
\hline 154 & WiDl1F12_6562 & 224678768 & 224566637 & 203002546 & 19675746 & 99.95 & 89.4 \\
\hline 155 & WiDl1F12_6566 & 238465728 & 238343821 & 213177688 & 21827644 & 99.95 & 88.73 \\
\hline 156 & WiDl1F12_6567 & 205132548 & 205033822 & 182009432 & 16774979 & 99.95 & 89.088 \\
\hline \hline
\end{tabular}


Supplemental Table S5. Outcome of an enrichment analysis on the 693 genes differentially expressed for infection and 939 genes significantly affected by time and infection. The enrichment is presented in fold-enrichment (overlap divided by expected overlap). And as significance; the column significance indicates the significance as found by the hypergeometric test, the FDR column shows the significance after correcting for multiple testing

\begin{tabular}{|c|c|c|c|c|c|c|c|c|c|}
\hline Nr. & Term & $\begin{array}{l}\text { Annota- } \\
\text { tion }\end{array}$ & Group & $\begin{array}{l}\text { Genes_ } \\
\text { in_group }\end{array}$ & $\begin{array}{l}\text { Overlap_ } \\
\text { expected }\end{array}$ & Overlap & $\begin{array}{l}\text { Fold_- } \\
\text { enrich- } \\
\text { ment }\end{array}$ & Sign. & FDR \\
\hline 1 & day & ITAG 4.0 & 7S RNA binding & 5 & 2.235 & 5 & 2.237 & 0 & 0 \\
\hline 2 & day & ITAG 4.0 & $\begin{array}{l}\text { ATP hydrolysis coupled } \\
\text { proton transport }\end{array}$ & 19 & 8.494 & 14 & 1.648 & 0.003 & 0.021 \\
\hline 3 & day & ITAG 4.0 & $\begin{array}{l}\text { ATP synthesis coupled } \\
\text { proton transport }\end{array}$ & 20 & 8.942 & 16 & 1.789 & 0.000 & 0.004 \\
\hline 4 & day & ITAG 4.0 & $\begin{array}{l}\text { cell wall macromolecule } \\
\text { catabolic process }\end{array}$ & 8 & 3.577 & 7 & 1.957 & 0.002 & 0.015 \\
\hline 5 & day & ITAG 4.0 & $\begin{array}{l}\text { cellular amino acid } \\
\text { metabolic process }\end{array}$ & 11 & 4.918 & 9 & 1.830 & 0.002 & 0.019 \\
\hline \multicolumn{10}{|l|}{$\ldots$} \\
\hline 64 & treatment & ITAG 4.0 & chitinase activity & 8 & 0.295 & 3 & 10.168 & 0.000 & 0.002 \\
\hline 65 & treatment & ITAG 4.0 & metal ion binding & 118 & 4.352 & 10 & 2.298 & 0.004 & 0.032 \\
\hline 66 & treatment & ITAG 4.0 & $\begin{array}{l}\text { trehalose biosynthetic } \\
\text { process }\end{array}$ & 17 & 0.627 & 5 & 7.975 & 0.000 & 0.000 \\
\hline
\end{tabular}

Supplemental Table S6. Outcome of an enrichment analysis on 1,198 unique genes that were associated with susceptibility of an accession. The enrichment is presented in fold-enrichment (overlap divided by expected overlap). And as significance; the column significance indicates the significance as found by the hypergeometric test, the FDR column shows the significance after correcting for multiple testing.

\begin{tabular}{|c|c|c|c|c|c|c|c|c|c|}
\hline $\mathrm{Nr}$. & Term & Annotation & Group & $\begin{array}{l}\text { Genes_ } \\
\text { in_group }\end{array}$ & $\begin{array}{l}\text { Overlap_ } \\
\text { expected }\end{array}$ & Overlap & $\begin{array}{l}\text { Fold_- } \\
\text { enrich- } \\
\text { ment }\end{array}$ & Sign & FDR \\
\hline 1 & $\begin{array}{l}\text { Galls_norm } \\
\text { mean }\end{array}$ & ITAG4.0 & $\begin{array}{l}\text { ATP synthesis } \\
\text { coupled proton } \\
\text { transport }\end{array}$ & 20 & 0.417 & 3 & 7.190 & 0.001 & 0.009 \\
\hline 2 & $\begin{array}{l}\text { Galls_norm } \\
\text { mean }\end{array}$ & ITAG4.0 & $\begin{array}{l}\text { electron transfer } \\
\text { activity }\end{array}$ & 68 & 1.419 & 5 & 3.525 & 0.003 & 0.028 \\
\hline 3 & $\begin{array}{l}\text { Galls_norm } \\
\text { mean }\end{array}$ & ITAG4.0 & $\begin{array}{l}\text { flavin adenine } \\
\text { dinucleotide } \\
\text { binding }\end{array}$ & 43 & 0.897 & 4 & 4.459 & 0.002 & 0.020 \\
\hline 4 & $\begin{array}{l}\text { Galls_norm } \\
\text { mean }\end{array}$ & ITAG 4.0 & nucleosome & 52 & 1.085 & 4 & 3.687 & 0.004 & 0.032 \\
\hline 5 & $\begin{array}{l}\text { Galls_norm } \\
\text { mean }\end{array}$ & ITAG4.0 & $\begin{array}{l}\text { oxidation-reduction } \\
\text { process }\end{array}$ & 721 & 15.041 & 31 & 2.061 & 0.000 & 0.001 \\
\hline \multicolumn{10}{|l|}{$\ldots$} \\
\hline 28 & $\begin{array}{l}\text { Galls_per_tip_ } \\
\text { q90 }\end{array}$ & ITAG4.0 & $\begin{array}{l}\text { polygalacturonase } \\
\text { activity }\end{array}$ & 20 & 0.662 & 3 & 4.532 & 0.004 & 0.030 \\
\hline 29 & $\begin{array}{l}\text { Galls_per_tip_ } \\
\text { q90 }\end{array}$ & ITAG4.0 & $\begin{array}{l}\text { squalene } \\
\text { monooxygenase } \\
\text { activity }\end{array}$ & 4 & 0.132 & 3 & 22.658 & 0.000 & 0.000 \\
\hline 30 & $\begin{array}{l}\text { Galls_per_tip_ } \\
\text { q90 }\end{array}$ & ITAG4.0 & $\begin{array}{l}\text { transferase activity, } \\
\text { transferring glycosyl } \\
\text { groups }\end{array}$ & 81 & 2.681 & 7 & 2.611 & 0.005 & 0.035 \\
\hline
\end{tabular}


R-gene independent variation in susceptibility of tomato 


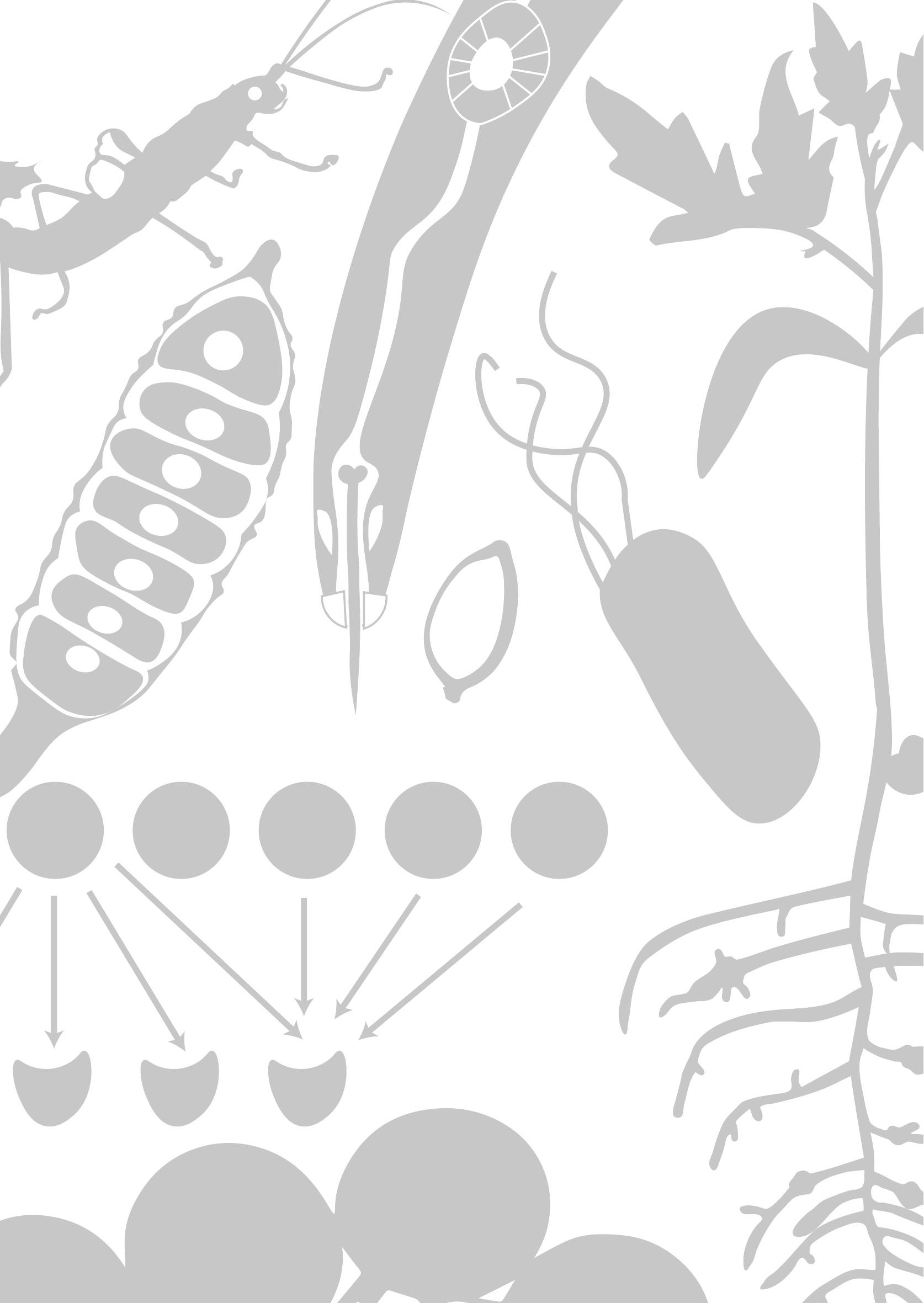




\section{Chapter 6}

\section{General discussion}

Ava Verhoeven

Laboratory of Nematology, Department of Plant Sciences, Wageningen University \& Research, Wageningen, The Netherlands 


\section{Introduction}

The focus of my thesis is entirely on the obligate parasite Meloidogyne incognita, an asexually reproducing nematode which ranks high amongst the most serious biological threats to global agriculture (Jones et al., 2013; Bebber et al., 2014). M. incognita owes this status to its large host range, which includes important food crops such as tomato, corn, pepper, tobacco and common beans (Wesemael et al., 2011; Mitchum et al., 2013). Another reason for its success as a plant parasite is the capacity of $M$. incognita to adapt to varying environmental constrains (Blanc-Mathieu et al.., 2017: Castagnone-Sereno et al., 2019). When confronted with a resistant host, it can overcome this resistance within a few generations (Castagnone-Sereno, 2006). To be successful as a plant parasite, M. incognita uses a large repertoire of effectors to suppress plant defense at the one hand and promote parasitism at the other hand (see Chapter 1 for an overview).

The frequent reports of newly discovered effectors in literature suggests that the known $M$. incognita effector repertoire is yet far from complete. In Chapter 2, we aimed to use the high adaptability of genes to identify effectors of $M$. incognita based on genetic variation (Figure 1). We selected the putative effector MiMSP32 for additional functional characterization, because it belongs to a highly expanded gene family under strong positive selection. In Chapter 3 , we showed that MiMSP32 acts as an effector of M. incognita and identified six host targets of MiMSP32 in tomato. Of these six host targets, we describe in Chapter 4 that only AtOPR2

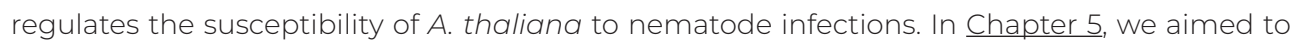
further resolve the genetic basis of susceptibility to $M$. incognita in plants, using variation in susceptibility to $M$. incognita parasitism in a collection of tomato accessions lacking known

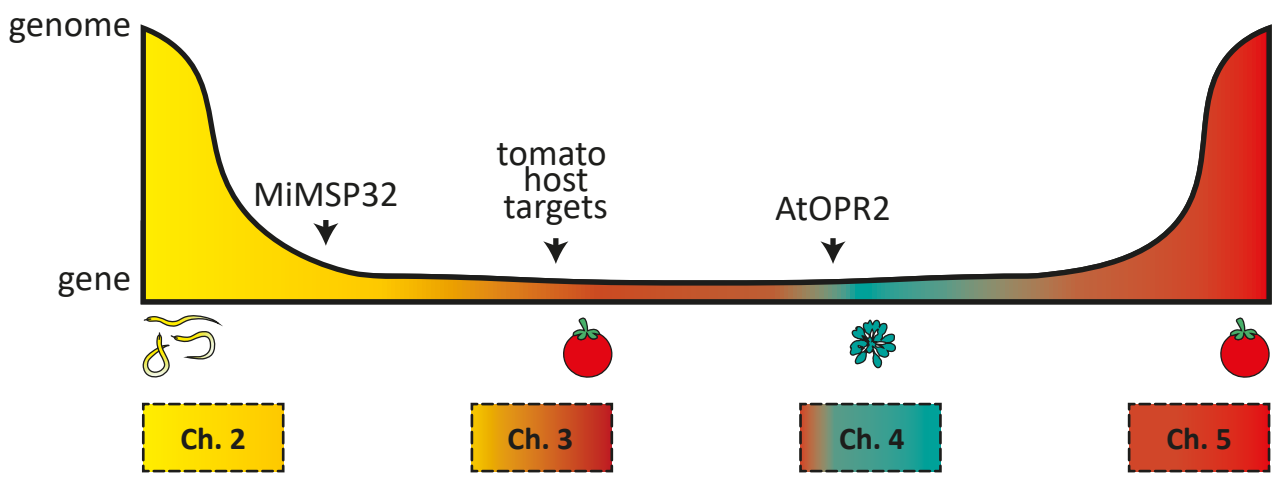

Figure 1: Schematic representation of the flow of knowledge in the research chapters in this thesis. The $y$-axis represents the scope of the study, whether it is genome-wide or on specific gene level. At the x-axis, the chapters are visualized and coloured according to the genes/genome of the main study organism involved; yellow for Meloidogyne incognita (tropical root-knot nematode), turquoise for Arabidopsis thaliana (thale cress) and red for Solanum Iycopersicum (tomato). Hallmark discoveries in the thesis are labelled with arrows. 
dominant resistance genes. We identified 37 differentially regulated genes within the 380 gene candidates from the genome-wide association (GWA). In this final chapter, Chapter 6, I will reflect on the initial aim to connect genetic variation in the genome of $M$. incognita to genetic variation in the genomes of A. thaliana and S. Iycopersicum via nematode effectors and the corresponding effector targets in the host. Here, I will discuss hypotheses for further research and the recommendations to address technical, methodological and biological challenges.

\section{Linking genome diversity to virulence of nematodes}

At the basis of plant parasitism in nematodes lies the emergence of effector genes, which occurs by horizontal gene transfer, gene duplication, and neofunctionalization (Kikuchi et al., 2017: Sánchez-Vallet et al., 2018). Horizontal gene transfer is thought to be a prerequisite for successful plant parasitism in nematodes because multiple events of horizontal gene transfer seem to have occurred in all plant parasitic nematode clades (Scholl et al., 2003; Haegeman et al., 2011). For instance, most nematode effectors functioning in plant cell wall degradation, and thus host invasion, have a likely origin in fungi and bacteria (Bird et al., 2015; Danchin et al., 2016). From there on, the horizontally transferred genes have been under diversifying selection imposed by the host plant, resulting in large and diversified effector families (Vieira \& Gleason, 2019). However, the vast majority of nematode effectors are pioneer proteins without obvious homologies in bacteria or fungi (Bournaud et al., 2018; Mejias et al., 2019). MiMSP32, for example, is a pioneer protein without a likely origin outside the nematode phylum. The lack of homology to well-characterized proteins with known functions also hampered the functional characterization of MiMSP32. To find leads towards its activities in plant cells, we first investigated secondary protein structure predictions of fragments of MiMSP32 with homologous parts of known structure models of proteins with ascribed biochemical activities (Chapter 2). Second, we identified host targets of MiMSP32 in tomato to reveal molecular and cellular processes manipulated by this nematode effector (Chapter 3 ).

Besides horizontal gene transfer, effector emergence in $M$. incognita also results from gene duplication and neofunctionalization (Castagnone-Sereno et al., 2013). Allopolyploid organisms, such as M. incognita, have a duplicated genome originating from hybridization events (Soltis et al., 2014; Schoonmaker et al., 2020). Hence, multiple divergent gene copies are expected to be a common feature of M. incognita (Szitenberg et al., 2017), which makes it possible for a gene copy to develop a new function (neofunctionalization). Indeed, the expansin-like MiMAPT effector gene family within the Meloidogyne genus contains at least seven different members (Castagnone-Sereno et al., 2009; Tomalova et al., 2012). Likewise, we identified at least thirty gene variants of MiMSP32, all residing specifically among root-knot nematodes of the Meloidogyne genus (Chapter 2). Among the thirty gene variants, we noticed that many MiMSP32-like potential genes are from nematodes of Meloidogyne clade I, consisting of mainly allopolyploid nematodes (Holterman et al., 2009; Denver et al., 2011; Castagnone-Sereno \& Danchin, 2014: Álvarez-Ortega et al.. 2019). 
Likewise, similar mechanisms of gene duplication and neofunctionalization can be observed in genes of sexually reproducing cyst nematodes, such as the endogenous housekeeping gene glutathione synthetase (CS). This gene has undergone extensive duplications and functional modifications during the evolution of plant parasitism among nematodes. In cyst nematodes, multiple copies of glutathione synthetases exist which have acquired novel functions in parasitism by neofunctionalization, resulting in a family of GS-like effectors (Lilley et al., 2018). Even more remarkably, an unparalleled diversity was observed within the complex multi-gene family of hyper-variable HYP-effectors (Eves-van den Akker et al., 2014). Eves-van den Akker et al. (2014) showed that variations in number, size, and type of HYP-effectors even occur at the level of individual potato cyst nematodes within a population.

Gene duplications and subsequent sequence diversification make it possible to assess if a gene family within a genome has undergone positive selection. High levels of positive selection point at the involvement of genes in a molecular arms race with other organisms (Baskaran et al., 2017). For the first time, we showed that evidence of strong positive selection can be used as an additional criterium to identify genuine root-knot nematode effectors within a catalogue of effector candidates (Chapter 2). Current bioinformatic pipelines aiming to establish a catalogue of effector candidates from the genome of $M$. incognita vary in the type of sequence data that they use as input (i.e. whole genome sequence or transcriptome) and the selection criteria for filtering the data (Jaouannet et al., 2012; Nguyen et al., 2018; Shi et al., 2018). Most M. incognita effector candidates have been identified by the presence of classical signal peptide for secretion and the absence of transmembrane domains. For the cyst nematode Globodera rostochiensis and the pinewood nematode Bursaphelenchus xylophilus, effector specific motifs in promotors (i.e. ATCCCA and STATAWAARS) have been used to identify novel effector genes specifically within whole genome sequence data (Eves-van den Akker et al. 2016; Espada et al., 2018; Masonbrink et al., 2019). Thus far, no such effector-specific motif has been discovered in the genome of $M$. incognita.

Transcriptomic datasets reveal whether (predicted) genes are actually expressed, as well as their expression profiles/dynamics during parasitism, which is an important characteristic to use in bioinformatic effector identification pipelines. For example, Jaouannet et al. (2012) designed a pipeline based on comparative transcriptomics of expressed sequence tags from five different datasets. As selection criteria, Jaouannet et al. (2012) filtered for sequences specifically expressed in parasitic juveniles of $M$. incognita without homologs in a transcriptomic dataset of unhatched juveniles in eggs, preparasitic J2, or adult females. Likewise, Nguyen et al. (2018) incorporated the same strategy and searched in a more elaborate transcriptome dataset with a higher resolution in parasitic stages for genes highly expressed during plant parasitism. Shi et al. (2018) on the other hand, based their pipeline on a different strategy, i.e. the identification of nematode effector candidates that localize in the host cell nucleus by detection of nuclear localization signals.

To test if evidence of positive selection can be used as a selection criterion to identify genes in 
the genome of $M$. incognita important for nematode virulence on host plants, we focused on a relatively short list of 27 effector candidates (Huang et al., 2003; Abad et al., 2008). These candidates were originally identified based on mRNA isolated from esophageal gland cells of $M$. incognita (Huang et al..2003) and confirmed as pioneer genes in the first published genome (Abad et al., 2008). We screened the published genomes for predicted cDNA sequences with homology to the complete coding sequences of the 27 MiMSPs. Alternatively, instead of predicted transcript transcripts and splice variants, it would be even better to include actual transcriptomic datasets as input in a future study. In that way, gene expression during infection can be included as a criterium and potential mistakes in gene prediction models are avoided. The short list of 27 cDNA sequences was sufficient to identify two groups of putatively secreted proteins under significant positive selection.

In future studies, novel M. incognita effectors can be found by combining the complete expression profile of genes uniquely associated with parasitic stages and genome-wide analysis of positive, diversifying selection. To this purpose, I would propose a pipeline, starting with transcriptome data of different nematode stages which can be grouped in clusters of transcripts and splice variants with significant resemblance, possibly with a tool as OrthoFinder (Emms \& Kelly, 2015,2019). Hereafter, the clusters can be selected to exclude those that do not include genes expressed during (pre-)parasitic nematode stages. Next, all resulting clusters can be scanned for positive, diversifying selection with the CODEML algorithm of PAML 4.7 (phylogenetic analysis by maximum likelihood) (Yang, 1997; Yang \& Bielawski, 2000; Yang, 2007) within EasyCodeML (Gao et al., 2019). Finally, the clusters can be checked for presence of a signal peptide by SignalP (Nielsen, 2017), combined with the absence of a transmembrane domain in PHOBIUS (Käll et al., 2004). The output of the proposed pipeline will likely result in the discovery of a range of novel putative M. incognita effectors (Chapter 2 ).

\section{Linking nematode effectors to host targets in plants}

The complete interaction network of effectors and host targets is often not a gene-for-gene type of network (Gassmann \& Bhattacharjee, 2012). Although effector promiscuity is rarely reported for root-knot nematodes, many other nematodes and phytopathogens are known to use effectors targeting multiple unrelated host components (Win et al., 2012). For example, the cyst nematode effector 10A07 interacts with a plant kinase and the transcription factor IAA16 (Hewezi et al., 2015). Likewise, bacterial type III effectors (Khan et al.., 2018) and fungal effectors often have more than one host target (Białas et al., 2018). As we showed in Chapter 3, a root-knot nematode effector can also be promiscuous and bind to multiple host targets, resulting in complicated interaction patterns. I propose that three variants of effector-host target promiscuity exist, i.e. 1) host target promiscuity, 2) effector promiscuity, or 3) combinations of effector and host target promiscuity.

Host target promiscuity (Figure 2A) can be illustrated by the heavily targeted transcriptional regulator TCP14 in Arabidopsis. In a bioinformatics study, TCP14 was predicted to be targeted 
in a effector-host network by a remarkable 60 candidate effectors of Golovinomyces orontii, Pseudomonas syringae, and Hyaloperonospora arabidopsidis (We $\underline{\beta}$ ling et al., 2014). Several interactions of effectors with Arabidopsis TCP14 have indeed been experimentally confirmed, such as the Pseudomonas syringae effector HopBB1 (Yang et al., 2017). In contrast, MiMSP32 is a typical example of a promiscuous effector (Figure 2B). In Chapter 3, we identified six host targets that have not shown to function as host target of nematodes or other plant attackers in previous studies. Likewise, the highly promiscuous RxLR effector AVR3a of Phytophthora interacts with at least three different host targets to induce infection. First, it interacts with the host E3 ubiquitin ligase CMPG1 to reduce INF-triggered cell death (Bos et al., 2010; Gilroy et al., 2011). Second, AVR3a also interacts with host GTPase dynamin-related protein 2 (DRP2) to reduce immune receptor-mediated endocytosis and reduce PTI triggered by flg22 (Chaparro-Garcia et al., 2015). Third, AVR3a also interacts with members of host cinnamyl alcohol dehydrogenase CAD7s, hereby using them as negative regulators of plant immunity (ㄴi et al., 2019).

A combination of effector-host target promiscuity (Figure $2 \mathrm{C}$ ) is likely the most occurring variant of effector-host target promiscuity, as still many effector-host target interactions remain undiscovered. At present (August 2020), no other effectors from phytopathogens have shown to interact with AtOPR2, the host target of MiMSP32 (Chapter 4) (González-Fuente et al. 2020). However, AtOPR2 would fall into the third category if additional interacting effectors are identified in future studies. Alternatively, MiMSP32 could target another host protein that also functions as common target for additional effectors. For example, the tomato 14-3-3-protein SITFT7 (Solyc04g074230.2.1), which was identified in our yeast-two-hybrid screening to interact with MiMSP32 (Chapter 3), is also a known host target of the aphid effector MelO (Chaudhary et al., 2019). SITFT7 induces programmed cell death together with SIMAPKKKa and SIMKK2 in reaction to Pseudomonas syringae (Oh et al.., 2010; Oh \& Martin, 2011). I expect the abundance of promiscuous effectors and host targets to be higher within particular subgroups of host targets. Therefore, these interactions are likely the most common in effector hubs such as phytohormone pathways (Kazan \& Lyons, 2014; Blüher et al., 2017), or the proteasome pathway (Banfield, 2015; Hewezi, 2015; Langin et al., 2020). For example, the type III effector protein HopM1 from Pseudomonas syringae interacts with several E3 ubiquitin ligases and proteasome subunits, leading to inhibition of the proteasome (Üstün et al., 2016). Pseudomonas syringae effectors $\mathrm{HopAO}$, HopAl, and $\mathrm{HopGl}$ also inhibit the proteasome, possibly even by using partly the same host targets.

Why does one effector show binding to multiple host targets? The most obvious reason is that the effector possesses 'sticky' properties under experimental conditions. The observed effector promiscuity may therefore be an artifact and only the interaction with one of the host proteins may be biologically relevant. For MiMSP32, we could not identify any physiochemical protein characteristics such as highly charged regions or a strong hydrophobicity explaining an exceptional 'stickiness' of the effector or the candidate interactors. In contrast, the effector and all of its host targets differ much in individual properties as stability or hydrophobicity, which suggests that MiMSP32 is indeed a promiscuous effector with biologically relevant 
A
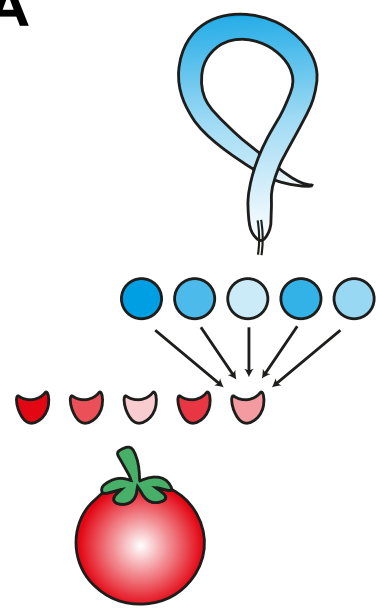

B
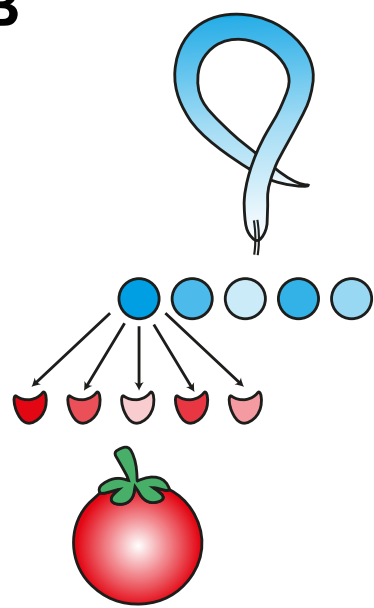

C
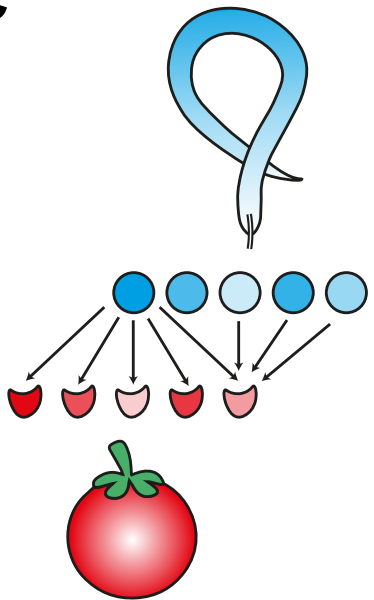

Figure 2. The three variants of effector-host target promiscuity. (A) Host target promiscuity, where multiple effectors interact with one single host target; (B) effector promiscuity, where one effector interacts with multiple host targets; or (C) combinations of effector and host target promiscuity, where multiple effectors interact with multiple host targets that partially overlap.

binding to mul tiple host targets. Effector promiscuity could be beneficial for the phytopathogen by using one effector that binds to different targets during different phases of an infection (Thordal-Christensen et al., 2018). Alternatively, the range of host targets could reflect the different plant cell types wherein the effector regulates different cellular processes by interacting with different host proteins (Walker et al., 2017; Schürholz et al., 2018). If a single effector is used at multiple timepoints and in different cell types during infection, a pathogen becomes more efficient and reduces risks of being detected by the plant defense system. Possibly, this hold true for MiMSP32 (hapter 3), as it is expressed during different phases of nematode infection (Huang et al., 2003; Shukla et al., 2018). Moreover, as silencing of the effector resulted in lower nematode virulence, it seems less likely that other effectors have the same host targets as MiMSP32.

\section{Linking genome diversity to susceptibility of plants}

Some host targets of effectors are responsible for quantitative variation in plant susceptibility to phytopathogens by being targets of pathogen effectors and thereby promoting plant susceptibility (Pavan et al., 2009; Boevink et al., 2016). These so-called susceptibility genes (S-genes) facilitate the infection process or support the compatibility of host and pathogen (van Schie \& Takken, 2014). For example, the stripe rust - f. sp. tritici effector Pst18363 targets and stabilizes wheat Nudix hydrolase 23 TaNUDX23, which functions in decreasing reactive oxygen species (ROS) accumulation, thereby promoting stripe rust infection (Yang et al., 2020). In Ralstonia solanacearum, the effector Ripl uses plant glutamate decarboxylases (GADs) to alter plant metabolism and support bacterial growth (Xian et al., 2020). Xian et al. (2020) showed that 
when Ripl was silenced, tomato plants obtained an increased resistance against the bacterial pathogen. However, most host targets of effectors inhibit the infection process of phytopathogens instead of facilitating it (Deslandes \& Rivas, 2012; He et al.., 2020). Phytopathogens use their effectors to inhibit regular functions of the host target, hereby promoting the infection process. For example, the Phytophthora capsica RxLR effector PCAvr3a12 inhibits host plant peptidyl-prolyl cis-trans isomerase FKBP15-2 to reduce endoplasmic reticulum stress-mediated plant immunity (Fan et al., 2018). To prove this hypothesis, Fan et al. (2018) show that fkbp15-2 mutant plants are more susceptible to P. capsica. Likewise, the opr2-7 mutant plants are more susceptible to $M$. incognita, leading us to the conclusion that AtOPR2 somehow inhibits M. incognita infection (Chapter 4).

Genetic variation in susceptibility-associated host genes targeted by novel effectors may be partially responsible for a natural, quantitative variation in tomato plant susceptibility to $M$. incognita. Hopefully, this genetic variation can be used in future breeding programs as an alternative crop protection method to the growing number of Mi-7.2 resistance-breaking, virulent M. incognita populations (Kaloshian et al., 1996; Iberkleid et al.. 2014; Guan et al., 2017). Genetic variation leading to change on amino acid level could cause the resulting protein to obtain an altered protein folding or dysfunctional domains. Such changes in host proteins often result in the disruption of an interaction with other proteins such as effectors or even disrupt the general protein functioning. For example, mutations in AtOPR2 could induce plant susceptibility to $M$. incognita by disturbing its protein fold, thereby either disrupting its binding to MiMSP32 or its capacities to inhibit M. incognita infection.

A

Plant GWA

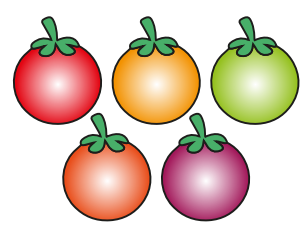

X

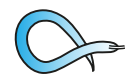

B

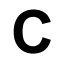

Nematode
GWA

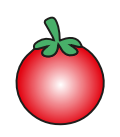

X

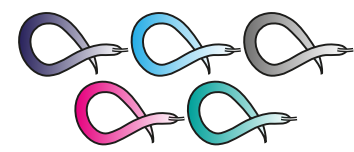

Supergenome GWA

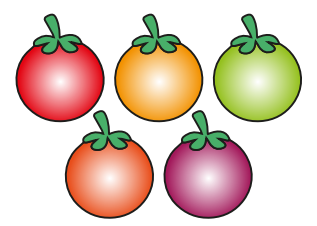

$\mathrm{x}$

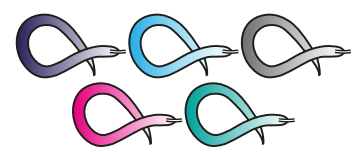

Figure 3. Different options available for GWA analysis. (A) Plant-focused GWA, with multiple genotypes of the host and only one pathogen genotype, (B) nematode-focused GWA, with only one host genotype and multiple pathogen genotypes, (C) 'supergenome'-based GWA, with multiple genotypes of the host and the pathogen. Here, virtually merged chromosomes make it possible to associate traits to both host and pathogen genomes. 
In Chapter 5, we used an integrated approach of a CWA analysis on 156 tomato accessions (genomic and phenotypic data) in combination with transcriptomic data of ten different tomato accessions during $M$. incognita infection to identify potential susceptibility-associated genes of tomato plants. We discovered a significant heritable variation of susceptibility to $M$. incognita in tomato independent of major R-genes. To potentially link the susceptibility-associated genes to putative effector targets of M. incognita, we compared 380 tomato genes identified in the CWA analysis with the 51 putative host target genes of the effector MiMSP32 as obtained by a yeast two-hybrid screening on a library generated from nematode-infected roots of tomato ( Chapter 3). Hereby, we identified the auxin response factor SIARF24 (Solyc05g056040.3.1) as a candidate susceptibility-associated gene in GWA of tomato infected with M. incognita and a candidate host target of the effector MiMSP32. Auxin response factors encode sequence-specific transcription factors binding to auxin response elements (AuxREs) in promotors of auxin response genes (Tiwari et al., 2003; Wu et al., 2011). Therefore, they are key for the transcriptional responses to auxin (Weijers \& Wagner, 2016; Blázquez et al., 2020). Auxin functions as a key regulator in plant development and organogenesis, and root-knot nematodes use auxin in the formation of feeding sites (Grunewald et al., 2008; Gheysen \& Mitchum. 2019). SIARF24 could be an interesting candidate for future studies of tomato infected by $M$. incognita.

Why was there such a small overlap between the yeast two-hybrid host targets of MiMSP32 and the GWA in tomato? The absence of our six confirmed host targets of MiMSP32 in the list of genes associated with tomato susceptibility could have multiple causes. The most likely cause is the genetic structure of this particular set of tomato accessions, which consists of old landraces and earlier breeding material. The genetic structure of our CWA panel is far less diverse than a natural inbred population or a population of wild isolates (Bergougnoux, 2014: The 100 Tomato Genome Sequencing Consortium et al., 2014; Sul et al., 2018). After many years of breeding, it is reasonable to assume that a substantial part of the natural genetic variation in tomato was not included in the GWA panel used in our study (The 100 Tomato Genome Sequencing Consortium et al.,2014). This lack of genetic diversity limits the number of genes identified in our study, and including original wild tomato genotypes in a future CWA analysis might reveal many more genes associated with plant susceptibility to nematodes and potentially include the MiMSP32 host targets. Another reason for the absence of overlapping genes between the GWA and the yeast two-hybrid is the different study design. For example, the nematode-induced galls were counted at different timepoints after inoculation. In addition, the increase in susceptibility of opr2-7 Arabidopsis mutants to M. incognita was significant, but not very high in our bioassays. The smaller samplesize in the tomato GWA might have caused us to miss such subtle differences.

To date, most of the CWA analyses on plant parasitic nematodes focus on genetic diversity in plants (Figure 3A). For example, plant genomes have been assessed for quantitative susceptibility to root-knot nematodes in Arabidopsis thaliana, soybean (Glycine max), sweet potato (/pomoea batatas), and rice (Oryza sativa) (Dimkpa et al., 2015; Passianotto et al., 2017; Warmerdam et al., 2018; Sasai et al., 2019; Warmerdam et al., 2019). However, GWA can also 
be used to identify genes responsible for variation among nematode populations (Figure 3B) (Falcke et al.,2018). Furthermore, the variation in plant susceptibility is largely dependent on the virulence of the particular nematode population used (Hallmann \& Kiewnick, 2018; Kyriakos et al., 2019). Recently, Guo et al. (2017) performed a first plant-parasitic nematode centered study of genetic variation in 98 recombinant inbred lines of the plant parasitic nematode $M$. hapla propagated on Medicago truncatula. Guo et al. (2017) showed a significant effect of the nematode genotype on the transcriptome of the host plant $M$. truncatula. This largely undiscovered side of the interaction could reveal additional genes responsible for virulence in plant-parasitic nematodes.

An alternative method would be to simultaneously study genetic variation in both host and pathogen and associate these data to phenotypic traits (Figure $3 \mathrm{C}$ ). The potential of this method has been shown previously in other systems (Choi et al., 2014; Wilk et al., 2015; Westermann et al., 2016). For example, Yamagishi et al. (2014) used the interactive transcriptome of 116 clinical malaria patients to identify genetic variations of the malaria parasite Plasmodium falciparum and humans together and associated these variations to disease symptoms. Recently, the idea of one composite 'supergenome' for both pathogen and host together has been introduced for tomato and M. hapla (Maulana et al., 2020). Maulana et al. (2020) propose to identify quantitative trait loci within a combined superorganism; a combination of multiple strains of M. hapla and S. lycopersicum with virtually merged chromosomes. Likely, the combination of both sides of the interaction will offer new leads for disease resistance breeding.

\section{Future perspectives}

In this thesis, I aimed to connect genetic variation in the genome of M. incognita to genetic variation in the genomes of $A$. thaliana and S. Iycopersicum via nematode effectors and the corresponding effector targets in the host. To achieve this, we used the genetic variation in $M$. incognita to identify novel effectors and the genetic variation in S. Iycopersicum to identify novel host targets (Figure 4). To link the nematode effectors to plant host targets, we focused on functionally characterizing the putative effector MiMSP32 and studied its six host targets in tomato and A. thaliana. However, via this approach, we could not establish a clear link between the genetic variation in the genome of $M$. incognita with genetic variation in the genome of tomato. One major shortcoming of our approach was the required lowering of the study scope from genome-wide to single genes. Thanks to this approach, we were able to study the molecular mechanisms of MiMSP32 and its host target OPR2. However, to study genetic variation, the preferred method should be to focus on the whole genome. Therefore, I propose that future studies should directly link genome diversity of both host- and parasite with a 'supergenome'-based GWA, for a more multi-dimensional screen of host-parasite interactions. Using this methodology, susceptibility-associated genes of the host can be compared with virulence-associated genes in the parasite. By observing the plasticity of the two genomes working together, it might be possible to take an important next step on the path to a more durable crop protection against root-knot nematodes. 


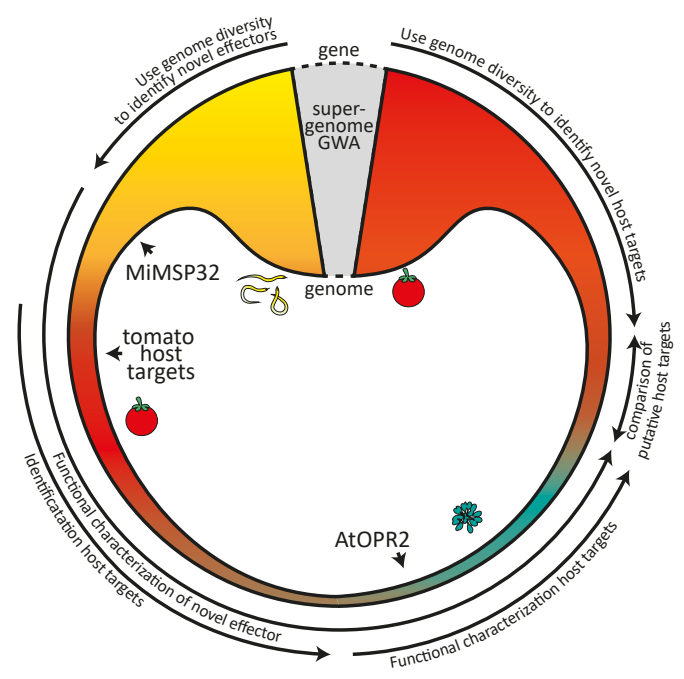

Figure 4: Schematic representation of the thesis contents. Altered version of the research chapter content in Figure 1, which is here represented as a circle. The amplitude to the inside of the circle represents the scope of the study, whether it is genome-wide or on specific gene level. Around the circle, the separate goals and methodology of the thesis are visualized. The dashed grey box is the potential shortcut to directly link genome diversity of both host- and parasite with a 'supergenome'-based GWA. Hallmark discoveries in the thesis are represented in the inside of the circle and labelled with arrows, and the colour gradient matches the genes/genome of the main study organism involved; yellow for Meloidogyne incognita (tropical root-knot nematode), turquoise for Arabidopsis thaliana (thale cress) and red for Solanum lycopersicum (tomato)

\section{References}

Abad P, Gouzy J, Aury J-M, Castagnone-Sereno P, Danchin EGJ, Deleury E, Perfus-Barbeoch L, Anthouard V, Artiguenave F, Blok VC, et al. 2008. Genome sequence of the metazoan plant-parasitic nematode Meloidogyne incognita. Nature biotechnology 26(8): 909-915.

Álvarez-Ortega S, Brito JA, Subbotin SA. 2019. Multigene phylogeny of root-knot nematodes and molecular characterization of Meloidogyne nataliei Golden, Rose \& Bird, 1981 (Nematoda: Tylenchida). Scientific Reports 9: 11788

Banfield MJ. 2015. Perturbation of host ubiquitin systems by plant pathogen/pest effector proteins. Cellular Microbiology 17(1): $18-25$.

Baskaran P, Jaleta TG, Streit A, Rödelsperger C. 2017. Duplications and positive selection drive the evolution of parasitism-associated gene families in the nematode Strongyloides papillosus. Genome Biology and Evolution 9(3): 790-801.

Bebber DP, Holmes T, Gurr SJ. 2014. The global spread of crop pests and pathogens. Global Ecology and Biogeography 23(12): 1398-1407.

Bergougnoux V. 2014. The history of tomato: From domestication to biopharming. Biotechnology Advances 32(1): 170-189.

Bhavana P, Singh AK, Kumar R, Prajapati GK, Thamilarasi K, Manickam R, Maurya S, Choudhary JS. 2019. Identification of resistance in tomato against root knot nematode (Meloidogyne incognita) and comparison of molecular markers for Mi gene. Australasian Plant Pathology 48(2): 93-100.

Białas A, Zess EK, De la Concepcion JC, Franceschetti M, Pennington HG, Yoshida K, Upson JL, Chanclud E, Wu C-H, Langner T, et al. 2018. Lessons in effector and NLR biology of plant-microbe systems. Molecular Plant-Microbe Interactions 31(1): 34-45.

Bird DM, Jones JT, Opperman CH, Kikuchi T, Danchin EGJ. 2015. Signatures of adaptation to plant parasitism in nematode genomes. Parasitology 142: S71-S84.

Blanc-Mathieu R, Perfus-Barbeoch L, Aury J-M, Da Rocha M, Gouzy J, Sallet E, Martin-Jimenez C, Bailly-Bechet M, Castagnone-Sereno P, Flot J-F, et al. 2017. Hybridization and polyploidy enable genomic plasticity without sex in the most 
devastating plant-parasitic nematodes. PLoS Genetics 13(6): e1006777.

Blázquez MA, Nelson DC, Weijers D. 2020. Evolution of plant hormone response pathways. Annual review of plant biology 71(1): 327-353.

Blüher D, Laha D, Thieme S, Hofer A, Eschen-Lippold L, Masch A, Balcke G, Pavlovic I, Nagel O, Schonsky A, et al. 2017. A 1-phytase type III effector interferes with plant hormone signaling. Nature Communications 8(1): 2159.

Boevink PC, McLellan H, Gilroy EM, Naqvi S, He Q, Yang L, Wang X, Turnbull D, Armstrong MR, Tian Z, et al. 2016. Oomycetes seek help from the plant: Phytophthora infestans effectors target host susceptibility factors. Molecular plant 9(5): 636-638.

Bos JIB, Armstrong MR, Gilroy EM, Boevink PC, Hein I, Taylor RM, Zhendong T, Engelhardt S, Vetukuri RR, Harrower B, et al. 2010. Phytophthora infestans effector AVR3a is essential for virulence and manipulates plant immunity by stabilizing host E3 ligase CMPG1. Proc Natl Acad Sci U S A 107(21): 9909

Bournaud C, Gillet F-X, Murad AM, Bresso E, Albuquerque EVS, Grossi-de-Sá MF. 2018. Meloidogyne incognita PASSE-MURAILLE (MiPM) gene encodes a cell-penetrating protein that interacts with the CSN5 subunit of the COP9 signalosome. Frontiers in plant science $\mathbf{9}(904)$

Castagnone-Sereno P. 2006. Genetic variability and adaptive evolution in parthenogenetic root-knot nematodes. Heredity 96(4): 282

Castagnone-Sereno P, Danchin EG, Perfus-Barbeoch L, Abad P. 2013. Diversity and evolution of root-knot nematodes, genus Meloidogyne: new insights from the genomic era. Annual review of phytopathology 51: 203-220.

Castagnone-Sereno P, Danchin EGJ. 2014. Parasitic success without sex - the nematode experience. Journal of Evolutionary Biology 27(7): 1323-1333.

Castagnone-Sereno P, Mulet K, Danchin EGJ, Koutsovoulos GD, Karaulic M, Da Rocha M, Bailly-Bechet M, Pratx L, Perfus-Barbeoch L, Abad P. 2019. Gene copy number variations as signatures of adaptive evolution in the parthenogenetic, plant-parasitic nematode Meloidogyne incognita. Molecular Ecology 28(10): 2559-2572.

Castagnone-Sereno P, Semblat J-P, Castagnone C. 2009. Modular architecture and evolution of the map-1 gene family in the root-knot nematode Meloidogyne incognita. Molecular Genetics and Genomics 282(5): 547.

Chaparro-Garcia A, Schwizer S, Sklenar J, Yoshida K, Petre B, Bos JIB, Schornack S, Jones AME, Bozkurt TO, Kamoun S. 2015. Phytophthora infestans RXLR-WY effector AVR3a associates with dynamin-related protein 2 required for endocytosis of the plant pattern recognition receptor FLS2. PLOS ONE 10(9): e0137071.

Chaudhary R, Peng H-C, He J, MacWilliams J, Teixeira M, Tsuchiya T, Chesnais Q, Mudgett MB, Kaloshian I. 2019. Aphid effector MelO interacts with tomato TFT7, a 14-3-3 isoform involved in aphid resistance. New Phytologist 221(3): 1518-1528.

Choi Y-J, Aliota MT, Mayhew GF, Erickson SM, Christensen BM. 2014. Dual RNA-seq of parasite and host reveals gene expression dynamics during filarial worm-mosquito interactions. PLoS Neglected Tropical Diseases 8(5): e2905.

Danchin EGJ, Guzeeva EA, Mantelin S, Berepiki A, Jones JT. 2016. Horizontal gene transfer from bacteria has enabled the plant-parasitic nematode Clobodera pallida to feed on host-derived sucrose. Molecular biology and evolution 33(6): 15711579

Denver DR, Clark KA, Raboin MJ. 2011. Reproductive mode evolution in nematodes: Insights from molecular phylogenies and recently discovered species. Molecular phylogenetics and evolution 61(2): 584-592.

Deslandes L, Rivas S. 2012. Catch me if you can: bacterial effectors and plant targets. Trends in Plant Science 17(11): 644-655.

Dimkpa SON, Lahari Z, Shrestha R, Douglas A, Gheysen G, Price AH. 2015. A genome-wide association study of a global rice panel reveals resistance in Oryza sativa to root-knot nematodes. Journal of experimental botany 67(4): 1191-1200.

Emms DM, Kelly S. 2015. OrthoFinder: solving fundamental biases in whole genome comparisons dramatically improves orthogroup inference accuracy. Cenome biology 16(1): 157.

Emms DM, Kelly S. 2019. OrthoFinder: phylogenetic orthology inference for comparative genomics. Genome biology 20(1): 238.

Espada M, Eves-van den Akker S, Maier T, Vijayapalani P, Baum T, Mota M, Jones JT. 2018. STATAWAARS: a promoter motif associated with spatial expression in the major effector-producing tissues of the plant-parasitic nematode Bursaphelenchus xylophilus. BMC Genomics 19(1): 553.

Eves-van den Akker S, Laetsch DR, Thorpe P, Lilley CJ, Danchin EGJ, Da Rocha M, Rancurel C, Holroyd NE, Cotton JA, Szitenberg A, et al. 2016. The genome of the yellow potato cyst nematode, Globodera rostochiensis, reveals insights into the basis of parasitism and virulence. Genome biology 17(1): 124.

Eves-van den Akker S, Lilley CJ, Jones JT, Urwin PE. 2014. Identification and characterisation of a hyper-variable apoplastic effector gene family of the potato cyst nematodes. PLoS Pathogens 10(9): el004391.

Falcke JM, Bose N, Artyukhin AB, Rödelsperger C, Markov GV, Yim JJ, Grimm D, Claassen MH, Panda O, Baccile JA, et al. 2018. Linking genomic and metabolomic natural variation uncovers nematode pheromone biosynthesis. Cell chemical biology 25(6): 787-796.e712.

Fan G, Yang Y, Li T, Lu W, Du Y, Qiang X, Wen Q, Shan W. 2018. A Phytophthora capsici RXLR effector targets and inhibits a 
plant PPlase to suppress endoplasmic reticulum-mediated immunity. Molecular plant 11(8): 1067-1083.

Gao F, Chen C, Arab DA, Du Z, He Y, Ho SYW. 2019. EasyCodeML: A visual tool for analysis of selection using CodeML. Ecology and Evolution 9(7): 3891-3898.

Gassmann W, Bhattacharjee S. 2012. Effector-triggered immunity signaling: from gene-for-gene pathways to protein-protein interaction networks. Molecular Plant-Microbe Interactions 25(7): 862-868

Gheysen G, Mitchum MG. 2019. Phytoparasitic nematode control of plant hormone pathways. Plant Physiology: pp.01067.02018.

Gilroy EM, Taylor RM, Hein I, Boevink P, Sadanandom A, Birch PRJ. 2011. CMPGT-dependent cell death follows perception of diverse pathogen elicitors at the host plasma membrane and is suppressed by Phytophthora infestans RXLR effector AVR3a. New Phytologist 190(3): 653-666.

González-Fuente M, Carrère S, Monachello D, Marsella BG, Cazalé A-C, Zischek C, Mitra RM, Rezé N, Cottret L, Mukhtar MS, et al. 2020. Effectork, a comprehensive resource to mine for Ralstonia, Xanthomonas, and other published effector interactors in the Arabidopsis proteome. Molecular Plant Pathology 21(10): 1257-1270.

Grunewald W, Karimi M, Wieczorek K, Van de Cappelle E, Wischnitzki E, Grundler F, Inzé D, Beeckman T, Gheysen G. 2008. A role for AtWRKY23 in feeding site establishment of plant-parasitic nematodes. Plant Physiology 148(1): 358.

Guan T, Shen J, Fa Y, Su Y, Wang X, Li H. 2017. Resistance-breaking population of Meloidogyne incognita utilizes plant peroxidase to scavenge reactive oxygen species, thereby promoting parasitism on tomato carrying Mi-7 gene. Biochemical and Biophysical Research Communications 482(1): 1-7.

Guo Y, Fudali S, Gimeno J, DiGennaro P, Chang S, Williamson VM, Bird DM, Nielsen DM. 2017. Networks underpinning symbiosis revealed through cross-species eQTL mapping. Genetics 206(4): 2175.

Haegeman A, Jones JT, Danchin EG. 2011. Horizontal gene transfer in nematodes: a catalyst for plant parasitism? Molecular Plant-Microbe Interactions 24(8): 879-887.

Hallmann J, Kiewnick S. 2018. Virulence of Meloidogyne incognita populations and Meloidogyne enterolobii on resistant cucurbitaceous and solanaceous plant genotypes. Journal of Plant Diseases and Protection 125(4): 415-424.

He Q, McLellan H, Boevink PC, Birch PRJ. 2020. All roads lead to susceptibility: the many modes-of-action of fungal and oomycete intracellular effectors. Plant Communications: 100050.

Hewezi T. 2015. Cellular Signaling Pathways and Posttranslational Modifications Mediated by Nematode Effector Proteins. Plant Physiology 169(2): 1018

Hewezi T, Juvale PS, Piya S, Maier TR, Rambani A, Rice JH, Mitchum MG, Davis EL, Hussey RS, Baum TJ. 2015. The cyst nematode effector protein $10 \mathrm{A07}$ targets and recruits host posttranslational machinery to mediate its nuclear trafficking and to promote parasitism in arabidopsis. The Plant Ce// 27(3): 891-907.

Holterman M, Karssen G, van den Elsen S, van Megen H, Bakker J, Helder J. 2009. Small subunit rDNA-based phylogeny of the Tylenchida sheds light on relationships among some high-impact plant-parasitic nematodes and the evolution of plant feeding. Phytopathology 99(3): 227-235.

Hoogstraten JGJ, Braun CJ, Seminis Vegetable Seeds Inc. 2014. Methods for coupling resistance alleles in tomato US8785720B2.

Huang G, Gao B, Maier T, Allen R, Davis EL, Baum TJ, Hussey RS. 2003. A profile of putative parasitism genes expressed in the esophageal gland cells of the root-knot nematode Meloidogyne incognita. Molecular Plant-Microbe Interactions 16(5): 376-381.

Iberkleid I, Ozalvo R, Feldman L, Elbaz M, Patricia B, Horowitz SB. 2014. Responses of tomato genotypes to avirulent and Mi-virulent Meloidogyne javanica isolates occurring in Israel. Phytopathology 104(5): 484-496.

Jaouannet M, Perfus-Barbeoch L, Deleury E, Magliano M, Engler G, Vieira P, Danchin EG, Rocha MD, Coquillard P, Abad P. 2012. A root-knot nematode-secreted protein is injected into giant cells and targeted to the nuclei. New Phytologist 194(4): 924-931.

Jones JT, Haegeman A, Danchin EG, Gaur HS, Helder J, Jones MG, Kikuchi T, Manzanilla-López R, Palomares-Rius JE, Wesemael WM. 2013. Top 10 plant-parasitic nematodes in molecular plant pathology. Molecular Plant Pathology 14(9): 946-961.

Käll L, Krogh A, Sonnhammer EL. 2004. A combined transmembrane topology and signal peptide prediction method. Journal of molecular biology 338(5): 1027-1036.

Kaloshian I, Williamson VM, Miyao G, Lawn DA, Westerdahl BB. 1996. "Resistance-breaking" nematodes identified in California tomatoes. California Agriculture 50(6): 18-19.

Kazan K, Lyons R. 2014. Intervention of phytohormone pathways by pathogen effectors. The P/ant Ce// 26(6): 2285-2309.

Khan M, Seto D, Subramaniam R, Desveaux D. 2018. Oh, the places they'll go! A survey of phytopathogen effectors and their host targets. The Plant Journal 93(4): 651-663.

Kikuchi T, Eves-van den Akker S, Jones JT. 2017. Genome evolution of plant-parasitic nematodes. Annual review of phytopathology 55(1) 
Kyriakos V, John TJ, Vivian CB. 2019. Susceptibility of potato varieties to populations of Globodera pallida selected for increased virulence. Nematology 21(9): 995-998.

Langin G, Gouguet P, Üstün S. 2020. Microbial Effector Proteins - A Journey through the Proteolytic Landscape. Trends in Microbiology.

Li T, Wang Q, Feng R, Li L, Ding L, Fan G, Li W, Du Y, Zhang M, Huang G, et al. 2019. Negative regulators of plant immunity derived from cinnamyl alcohol dehydrogenases are targeted by multiple Phytophthora Avr3a-like effectors. New Phytologist $\mathrm{n} / \mathrm{a}(\mathrm{n} / \mathrm{a})$.

Lilley CJ, Maqbool A, Wu D, Yusup HB, Jones LM, Birch PR, Banfield MJ, Urwin PE, Eves-van den Akker S. 2018. Effector gene birth in plant parasitic nematodes: Neofunctionalization of a housekeeping glutathione synthetase gene. PLoS Genetics 14(4): el007310.

Masonbrink R, Maier TR, Muppirala U, Seetharam AS, Lord E, Juvale PS, Schmutz J, Johnson NT, Korkin D, Mitchum MG, et al. 2019. The genome of the soybean cyst nematode (Heterodera glycines) reveals complex patterns of duplications involved in the evolution of parasitism genes. BMC Cenomics 20(1): 119 .

Maulana M, Smant G, Goverse A, Kammenga JE, Sterken MG. 2020. The host-parasite supergenome: an untapped source for disease resistance. Evoworm 2020 virtual meeting.

Mejias J, Truong NM, Abad P, Favery B, Quentin M. 2019. Plant proteins and processes targeted by parasitic nematode effectors. Frontiers in plant science 10: 970-970.

Mitchum MG, Hussey RS, Baum TJ, Wang X, Elling AA, Wubben M, Davis EL. 2013. Nematode effector proteins: an emerging paradigm of parasitism. New Phytologist 199(4): 879-894

Nguyen CN, Perfus-Barbeoch L, Quentin M, Zhao J, Magliano M, Marteu N, Da Rocha M, Nottet N, Abad P, Favery B. 2018. A root-knot nematode small glycine and cysteine-rich secreted effector, MiSGCRT, is involved in plant parasitism. New Phytologist 217(2): 687-699.

Nielsen H. 2017. Predicting secretory proteins with SignalP. In: Kihara D ed. Protein Function Prediction. Methods and Protocols. New York, NY: Humana Press, 59-73

Oh C-S, Martin GB. 2011. Tomato 14-3-3 Protein TFT7 Interacts with a MAP Kinase Kinase to Regulate Immunity-associated Programmed Cell Death Mediated by Diverse Disease Resistance Proteins. Journal of Biological Chemistry 286(16): 14129-14136.

Oh C-S, Pedley KF, Martin GB. 2010. Tomato 14-3-3 protein 7 positively regulates immunity-associated programmed cell death by enhancing protein abundance and signaling ability of MAPKKKa. The Plant Cel/ 22(1): 260-272

Passianotto ALdL, Sonah H, Dias WP, Marcelino-Guimarães FC, Belzile F, Abdelnoor RV. 2017. Genome-wide association study for resistance to the southern root-knot nematode (Meloidogyne incognita) in soybean. Molecular Breeding 37(12): 148.

Pavan S, Jacobsen E, Visser RGF, Bai Y. 2009. Loss of susceptibility as a novel breeding strategy for durable and broad-spectrum resistance. Molecular Breeding 25(1): 7 .

Sánchez-Vallet A, Fouché S, Fudal I, Hartmann FE, Soyer JL, Tellier A, Croll D. 2018. The genome biology of effector gene evolution in filamentous plant pathogens. Annual review of phytopathology 56(1): 21-40.

Sasai R, Tabuchi H, Shirasawa K, Kishimoto K, Sato S, Okada Y, Kuramoto A, Kobayashi A, Isobe S, Tahara M, et al. 2019. Development of molecular markers associated with resistance to Meloidogyne incognita by performing quantitative trait locus analysis and genome-wide association study in sweetpotato. DNA Research 26(5): 399-409.

Scholl EH, Thorne JL, McCarter JP, Bird DM. 2003. Horizontally transferred genes in plant-parasitic nematodes: a high-throughput genomic approach. Genome biology 4(6): R39.

Schoonmaker A, Hao Y, Bird DM, Conant GC. 2020. A single, shared triploidy in three species of parasitic nematodess. C3: Genes, Genomes, Genetics 10(1): 225-233.

Schürholz A-K, López-Salmerón V, Li Z, Forner J, Wenzl C, Gaillochet C, Augustin S, Barro AV, Fuchs M, Gebert M, et al. 2018. A comprehensive toolkit for inducible, cell type-specific gene expression in Arabidopsis. Plant Physiology 178(1): 40.

Shi Q, Mao Z, Zhang X, Ling J, Lin R, Zhang X, Liu R, Wang Y, Yang Y, Cheng X, et al. 2018. The novel secreted Meloidogyne incognita effector MilSE6 targets the host nucleus and facilitates parasitism in Arabidopsis. Frontiers in plant science 9(252).

Shukla N, Yadav R, Kaur P, Rasmussen S, Goel S, Agarwal M, Jagannath A, Gupta R, Kumar A. 2018. Transcriptome analysis of root-knot nematode (Meloidogyne incognita)-infected tomato (Solanum lycopersicum) roots reveals complex gene expression profiles and metabolic networks of both host and nematode during susceptible and resistance responses. Molecular Plant Pathology 19(3): 615-633.

Soltis DE, Visger CJ, Soltis PS. 2014. The polyploidy revolution then....and now: Stebbins revisited. American journal of botany 101(7): 1057-1078.

Sul JH, Martin LS, Eskin E. 2018. Population structure in genetic studies: Confounding factors and mixed models. PLOS Genetics 14(12): el007309.

Szitenberg A, Salazar-Jaramillo L, Blok VC, Laetsch DR, Joseph S, Williamson VM, Blaxter ML, Lunt DH. 2017. Comparative 
genomics of apomictic root-knot nematodes: hybridization, ploidy, and dynamic genome change. Genome Biology and Evolution 9(10): 2844-2861.

The 100 Tomato Genome Sequencing Consortium, Aflitos S, Schijlen E, de Jong H, de Ridder D, Smit S, Finkers R, Wang J, Zhang G, Li N, et al. 2014. Exploring genetic variation in the tomato (Solanum section Lycopersicon) clade by whole-genome sequencing. The Plant Journal 80 (1): 136-148.

Thordal-Christensen H, Birch PRJ, Spanu PD, Panstruga R. 2018. Why did filamentous plant pathogens evolve the potential to secrete hundreds of effectors to enable disease? Molecular Plant Pathology 19(4): 781-785.

Tiwari SB, Hagen G, Guilfoyle T. 2003. The roles of auxin response factor domains in auxin-responsive transcription. The Plant Cell 15(2): 533

Tomalova I, lachia C, Mulet K, Castagnone-Sereno P. 2012. The map-1 gene family in root-knot nematodes, Meloidogyne spp. A set of taxonomically restricted genes specific to clonal species. PLOS ONE 7(6): e38656.

Üstün S, Sheikh A, Gimenez-Ibanez S, Jones A, Ntoukakis V, Börnke F. 2016. The proteasome acts as a hub for plant immunity and is targeted by Pseudomonas type III effectors. Plant Physiology 172(3): 1941-1958.

van Schie CCN, Takken FLW. 2014. Susceptibility genes 101: How to be a good host. Annual review of phytopathology 52(1): 551-581.

Vieira P, Gleason C. 2019. Plant-parasitic nematode effectors - insights into their diversity and new tools for their identification. Current opinion in plant biology 50: 37-43.

Walker L, Boddington C, Jenkins D, Wang Y, Grønlund JT, Hulsmans J, Kumar S, Patel D, Moore JD, Carter A, et al. 2017. Changes in gene expression in space and time orchestrate environmentally mediated shaping of root architecture. The Plant Cell 29(10): 2393.

Warmerdam S, Sterken MG, van Schaik C, Oortwijn ME, Sukarta OC, Lozano-Torres JL, Dicke M, Helder J, Kammenga JE, Goverse A. 2018. Genome-wide association mapping of the architecture of susceptibility to the root-knot nematode Meloidogyne incognita in Arabidopsis thaliana. New Phytologist 218(2): 724-737.

Warmerdam S, Sterken MG, Van Schaik C, Oortwijn MEP, Lozano-Torres JL, Bakker J, Goverse A, Smant G. 2019. Mediator of tolerance to abiotic stress ERF6 regulates susceptibility of Arabidopsis to Meloidogyne incognita. Molecular Plant Pathology 20(1): 137-152.

Weijers D, Wagner D. 2016. Transcriptional responses to the auxin hormone. Annual review of plant biology 67(1): 539-574

Wesemael W, Viaene N, Moens M. 2011. Root-knot nematodes (Meloidogyne spp.) in Europe. Nematology $13(1): 3-16$.

Weßling R, Epple P, Altmann S, He Y, Yang L, Henz Stefan R, McDonald N, Wiley K, Bader Kai C, Gläßer C, et al. 2014. Convergent targeting of a common host protein-network by pathogen effectors from three kingdoms of life. Cell Host \& Microbe 16(3): 364-375.

Westermann AJ, Förstner KU, Amman F, Barquist L, Chao Y, Schulte LN, Müller L, Reinhardt R, Stadler PF, Vogel J. 2016. Dual RNA-seq unveils noncoding RNA functions in host-pathogen interactions. nature 529(7587): 496-501.

Wilk E, Pandey AK, Leist SR, Hatesuer B, Preusse M, Pommerenke C, Wang J, Schughart K. 2015. RNAseg expression analysis of resistant and susceptible mice after influenza A virus infection identifies novel genes associated with virus replication and important for host resistance to infection. BMC Genomics 16(1): 655 .

Win J, Chaparro-Garcia A, Belhaj K, Saunders DGO, Yoshida K, Dong S, Schornack S, Zipfel C, Robatzek S, Hogenhout SA, et al. 2012. Effector Biology of Plant-Associated Organisms: Concepts and Perspectives. Cold Spring Harbor Symposia on Quantitative Biology 77: 235-247.

Wu J, Wang F, Cheng L, Kong F, Peng Z, Liu S, Yu X, Lu G. 2011. Identification, isolation and expression analysis of auxin response factor (ARF) genes in Solanum lycopersicum. Plant cell reports 30(11): 2059.

Xian L, Yu G, Wei Y, Rufian JS, Li Y, Zhuang H, Xue H, Morcillo RJL, Macho AP. 2020. A bacterial effector protein hijacks plant metabolism to support pathogen nutrition. Cell Host \& Microbe.

Yamagishi J, Natori A, Tolba MEM, Mongan AE, Sugimoto C, Katayama T, Kawashima S, Makalowski W, Maeda R, Eshita Y, et al. 2014. Interactive transcriptome analysis of malaria patients and infecting Plasmodium falciparum. Genome research 24(9): 1433-1444.

Yang L, Teixeira PJPL, Biswas S, Finkel OM, He Y, Salas-Gonzalez I, English ME, Epple P, Mieczkowski P, Dangl JL. 2017. Pseudomonas syringae type III effector HopBB1 promotes host transcriptional repressor degradation to regulate phytohormone responses and virulence. Cell Host \& Microbe 21(2): 156-168.

Yang Q, Huai B, Lu Y, Cai K, Guo J, Zhu X, Kang Z, Guo J. 2020. A stripe rust effector Pst18363 targets and stabilises TaNUDX23 that promotes stripe rust disease. New Phytologist 225(2): 880-895.

Yang Z. 1997. PAML: a program package for phylogenetic analysis by maximum likelihood. Bioinformatics 13(5): 555-556. Yang Z. 2007. PAML 4: phylogenetic analysis by maximum likelihood. Molecular biology and evolution 24(8): 1586-1591.

Yang Z, Bielawski JP. 2000. Statistical methods for detecting molecular adaptation. Trends in ecology \& evolution 15(12): 496-503. 


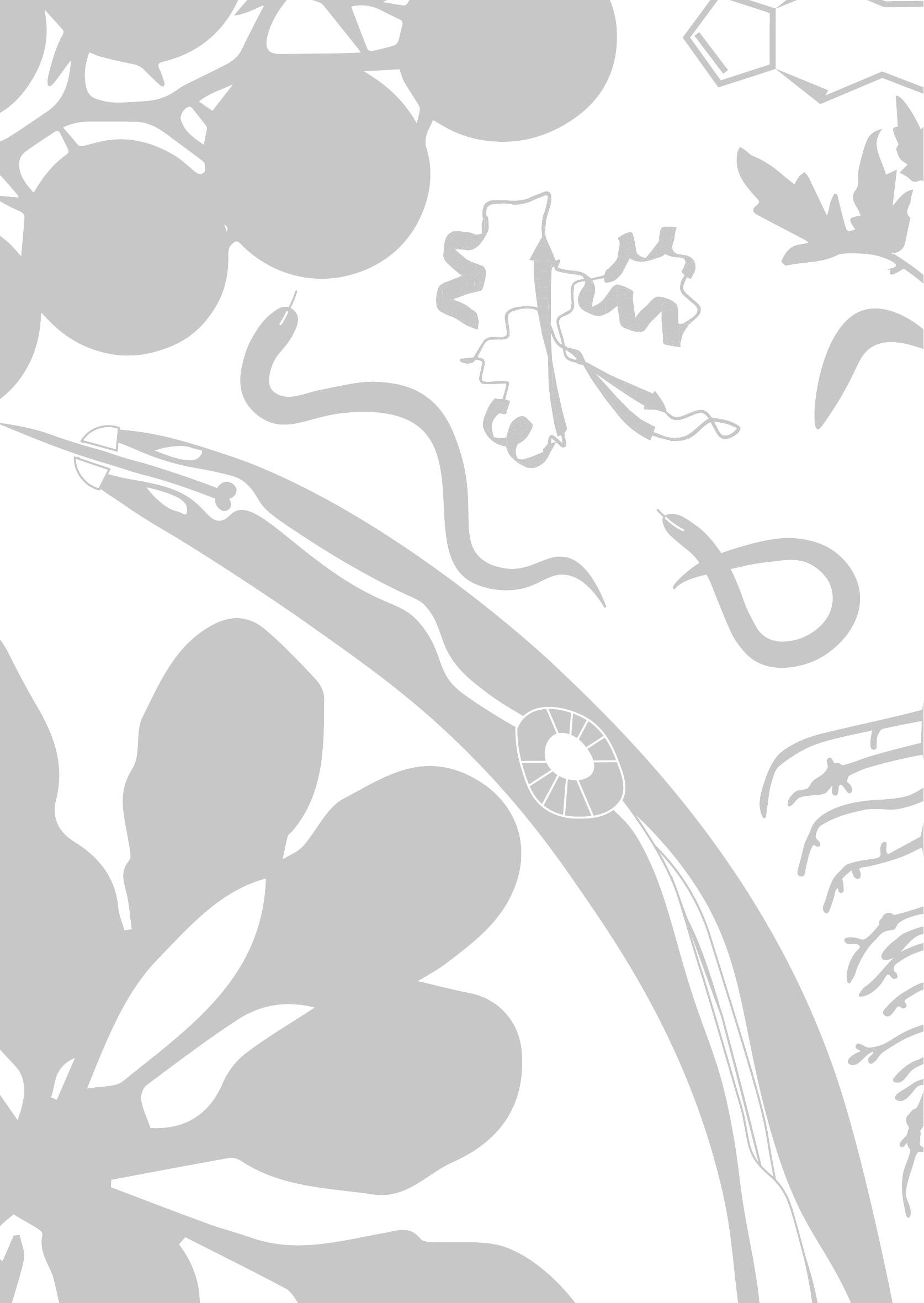




\section{Addendum}

Summary

Samenvatting

Acknowledgements

About the author 


\section{Summary}

The sedentary root-knot nematode Meloidogyne incognita is a widely distributed and highly polyphagous phytopathogen, which causes annual losses in the order of millions of dollars in damage to crops. M. incognita juveniles initiate the development of a permanent feeding site consisting of so-called giant cells. These giant cells nourish the nematodes during their life, while cells surrounding the giant cells are also hypertrophic and hyperplastic and form a large protective gall. The elaborate changes in plant roots leading to the formation of feeding sites are orchestrated by effectors in secretions of $\mathrm{M}$. incognita. To introduce the current concepts of this close interaction at a molecular level in Chapter 1, the latest progress with regard to identification and functional characterization of M. incognita effectors is summarized. Furthermore, it is explained how effectors can play a role in the adaptive evolution of nematodes and hosts.

Chapter 2 describes the identification of the effector MiMSP32 based on specific patterns of genetic variation in the M. incognita genome. As a consequence of adaptive evolution, an ancestral gene of MiMSP32 gene has duplicated and diversified into a gene family with at least thirty identified variants, all taxonomically restricted to root-knot nematodes. These gene variants can be subdivided into six clusters based on their similarities. As a pioneer gene, MiMSP32 shows no similarity to any other functionally characterized genes or proteins However, we used the predicted secondary structure to identify a remote homology with several proteins adopting three-layer beta-alpha-beta ( $\beta a \beta)$-sandwich architecture. Based on the positive selection and gene expansion, we hypothesize that MiMSP32 has undergone functional diversification.

In Chapter 3, we study the biological relevance of MiMSP32 for infectivity of M. incognita on tomato plants. We functionally characterized MiMSP32 in planta and show that it is indeed an important effector with a role in nematode virulence and host plant susceptibility. Moreover, MiMSP32 proved to be a promiscuous effector, as we identified six host targets by screening a tomato cDNA library in yeast. We confirmed these interactions by multiple protein-protein interaction assays, such as co-immunoprecipitation, co-localization, and FRET-FLIM after transient expression in Nicotiana benthamiana leaves. From these results, a model emerges wherein the effector MiMSP32 promotes the virulence of M. incognita by interacting with multiple unrelated host proteins in tomato.

Next, we tested the susceptibility of existing T-DNA knock-out mutants of homologs of the six MiMSP32 host targets in Arabidopsis thaliana, which is a host of M. incognita. We show in Chapter 4 that the Arabidopsis knock-out opr2-7 mutant is significantly more susceptible to M. incognita than wild-type plants. AtOPR2 is thought to take part in an alternative jasmonic acid (JA) biosynthesis pathway downstream of 12-oxo-phytodienoate (OPDA) in the conversion of 4,5-didehydrojasmonate (4,5-ddh-JA) to JA, thereby suggesting that AtOPR2 may function in JA-dependent plant defense. However, our bioassays and transcriptional data provide evidence that AtOPR2 regulates susceptibility of Arabidopsis to $M$. incognita independent 
from basal plant immune responses by conversion of the signaling molecule 4,5-ddh-JA.

In Chapter 5, we describe an alternative approach to identify sources of tomato resistance to M. incognita. To this purpose, we used a collection of 178 domesticated tomato lines without known major R-genes to gauge the quantitative variation in tomato susceptibility to $M$. incognita. Next, we linked this trait to genomic regions of 156 of these tomato lines using genomewide association (GWA), resulting in a catalogue of 380 genes associated with tomato susceptibility to M. incognita. By using additional RNA-Seq of isolated nematode-induced galls on a representative subset of ten tomato accessions, we identified 37 differentially regulated genes within the 380 gene candidates from the CWA. These susceptibility-associated genes likely contain new sources of resistance for use in future studies and breeding applications.

In the final chapter of this thesis (Chapter 6), it is argued that genome diversity can help to identify key factors involved in the diversity of nematode virulence and host susceptibility. MiMSP32 was selected for further analyses based on positive, diversifying selection in the $M$. incognita genome. Likewise, the variation in the S. Iycopersicum genome was used to identify genes significantly associated with quantitative variation in plant susceptibility. Host targets of positively selected nematode effectors are likely to generate a detectable genetic signal in studies of host susceptibility. To test this hypothesis, the 380 tomato susceptibility-associated genes (GWA) were compared with the 51 putative host target genes of MiMSP32 (Y2H). With this comparison, the hypothesis could not yet be confirmed, as the overlapping susceptibility-associated gene needs additional confirmation as a host target. However, confirmation of the hypothesis was possible based on the host target AtOPR2, as it regulates susceptibility of Arabidopsis to M. incognita. Therefore, a suggestion for future studies would be to integrate genome diversity of both nematode and host and use the obtained information of this thesis to formulate more efficient plant protection strategies. 


\section{Samenvatting}

Het sedentaire wortelknobbelaaltje Meloidogyne incognita is een wijdverspreide plant parasitaire nematode met veel verschillende waardplanten, die jaarlijks voor wel miljoenen dollars opbrengstverlies zorgt. Juveniele stadia van M. incognita induceren de ontwikkeling van permanente voedingscellen, de zogeheten reuzencellen. De wortelknobbelaaltjes voeden zich op deze reuzencellen gedurende hun verdere leven en zijn daar geheel van afhankelijk voor de ontwikkeling. Ook de cellen om de reuzencellen heen nemen toe in aantal en in grootte en ontwikkelen zich tot beschermende gallen die zichtbaar zijn op de wortels als kenmerkende knobbels. Deze enorme veranderingen in plantenwortels worden veroorzaakt door effectoren in het speeksel van M. incognita, die ertoe leiden dat voedingscellen gevormd worden. De huidige concepten van deze nauwe interactie op moleculair niveau wordt geïntroduceerd in Hoofdstuk 1, waarin de laatste ontwikkelingen worden samenvat op het gebied van de identificatie en de functionele karakterisering van $M$. incognita effectoren. Verder wordt er uitgelegd hoe effectoren een rol kunnen spelen in de gezamenlijke evolutie van nematoden en waardplanten.

Hoofdstuk 2 beschrijft de identificatie van de effector MiMSP32 gebaseerd op specifieke patronen en variatie in het M. incognita genoom. Als een consequentie van adaptieve evolutie is een voorouderlijk gen van het MiMSP32-gen gedupliceerd en gediversifieerd naar een gen-familie met minstens dertig geïdentificeerde varianten binnen de wortelknobbelaaltjes. Deze gen-varianten kunnen gebaseerd op hun overeenkomsten onderverdeeld worden naar zes clusters. MiMSP32 heeft tot op heden geen enkele overeenkomst met andere functioneel gekarakteriseerde genen of eiwitten. Desondanks toonde de voorspelde secundaire structuur homologie aan met verschillende eiwitten die een typische beta-alpha-beta ( $\beta a \beta$ )-architectuur vertonen. Gebaseerd op de positieve selectie en de expansie van dit gen is de hypothese dat de diversificatie van MiMSP32 gedreven is door een belangrijke functie in de plant-nematode interactie.

In Hoofdstuk 3 is de biologische relevatie van MiMSP32 bestudeerd voor de virulentie van M. incognita op tomatenplanten. De functionele karakterisatie van MiMSP32 liet zien dat het inderdaad een belangrijke effector is met een rol in de virulentie van nematode en de vatbaarheid van waardplanten. Verder toonde een screening van een tomaten cDNA collectie in gist aan dat MiMSP32 met verschillende tomateneiwitten bindt. Zes van deze waardplanteiwitten als effector targets zijn bevestigd in diverse eiwit-interactie studies, na heterologe expressie in Nicotiana benthamiana bladeren. Uit deze resultaten komt een model naar voren waarin de effector MiMSP32 de virulentie van M. incognita promoot door met meerdere, ongerelateerde, waardplant-eiwitten te binden.

Vervolgens is er getest of de vatbaarheid verandert wanneer homologe genen van de zes host targets van MiMSP32 gemuteerd zijn in Arabidopsis thaliana, een alternatieve waardplant 
van M. incognita die als modelplant gebruikt wordt. Hoofdstuk 4 laat zien dat de Arabidopsis knock-out mutant opr2-7 significant vatbaarder is voor M. incognita dan de wild-type planten. AtOPR2 functioneert vermoedelijk in een alternatieve jasmonzuur (JA) biosyntheseroute vanaf 12-oxo-phytodienoaat (OPDA). Hier wordt 4,5-didehydrojasmonaat (4,5-ddh-JA) omgezet naar JA, waarbij het dus mogelijk is dat AtOPR2 functioneert in de JA-afhankelijke plant verdediging. De bioassays en transcriptionele data daarentegen suggereren dat AtOPR2 de vatbaarheid regelt van Arabidopsis voor M. incognita door het omzetten van het signaalmolecuul 4,5-ddhJA, terwijl deze volledig onafhankelijk is van basale immuniteitsreacties van de waardplant.

Hoofdstuk 5 beschrijft een alternatieve aanpak om bronnen van resistentie tegen M. incognita te vinden in tomaat. Hiervoor is een collectie van 178 gedomesticeerde tomatenlijnen zonder bekende resistentiegenen gebruikt om te peilen wat de kwantitatieve variatie is in de vatbaarheid van tomaat voor M. incognita. Vervolgens is deze eigenschap aan genomische locaties van 156 van deze tomatenlijnen gekoppeld door middel van genome-wide association (CWA), wat een verzameling van 380 genen opleverde die worden geassocieerd met de vatbaarheid van tomaat voor M. incognita. Door gebruik van een additionele transcriptoom analyse van geisoleerde gallen op een representatieve subgroep van tien tomatenlijnen konden 37 genen geïdentificeerd worden binnen de 380 van GWA die verschillend tot expressie komen. Nader onderzoek naar deze vatbaarheid-geassocieerde genen zal bijdragen aan nieuwe inzichten in de plant-nematode interactie. Deze genen bevatten naar grote waarschijnlijkheid nieuwe bronnen van resistentie voor toepassingen in de plantenveredeling.

In het laatste hoofdstuk van deze thesis ( het genoom kan helpen om belangrijke factoren te identificeren in de diversiteit van nematodevirulentie en de vatbaarheid van waardplanten. MiMSP32 was geselecteerd voor verdere karakteriseringen gebaseerd op de positieve selectie en diversificatie in het $M$. incognita genoom. Eveneens is de variatie gebruikt in het S. lycopersicum genoom om genen te identificeren die verantwoordelijk zijn voor kwantitatieve variatie in de vatbaarheid van waardplanten. Host targets van positief geselecteerde nematode effectoren geven vermoedelijk een detecteerbaar genetisch signaal af in studies naar de vatbaarheid van waardplanten. Om deze hypothese te testen zijn de 380 genen geassocieerd met vatbaarheid (GWA) vergeleken met de 51 mogelijke host targets van MiMSP32 uit de gist-screening. Deze vergelijking kon de hypothese nog niet bevestigen vanwege aanvullend onderzoek dat nodig is. De hypothese kon daarentegen wel bevestigd worden dankzij de host target AtOPR2, omdat dit gen de vatbaarheid van Arabidopsis reguleert voor M. incognita. Daarom zouden toekomstige studies de diversiteit van de genomen van nematode en waardplant kunnen integreren. De verkregen informatie uit deze thesis is te gebruiken voor vervolgonderzoek naar de rol van genen in de plant-nematode interactie en om efficiëntere strategieën te ontwikkelen voor resistentieverdeling in gewassen. 


\section{Acknowledgements}

This book is of course not written by me as an individual. There have been a great many people who have helped me along the way with the usual daily struggles of any PhD student, such as a helicopter rescue operation in Alaska, or a worldwide pandemic.

Because there are so many people joining, leaving and staying at Nematology, I cannot aim to mention everybody here individually. I therefore wish to be inclusive and say a general thank you to the whole Nema-family. Additional to the science, the Nema-family is very a welcoming group with many different social activities. We had of course the main activities, such as the daily coffee breaks and the yearly lab outing, Christmas lunch, and the traditional barbeque at Jaap's house. I also greatly appreciated the other activities in smaller subgroups, such as the PNI activities, conference visits, PhD-dinners, hot-pots, bouldering trips, WE-days, sushi-festivities, klompenpad hikes, the Nema Cooking Club, and the more recent online activities.

Within Nema, I would first like to thank my promoter and daily supervisor Geert. Thank you for your patience, advice, guidance and optimism. I really enjoyed the time together in our little office, with your surprising dislike of plants and an overdose of sarcastic humor. A lot of thanks as well to my co-promotors: Aska, thank you for always taking the time to freely distribute valuable feedback, new insights and interesting ideas. You and Geert are indeed a very additive combination as supervisors. And Mark, even though you joined my PhD-team only halfway, I wouldn't have been able to finish this book without you. Thanks for teaching me how to handle big piles of data and as well for drinking coffee together and talking about random stuff every now and then.

Next, I wish to thank the lab magicians who make the Nema lab a happy and very functional place. Debbie, you guided me into the world of molecular labwork and taught me the ins and outs in my first year. I was very grateful that you only left for a nice new job after I felt safe in the lab. CaSper, you are responsible for the great atmosphere at the SPIT-lab. It is very comforting that you are always available to help, and of course that you are even more OCD than I am (yes, you know you are). Hein, it is impressive how much time you invest in helping others with your overdose of lab experience. Don't forget to go on really nice cycling holidays and to show me the pictures afterwards. Rikus, I have always admired your positive view and attitude. I am sure that the roof-terrace ducks would have never successfully raised their first offspring years ago if you hadn't been there to help them. Joost, I always enjoy talking about our mutual affection of plants, even though you're definitely the pro. It is awesome how you take your lab experience to sterilize holiday orchid seeds and grow them on medium at home. Sven, I am very happy that you share my love for Peruvian baby stick-insects. Hopefully our babies will become very old under your guidance and generate many new adorable babies.

For some of the experiments, I have been lucky to profit from the knowledge of more experienced users. Jan-Willem, thank you for making confocal and lifetime imaging possible for us at the biochemistry department. Also a first thank you here to Erik: you are responsible for 
making most of the confocal pictures in this booklet. I also would like to say thanks to Bert and Erik from Unifarm, for always taking care of our plants. For protein structural analyses, I am very grateful to Eliza, Laura, and Andrei, whose knowledge and experience in these kind of analyses aided me in finding out a lot more about my protein of interest than I would have achieved on my own.

Jaap and Arjen, I've known you both since I arrived in Wageningen in my first year, and it has been great talking to you about race rowing, other sport activities, plant sciences and nematodes ever since. I would also like to thank the other Nematology PI's Hans and Jan. You are very approachable and I liked running into you every now and then around Wageningen. Jose, thanks for inspiring us with new lab tools and interesting ideas. One day, we will learn your secret of how to get fungus-free H. schachtii. Martijn, thank you for all the times we both stayed way too long at parties and could cycle all the way back to Renkum together. Misghina, thank you for your happy attitude on all moments of the day. I don't think I have ever been greeted so enthusiastically as by your 'Aviva!!!!'. Another big thank you to the postdocs and tenure-trackers Sanja, Stefan, and André, and the secretary's Christel, Manouk, and Lisette. Together, you make Nematology work and you have been a great inspiration and/or a source of knowledge and information.

Next, I would like to thank all members of the Nema-cooking club for the incredible dishes and the even better atmosphere during our dinners. Jet, you were responsible for my first introduction to Nematology and one of the reasons I came back as a PhD student. As my very much appreciated office companion, I have to apologize for all the times you just needed a tiny positive remark and received only sarcasm. Liesbeth, thank you for your kindness over the years. It has been great to be your colleague and share interests as garden-neighbors, cooking-club members, and cacti-crochet-fans. Ruud, it has been very entertaining to observe (and profit from) your yearly Christmas lunch-battle for The Best Dish with Joost. Even your failed attempts for the Nema-cooking club resulted in dishes most fancy restaurants would love to serve.

The Nematology atmosphere wouldn't be complete without fellow PhD's who go through the same process. Koen, you were always the one I would go to for help in the lab. I really enjoy your enthusiasm about work, sports, board games, travelling and many other hobbies and interests. Kim, you were the most sane PhD in my eyes. Thank you for your skill to put things into perspective. I always liked your dry humor and your very kind personality. Lisa, we started as newbies on the exact same day. It has been great sharing experiences with you, from both working at student spots to going on writing retreats and finally becoming 'old' PhD's. Octavina, thank you for your help with the initial microscopy experiments. You always manage to make time in your schedule to help others, which I really admire in you. joris, it has been great that you joined Nematology as a self-proclaimed 'nerd-next-door'. Thank you for your help with the bioinformatics. I sometimes still wonder how you manage to be the personification of a nice guy and evil at once. JJ, thank you for the humor you brought into the SPIT-lab, and of course your great taste of 'music', which was the perfect motivation to speed up my labwork. Amalia, 
although I was very afraid of you when we first met, I'm happy I got over this initial impression and managed to know you better. I secretly hope to visit you in Colombia one day. Sonja, you remain the queen of counting egg masses. Yiru, thank you for inviting us to Canterbury! You enlightened my days by always waving back, no matter the time, how often we already met that day, or who was watching us wave like idiots. Paula, thanks for sharing your first ever publication with me and for all the 'what are you going to do this weekend'- and 'how was your weekend'-coffee breaks filled with surprises. Casper $\mathrm{Q}$, thanks for your help during my thesis and for showing me how it is to do a PhD. Also thanks for the first 'parasolzwammen' I ever ate and the happy fact that we didn't get poisoned. Irene, you've managed to make many conferences and meetings (and also rowing trips on the Rhine) way more enjoyable. Thanks for joining me on hiking trips through random cities and forests. Vivian, I owe you a big thanks for your company, especially during the Corona-period. You are a wonderful crazy person and I really enjoyed getting to know you and share a vegetable garden.

But there is even more PhD's! Thank you all for the nice PhD-community within Nema with the PhD-meetings, PhD-dinners, PhD-parties, PhD-writing retreats (no, you don't have to join if you don't want to JJ), and other activities we joined and organized together. Katharina, the best of luck with your two newborns! Matthijs, keep up the enthusiastic storytelling, especially the volleyball-story. Nina and Yuqing, your fusion dish during the last Christmas dinner was amazing. I still need this recipe. Qi, thank you for sharing the Chinese culture every now and then (the hotpot dinners were great!), and also for adopting so many of my buffers, it is nice to know they are being used. I want to wish the newer PhD's Yuqi, Marijke, Sara, Myrna, Iqbal, Vera, and Alejandro all the best of luck with the whole process. I also want to thank my thesis students Tim, Sanne, Suze, Yixuan, Wannes, and Thomas for their insights and enthusiasm while trying to finish a thesis project with me as a supervisor.

Next to colleagues, I happen to be surrounded with awesome friends and family who helped me get through the PhD-period. If not directly with help, support and advice, then surely indirect by providing me with all kinds of distractions.

First of all, I would like to thank the 'Roeidamesch der W.S.R', for being there even now the very happy rowing period is over (for me at least). Especially Jolien, Rosalie, and Merle: although you all still can be spotted in rowing boats, you managed to spread your wings and leave Wageningen for extremely remote destinations within the Netherlands such as Friesland and Maastricht. It makes me happy that we still meet to do random sport activities and enjoy our shared favorite activity: eating. Daan, Roos \& Eefke, thank you for putting things here in perspective and taking me along on very distracting holidays to beautiful far-away places around the globe and especially for always getting back home safely.

When talking about far-away places, I always think of David and Young. I will never forget the awesome trip to the Johns Hopkins University, the truly inspiring work mentality of Young, the proactivity and perseverance of David whenever necessary, and of course how amazing David looks while wearing wooden shoes. I'm very happy I got to know both of you, and I will absolutely go and visit you again when possible! 
A massive thank you to a very supportive group of friends from a period long gone but definitely not forgotten. Thomas, Daan, Thijs-Jan, Sjoerd, Joris, Davide, Jaap, Hein, Eva, Max, Carmen, and Eliza. Thank you for making all the difference. I also wish to thank Wilma, Bart, Leo, Berthy and Jos for their continued kindness, genuine interest and support. Doreth, Koen, Rick, and Wesley, you are great long-time friends in Brabant. Thank you all for your friendship and your continued support!

More recent contributions to the list of awesome people include a group of biologists: Erik, Nienke, Erwin, Judith, Mark, Christien and their Fl: Myrthe, Wende, Koen and Nora. Thank you for always happily providing various distractions, such as camping trips, orchid hikes, Risk evenings, new year celebrations, chromosome parties and other excuses to meet. 化

I would of course like to thank my family for always supporting me in whatever I decide to do and helping me in whatever ways possible. Ad, Anneke, Tineke, Thomas, Raaf, Jonas, Evert, Lisenka, Savi, Noek, Arjen, Erwin, Mirjam, and Annemieke, a.k.a. familie Slootweg, I'm very happy and grateful to be a part of your family. Thank you for your warm welcome and all the nice family-activities.

Marga \& Willem, thanks a lot for being there. It has been such a reassurance over the years, knowing that you always took care of everything. One day, I wish to get a house with a kitchen nearly as fancy as yours to handle all the left-over quinces from your garden.

Ymke and Fenna, thank you for being the best cousins one could wish for. I'm very happy to have lived with you as housemates during our studies, and to find you both amongst my best friends. It also makes me happy that you two found Joost and Arwin as additions to our tiny family. Let's keep up our crochet-evenings at varying locations, because these evenings are also great when nobody is actually doing crochet.

Papa \& Mama, thanks a lot for all your support over the years. It makes me very happy to see the two of you happily 'keutelen' in and around the house. Even though my mission when I was younger was to study plants in a totally different way than either of you, I happily ended up with the same courses as Mams and working in the same building as Paps. Mission failed. Secretly, I have always been very proud when others mention that 'de appel niet heel ver van de boom valt'. I know January the $18^{\text {th }}$ will be tough for all of us, but I hope to take away a tiny part of the pressure that is now linked to this day and add some happier memories.

Last but not least, another big thank you to Erik here for a second time, although this time not as a colleague or microscopy expert. Thank you for your support, kindness, and optimism. Another thank you for often dragging me outside to spend time together on a quest for a specific plant or a very rare fungus. It is funny how 'our' finds usually look like tiny weeds with fuzzy brown spots to the untrained eye (me). Still, wandering around outside with you is always great, and it is a privilege to see the world through your eyes. I might be a tiiiny bit prejudiced, but you are the best! 
Addendum

$\Delta$ 


\section{About the author}

Ava Verhoeven was born on January the $28^{\text {th }}$, 1990 in Eindhoven. She was interested in nature and in plants in particular, and graduated high school at Gymnasium Bernrode in Heeswijk-Dinther.

She left Brabant and moved to Wageningen to start the BSc Plant Sciences in Wageningen. During her studies, she was a very active race rower for three years at W.S.R. Argo. After a BSC thesis with dr. ing. Rieta Gols and prof. dr. ir. Joop van Loon at the Laboratory of Entomology, she

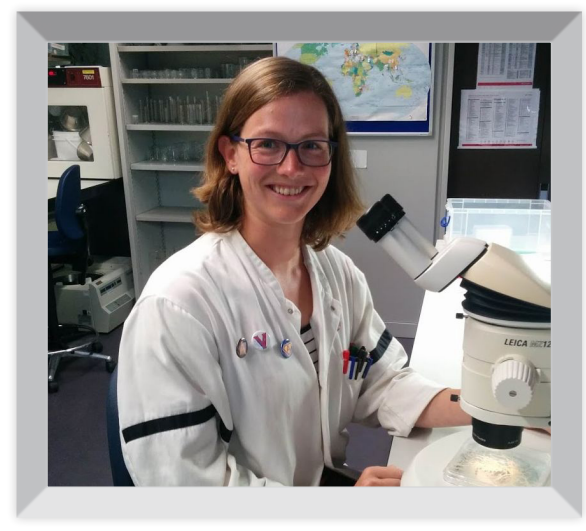
obtained the degree.

During her MSc Plant Sciences with a specialization in Plant Pathology and Entomology, she chose to write two theses instead of following more courses. At the Laboratory of Nematology, she studied the plant rhizosphere to compare nematode communities of differently aged and related plants together with dr. Jet Vervoort. At the Laboratory of Entomology, she worked with dr. Jenny Lazebnik on the complex interactions between potato plants, Colorado potato beetles, Phytophthora infestans and aphids.

For the final part of her study, she had the opportunity to work with the senior onion breeder dr. Luigi Selleri at Enza Zaden in Tarquinia, Italy for 6 months. At this location, she performed a field trial to study which plant traits are important in the susceptibility of onion to Thrips tabaci.

After graduation, she worked with prof. dr. ir. Rene van der Vlugt at the Laboratory of Virology to characterize an unknown latent virus infecting Arabidopsis and write a PhD project proposal. However, after a few months, she was offered a PhD position at the Laboratory of Nematology. Together with prof. dr. ir Geert Smant, dr. ir. Aska Goverse, and dr. ir. Mark Sterken, she has been working since 2016 on root-knot nematode effectors and host genes in tomato.

From October 2020 onwards, Ava works as postdoc at the Plant Ecophysiology group of Utrecht University with dr. Rashmi Sasidharan and dr. ir. Martijn van Zanten to unravel the transcriptomic regulation of Arabidopsis plants under several (a)biotic stresses. 
The research described in this thesis was financially supported by the Dutch Research Council NWO-TTW grant 11042. Financial support from Wageningen University for printing this thesis is gratefully acknowledged.

Cover design and layout by Ava Verhoeven

Printed by GVO drukkers \& vormgevers B.V. on recycled paper 